\title{
Copyright
}

by

Azubuike Michael Egwuenu

2004 


\title{
Improved Fluid Characterization for Miscible Gas Floods
}

\author{
by
}

Azubuike Michael Egwuenu, B.Sc.

\author{
Thesis \\ Presented to the Faculty of the Graduate School of \\ The University of Texas at Austin \\ in Partial Fulfillment \\ of the Requirements \\ for the Degree of
}

Master of Science in Engineering

The University of Texas at Austin

December 2004 


\section{Improved Fluid Characterization for Miscible Gas Floods}

Approved by
Supervising Committee:

Russell T. Johns, Supervisor

Steven L. Byrant 


\section{Dedication}

To the memory of my late father, Matthew Egwuenu, birth mother, Betty Egwuenu, adoptive parents, Mr. and Mrs. Chidi, I. Egwuenu, and my sister Mrs. Amalaonye Ebinum for their sacrifices and support through my education. 


\section{Acknowledgements}

My gratitude goes to Dr. Russell Johns for believing in my research potential. Thank you for a wonderful and tremendous learning experience. I believe my knowledge and skills have appreciated $100 \%$ after working with you. If I had the opportunity to do it all over again I wouldn't change a thing. I also want to thank my parents for all the moral and financial support they gave in the course of my degree. How can I forget my lovely and supportive sister, Amalaonye and her husband Cyril. I assure you that your financial support and encouragement were well invested.

I want to acknowledge my friends, Tunde Oyenekan and Rotimi ojifinni for all the moral support when the chips were down. Thank you for the late night rides from school. Thank you Risi and Titi for all your encouragement and for believing in me. My sincere appreciation goes to my research group colleagues. Thanks Tara for all the inputs you made to help resolve research issues. Yinghui, your contribution was invaluable. Thank you for all the brainstorming and direct assistance rendered to accomplish this research work. Hung, words are few to express my gratitude for all the late night rides home from research work in school. I am truly honored to have worked with you all.

The research described here was sponsored by the U.S. Dept. of Energy under Grant No. DE-RA26-98BC15200. That support is gratefully acknowledged.

December 2004 


\title{
Abstract \\ Improved Fluid Characterization for Miscible Gas Floods
}

\author{
Azubuike Michael Egwuenu, M.S.E
}

The University of Texas at Austin, 2004

Supervisor: Russell T. Johns

Injection of gases into a reservoir for enhanced oil recovery results in complex fluid phase behavior that cannot be modeled by black oil simulators. This interaction of flow and phase behavior is best captured by fully compositional simulators. A drawback of fully compositional simulators is that they require accurate reservoir fluid characterizations by equations of state (EOS) to capture the phase interactions in miscible gas floods. Another disadvantage is that EOS are computationally intensive. An EOS is typically tuned to standard PVT data, which may include multicontact experiments and swelling tests. The standard method of tuning, however, does not incorporate important displacement parameters such as the minimum miscibility pressure or enrichment (MMP or MME) or the likely compositions that result in a reservoir from condensing-vaporizing displacements. 
The currently available correlations for the estimation of MMP for $\mathrm{CO}_{2}$ floods in literature are not robust enough for the wide range of reservoir oil types and conditions. The MMP correlation available in literature for impure $\mathrm{CO}_{2}$ floods is so limited in its application that it is only suitable for a certain West Texas reservoir oil type.

This thesis presents new MMP correlations for the displacement of multicomponent oil by $\mathrm{CO}_{2}$ and impure $\mathrm{CO}_{2}$. The approach is to use recently developed analytical theory for MMP calculations from EOS to generate MMP correlations for displacements by pure and impure $\mathrm{CO}_{2}$. The advantage of this approach is that MMPs for a wide range of temperatures and reservoir fluids can be calculated quickly and accurately without introducing uncertainties associated with slim-tube MMPs and other numerical methods. The improved MMP correlation is based solely on the reservoir temperature, molecular weight of $\mathrm{C}_{7+}$, and percentage of intermediates $\left(\mathrm{C}_{2}-\mathrm{C}_{6}\right)$ in the oil. The MMPs from the improved correlation are compared to currently used correlations and 41 experimentally measured MMPs. Correlations are also developed for impure $\mathrm{CO}_{2}$ floods, where the injection stream may contain up to $40 \%$ methane. The new correlations are significantly more accurate and applicable than currently used correlations.

An improved tuning procedure for miscible gas floods that can more accurately represent the interaction of flow and phase behavior is also presented. Two displacements are used to demonstrate the approach; an eleven-component $\mathrm{CO}_{2}$ flood and a twelvecomponent enriched gas flood. The MOC analytical theory is used to determine the MME (or MMP) of both lumped and unlumped pseudocomponent EOS models.

The results show that by tuning to the MME or MMP, fewer pseudocomponents were required to obtain the same degree of accuracy as the standard approach with more pseudocomponents. The lumped model gave good oil recovery prediction and composition velocities even when lumped to four pseudocomponents. The MME or 
MMP is shown to be the key tuning parameter. Furthermore, for the cases studied, the lumped models tuned with the proposed characterization method gave more reliable results compared to traditional tuning methods over a wide range of dispersion found in reservoirs. The reduced number of components will reduce the computational time required for compositional simulators. 


\section{Table of Contents}

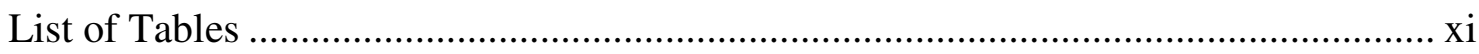

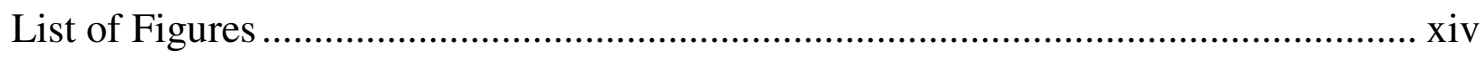

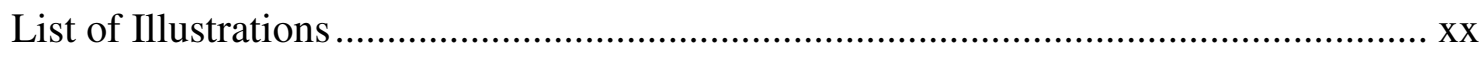

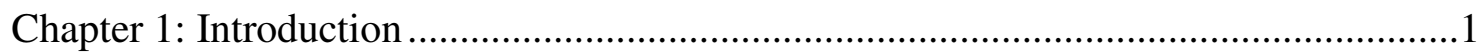

1.1 Development of miscibility and drive mechanism .........................................

1.2 Methods for estimating mmp and mme ..................................................

1.2.1 Experimental methods ....................................................................

1.2.2 Numerical methods ..........................................................................

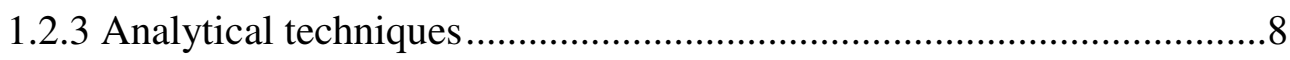

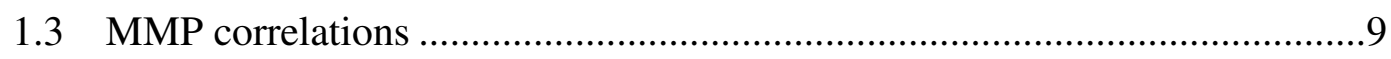

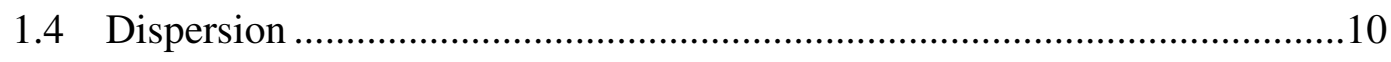

1.5 Equation of state fluid characterization ...................................................11

1.5.1 Reservoir fluid analysis....................................................................11

1.5.2 Pseudocomponent selection ..............................................................11

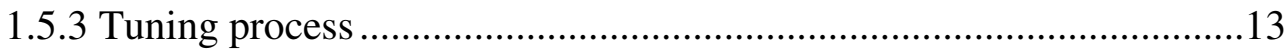

1.6 Objectives and organizaton .......................................................................

Chapter 2: New MMP Correlations …………………………………………......17

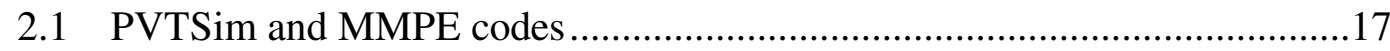

2.2 New MMP correlation for pure $\mathrm{CO} 2$ injection ................................................ 21

2.3 Analytical MMP correlation for impure $\mathrm{CO} 2$ floods......................................31

Chapter 3: Improved Fluid Characterizations Using Equations of State ........................41

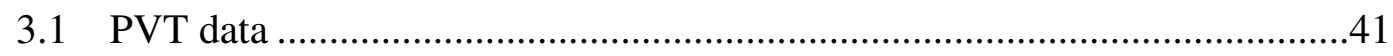

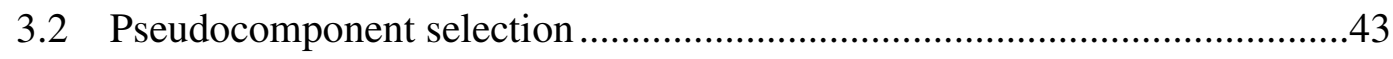

3.3 Improved tuning procedure for EOS.........................................................

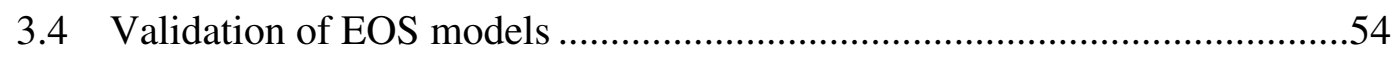

3.5 Application of the improved tuning technique ...........................................5

3.5.1 Twelve-component EOS pseudoization...............................................55 
3.5.2 Eleven-component EOS pseudoization.................................................71

3.6 Effect of dispersion on recovery using the EOS models ................................85

Chapter 4: Conclusions and Recommendations ..........................................................90

Appendix A: Steps for MMP Calculations in PVTSim .............................................93

Appendix B: EOS Properties for Oils Used in the MMP Correlations...........................96

Appendix C: PVTSim MMP Calculation Failure ........................................................102

Appendix D: Computer Code for Pseudocomponent Selection .....................................103

Appendix E: PVTSim EOS Tuning Module ..............................................................112

Appendix F: Compositional Simulation Sample Input and Output .............................114

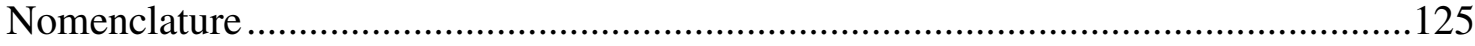

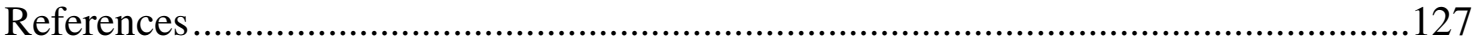

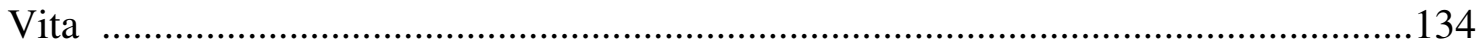




\section{List of Tables}

Table 2.1: Oils used to generate the new MMP correlations for $\mathrm{CO}_{2}$ floods by analytical method.

Table 2.3: Comparison of MMPs estimated from correlations for oil displacements by $\mathrm{CO}_{2}$ to analytically calculated MMPs.

Table 2.4: Comparison of MMP ratio estimated from new correlation to analytically calculated MMP ratios for oil displacements by impure $\mathrm{CO}_{2}$ 38

Table 2.5: Comparison of MMP ratio estimated from correlations to slim-tube MMP ratios for oil displacements by impure $\mathrm{CO}_{2}$

Table 3.1: Component properties for twelve-component EOS model.

Table 3.2: Non-zero binary interaction parameters for twelve-component EOS model.

Table 3.3: $\quad$ Pseudocomponents selection for twelve-component EOS model. .48

Table 3.4: Injection gas composition and the flash data for twelve-component feed composition at $200^{\circ} \mathrm{F}$.

Table 3.5: Component properties for untuned four-component EOS model.

Table 3.6: Binary interaction parameters for untuned four-component EOS model. .49

Table 3.7: Component properties for eleven-component EOS model.......................50

Table 3.8: Non-zero binary interaction parameters for eleven-component EOS model. .50

Table 3.9: Pseudocomponent selection for eleven-component model......................51

Table 3.10: Eleven-component EOS model flash data at 1553 psia and $150^{\circ} \mathrm{F} \ldots \ldots \ldots . . .51$

Table 3.11: Component properties for untuned five-component EOS model. .52 
Table 3.12: Binary interaction parameters for untuned five-component EOS model...52

Table 3.13: Component properties for four-component EOS model tuned to only PVT data at $200^{\circ} \mathrm{F}$.

Table 3.14: Binary interaction parameters for four-component model tuned to only PVT data.

Table 3.15: Component properties for four-component EOS model tuned to both the PVT data and MME at $200^{\circ} \mathrm{F}$. .58

Table 3.16: Binary interaction parameters for four-component model tuned to both PVT data and MME.

Table 3.17: Prediction of MMP and SVP by four-component EOS models. ...............58

Table 3.18: Prediction of MMP and SVP by five-component EOS models................72

Table 3.19: Component properties for five-component EOS model tuned to PVT data and MMP at $150^{\circ} \mathrm{F}$. 72

Table 3.20: Binary interaction parameters for tuned five-component model..............72

Table 3.21: Summary of grid-blocks used, Peclet numbers and dispersivities............85

Table B1: Component properties for Wang and Orr (2002) EOS model. ..................96

Table B2: Non-zero binary interaction parameters Wang and Orr (2002) EOS model. .96

Table B3: Component properties for Oil A (Yuan et al., 2002) EOS model. ............97

Table B4: $\quad$ Binary interaction parameters for oil A (Yuan, et al. 2002) EOS model. .97

Table B5: Component properties for oil B (unpublished) EOS model......................98

Table B6: Binary interaction parameters for oil B (unpublished) EOS model...........98

Table B7: Component properties for oil C (unpublished) EOS model......................99

Table B8: Non-zero binary interaction parameters for oil C (unpublished) EOS model .99 
Table B9: Component properties for oil D (Jutila, et al. 2001) EOS model. ...........100

Table B10: Non-zero binary interaction parameters for oil D (Jutila, et al. 2001)

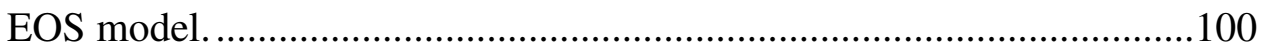

Table B11: Component properties for Hong oil (1982) EOS model.........................101

Table B12: Binary interaction parameters for Hong oil (1982) EOS model.............101

Table C1: Comparison of 11-component EOS MMP calculation results at different

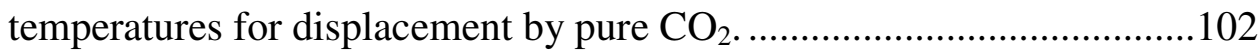




\section{List of Figures}

Figure 1: Estimation of MMP by slim-tube experiments. The smooth curve is slim-tube recovery and the other solid curve is dispersion-free recovery. The thermodynamic MMP is the pressure at the sharp bend of the curve as determined by construction of two intersecting tangent lines (the dashed lines). The pressure at the intersection point is often taken as the slim-tube MMP.

Figure 2.1: Tie-line lengths for key tie lines in the displacement of oil A by pure $\mathrm{CO}_{2}$ at $189^{\circ} \mathrm{F}$. The MMP is 3322 psia where one of the key tie lines first reaches zero length.....................................................................19

Figure 2.2: Comparison of MMPs calculated for the displacement of Oil A by gas mixtures containing $\mathrm{CO}_{2}$ and $\mathrm{C}_{1}$ at $189^{\circ} \mathrm{F}$ using PVTSim and MMPE code.

Figure 2.3: Comparison of MMPs calculated for the displacement of 12-component oil by gas mixtures at $182^{\circ} \mathrm{F}$ using PVTSim and MMPE code.

Figure 2.4: MMP estimated from different correlations and calculated from analytical method for black oil A. The MMPs are fit to a quadratic function.

Figure 2.5: MMPs calculated from analytical method for volatile oil D. The MMPs are fit to a quadratic function.

Figure 2.6: Comparison of the analytical MMP correlation with other currently used correlations. The correlation is based solely on analytically calculated MMPs 
Figure 2.7: Comparison of the new correlation with other currently used correlations. The correlation is based on both the analytically calculated MMPs and slim-tube MMPs .25

Figure 2.8: MMP ratios calculated from the analytical method and Sebastian's correlation for displacement of oil A (black oil) by mixtures of $\mathrm{CO}_{2}$ and $\mathrm{C} 1$ at different reservoir temperatures.

Figure 2.9: MMP ratios calculated from the analytical method for displacement of oil D (light oil) by mixtures of $\mathrm{CO}_{2}$ and $\mathrm{C}_{1}$ at different reservoir temperatures.

Figure 2.10: Comparison of estimated MMP ratios from the new correlation and those calculated from the analytical method.

Figure3.1: Tuned four-component model prediction for oil formation volume factor from differential liberation test at $200^{\circ} \mathrm{F}$.

Figure 3.2: Tuned four-component model prediction for solution gas-oil ratio from differential liberation test at $200^{\circ} \mathrm{F}$.

Figure 3.3: Tuned four-component model prediction for gas formation volume factor from differential liberation test at $200^{\circ} \mathrm{F}$.

Figure3.4: Tuned four-component model prediction for oil viscosity from differential liberation test at $200^{\circ} \mathrm{F}$.

Figure 3.5: Four-component model predictions for the pressure composition data from swelling test at $200^{\circ} \mathrm{F}$.

Figure 3.6: Tuned four-component model prediction for the swollen volume from swelling test at $200^{\circ} \mathrm{F}$.

Figure 3.7: Tuned four-component model prediction for the oil/gas mixture density from swelling test at 3200 psia and $200^{\circ} \mathrm{F}$. 
Figure 3.8: Four-component model prediction for relative volume from constant mass expansion test at $200^{\circ} \mathrm{F}$. 64

Figure 3.9: Comparison of simulated gas saturationvelocitiesfor four-component models at $0.3 \mathrm{HCPVI}, 3650$ psia, $200^{\circ} \mathrm{F}$ and fixed injection gas enrichment .66

Figure 3.10: Analytical MME predictions by EOS models at $200^{\circ} \mathrm{F}$ and different pressuress 66

Figure 3.11: Comparison of 12- and four-component EOS models simulated gas saturation velocities for $0.3 \mathrm{HCPVI}$ at $3650 \mathrm{psia}, 200^{\circ} \mathrm{F}$ and fixed injection gas enrichment.

Figure 3.12: Comparison of 12- and four-component EOS models simulated $\mathrm{C}_{1} \mathrm{~N}_{2}$ component profile for $0.3 \mathrm{HCPVI}$ at $3650 \mathrm{psia}, 200^{\circ} \mathrm{F}$ and fixed injection gas enrichment.

Figure 3.13: Comparison of 12- and four-component EOS models simulated $\mathrm{C}_{2+}$ component velocities for $0.3 \mathrm{HCPVI}$ at $3650 \mathrm{psia}, 200^{\circ} \mathrm{F}$ and fixed injection gas enrichment. .68

Figure 3.14: Comparison of 12- and four-component EOS models simulated $\mathrm{C}_{5+}$ component velocities for $0.3 \mathrm{HCPVI}$ at $3650 \mathrm{psia}, 200^{\circ} \mathrm{F}$ and fixed injection gas enrichment.

Figure 3.15: Comparison of 12- and four-component EOS models simulated $\mathrm{C}_{30+}$ component profile for $0.3 \mathrm{HCPVI}$ at $3650 \mathrm{psia}, 200^{\circ} \mathrm{F}$ and fixed injection gas enrichment.

Figure 3.16: Comparison of 12- and four-component EOS models simulated $\mathrm{C}_{5+}$ component recovery at 3650 psia, $200^{\circ} \mathrm{F}$ and fixed injection gas enrichment .69 
Figure 3.17: Comparison of 12- and four-component EOS models simulated $\mathrm{C}_{30+}$ component recovery at 3650 psia, $200^{\circ} \mathrm{F}$ and fixed injection gas

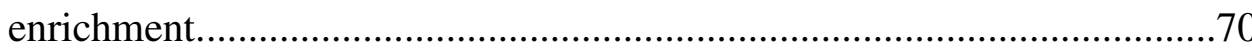

Figure 3.18: Comparison of 12- and four-component EOS models simulated oil recovery at $3650 \mathrm{psia}, 200^{\circ} \mathrm{F}$ and fixed injection gas enrichment. .70

Figure 3.19: Tuned five-component model prediction for oil formation volume factor from differential liberation test at $150^{\circ} \mathrm{F}$

Figure 3.20: Tuned five-component model prediction for solution gas-oil ratio from differential liberation test at $150^{\circ} \mathrm{F}$. .73

Figure 3.21: Tuned five-component model prediction for gas formation volume factor from differential liberation test at $150^{\circ} \mathrm{F}$

Figure 3.22: Tuned five-component model prediction for oil viscosity from differential liberation test at $150^{\circ} \mathrm{F}$.

Figure 3.23: Tuned five-component model prediction for the pressure composition data from swelling test at $150^{\circ} \mathrm{F}$.

Figure 3.24: Tuned five-component model prediction for the swollen volume from swelling test at $150^{\circ} \mathrm{F}$ 75

Figure 3.25: Tuned five-component model prediction for the oil/ $/ \mathrm{CO}_{2}$ mixture density from swelling test at $150^{\circ} \mathrm{F}$.

Figure 3.26: Tuned five-component model prediction for relative volume from constant mass expansion test at $150^{\circ} \mathrm{F}$.

Figure 3.27: Comparison of 11- and five-component EOS simulated gas saturation velocities at $0.3 \mathrm{HCPVI}, 2200$ psia and $150^{\circ} \mathrm{F}$. 79

Figure 3.28: Comparison of 11-and five-component EOS models analytical MMP predictions for pure $\mathrm{CO}_{2}$ injection. 
Figure 3.29: Comparison of 11- and five-component EOS simulated gas saturation velocities at for $0.3 \mathrm{HCPVI}$ at $2200 \mathrm{psia} 150^{\circ} \mathrm{F}$. The displacement is by pure $\mathrm{CO}_{2}$

Figure 3.30: Comparison of 11- and five-component EOS models simulated $\mathrm{CO}_{2}$ component velocities for $0.3 \mathrm{HCPVI}$ at $2200 \mathrm{psia}, 150^{\circ} \mathrm{F}$. The displacement is by pure $\mathrm{CO}_{2}$.

Figure 3.31: Comparison of 11- and five-component EOS models simulated $\mathrm{C}_{1+}$ component velocities for $0.3 \mathrm{HCPVI}$ at $2200 \mathrm{psia}$ and $150^{\circ} \mathrm{F}$. The displacement is by pure $\mathrm{CO}_{2}$

Figure 3.32: Comparison of 11- and five-component EOS models simulated $\mathrm{C}_{3+}$ component velocities for $0.3 \mathrm{HCPVI}$ at $2200 \mathrm{psia}$ and $150^{\circ} \mathrm{F}$. The displacement is by pure $\mathrm{CO}_{2}$.

Figure 3.33: Comparison of 11- and five-component EOS models simulated $\mathrm{C}_{7+}$ component velocities for $0.3 \mathrm{HCPVI}$ at $2200 \mathrm{psia}$, and $150^{\circ} \mathrm{F}$. The displacement is by pure $\mathrm{CO}_{2}$

Figure3.34: Comparison of 11- and five-component EOS models simulated $\mathrm{C}_{14+}$ component velocities for $0.3 \mathrm{HCPVI}$ at $2200 \mathrm{psia}$, and $150^{\circ} \mathrm{F}$. The displacement is by pure $\mathrm{CO}_{2}$ .82

Figure 3.35: Comparison of 11- and five-component EOS models simulated $\mathrm{C}_{7+}$ component cumulative mole percent recovery at 2200 psia and $150^{\circ} \mathrm{F} \ldots . .83$

Figure 3.36: Comparison of 11- and five-component EOS models simulated $\mathrm{C}_{14+}$ component cumulative mole percent recovery at 2200 psia and $150^{\circ} \mathrm{F}$....40

Figure 3.37: Twelve-component EOS model simulated gas saturation velocities for different levels of dispersion at $0.3 \mathrm{HCPVI}, 3650$ psia and $200^{\circ} \mathrm{F}$. .88 
Figure 3.38: Four-component EOS model simulated gas saturation velocities for different levels of dispersion at $0.3 \mathrm{HCPVI}, 3650 \mathrm{psia}$ and $200^{\circ} \mathrm{F}$...........88

Figure 3.39: Eleven-component EOS model simulated gas saturation velocities for different levels of dispersion at $0.3 \mathrm{HCPVI}, 2200$ psia and $150^{\circ} \mathrm{F} \ldots \ldots \ldots . . .89$

Figure 3.40: Five-component EOS model simulated gas saturation velocities for different levels of dispersion at $0.3 \mathrm{HCPVI}, 2200 \mathrm{psia}$ and $150^{\circ} \mathrm{F}$..........89 


\section{List of Illustrations}

Illustration A1 PVTSim input menu for fluid composition and properties.................93

Illustration A.2: PVTSim input field for binary interaction parameters. .....................95

Illustration A.3: MMP simulation menu for PVTSim.............................................95

Illustration D.1: PVT data selection menu for PVTSim regression tool......................112

Illustration D.2: Menu of EOS parameters for regression......................................113 


\section{Chapter 1: Introduction}

The injection of gases into mature reservoir fields for the purpose of increasing the amount of oil recovered is a well-established tertiary recovery method. The choice of injection gas depends primarily on the reservoir temperature, pressure, oil composition, and economic considerations. Gases commonly injected in enhanced oil recovery projects (EOR) include; flue gases, mixture of hydrocarbon gases (or enriched gases), nitrogen, methane, and carbon dioxide. Gas injection increases the mobility of the remaining or residual oil after primary depletion or secondary water floods by reducing the oil viscosity and density. Repeated mass transfer of components between the gas stream and the reservoir oil also cause the oil to become more miscible with the vapor stream in the reservoir. An increase in the oil miscibility and mobility results in an increase in the displacement efficiency and ultimately the recovery efficiency.

The number of EOR gas injection projects in the U.S. has remained relatively unchanged for the past ten years (Guntis 2004). However, the number of miscible $\mathrm{CO}_{2}$ floods has continued to grow steadily from 54 in 1994 to 70 in 2004. In addition, the amount of oil recovered by this process has increased steadily from 161,000 barrels/day to 205,000 barrels/day over the last ten years. The rise in the number of $\mathrm{CO}_{2}$ floods is likely because $\mathrm{CO}_{2}$ achieves miscibility with the oil at relatively lower pressures than natural gas or flue gas. In addition, $\mathrm{CO}_{2}$ is available naturally in large deposits (Stalkup 1981) and as a byproduct of many industrial processes. All reservoir fields will eventually reach maturity and as the number of new reserves discovered decline, miscible gas injection will contribute a greater percentage to production around the world.

One goal in the design of miscible floods is to operate the reservoir at conditions favorable for miscibility to develop between the injection gas and reservoir fluid. The 
percentage of oil recovered increases when the injected gas and reservoir fluids are near miscibility. When fluids are miscible in all proportions, the flood is described as first contact miscible (FCM). Miscibility may also develop by repeated contact with the reservoir fluid in a multicontact miscible (MCM) process. It is rare to find reservoir conditions that favor first contact miscibility because it usually occurs at very high pressures not attainable in most naturally existing reservoirs. The determination of the minimum miscibility pressure or enrichment (MMP or MME) for MCM flow is very important for design considerations.

The injection of a miscible gas into the reservoir often results in complex phase behavior that can be captured only by compositional simulators. Compositional simulators require accurate EOS fluid characterization to make useful predictions. Several researchers (Whitson 1980, Newley \& Merrill 1991, Rafael et al. 2002, Liu 1999, Khan \& Pope 1992) have developed different methods of characterization. The process of describing reservoir oil with an EOS is an expensive and tedious process. There are a number of important questions that need to be addressed in order to design a successful miscible gas flood as well as provide the necessary EOS characterization required for a good compositional simulation. These questions are:

1. What kind of phase behavior will result from the interaction of the oil and injected gas at the prevailing reservoir condition?

2. What kind of mechanism drives the miscible process?

3. How will the MMP or MME for the reservoir be estimated?

4. What approach will be adopted in characterizing the reservoir oil?

5. What PVT experiments are necessary to develop a good EOS fluid characterization?

6. How will the pseudocomponents be selected? 
7. What tuning approach and mixing rule will be applied in the pseudoization process to determine the EOS fluid properties?

8. What is the level of dispersion in the reservoir, how will this affect miscibility and consequently oil recovery?

Extensive studies into these questions have been carried out over the years as are described next.

\subsection{DEVELOPMENT OF MISCIBILITY AND DRIVE MECHANISM}

When injected gas and oil mix in the reservoir, equilibrium gas and oil may result depending on the phase behavior. When the conditions favor first contact miscibility, only a single phase results. However, when the process is multicontact miscible, as many as three phases may co-exist in equilibrium during the contacting process. Propane or liquid petroleum gas (LPG) mixtures are solvents typically used for first contact miscible floods. Multicontact miscible floods usually involve the injection of $\mathrm{CO}_{2}, \mathrm{~N}_{2}, \mathrm{CH}_{4}$ or a mixture of hydrocarbon gases. When $\mathrm{CO}_{2}$ contacts reservoir oil at a high temperature, two phases typically develop, a vapor phase and a liquid phase. This forms the basis for most fluid characterization PVT experimental data. However, when the fluids contact at temperatures below $120^{\circ} \mathrm{F}$, the phase behavior is more complex because three hydrocarbon phases can form.

Experimental measurements of the phase behavior of $\mathrm{CO}_{2} /$ oil mixtures at low temperatures (Orr \& Jessen 1984, Monger et al. 1981, Turek et al. 1984, Shelton and Yarborough 1977) reveal the existence of a liquid/vapor (LV) region, a liquid/liquid/vapor (LLV) region and a liquid/liquid (LL) region. These phases have been shown to occur within different pressure ranges (Stalkup 1983). Several researchers (Ngheim \& Li 1986, Khan \& Pope 1992, Turek et al. 1984, Negahban \& Kremesec 1989) have developed EOS characterizations that predict the three-phase region for $\mathrm{CO}_{2} / \mathrm{oil}$ 
mixtures. Pontious and Tham (1978) speculated that the mobility of $\mathrm{CO}_{2}$ in the transition zone, may be affected by the co-existence of an LL and LV phase at the flood front region and therefore improve the sweep efficiency. It has also been suggested that the high recovery of $\mathrm{CO}_{2}$ floods above a certain pressure (MMP) is a result of the formation of a dense $\mathrm{CO}_{2}$ rich liquid phase that is efficient in extracting the $\mathrm{C}_{5+}$ fraction of the oil (Ngheim \& Li 1986).

Multicontact miscibility (MCM) in real displacements occurs by either pure vaporizing or combined condensing-vaporizing drive (CV) mechanisms. Pseudo-ternary diagrams have traditionally being used to explain the mechanism for development of miscibility. In ternary systems, a displacement is MCM only if either the injected gas composition (condensing drive) or the oil composition (vaporizing drive) lies outside the region of tie-line extensions on a ternary phase diagram. The mechanism for miscibility can be either condensing or vaporizing but never both. Studies have since shown that the ternary diagrams are inadequate to describe the displacement process for most MCM floods. Zick (1986) and Stalkup (1987) showed that many multicomponent displacements contain aspects of both drive mechanisms (CV drive). Johns et al. (1993) proved that at least four components are required for combined CV displacements. MMPs and MMEs estimated using ternary methods can be significantly different from that observed for CV drives. Therefore, new methods were developed for estimation of MMPs and MMEs.

\subsection{METHODS FOR ESTIMATING MMP AND MME}

There are three primary methods for estimating the MMP or MME for fluid displacements: experimental methods, numerical methods, and analytical techniques. Experimental methods include slim-tube tests (Jarrell et al. 2002), rising bubble apparatus (RBA) etc, while numerical methods include the use of mixing cell models (Zick 1986, Jessen and Orr 2002) and 1-D compositional simulations (Rathmell et al. 
1971). Analytical techniques (Johns and Orr 1996, Wang and Orr 1998, Yuan et al. 2002, Jessen et al. 1998) are more recent developments that calculate the MP and MME exactly for dispersion-free displacements. Each of these methods has advantages and disadvantages.

\subsubsection{Experimental Methods}

Slim-tube experiments remain the most widely used method for estimation of MMP. The apparatus (Klins 1984) is made up of a coil usually 20-200 ft long packed with sand or glass beads. The tubing for the coil has a small diameter to ensure the displacement is approximately one-dimensional (1-D). The tube should be long enough for transitional mixing of MCM flow to takes place. The permeability of the slim-tube apparatus is very high so that the whole process remains approximately at constant pressure. The dispersion level is small relative to field scale dispersion. Miscible displacements are carried out in the apparatus at different pressures or injection gas enrichments for a given reservoir temperature. The primary results from slim-tube experiments are plots of cumulative oil recovery at a particular time as a function of pressure.

Figure 1 (Yuan 2003) demonstrates a typical plot of oil recovery with pressure for a slim-tube experiment as well as that for dispersion-free displacement. The dispersionfree displacements show a sharp bend at $100 \%$ oil recovery. The pressure at which this occurs is the thermodynamic MMP. The slim-tube however includes dispersion and the MMP is determined using several different criteria. Some of the well-known criteria are:

- Oil recovery of $90 \%$ at 1.0 pore volume (PV) of gas injected.

- Oil recovery of $90 \%$ at $1.2 \mathrm{PV}$ gas injection.

- Oil recovery of $95 \%$ at gas breakthrough or more than $80 \%$ at gas breakthrough.

- Oil recovery of $94 \%$ when the gas-oil ratio (GOR) reaches $4000 \mathrm{scf} / \mathrm{bbl}$. 
- Distinct point of maximum curvature when cumulative recovery of oil at $1.2 \mathrm{PV}$ gas injected is plotted against pressure.

- Distinct point of maximum curvature when recovery of oil at gas breakthrough is plotted versus pressure.

The non-unique nature of the criteria leads to uncertainty in the estimation of MMP. For example, Figure 1 illustrates the determination of the point of maximum curvature by the construction of two tangents to the recovery curve. The point of intersection of the two tangent lines gives the estimated MMP. These tangent lines could be drawn in many ways.

Zhou and Orr (1998) have shown that the rising bubble apparatus gives comparable results to the slim-tube experiments with less time. Zhou and Orr reported that RBA is suitable for predicting MMPs for vaporizing drives but not for CV drives. MMP estimates obtained by this method are also subject to experimental errors.

\subsubsection{Numerical Methods}

These methods to estimate MMP include fine grid 1-D compositional simulations and mixing cell models. In the 1-D compositional simulation method, simulations of the displacement process are made for relatively constant pressure using different grid-block sizes. The oil recovery at extrapolation to zero-dispersion (infinite number of grid-blocks) is estimated for each pressure and a plot of recovery versus pressure is made (such as Figure 1). The MMP is estimated as the pressure at the point of maximum curvature of the curve. Stalkup et al. (1990) have reported that there is not always a clear trend for some of the oils studied. This is caused by numerical dispersion. Numerical dispersion arises from the truncation error that results from the approximation of the partial differential equations governing the displacement. 


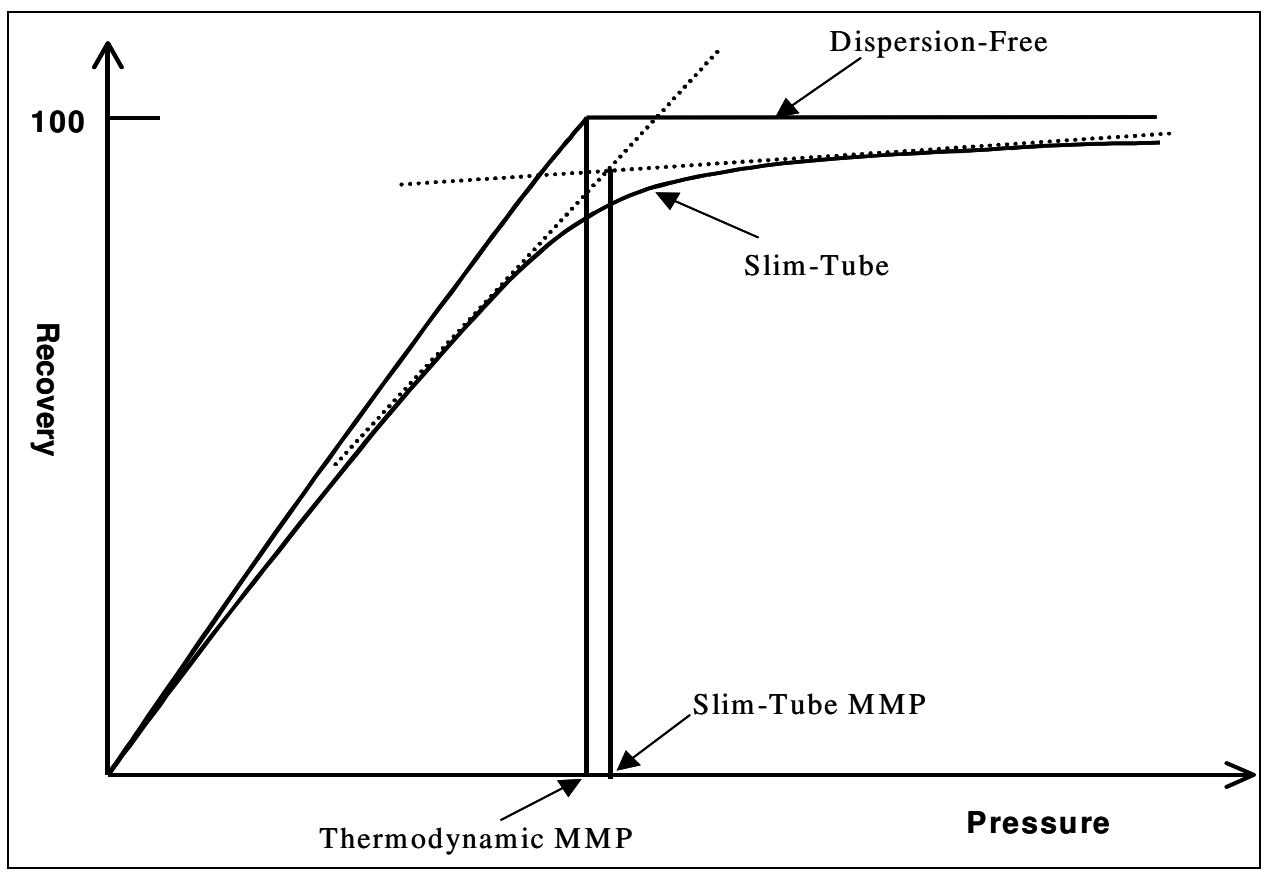

Figure 1: Estimation of MMP by slim-tube experiments. The smooth curve is slimtube recovery and the other solid curve is dispersion-free recovery. The thermodynamic MMP is the pressure at the sharp bend of the curve as determined by construction of two intersecting tangent lines (the dashed lines). The pressure at the intersection point is often taken as the slim-tube MMP.

Mixing-cell models are of two types: forward contacting and backward contacting. The models operate in the same way as multicontact experiments. Repeated flash calculations are done for a mixture of equilibrium oil and injection gas (backward contacting) or a mixture of equilibrium gas and reservoir oil (forward contacting). The MMP is estimated to be the pressure at which the fluid mixture remains single phase (i.e. the gas or oil tie line becomes the limiting tie line at the critical point). These calculations assume that the drive mechanism is either purely vaporizing or condensing. Such a major shortcoming makes it unsuitable for $\mathrm{CV}$ drive displacements. 


\subsubsection{Analytical Techniques}

Analytical techniques for MMP or MME calculation have recently been developed using the method of characteristics (MOC). The calculations are very fast so that MMPs (or MMEs) can be determined for many different reservoir conditions, oil compositions, and gas enrichments. Analytical solutions by MOC were first determined for two-phase, three-component flow by Helfferich (1981). This approach has been extended to other displacments such as surfactant flooding (Hirasaki 1981, Pope 1980).

Monroe et al. (1990) extended the analytical method to quaternary systems where they showed that a third key tie line exists, known as the crossover tie line. Johns et al. (1993) analytically proved that the crossover tie line controls the development of miscibility for a CV drive for a quaternary system. Furthermore, Johns and Orr (1996) extended the theory to multicomponent displacements where they showed that the displacement path for dispersion-free flow is controlled by nc-1 key tie lines and nc-3 crossover tie lines. They showed that MCM is obtained when any of these key tie lines intersects the critical locus as pressure or enrichment is increased.

Wang and Orr (1998) implemented a technique for the calculation of MMP for oil displacements by a multicomponent injection gas based on the geometric construction approach of Johns and Orr (1996). The algorithm developed was modified by Jessen et al. (1998) to increase its speed and robustness. However, the number of unknowns to be determined by the modified scheme was still very large, which can cause convergence to false solutions. They reported convergence problems near the critical locus. Yuan et al. (2002) have developed a new more robust scheme with fewer unknowns and a welldefined initial guess to improve convergence to the true solution. Johns et al. (2002) have also proposed an accurate method for the quantification of the displacement mechanism and demonstrated this for a four-component system. 
The small computational time associated with analytical calculations of MMP offers significant promise for the development of new MMP correlations, compositional streamline simulations, and compositional simulations. The main disadvantage of this technique is that it requires an accurate EOS fluid characterization.

\subsection{MMP CORRELATIONS}

A variety of correlations for the estimation of MMP have been developed from regressions of slim-tube data. Although less accurate, correlations are quick and easy to use and generally require only a few input parameters. Hence, they are very useful for fast screening of reservoirs for potential $\mathrm{CO}_{2}$ flooding. They are also useful when detailed fluid characterizations are not available. One significant disadvantage of current MMP correlations is that the regressions use MMPs from slim-tube data, which are in themselves uncertain. Some MMP correlations require only the input of reservoir temperature and the API of the reservoir fluid. Other more accurate correlations require reservoir temperature and the total $\mathrm{C}_{2}-\mathrm{C}_{6}$ content of the reservoir fluid (Johnson and Pollin 1981, Cronquist 1977, Glaso 1985, Yellig, et al. 1980, Alston et al. 1985, Holm and Josendal 1980). A few require detailed EOS characterizations (Orr and Silva 1987, Kovarik 1985, Ahmed 1997). In nearly all of the correlations, the methane content of the oil is assumed to have negligible effect the MMP. Orr et al. (1993) showed why this is true using analytical theory.

The MMP for reservoir oil depends on its composition and that of the injection gas. Lighter oils have lower MMPs than heavier oils. The MMP for nitrogen or methane gas injection is usually higher than that for pure $\mathrm{CO}_{2}$ injection. However, for high temperature reservoirs, similar MMPs are obtained for these three gases (Jarrell et al. 2002). 
MMP correlations for impure $\mathrm{CO}_{2}$ injection (Alston et al. 1985, Sebastian et al 1985) have been developed to account for the type and amount of impurity. These correlations, however, are inaccurate for general use as they rely largely on one fluid type. The most widely used correlation by Sebastian et al. (1985) is solely based on the pseudocritical temperature of the injected fluid and was primarily developed based on slim-tube data from only one field, the Levelland field. The effect of reservoir temperature and reservoir fluid composition on the MMP is therefore not considered.

Dindoruk et al. (1997) used analytical theory to calculate MMPs for injection of nitrogen and methane mixtures. Their paper shows that the MMP depends strongly on the methane content of the injection gas, and at high nitrogen content on the methane content of the reservoir fluid. For small nitrogen contents in the injection gas, however, the MMP is only weakly dependent on the methane concentration in the oil. Hence, correlations for $\mathrm{CO}_{2}$ injection contaminated with small amounts of nitrogen do not need to incorporate the methane content of the oil.

This thesis uses the analytical theory developed for multicomponent multiphase flow to calculate MMPs for a variety of fluid characterizations, reservoir temperatures, and injection compositions. The primary advantage in this approach is that the analytical calculation is fast and accurate and thus a wider range of input parameters can be considered. The correlations for pure and impure $\mathrm{CO}_{2}$ injection are developed from regressions of the calculated MMPs. Available MMPs estimated from slim-tube experiments are compared to those predicted from the new correlations.

\subsection{DISPERSION}

Dispersion is a physical property of a reservoir or porous media that causes' mixing between two fluids in a displacement process because the level of dispersion found in slim-tubes is very small compared to field scale. There is no known way to scale 
up dispersivity for cores to field scale. Dispersion adversely affects the local displacement efficiency (Johns, et al. 2002, Solano et al. 2001) and consequently the ultimate oil recovery. Johns et al. (1992) have examined the effect of dispersion on nearly miscible displacements for $\mathrm{CV}$ drives. In compositional simulations, adjusting the gridblock sizes approximately captures the effect of dispersion in that numerical dispersion closely mimics the effect of physical dispersion on compositional and saturation profiles.

\subsection{EQUATION OF STATE FLUID CHARACTERIZATION}

The increase in the number of $\mathrm{CO}_{2}$-miscible gas projects makes it imperative that good compositional simulators are available to predict oil recovery. Compositional simulators require accurate EOS fluid characterizations. The process of characterizing fluids is complex and not unique. It requires an extended reservoir fluid analysis to obtain single carbon number compositions for developing detailed EOS fluid characterizations.

\subsubsection{Reservoir Fluid Analysis}

Several experimental methods are available for carrying out extended fluid analysis. The methods that give the greatest amount of information about the fluid are the true boiling point distillation method and gas chromatography. They can give fluid compositions for individual carbon numbers up to $\mathrm{C}_{35}$ (Hoffman, et al. 1953). Pedersen et al. (1989) carried out an extended reservoir fluid analysis to obtain single carbon number components up to $\mathrm{C}_{20}$ by the modification of the true boiling point distillation method. He also compared this method to the gas chromatography technique and found satisfactory agreement.

\subsubsection{Pseudocomponent Selection}

After the fluid analysis is complete, the next step is pseudocomponent selection. 
The lumping of components together into pseudocomponents is accomplished by the use of some predetermined criteria. Equations of state (EOS) can be calibrated for a large number of components or just a few components to accurately represent the fluid phase behavior. An EOS characterization, which consists of a large number of components, gives an accurate phase behavior prediction. However, excessive computation time and storage will be required to keep track of the simulation.

A detailed multicomponent model (say 24 components) may be necessary to study displacement processes in more detail in a limited section of the reservoir at the pattern scale while a model with a few components could be more applicable for field scale. The usual approach is to first lump the original fluid analysis to as few as 12-15 components, tune the EOS model to match the available PVT data, and then reduce the number of components further by lumping the already characterized model.

The components of the extended fluid analysis can be lumped by several different methods. The simplest methods assign pseudocomponents based on component mole (Cotterman et al. 1985) or mass fractions (Pedersen et al. 1985). Whitson (1980) proposed a method based on dividing the molecular weight range of the components into intervals. Components in each interval are then lumped together. Mehra et al. (1982) proposed a statistical method for lumping components into pseudocomponents. Li et al. (1985) proposed a tuning approach that divides components into intervals based on the logarithm of their K-values. Newley \& Merrill (1991) proposed a method that is based on minimizing an objective function such that the K-values of the original component are similar to the K-value of the pseudocomponent to which they are assigned.

In the pseudoization of an existing multicomponent model, the heart of the process lies in the selection of an appropriate mixing rule. Some of the already mentioned lumping schemes may not be appropriate to create reduced pseudocomponent models. 
Using a poor mixing rule to calculate the properties of reduced pseudocomponent models may result in a significant change in the phase behavior predictions. It is desirable that the reduced model be created with as little adjustment to the properties as possible. The Newley and Merrill (1991) method is an excellent method that calculates EOS properties that require only a little adjustment to match the phase behavior of the reservoir fluids. The method is adopted in this research.

\subsubsection{Tuning Process}

The goal of the tuning process is to adjust the EOS properties of the pseudocomponents to fit the PVT experimental data generated with the oil or multicomponent EOS model. Typical PVT data used for tuning include:

- Differential liberation test

- Constant composition expansion test

- Swelling test

- Constant volume depletion

- Multiple-contact test

- Separator test

Multicontact tests assume that the drive mechanism is either vaporizing or condensing. Thus, it generally does not provide useful data applicable to CV drives. An EOS tuned to match this data will give poor predictions of the $\mathrm{CV}$ displacements. However, when the drive mechanism is mostly vaporizing, the forward-contacting, multicontact test can give useful compositional data along the expected displacement path.

The type and number of PVT experiments required for tuning is dependent on the use of the resulting models. For gas compositional processes, Newley \& Merrill (1991) demonstrated that tuning to the differential depletion and swelling test data gave the best results. 
Shahin \& Kremesec et al. (1992) developed a tuning technique for $\mathrm{CO}_{2} /$ oil system, which involved fitting to the MMP. However, they tuned their model to slim-tube MMPs, which often have interpretation uncertainties. They also assumed a vaporizing gas drive mechanism for $\mathrm{CO}_{2}$ displacement. Displacements by $\mathrm{CO}_{2}$ have been shown to be $\mathrm{CV}$. In addition the method was designed for EOS characterization of extended fluid analysis. Thus, it may be unsuited for further pseudoization of existing multicomponent EOS models.

Several procedures have been suggested for tuning EOS characterizations (Khan and Pope 1992, Rafael et al. 2002, Liu, 1999, Fong et al 1992, Hong 1982). Tuning to match a set of PVT data is more of an art than an exact science. Jhaveri and Youngren (1984) recommend classifying PVT experimental data into volumetric and phase behavior data. Pre-selected EOS parameters are adjusted to match the phase behavior data first and then volumetric data are matched by adjusting the volumetric shift parameters. Whatever approach is adopted, the properties of pure components are usually not adjusted. Adjustments are made to only the most uncertain properties. When components are lumped, the properties of the heaviest pseudocomponents have the greatest level of uncertainty and are therefore, the first choice components parameter adjustment. The critical properties of the heaviest component as well as their binary interaction parameters are adjustable. EOS tuning is usually accomplished by regressing on the available data using a multivariate, non-linear regression tool. EOS tuned to match a specific set of data may not give reliable predictions for other data not included in the regression.

\subsection{OBJECTIVES AND ORGANIZATON}

This research focuses on two major areas. The first part deals with the development of correlations for pure $\mathrm{CO}_{2}$ and impure $\mathrm{CO}_{2}$ miscible displacements. The 
second half of the report focuses on an improved tuning approach for EOS characterization suitable for compositional studies. The objectives of this research are to:

1 Demonstrate the inadequacy of currently existing correlations for $\mathrm{CO}_{2}$ floods.

2 Show the advantages of the analytical determination of MMP by MOC.

3 Develop a more robust MMP correlation for impure $\mathrm{CO}_{2}$ floods applicable over a wide range of temperature and reservoir fluid types.

4 Demonstrate that the general tuning approach currently in use for gas compositional processes is not adequate for lumping multicomponent models to reduced pseudocomponent models.

5 Demonstrate that the reduction of multicomponent EOS models to four or five pseudocomponents can be achieved by inclusion of a displacement parameter such as the MMP (or MME) in the regression data.

6 Show that the lumped pseudocomponent model predicts the PVT data and matches the 1-D simulation results of the multicomponent model.

7 Demonstrate the effects of dispersion on the 1-D simulation results of both the lumped and unlumped models.

Chapter 2 deals with the development of new correlations for pure and impure $\mathrm{CO}_{2}$ floods. The method of characteristics is used to analytically determine the dispersion-free MMP for different oil types. The impurity in the $\mathrm{CO}_{2}$ gas stream is limited to only $\mathrm{CH}_{4}$ and $\mathrm{N}_{2}$. The analytically generated MMPs along with slim-tube MMPs are used to generate the new correlations.

Chapter 3 focuses on the improved tuning technique for miscible gas floods. The proposed tuning procedure is demonstrated for a 12-component and 11-component oil characterization using the Peng-Robinson EOS (1976). The 12-component model is lumped to four pseudocomponents by matching the MME for displacement using a 
multicomponent injection gas. The 11-component model is reduced to a five pseudocomponents by tuning to the MMP for pure $\mathrm{CO}_{2}$ injection. 1-D simulation results are presented to validate the improved tuning procedure

Chapter 3 also examines the effect of dispersion on both the lumped and unlumped models. Saturation profile at levels of dispersion of the order seen in slimtubes and that observed at the field scale are compared for both the lumped and unlumped models. Chapter 4 presents conclusions and recommendations for future research.

Equation Chapter 2 Section 2 


\section{Chapter 2: New MMP Correlations}

All currently available correlations for both pure and impure $\mathrm{CO}_{2}$ floods are based on the limited available slim-tube MMPs. These correlations do not accurately account for the temperature dependence of MMP and are not applicable to a wide range of reservoir fluid types. In this chapter, new correlations based on the analytically calculated dispersion-free MMPs and the available slim-tube data are presented. Analytical MMPs are calculated based on the analytical theory developed by Johns and Orr (1996) for multicomponent gas floods.

Johns and Orr showed that the displacement path for dispersion-free flow is controlled by nc-1 key tie lines, which includes nc-3 crossover tie lines. They showed that the extension of successive key tie lines must intersect in composition hyperspace. Miscibility (MCM) is obtained when any of the key tie lines intersect the critical locus (or has a length of zero) as pressure (MMP) or enrichment (MME) is increased. The analytical approach is implemented in PVTSim, a commercially available software and MMPE, an in-house code developed at the University of Texas for MMP/MME calculations. Both codes are used in this research.

\subsection{PVTSIM AND MMPE CODES}

The two codes differ in their solution approach to the analytical method. PVTSim employs the Jessen et al. (1998) approach where as the Yuan et a.l (2002) approach, which has substantially reduced number of parameters, is implemented in MMPE. The MMPE code makes both MME and MMP calculations while PVTSim is only capable of MMP calculations. PVTSim uses less computational time than the MMPE code for MMP calculations. The codes give similar MMP results for most of the cases studied (see 
appendix A), although, for some EOS models the PVTSim code had computational difficulties. For such cases, the MMPs were determined from the MMPE code.

Figure 2.1 illustrates the calculation of dispersion-free analytical MMP for an example eight-component oil (oil A) displacement by $\mathrm{CO}_{2}$ using the MMPE code. Oil A is black oil with a bubble-point pressure of 3375.5 psia at $189^{\circ} \mathrm{F}$. As shown in Figure 2.1, all key tie-line lengths decrease with pressure. The second crossover tie line (labeled C2), however, intersects the critical locus first (becomes zero length) at a pressure of $3322 \pm 1$ psia, which is the MMP. Because one of the crossover tie lines controls miscibility, the displacement of oil A by $\mathrm{CO}_{2}$ is a combined condensing/vaporizing displacement (Johns et al. 2002).

Figure 2.2 and 2.3 compare the analytical MMP and MME predictions of the two codes for oil A and an example 12-component oil respectively. As mentioned above, PVTSim does not carry out MME calculations. To determine MMEs using this code, the MMP for different injection gas enrichments are computed instead. The MMP determined is the pressure for which the injection gas composition is at the MME. In Figure 2.2, both codes show consistent results with an average difference in MMP values of only 4 psi. However, in Figure 2.3, the codes show much larger differences in MMP predictions for some gas enrichments considered. The largest difference was 268 psi. This difference is due to convergence errors in the calculation of MME for multicomponent gas displacement by the codes. 


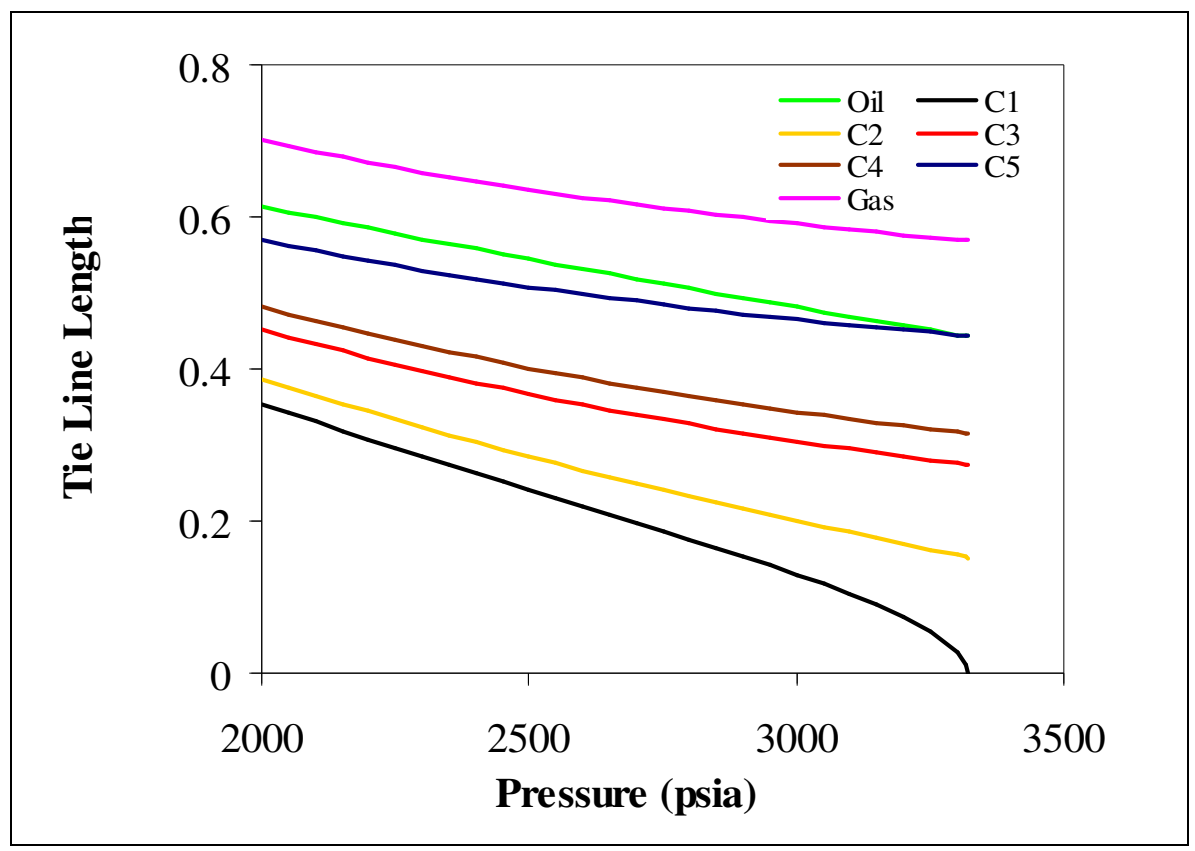

Figure 2.1: Tie-line lengths for key tie lines in the displacement of oil A by pure $\mathrm{CO}_{2}$ at $189^{\circ} \mathrm{F}$. The MMP is 3322 psia where one of the key tie lines first reaches zero length.

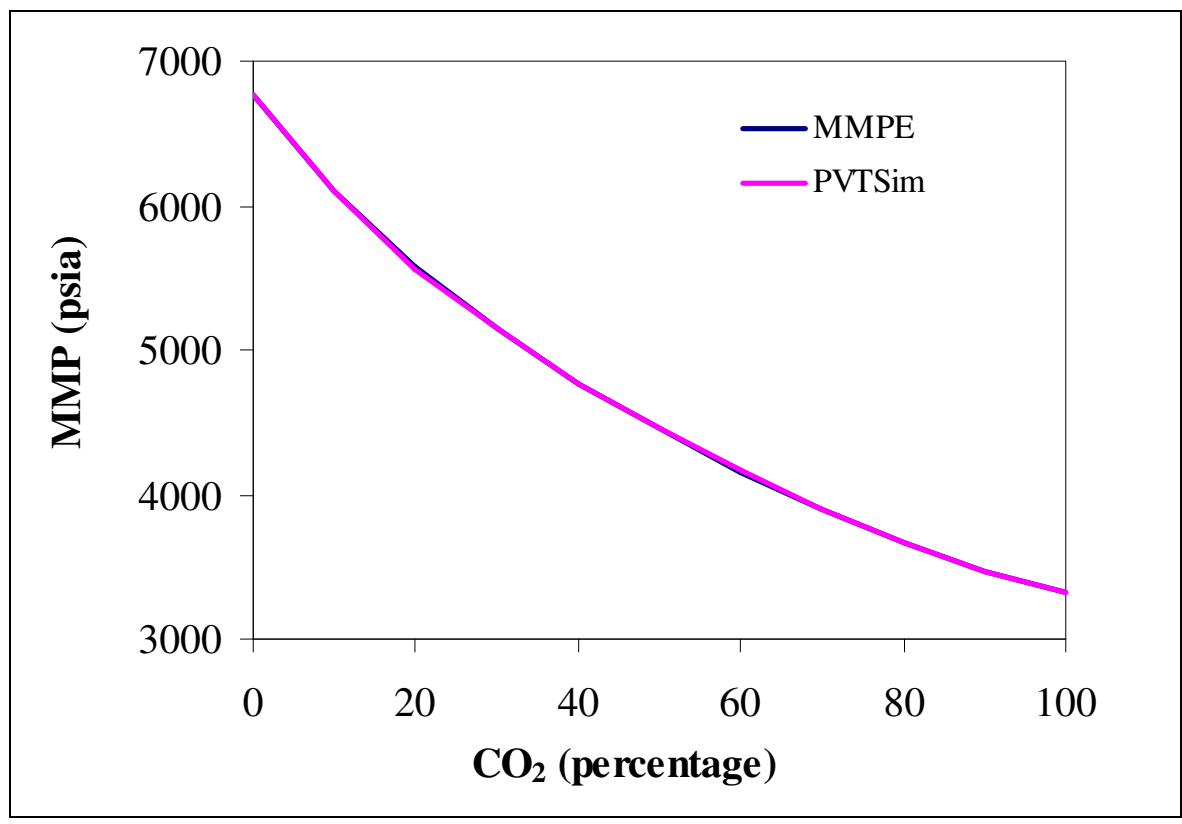

Figure 2.2: Comparison of MMPs calculated for the displacement of Oil A by gas mixtures containing $\mathrm{CO}_{2}$ and $\mathrm{C}_{1}$ at $189^{\circ} \mathrm{F}$ using PVTSim and MMPE code. 


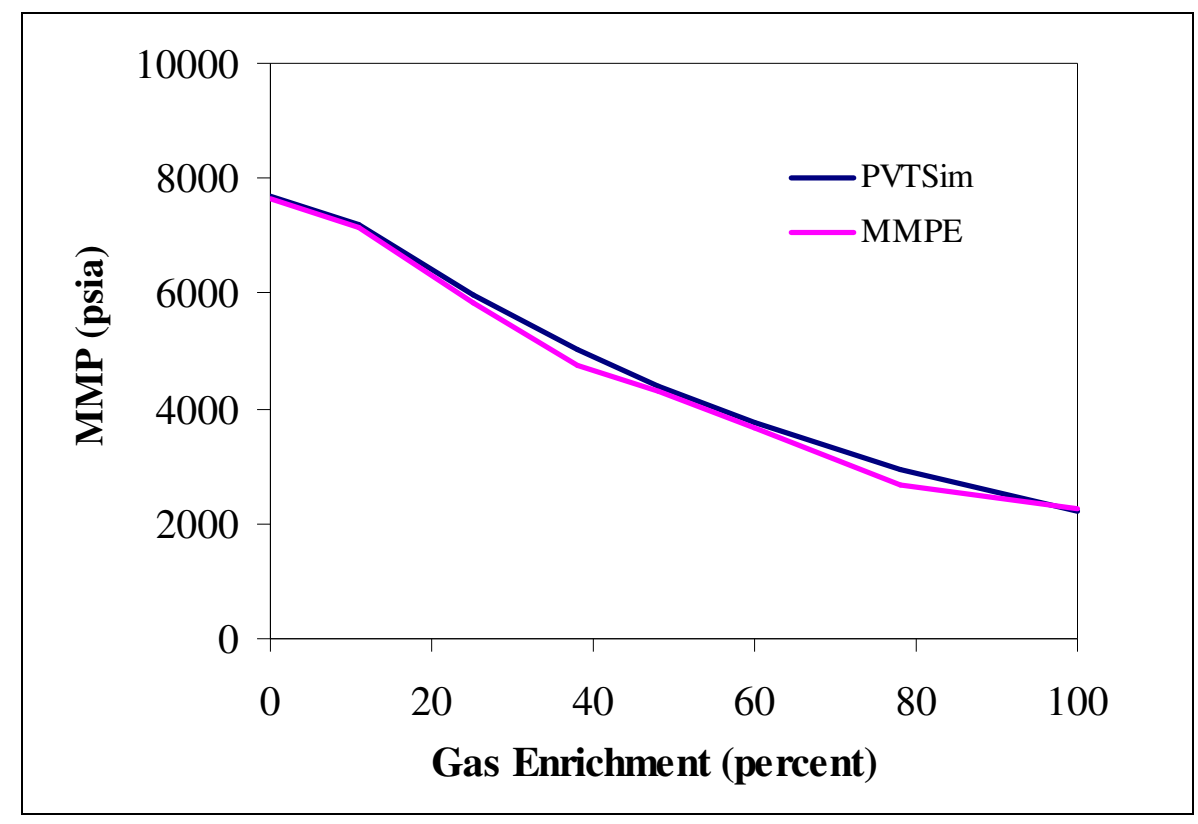

Figure 2.3: Comparison of MMPs calculated for the displacement of 12-component oil by gas mixtures at $182^{\circ} \mathrm{F}$ using PVTSim and MMPE code. 


\subsection{NEW MMP CORRELATION FOR PURE $\mathrm{CO}_{2}$ INJECTION}

Elsharkaway et al. (1992) reported three trends of MMP for different oils as a function of temperature. Depending on the oil used they observed concave downward, concave upward or linear trends with temperature. Figure 2.4 illustrates a slight concave downward trend in the analytically calculated MMPs with temperature. The trends for the correlations, however, are nearly linear and in some cases have the wrong slope. Figure 2.5 illustrates a similar downward trend, but for a different oil, in this case a volatile oil from Jutila et al. (2001) (referred to as oil D here).

Most correlations in the literature predict nearly linear behaviour of MMP with respect to temperature. However, as predicted by the analytical theory and experimental phase behaviour, the increase in MMP should decrease at higher temperatures, owing to the theoretical limit at which the system should transform into a gas/gas system at extreme temperatures. Therefore, we would not expect an indefinite increase in MMP with an increase in temperature.

The analytical MMPs for both oils A and D are fitted to a quadratic function of reservoir temperature with very little error as shown in Figs. 2.4 and 2.5. The approach, therefore, is to develop a new correlation for $\mathrm{CO}_{2}$ floods based on quadratic fits of analytical MMPs with temperature. The data set used consists of 70 analytically calculated MMPs from nine oils (see Table 2.1). As for other correlations, three input parameters were selected for the estimation of MMP: the molecular weight of $\mathrm{C}_{7+}$, the total mole fraction of $\mathrm{C}_{2}-\mathrm{C}_{6}$, and the reservoir temperature. We found a good fit to the analytical MMPs with the equation: 


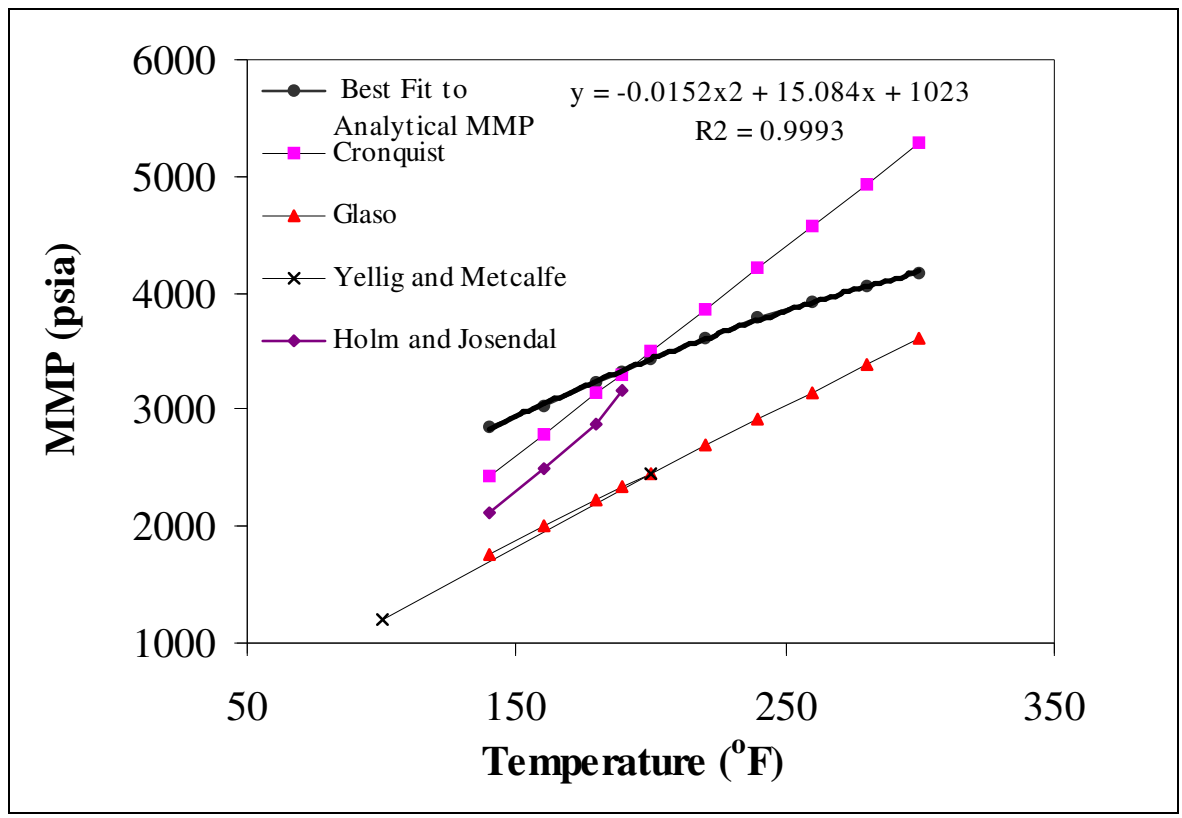

Figure 2.4: MMP estimated from different correlations and calculated from analytical method for black oil A. The MMPs are fit to a quadratic function.

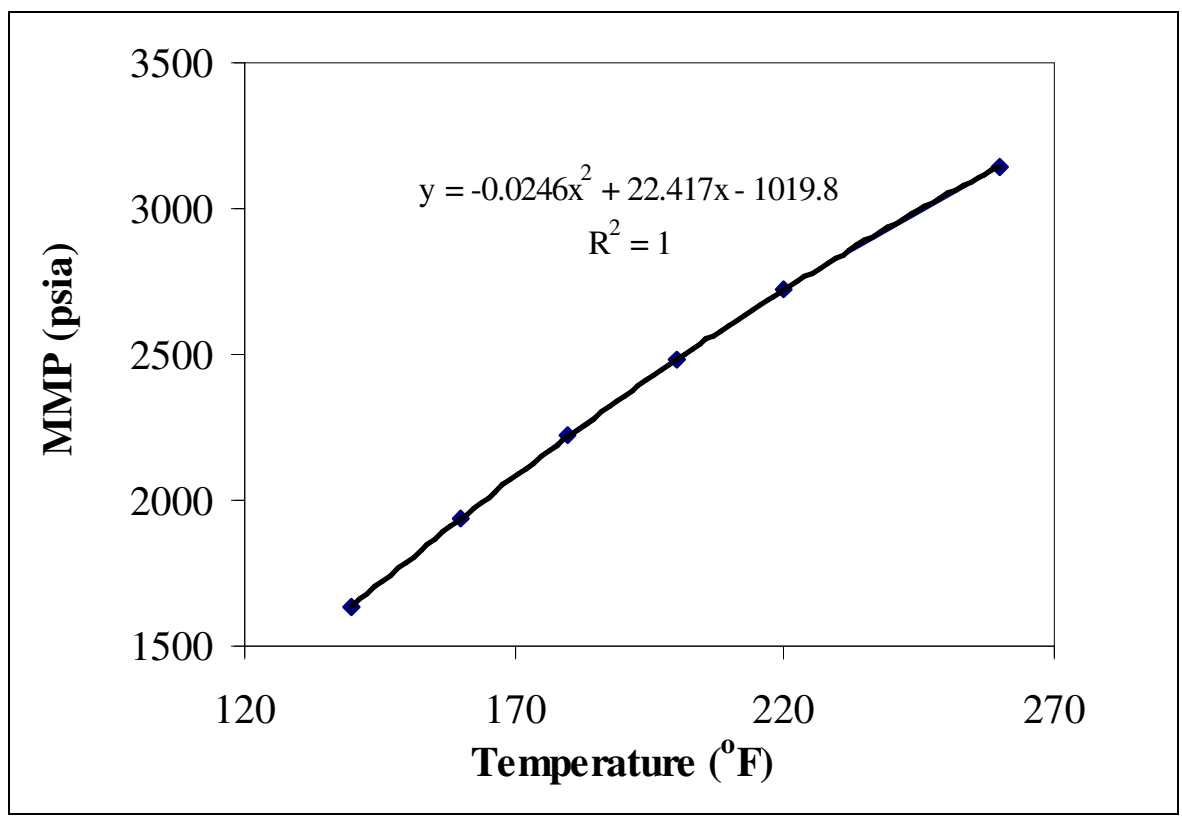

Figure 2.5: MMPs calculated from analytical method for volatile oil D. The MMPs are fit to a quadratic function. 
Table 2.1: Oils used to generate the new MMP correlations for $\mathrm{CO}_{2}$ floods by analytical method.

\begin{tabular}{|c|c|c|c|c|}
\hline Reference & $\begin{array}{c}\text { Molecular } \\
\text { Weight of } \mathrm{C}_{7+}\end{array}$ & $\begin{array}{l}\text { Mole \% } \\
\mathrm{C}_{2}-\mathrm{C}_{6}\end{array}$ & Mole $\% \mathrm{C}_{1}$ & $\begin{array}{c}\text { Reservoir } \\
\text { Temperature } \\
\left({ }^{0} \mathrm{~F}\right)\end{array}$ \\
\hline Wang and Orr (2002) & $140.60 * *$ & 20.16 & 34.67 & 150 \\
\hline Oil A (Yuan, et al. 2002) & $194.90 * *$ & 19.58 & 47.91 & 189 \\
\hline Johns et al (2002) & 241.30 & 25.21 & 30.97 & 157 \\
\hline Oil B (unpublished) & $211.30 * *$ & 24.68 & 46.30 & 180 \\
\hline Oil C (unpublished) & $179.50 * *$ & 18.26 & 75.60 & 140 \\
\hline Oil D (Jutila, et al. 2001) & $148.90 * *$ & 14.11 & 81.92 & 275 \\
\hline Hong (1982) & $245.40 * *$ & 35.57 & 31.00 & 130 \\
\hline Khan et al. (1992) & 215 & 40.36 & 17.52 & $94 *$ \\
\hline Oil E (unpublished) & $241.59 * *$ & 10.39 & 44.55 & 165 \\
\hline
\end{tabular}

* These temperatures resulted in three phases and were not used.

** The oils corresponding to these data were used in the impure $\mathrm{CO}_{2}$ correlation. 


$$
\begin{aligned}
M M P_{\text {pure }}=a_{1} & +a_{2} M_{C_{7+}}+a_{3} P_{C_{2-6}}+\left(a_{4}+a_{5} M_{C_{7+}}+a_{6} \frac{P_{C_{2-6}}}{M_{C_{7+}}^{2}}\right) T \\
& +\left(a_{7}+a_{8} M_{C_{7+}}+a_{9} M_{C_{7+}}{ }^{2}+a_{10} P_{C_{2-6}}\right) T^{2}
\end{aligned}
$$

where $M M P_{\text {pure }}$ is the estimated MMP from the correlation for pure $\mathrm{CO}_{2}$ injection, $a_{1}-a_{10}$ are coefficients determined from a regression of the data, $M_{C 7+}$ is the molecular weight of $\mathrm{C}_{7+}, P_{C_{2-6}}$ is the total molar percentage of $\mathrm{C}_{2}-\mathrm{C}_{6}$, and $T$ is the reservoir temperature. For the nine oils used in the regression, $M_{C 7+}$ ranged from 140 to $245, P_{C_{2-6}}$ ranged from 11.3 to $40.3 \%$, and the reservoir temperature was varied from 120 to $300^{\circ} \mathrm{F}$. The absolute average error of the fit to the 70 MMPs is $6.6 \%$. For example, if the estimated MMP is 3000 psia, the true MMP is likely between 2802 psia and 3198 psia.

Figure 2.6 compares the estimated MMPs from the fit to the analytical MMPs to several other correlations and also to the MMPs estimated from slim-tube experiments (see Table 2.2). As shown, the correlation predicts the slim-tube MMPs about as well as the other correlations. The average absolute error for the 41 slim-tube MMPs is $15.7 \%$ for the analytical MMP correlation, $12.6 \%$ for Glaso's correlation, $15.3 \%$ for Cronquist, 16.7\% for Holm and Josendal, and $17.5 \%$ for Yellig and Metcalf.

Although the average error is about the same as the other correlations, the fit to the analytical MMPs is significant when considering the nature of the test data set in Table 2.2. First, the analytical MMP correlation is applicable over a wider range of input parameters. For example, the correlation is valid for $M_{C_{5+}}<180$, where others such as the Holm and Josendal correlation are not. Second, the analytical correlation is significant because the coefficients and charts in the other correlations were determined largely on best fits to the slim-tube MMPs in Table 2.2. Hence, one would expect good predictions by the other correlations for this data set. The coefficients in Glaso's correlation for 


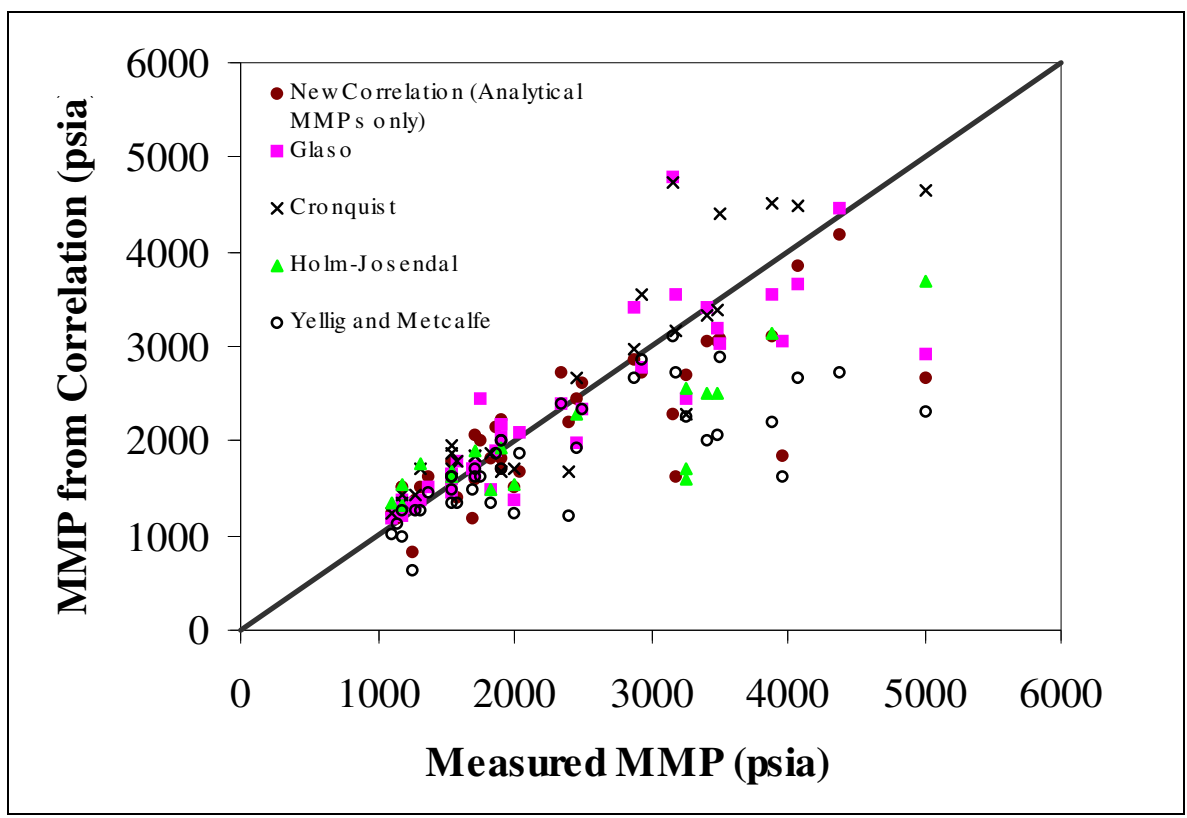

Figure 2.6: Comparison of the analytical MMP correlation with other currently used correlations. The correlation is based solely on analytically calculated MMPs.

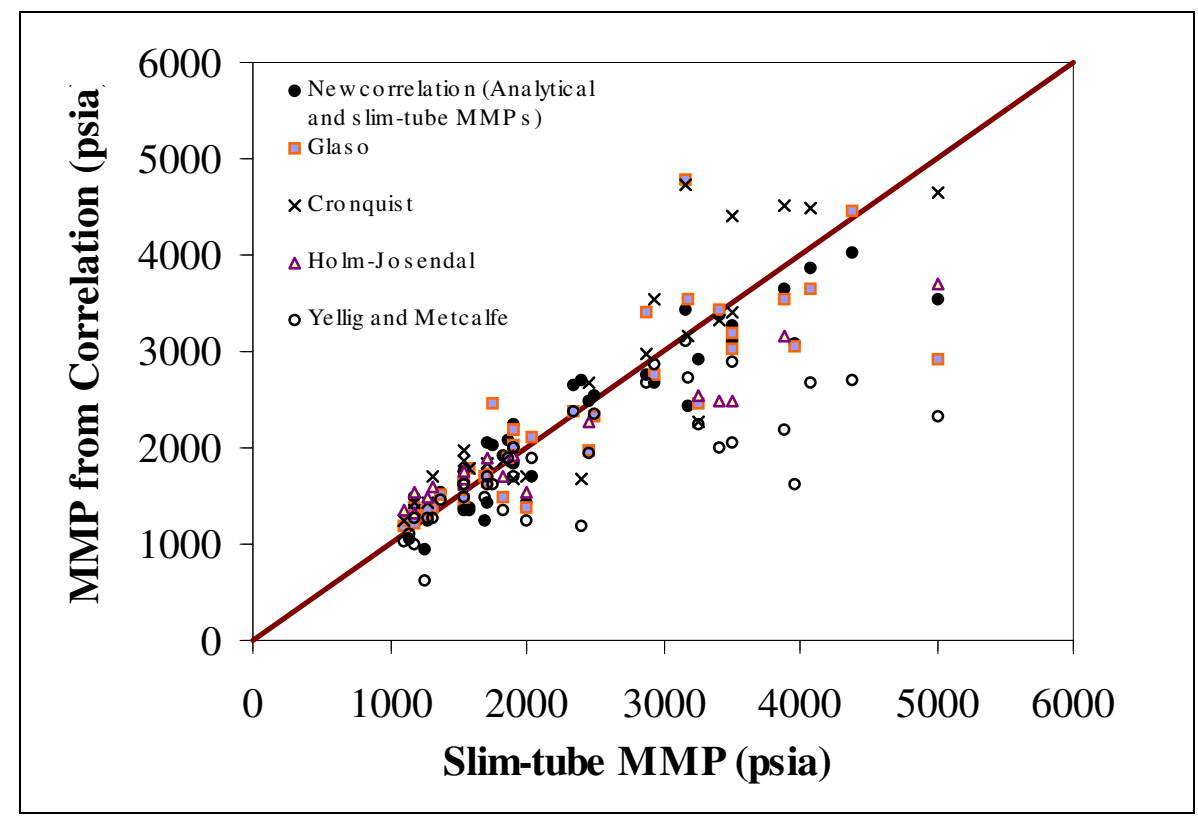

Figure 2.7: Comparison of the new correlation with other currently used correlations. The correlation is based on both the analytically calculated MMPs and slimtube MMPs. 
Table 2.2: Comparison of MMPs estimated from correlations to slim-tube MMPs for oil displacements by $\mathrm{CO}_{2}$. Blank spaces indicate data that were not available.

\begin{tabular}{|c|c|c|c|c|c|c|c|c|c|c|c|}
\hline Reference & $\begin{array}{c}\mathrm{T} \\
\left({ }^{\circ} \mathrm{F}\right)\end{array}$ & $\begin{array}{l}\text { Mol } \\
\% \mathrm{C}_{1}\end{array}$ & $\begin{array}{c}\mathrm{Mol} . \% \\
\mathrm{C}_{2}-\mathrm{C}_{6}\end{array}$ & $\mathrm{M}_{\mathrm{C} 5+}$ & $\mathrm{M}_{\mathrm{C} 7+}$ & $\begin{array}{l}\text { Slim- } \\
\text { Tube } \\
\text { MMP } \\
\text { (psia) }\end{array}$ & $\begin{array}{l}\text { MMP from } \\
\text { Eq. } 2.1 \\
\text { (psia) }\end{array}$ & $\begin{array}{l}\text { Glaso } \\
(1985) \\
\text { MMP } \\
\text { (psia) }\end{array}$ & $\begin{array}{c}\text { Cronquist } \\
\text { (1977) } \\
\text { MMP } \\
\text { (psia) }\end{array}$ & $\begin{array}{c}\text { Holm- } \\
\text { Josendal } \\
(1980) \\
\text { MMP } \\
\text { (psia) }\end{array}$ & $\begin{array}{c}\text { Yellig et } \\
\text { al (1980) } \\
\text { MMP } \\
(\mathrm{psia})\end{array}$ \\
\hline $\begin{array}{c}\text { Rathmell and } \\
\text { Stalkup } \\
(1971)\end{array}$ & 103 & 28 & 30 & 200 & 223 & 2000 & 1428 & 1376 & 1703 & 1550 & 1247 \\
\hline $\begin{array}{c}\text { Rathmell and } \\
\text { Stalkup } \\
(1971)\end{array}$ & 109 & 17 & 28.8 & 204 & 222 & 1550 & 1583 & 1450 & 1708 & 1625 & 1339 \\
\hline $\begin{array}{c}\text { Rathmell and } \\
\text { Stalkup } \\
(1971)\end{array}$ & 186 & 45 & 13 & 248 & 268 & 5000 & 3548 & 2909 & 4658 & 3700 & 2317 \\
\hline $\begin{array}{c}\text { Holm and } \\
\text { Josendal } \\
(1980)\end{array}$ & 135 & 2 & 15 & 183 & 193 & 1900 & 2253 & 2024 & 1683 & 1920 & 1696 \\
\hline $\begin{array}{c}\text { Holm and } \\
\text { Josendal } \\
(1980)\end{array}$ & 71 & & 15 & & 193 & 1250 & 959 & 1289 & & & 620 \\
\hline $\begin{array}{c}\text { Metcalfe } \\
(1982)\end{array}$ & 105 & 11 & 25 & 188 & 206 & 1190 & 1492 & 1368 & 1444 & 1550 & 1279 \\
\hline $\begin{array}{l}\text { Metcalfe } \\
(1982)\end{array}$ & 135 & 11 & 25 & 188 & 206 & 1720 & 2056 & 1728 & 1842 & 1900 & 1696 \\
\hline $\begin{array}{c}\text { Metcalfe } \\
(1982)\end{array}$ & 90 & 11 & 25 & 188 & 206 & 1100 & 1176 & 1188 & 1244 & 1350 & 1027 \\
\hline $\begin{array}{l}\text { Yellig and } \\
\text { Metcalfe } \\
(1980)\end{array}$ & 95 & & 20 & & 201 & 1150 & 1063 & 1245 & & & 1116 \\
\hline $\begin{array}{c}\text { Yellig and } \\
\text { Metcalfe } \\
(1980)\end{array}$ & 118 & & 20 & & 201 & 1375 & 1527 & 1516 & & & 1469 \\
\hline $\begin{array}{c}\text { Yellig and } \\
\text { Metcalfe } \\
(1980)\end{array}$ & 150 & & 20 & & 201 & 1875 & 2079 & 1893 & & & 1884 \\
\hline $\begin{array}{c}\text { Yellig and } \\
\text { Metcalfe } \\
(1980)\end{array}$ & 192 & & 20 & & 201 & 2350 & 2637 & 2388 & & & 2388 \\
\hline $\begin{array}{c}\text { Alston et al } \\
(1985)\end{array}$ & 219 & & 3 & & 195 & 4390 & 4023 & 4452 & & & 2716 \\
\hline $\begin{array}{c}\text { Alston et al } \\
(1985)\end{array}$ & 230 & 33 & 36 & 181 & 185 & 2930 & 2678 & 2770 & 3544 & & 2852 \\
\hline $\begin{array}{c}\text { Alston et al } \\
(1985)\end{array}$ & 160 & 41 & 7 & 221 & 227 & 3400 & 3392 & 3423 & 3317 & 2500 & 2005 \\
\hline $\begin{array}{c}\text { Alston et al } \\
(1985)\end{array}$ & 216 & 51 & 10 & 205 & 210 & 4085 & 3864 & 3652 & 4490 & & 2679 \\
\hline $\begin{array}{c}\text { Alston et al } \\
(1985)\end{array}$ & 100 & 4.9 & 2 & 236 & 245 & 2400 & 2695 & 3303 & 1687 & & 1199 \\
\hline $\begin{array}{l}\text { Alston et al } \\
\quad(1985)\end{array}$ & 154 & 31 & 23 & 204 & 210 & 2450 & 2477 & 1971 & 2676 & 2280 & 1933 \\
\hline
\end{tabular}


Table 2.2 cont'd.

\begin{tabular}{|c|c|c|c|c|c|c|c|c|c|c|c|}
\hline Reference & $\begin{array}{c}\mathrm{T} \\
\left({ }^{\circ} \mathrm{F}\right) \\
\end{array}$ & $\begin{array}{l}\text { Mol } \\
\% \mathrm{C}_{1} \\
\end{array}$ & $\begin{array}{c}\text { Mol \% } \\
\mathrm{C}_{2}-\mathrm{C}_{6} \\
\end{array}$ & $\mathrm{M}_{\mathrm{C} 5+}$ & $\mathrm{M}_{\mathrm{C} 7+}$ & $\begin{array}{l}\text { Slim- } \\
\text { Tube } \\
\text { MMP } \\
\text { (psia) } \\
\end{array}$ & $\begin{array}{c}\text { MMP from } \\
\text { Eq. } 2.1 \\
\text { (psia) }\end{array}$ & $\begin{array}{l}\text { Glaso } \\
(1985) \\
\text { MMP } \\
\text { (psia) }\end{array}$ & $\begin{array}{c}\text { Cronquist } \\
\text { (1977) } \\
\text { MMP } \\
\text { (psia) } \\
\end{array}$ & $\begin{array}{c}\text { Holm- } \\
\text { Josendal } \\
(1980) \\
\text { MMP } \\
\text { (psia) }\end{array}$ & $\begin{array}{c}\text { Yellig et al } \\
(1980) \\
\text { MMP } \\
\text { (psia) }\end{array}$ \\
\hline $\begin{array}{c}\text { Alston et al } \\
(1985)\end{array}$ & 234 & 33 & 28 & 214 & 220 & 3502 & 3111 & 3032 & 4402 & & 2902 \\
\hline $\begin{array}{l}\text { Alston et al } \\
\quad(1985)\end{array}$ & 176 & 53 & 9 & 241 & 245 & 3880 & 3657 & 3542 & 4514 & 3150 & 2197 \\
\hline $\begin{array}{c}\text { Sebastian et } \\
\text { al. }(1985)\end{array}$ & 88 & 12 & 24.2 & 205 & 240 & 1175 & 1495 & 1221 & 1339 & 1325 & 990 \\
\hline $\begin{array}{c}\text { Abdassah et } \\
\text { al. }(2000)\end{array}$ & 250 & 0.4 & 12.3 & 259 & 278 & 3160 & 3432 & 4790 & 4732 & & 3106 \\
\hline $\begin{array}{c}\text { Dichary et al. } \\
\text { (1973) }\end{array}$ & 130 & 29 & 40.4 & 171 & 197.4 & 1550 & 1368 & 1652 & 1871 & 1675 & 1631 \\
\hline $\begin{array}{c}\text { Cardenas et } \\
\text { al. (1984) }\end{array}$ & 164 & 49 & 8.84 & 210 & 218 & 3500 & 3281 & 3199 & 3397 & 2500 & 2053 \\
\hline $\begin{array}{l}\text { Zain et al. } \\
(2001)\end{array}$ & 215 & 9.8 & 31.9 & & 196 & 2875 & 2761 & 3414 & 2978 & & 2667 \\
\hline $\begin{array}{c}\text { Zhou et } \\
\text { al.(1999) }\end{array}$ & 180 & 4.4 & 24 & 185 & 234 & 3250 & 2923 & 2452 & 2283 & 2550 & 2245 \\
\hline $\begin{array}{c}\text { Chaback et al } \\
(1986)\end{array}$ & 130 & & 36.6 & & 198 & 1550 & 1499 & 1653 & & & 1631 \\
\hline $\begin{array}{c}\text { Spence } \text { et al. } \\
(1980)\end{array}$ & 104 & 24 & 30.7 & 202 & 221 & 1316 & 1404 & 1384 & 1700 & 1600 & 1263 \\
\hline $\begin{array}{c}\text { Spence et al. } \\
(1980)\end{array}$ & 109 & 17 & 23.4 & 221 & 235 & 1822 & 1910 & 1494 & 1861 & 1700 & 1339 \\
\hline $\begin{array}{l}\text { Frimodig et } \\
\text { al. (1983) }\end{array}$ & 130 & & 13.4 & & 319.7 & 3970 & 3084 & 3067 & & & 1631 \\
\hline $\begin{array}{c}\text { Chaback } \\
(1988) \\
\end{array}$ & 220 & 43 & 30.8 & 154 & 273 & 3190 & 2425 & 3543 & 3152 & & 2728 \\
\hline $\begin{array}{c}\text { Chaback } \\
(1988) \\
\end{array}$ & 130 & 30 & 37.3 & 169 & 190 & 1708 & 1424 & 1645 & 1847 & & 1631 \\
\hline $\begin{array}{c}\text { Hamoodi } \\
(1986) \\
\end{array}$ & 110 & 54 & 43.5 & 160 & 284 & 1572 & 1384 & 1792 & 1790 & & 1354 \\
\hline $\begin{array}{c}\text { Metcalfe et al. } \\
(1979)\end{array}$ & 160 & & 25 & & 142 & 1900 & 1861 & 2179 & & & 2005 \\
\hline $\begin{array}{l}\text { Metcalfe et al. } \\
\text { (1979) }\end{array}$ & 160 & & 30 & & 142 & 1900 & 1840 & 2179 & & & 2005 \\
\hline $\begin{array}{l}\text { Metcalfe et al. } \\
\text { (1979) }\end{array}$ & 120 & & 21 & & 142 & 1700 & 1240 & 1716 & & & 1497 \\
\hline $\begin{array}{l}\text { Whiston } \\
\text { (1984) }\end{array}$ & 150 & & 20 & & 139 & 2030 & 1706 & 2101 & & & 1884 \\
\hline $\begin{array}{c}\text { Henry et al. } \\
(1983)\end{array}$ & 120 & 16 & 31 & 214 & 227 & 1535 & 1744 & 1610 & 1960 & 1750 & 1497 \\
\hline $\begin{array}{l}\text { Henry et al. } \\
\text { (1983) }\end{array}$ & 104 & 8.3 & 31 & 191 & 205 & 1274 & 1252 & 1355 & 1432 & 1500 & 1263 \\
\hline Jacobson & 188 & & 31.1 & & 200 & 2500 & 2543 & 2337 & & & 2341 \\
\hline
\end{tabular}


example was developed using most of the data points (23 out of 41). When the other independent (non-fitted slim-tube MMPs) are considered, the error in the MMPs from Glaso's correlation increases to over 15\%. Glaso used a total of 28 experimental data points, four of which did not have reported $\mathrm{C}_{2}-\mathrm{C}_{6}$ mole fractions.

The analytical correlation is based only on nine EOS characterizations and is therefore limited to oils of similar type. The $15.7 \%$ average error in the prediction of the analytical correlation for the slim-tube data of Table 2.2, is due principally to three data points that fall outside the range of the nine EOS characterization $\left(M_{C 7+}>245\right)$ used to develop the correlation (see Figure 2.6). Excluding these three data points, the average error of prediction of the generated analytically correlation drops to $10.3 \%$ for the same independent data set. Therefore, in order to improve the predictability of our correlation (especially in the aforementioned data range), the 70 analytical MMPs (see Table 2.3) and 41 experimental slim-tube MMPs (see Table 2.2) were regressed to obtain a new set of coefficients. All the MMPs were weighted equally in the regression. The best fit coefficients for Eq. 1 were found to be

$$
\begin{aligned}
& a_{1}=-1.4634 \mathrm{E}+03 \\
& a_{2}=0.6612 \mathrm{E}+01 \\
& a_{3}=-4.4979 \mathrm{E}+01 \\
& a_{4}=0.2139 \mathrm{E}+01 \\
& a_{5}=1.1667 \mathrm{E}-01 \\
& a_{6}=8.1661 \mathrm{E}+03 \\
& a_{7}=-1.2258 \mathrm{E}-01 \\
& a_{8}=1.2883 \mathrm{E}-03 \\
& a_{9}=-4.0152 \mathrm{E}-06 \\
& a_{10}=-9.2577 \mathrm{E}-04
\end{aligned}
$$


Table 2.3: Comparison of MMPs estimated from correlations for oil displacements by $\mathrm{CO}_{2}$ to analytically calculated MMPs.

\begin{tabular}{|c|c|c|c|c|c|}
\hline Reference & $\begin{array}{c}\text { Temperat } \\
\text { ure }\left({ }^{0} \mathrm{~F}\right)\end{array}$ & $\begin{array}{l}\text { Molecular } \\
\text { Weight of } \\
\mathrm{C}_{7+}\end{array}$ & $\begin{array}{c}\text { Mole \% } \\
\mathrm{C}_{2}-\mathrm{C}_{6}\end{array}$ & $\begin{array}{c}\text { Analytical } \\
\text { MMP (psia) }\end{array}$ & $\begin{array}{l}\text { MMP from } \\
\text { Eq. } 2.1 \text { (psia) }\end{array}$ \\
\hline Wang and Orr (2002) & 120 & 140.56 & 20.16 & 1320 & 1236 \\
\hline Wang and Orr (2002) & 150 & 140.56 & 20.16 & 1879 & 1721 \\
\hline Wang and Orr (2002) & 180 & 140.56 & 20.16 & 2162 & 2134 \\
\hline Wang and Orr (2002) & 200 & 140.56 & 20.16 & 2308 & 2371 \\
\hline Wang and Orr (2002) & 220 & 140.56 & 20.16 & 2421 & 2575 \\
\hline Wang and Orr (2002) & 240 & 140.56 & 20.16 & 2502 & 2748 \\
\hline Wang and Orr (2002) & 260 & 140.56 & 20.16 & 2552 & 2890 \\
\hline Wang and Orr (2002) & 280 & 140.56 & 20.16 & 2575 & 3000 \\
\hline Oil A (Yuan, et al. 2002) & 140 & 194.88 & 19.581 & 2856 & 2214 \\
\hline Oil A (Yuan, et al. 2002) & 160 & 194.88 & 19.581 & 3034 & 2542 \\
\hline Oil A (Yuan, et al. 2002) & 180 & 194.88 & 19.581 & 3234 & 2837 \\
\hline Oil A (Yuan, et al. 2002) & 189 & 194.88 & 19.581 & 3322 & 2959 \\
\hline Oil A (Yuan, et al. 2002) & 200 & 194.88 & 19.581 & 3430 & 3098 \\
\hline Oil A (Yuan, et al. 2002) & 220 & 194.88 & 19.581 & 3612 & 3325 \\
\hline Oil A (Yuan, et al. 2002) & 240 & 194.88 & 19.581 & 3780 & 3519 \\
\hline Oil A (Yuan, et al. 2002) & 260 & 194.88 & 19.581 & 3928 & 3679 \\
\hline Oil A (Yuan, et al. 2002) & 280 & 194.88 & 19.581 & 4058 & 3805 \\
\hline Oil A (Yuan, et al. 2002) & 300 & 194.88 & 19.581 & 4170 & 3897 \\
\hline Johns et al. (2002) & 100 & 241.26 & 25.21 & 1771 & 1717 \\
\hline Johns et al. (2002) & 120 & 241.26 & 25.21 & 1924 & 2090 \\
\hline Johns et al. (2002) & 150 & 241.26 & 25.21 & 2170 & 2547 \\
\hline Johns et al. (2002) & 220 & 241.26 & 25.21 & 2730 & 3131 \\
\hline Johns et al. (2002) & 240 & 241.26 & 25.21 & 2876 & 3174 \\
\hline Johns et al. (2002) & 250 & 241.26 & 25.21 & 2946 & 3175 \\
\hline Johns et al. (2002) & 260 & 241.26 & 25.21 & 3014 & 3162 \\
\hline Johns et al. (2002) & 280 & 241.26 & 25.21 & 3145 & 3095 \\
\hline Johns et al. (2002) & 300 & 241.26 & 25.21 & 3269 & 2972 \\
\hline Oil D (Jutila et al. 2001) & 120 & 148.92 & 14.11 & 1276 & 1402 \\
\hline Oil D (Jutila et al. 2001) & 140 & 148.92 & 14.11 & 1637 & 1725 \\
\hline Oil D (Jutila et al. 2001) & 160 & 148.92 & 14.11 & 1941 & 2021 \\
\hline Oil D (Jutila et al. 2001) & 180 & 148.92 & 14.11 & 2222 & 2292 \\
\hline Oil D (Jutila et al. 2001) & 200 & 148.92 & 14.11 & 2482 & 2536 \\
\hline Oil D (Jutila et al. 2001) & 220 & 148.92 & 14.11 & 2722 & 2753 \\
\hline Oil D (Jutila et al. 2001) & 240 & 148.92 & 14.11 & 2943 & 2945 \\
\hline Oil D (Jutila et al. 2001) & 250 & 148.92 & 14.11 & 3048 & 3031 \\
\hline Oil D (Jutila et al. 2001) & 260 & 148.92 & 14.11 & 3150 & 3110 \\
\hline Oil D (Jutila et al. 2001) & 275 & 148.92 & 14.11 & 3298 & 3217 \\
\hline
\end{tabular}


Table 2.3 cont'd.

\begin{tabular}{|c|c|c|c|c|c|}
\hline Reference & $\begin{array}{c}\text { Temperat } \\
\text { ure }\left({ }^{0} \mathrm{~F}\right)\end{array}$ & $\begin{array}{c}\text { Molecular } \\
\text { Weight of } \\
\mathrm{C}_{7+}\end{array}$ & $\begin{array}{c}\text { Mole } \% \\
\mathrm{C}_{2}-\mathrm{C}_{6}\end{array}$ & $\begin{array}{l}\text { Analytical } \\
\text { MMP (psia) }\end{array}$ & $\begin{array}{l}\text { MMP from } \\
\text { Eq. } 2.1 \text { (psia) }\end{array}$ \\
\hline Oil D (Jutila et al. 2001) & 280 & 148.92 & 14.11 & 3346 & 3249 \\
\hline Oil D (Jutila et al. 2001) & 300 & 148.92 & 14.11 & 3533 & 3362 \\
\hline Hong (1982) & 120 & 245.40 & 35.57 & 1597 & 1685 \\
\hline Hong (1982) & 130 & 245.40 & 35.57 & 1712 & 1838 \\
\hline Hong (1982) & 140 & 245.40 & 35.57 & 1821 & 1974 \\
\hline Hong (1982) & 150 & 245.40 & 35.57 & 1923 & 2095 \\
\hline Hong (1982) & 160 & 245.40 & 35.57 & 2017 & 2199 \\
\hline Hong (1982) & 180 & 245.40 & 35.57 & 2177 & 2358 \\
\hline Hong (1982) & 200 & 245.40 & 35.57 & 2302 & 2453 \\
\hline Hong (1982) & 220 & 245.40 & 35.57 & 2394 & 2482 \\
\hline Khan et al. (1992) & 180 & 229.00 & 34.71 & 1751 & 2401 \\
\hline Khan et al. (1992) & 200 & 229.00 & 34.71 & 1895 & 2552 \\
\hline Khan et al. (1992) & 250 & 229.00 & 34.71 & 2293 & 2683 \\
\hline Oil B (unpublished) & 140 & 211.27 & 24.68 & 2633 & 2201 \\
\hline Oil B (unpublished) & 160 & 211.27 & 24.68 & 2760 & 2511 \\
\hline Oil B (unpublished) & 180 & 211.27 & 24.68 & 2923 & 2780 \\
\hline Oil B (unpublished) & 200 & 211.27 & 24.68 & 3088 & 3007 \\
\hline Oil B (unpublished) & 220 & 211.27 & 24.68 & 3242 & 3192 \\
\hline Oil B (unpublished) & 240 & 211.27 & 24.68 & 3379 & 3334 \\
\hline Oil B (unpublished) & 250 & 211.27 & 24.68 & 3440 & 3390 \\
\hline Oil B (unpublished) & 260 & 211.27 & 24.68 & 3496 & 3435 \\
\hline Oil B (unpublished) & 280 & 211.27 & 24.68 & 3592 & 3494 \\
\hline Oil B (unpublished) & 300 & 211.27 & 24.68 & 3667 & 3511 \\
\hline Oil C (unpublished) & 120 & 179.49 & 18.26 & 1335 & 1709 \\
\hline Oil C (unpublished) & 140 & 179.49 & 18.26 & 1673 & 2067 \\
\hline Oil C (unpublished) & 300 & 179.49 & 18.26 & 3495 & 3849 \\
\hline Oil E (unpublished) & 140 & 241.59 & 10.387 & 2493 & 3058 \\
\hline Oil E (unpublished) & 165 & 241.59 & 10.387 & 2833 & 3430 \\
\hline Oil E (unpublished) & 180 & 241.59 & 10.387 & 3024 & 3620 \\
\hline Oil E (unpublished) & 200 & 241.59 & 10.387 & 3260 & 3836 \\
\hline Oil E (unpublished) & 220 & 241.59 & 10.387 & 3469 & 4006 \\
\hline Oil E (unpublished) & 250 & 241.59 & 10.387 & 3733 & 4180 \\
\hline Oil E (unpublished) & 300 & 241.59 & 10.387 & 4040 & 4247 \\
\hline
\end{tabular}


The inclusion of the experimental data increased the absolute average error from $6.6 \%$ to $10.3 \%$ for all the data fitted. The absolute average error of estimation of the slimtube MMPs, however, decreased from $15.7 \%$ to $11.9 \%$. This level of error is on the order of measurement errors in slim-tube MMPs.

The new correlation with the above coefficients is based on all 111 MMPs. For that data, $M_{C 7+}$ ranged from 139 to $319, P_{C_{2-6}}$ ranged from 2.0 to $40.3 \%$, and the reservoir temperature was varied from 71 to $300^{\circ} \mathrm{F}$. The new correlation incorporating the slimtube MMPs is still weighted in favour of the more accurate analytical data. The calculated MMPs using the new correlation are shown in Tables 2.2 and 2.3. A comparison of the new correlation and other available correlations from literature to the slim-tube MMPs is shown in Figure 2.7. As shown the new correlation is superior to all others.

\subsection{ANALYTICAL MMP CORRELATION FOR IMPURE $\mathrm{CO}_{2}$ FLOODS.}

The injection stream in $\mathrm{CO}_{2}$ floods often contains impurities such as methane, nitrogen, hydrogen sulfide, or ethane that are mostly the result of recycling and separation inefficiencies. Because achieving greater $\mathrm{CO}_{2}$ purity is quite costly, the maximum allowable dilution (MAD) is an important economic parameter. Methane is the most prevalent impurity found associated with naturally occurring $\mathrm{CO}_{2}$ deposits. In this section, we derive a new MMP correlation that accounts for the oil and gas composition, as well as the reservoir temperature. Analytical techniques bring a significant advantage to MMP calculations. They give very quick calculations, so that we can examine the effect of several factors like temperature and gas composition on MMP. Yuan et al. (2002) have demonstrated that MMP has a quadratic dependence on temperature.

The correlation for injection of $\mathrm{CO}_{2}$ contaminated with methane is developed from seven of the oil characterizations. Table 2.1 shows the properties of the seven oils 
used in the regression. $M_{C 7+}$ ranged from 140 to $245, C_{2-6}$ ranged from 10.4 to $24.7 \%$, and the reservoir temperature was varied from 110 to $300^{\circ} \mathrm{F}$. MMPs were calculated for displacements of the oils by various gas mixtures of $\mathrm{CO}_{2}$ and $\mathrm{C}_{1}$. For example, Figure 2.8 shows the MMP ratio (MMP for impure $\mathrm{CO}_{2}$ injection divided by the MMP for pure $\mathrm{CO}_{2}$ injection) for oil $\mathrm{A}$ as a function of $\mathrm{CO}_{2}$ content in the injection gas at different reservoir temperatures. As expected, the MMP ratio increases as the methane content in the injection gas increases at constant temperature and decreases as the reservoir temperature is increased at constant gas composition.

Figure 2.9 shows a similar plot of the MMP ratio for oil D. The MMP ratio for the volatile oil (oil D) is substantially greater than the black oil (oil A), especially for gas mixtures that contain significant amounts of methane. Sebastian's correlation (1985) is the widely reported correlation for impure $\mathrm{CO}_{2}$ floods. His correlation gives the MMP ratio as a function of the average critical temperature of the injection gas alone. This means that the composition and temperature of the reservoir were considered irrelevant. Figs. 2.8 and 2.9 demonstrate that this is incorrect. Figure 2.8 shows values from Sebastian's correlation for the MMP ratios at the different temperatures. The correlation predicts inaccurate MMP ratios for this oil sample. It has only one curve to represent the four curves given for oil A. The correlation has been shown to work effectively (Sebastian, et al. 1985) for only oil samples from the West Texas field from which it was developed. 


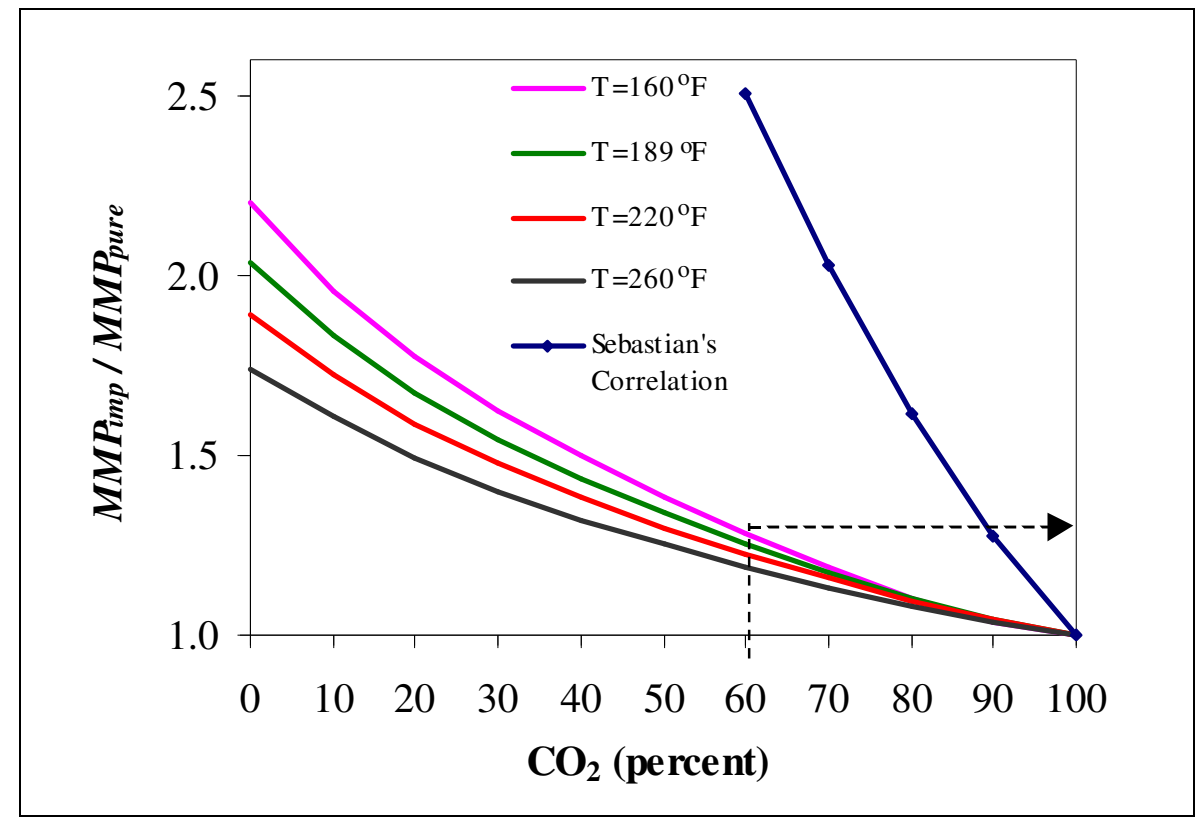

Figure 2.8: MMP ratios calculated from the analytical method and Sebastian's correlation for displacement of oil A (black oil) by mixtures of $\mathrm{CO}_{2}$ and $\mathrm{C}_{1}$ at different reservoir temperatures.

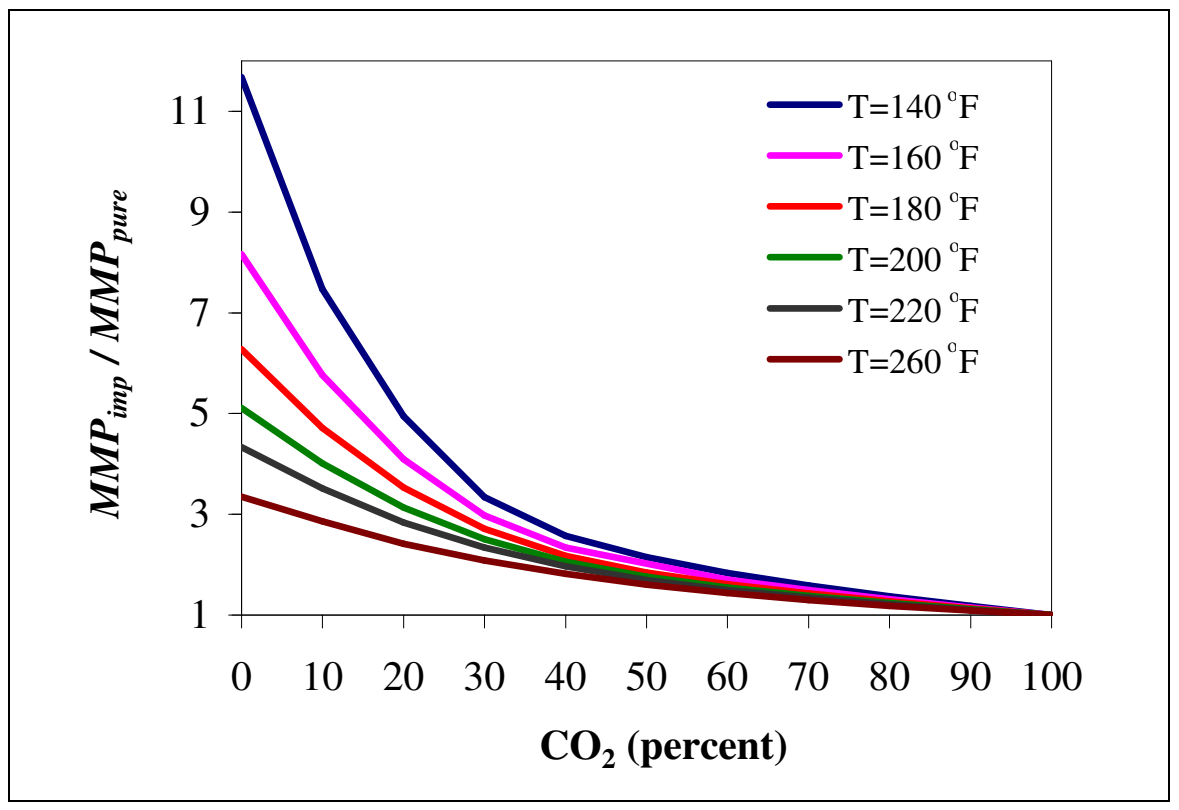

Figure 2.9: MMP ratios calculated from the analytical method for displacement of oil D (light oil) by mixtures of $\mathrm{CO}_{2}$ and $\mathrm{C}_{1}$ at different reservoir temperatures. 
For both oils A and D, the trends in the MMP ratio are concave upward. However, the trends in the region of interest (small methane contamination) are nearly linear between pure $\mathrm{CO}_{2}$ injection and injection of a gas mixture with about $60 \% \mathrm{CO}_{2}$ and $40 \%$ $\mathrm{C}_{1}$. Only the linear portions were used in the development of the new correlation. Based on seven oil characterizations, 119 analytical MMPs (see Table 2.2) were calculated and regressed to give the new correlation for impure $\mathrm{CO}_{2}$ as,

$$
\begin{aligned}
& \frac{M M P_{\text {imp }}}{M M P_{\text {pure }}}=1+m\left(P_{\mathrm{CO}_{2}}-100\right) \\
& m=f\left(M_{C_{7+}}, P_{C_{2-6}}, T\right)
\end{aligned}
$$

with

$$
\begin{array}{r}
m=a_{1}+a_{2} M_{C_{7+}}+a_{3} P_{C_{2-6}}+\left(a_{4}+a_{5} M_{C_{7+}}+a_{6} \frac{P_{C_{2-6}}}{M_{C_{7+}}{ }^{2}}\right) T \\
+\left(a_{7}+a_{8} M_{C_{7+}}+a_{9} M_{C_{7+}}{ }^{2}+a_{10} P_{C_{2-6}}\right) T^{2}
\end{array}
$$

and

$$
\begin{aligned}
& a_{1}=6.5996 E-02 \\
& a_{2}=-1.5246 E-04 \\
& a_{3}=1.3807 E-03 \\
& a_{4}=6.2384 E-04 \\
& a_{5}=-6.7725 E-07 \\
& a_{6}=-2.7344 E-02 \\
& a_{7}=-2.6953 E-06 \\
& a_{8}=1.7279 E-08
\end{aligned}
$$




$$
\begin{aligned}
& a_{9}=-3.1436 E-11 \\
& a_{10}=-1.9566 E-08
\end{aligned}
$$

Sebastian's correlation is given by:

$$
\frac{M M P_{\text {imp }}}{M M P_{\text {pure }}}=1.0-A\left(0.0213-2.51 * 10^{-4} A+2.35 A^{2}\right)
$$

where

$$
A=\frac{\left(\sum_{i=1}^{n_{c}} y_{i} T_{c i}-87.89\right)}{1.8}
$$

The correlation given by Eq. 2.2 is strictly valid only for methane contents in the gas up to $40 \%$.

Figure 2.10 and Table 2.4 compare the MMP ratio estimated from the new correlation and those calculated from the analytical method. As is shown, a good match is obtained with an average error of only $3 \%$ in the MMP ratio.

There is limited slim-tube data in the literature to validate the new correlation. The only usable slim-tube MMP data we could find are from the Levelland field Sebastian, et al. 1985). Because the Levelland oil was also used by Sebastian et al (1985) in their correlation, it does not represent an independent set of data to compare both correlations. As also shown by Kovarik (1985), their correlation is likely inaccurate for other oils. The new correlation developed here predicted the Levelland MMPs with good accuracy with a maximum average error of $9 \%$ in the MMP ratio for an injection stream 
that contains about 10 to $20 \%$ methane (see Table 2.5). The accuracy of the new correlation could be improved if additional EOS characterizations become available. 


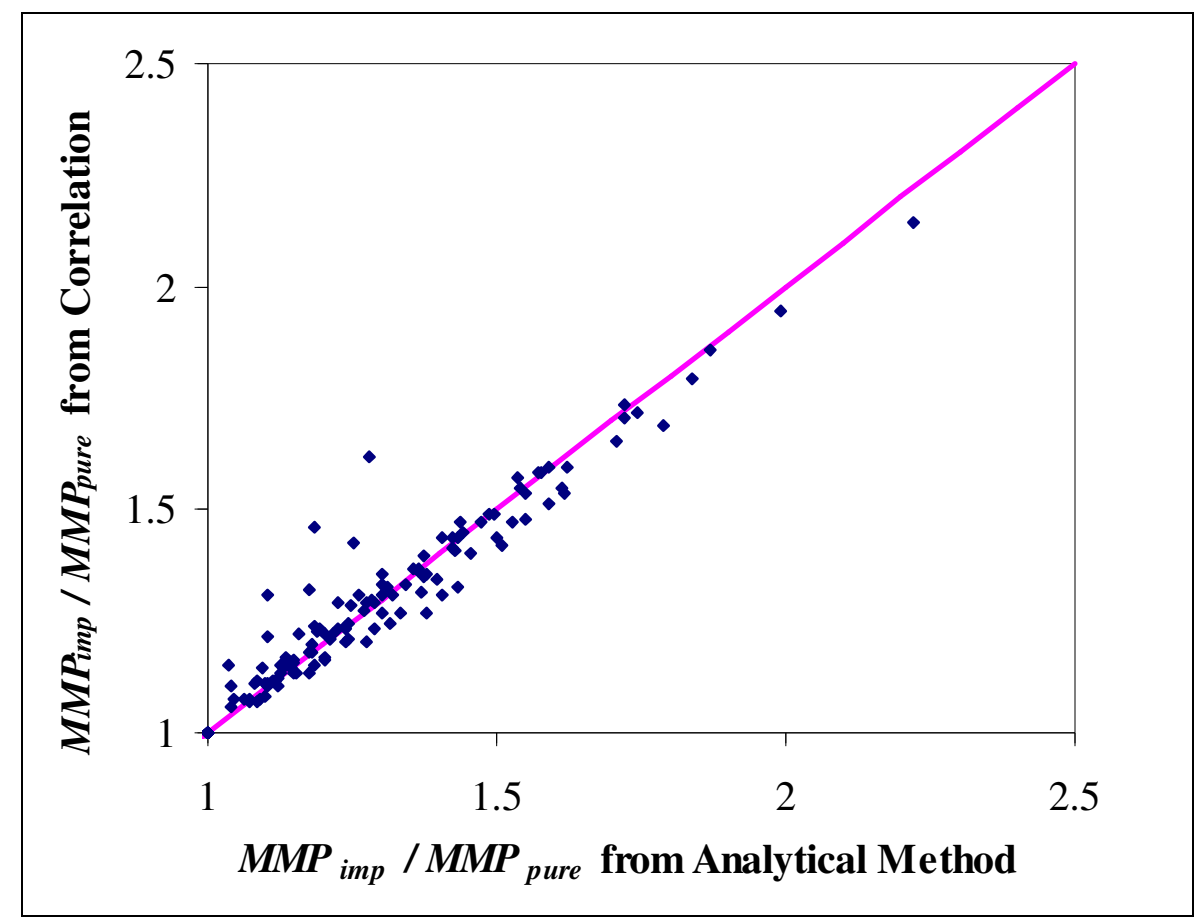

Figure 2.10: Comparison of estimated MMP ratios from the new correlation and those calculated from the analytical method. 
Table 2.4: Comparison of MMP ratio estimated from new correlation to analytically calculated MMP ratios for oil displacements by impure $\mathrm{CO}_{2}$.

\begin{tabular}{|c|c|c|c|c|c|c|}
\hline Reference & $\begin{array}{l}\text { Mole \% } \\
\mathrm{C}_{2}-\mathrm{C}_{6}\end{array}$ & $\begin{array}{c}\text { Molecular } \\
\text { Weight of } \\
\mathrm{C}_{7+}\end{array}$ & $\begin{array}{c}\text { Temperature } \\
\left({ }^{0} \mathrm{~F}\right)\end{array}$ & $\begin{array}{c}\% \mathrm{CO}_{2} \text { in } \\
\text { injection } \\
\text { gas }\end{array}$ & $\begin{array}{l}\frac{\mathrm{MMP}_{\text {imp }}}{\mathrm{MMP}_{\text {pure }}} \\
\text { (Analytical) }\end{array}$ & $\begin{array}{c}\frac{\mathrm{MMP}_{\text {imp }}}{\mathrm{MMP}_{\text {pure }}} \\
\text { (from Eq. 2.2) }\end{array}$ \\
\hline Wang and Orr (2002) & 20.16 & 140.6 & 120 & 100 & 1.00 & 1.00 \\
\hline Wang and Orr (2002) & 20.16 & 140.6 & 120 & 90 & 1.18 & 1.18 \\
\hline Wang and Orr (2002) & 20.16 & 140.6 & 120 & 80 & 1.36 & 1.36 \\
\hline Wang and Orr (2002) & 20.16 & 140.6 & 120 & 70 & 1.55 & 1.54 \\
\hline Wang and Orr (2002) & 20.16 & 140.6 & 120 & 60 & 1.74 & 1.72 \\
\hline Wang and Orr (2002) & 20.16 & 140.6 & 140 & 100 & 1.00 & 1.00 \\
\hline Wang and Orr (2002) & 20.16 & 140.6 & 140 & 90 & 1.13 & 1.15 \\
\hline Wang and Orr (2002) & 20.16 & 140.6 & 140 & 80 & 1.28 & 1.29 \\
\hline Wang and Orr (2002) & 20.16 & 140.6 & 140 & 70 & 1.42 & 1.44 \\
\hline Wang and Orr (2002) & 20.16 & 140.6 & 140 & 60 & 1.57 & 1.58 \\
\hline Wang and Orr (2002) & 20.16 & 140.6 & 160 & 100 & 1.00 & 1.00 \\
\hline Wang and Orr (2002) & 20.16 & 140.6 & 160 & 90 & 1.12 & 1.12 \\
\hline Wang and Orr (2002) & 20.16 & 140.6 & 160 & 80 & 1.24 & 1.25 \\
\hline Wang and Orr (2002) & 20.16 & 140.6 & 160 & 70 & 1.36 & 1.37 \\
\hline Wang and Orr (2002) & 20.16 & 140.6 & 160 & 60 & 1.49 & 1.49 \\
\hline Wang and Orr (2002) & 20.16 & 140.6 & 180 & 100 & 1.00 & 1.00 \\
\hline Wang and Orr (2002) & 20.16 & 140.6 & 180 & 90 & 1.10 & 1.11 \\
\hline Wang and Orr (2002) & 20.16 & 140.6 & 180 & 80 & 1.20 & 1.22 \\
\hline Wang and Orr (2002) & 20.16 & 140.6 & 180 & 70 & 1.30 & 1.33 \\
\hline Wang and Orr (2002) & 20.16 & 140.6 & 180 & 60 & 1.40 & 1.44 \\
\hline Oil A (Yuan, et al. 2002) & 19.58 & 194.9 & 160 & 100 & 1.00 & 1.00 \\
\hline Oil A (Yuan, et al. 2002) & 19.58 & 194.9 & 160 & 90 & 1.04 & 1.15 \\
\hline Oil A (Yuan, et al. 2002) & 19.58 & 194.9 & 160 & 80 & 1.10 & 1.31 \\
\hline Oil A (Yuan, et al. 2002) & 19.58 & 194.9 & 160 & 70 & 1.19 & 1.46 \\
\hline Oil A (Yuan, et al. 2002) & 19.58 & 194.9 & 160 & 60 & 1.28 & 1.62 \\
\hline Oil A (Yuan, et al. 2002) & 19.58 & 194.9 & 189 & 100 & 1.00 & 1.00 \\
\hline Oil A (Yuan, et al. 2002) & 19.58 & 194.9 & 189 & 90 & 1.04 & 1.11 \\
\hline Oil A (Yuan, et al. 2002) & 19.58 & 194.9 & 189 & 80 & 1.10 & 1.21 \\
\hline Oil A (Yuan, et al. 2002) & 19.58 & 194.9 & 189 & 70 & 1.17 & 1.32 \\
\hline Oil A (Yuan, et al. 2002) & 19.58 & 194.9 & 189 & 60 & 1.25 & 1.43 \\
\hline Oil A (Yuan, et al. 2002) & 19.58 & 194.9 & 220 & 100 & 1.00 & 1.00 \\
\hline Oil A (Yuan, et al. 2002) & 19.58 & 194.9 & 220 & 90 & 1.04 & 1.07 \\
\hline Oil A (Yuan, et al. 2002) & 19.58 & 194.9 & 220 & 80 & 1.10 & 1.15 \\
\hline Oil A (Yuan, et al. 2002) & 19.58 & 194.9 & 220 & 70 & 1.16 & 1.22 \\
\hline Oil A (Yuan, et al. 2002) & 19.58 & 194.9 & 220 & 60 & 1.22 & 1.29 \\
\hline Oil A (Yuan, et al. 2002) & 19.58 & 194.9 & 260 & 100 & 1.00 & 1.00 \\
\hline Oil A (Yuan, et al. 2002) & 19.58 & 194.9 & 260 & 90 & 1.04 & 1.06 \\
\hline Oil A (Yuan, et al. 2002) & 19.58 & 194.9 & 260 & 80 & 1.08 & 1.11 \\
\hline Oil A (Yuan, et al. 2002) & 19.58 & 194.9 & 260 & 70 & 1.13 & 1.17 \\
\hline Oil A (Yuan, et al. 2002) & 19.58 & 194.9 & 260 & 60 & 1.19 & 1.23 \\
\hline Oil A (Yuan, et al. 2002) & 14.11 & 148.9 & 140 & 100 & 1.00 & 1.00 \\
\hline Oil A (Yuan, et al. 2002) & 14.11 & 148.9 & 140 & 90 & 1.18 & 1.20 \\
\hline Oil A (Yuan, et al. 2002) & 14.11 & 148.9 & 140 & 80 & 1.37 & 1.40 \\
\hline
\end{tabular}


Table 2.4 cont'd

\begin{tabular}{|c|c|c|c|c|c|c|}
\hline Reference & $\begin{array}{l}\text { Mole \% } \\
\mathrm{C}_{2}-\mathrm{C}_{6}\end{array}$ & $\begin{array}{c}\text { Molecular } \\
\text { Weight of } \\
\mathrm{C}_{7+}\end{array}$ & $\begin{array}{c}\text { Temperature } \\
\left({ }^{0} \mathrm{~F}\right)\end{array}$ & $\begin{array}{c}\% \mathrm{CO}_{2} \text { in } \\
\text { injection } \\
\text { gas }\end{array}$ & $\begin{array}{c}\frac{\mathrm{MMP}_{\text {imp }}}{\mathrm{MMP}_{\text {pure }}} \\
\text { (Analytical) }\end{array}$ & $\begin{array}{c}\frac{\mathrm{MMP}_{\mathrm{imp}}}{\mathrm{MMP}_{\text {pure }}} \\
\text { (from Eq. 2.2) }\end{array}$ \\
\hline Oil A (Yuan, et al. 2002) & 14.11 & 148.9 & 140 & 70 & 1.59 & 1.60 \\
\hline Oil A (Yuan, et al. 2002) & 14.11 & 148.9 & 140 & 60 & 1.84 & 1.80 \\
\hline Oil A (Yuan, et al. 2002) & 14.11 & 148.9 & 160 & 100 & 1.00 & 1.00 \\
\hline Oil D (Jutila, et al. 2001) & 14.11 & 148.9 & 160 & 90 & 1.15 & 1.16 \\
\hline Oil D (Jutila, et al. 2001) & 14.11 & 148.9 & 160 & 80 & 1.31 & 1.33 \\
\hline Oil D (Jutila, et al. 2001) & 14.11 & 148.9 & 160 & 70 & 1.49 & 1.49 \\
\hline Oil D (Jutila, et al. 2001) & 14.11 & 148.9 & 160 & 60 & 1.71 & 1.65 \\
\hline Oil D (Jutila, et al. 2001) & 14.11 & 148.9 & 180 & 100 & 1.00 & 1.00 \\
\hline Oil D (Jutila, et al. 2001) & 14.11 & 148.9 & 180 & 90 & 1.13 & 1.14 \\
\hline Oil D (Jutila, et al. 2001) & 14.11 & 148.9 & 180 & 80 & 1.27 & 1.27 \\
\hline Oil D (Jutila, et al. 2001) & 14.11 & 148.9 & 180 & 70 & 1.43 & 1.41 \\
\hline Oil D (Jutila, et al. 2001) & 14.11 & 148.9 & 180 & 60 & 1.61 & 1.55 \\
\hline Oil D (Jutila, et al. 2001) & 14.11 & 148.9 & 200 & 100 & 1.00 & 1.00 \\
\hline Oil D (Jutila, et al. 2001) & 14.11 & 148.9 & 200 & 90 & 1.11 & 1.12 \\
\hline Oil D (Jutila, et al. 2001) & 14.11 & 148.9 & 200 & 80 & 1.24 & 1.24 \\
\hline Oil D (Jutila, et al. 2001) & 14.11 & 148.9 & 200 & 70 & 1.38 & 1.36 \\
\hline Oil D (Jutila, et al. 2001) & 14.11 & 148.9 & 200 & 60 & 1.55 & 1.48 \\
\hline Oil D (Jutila, et al. 2001) & 14.11 & 148.9 & 220 & 100 & 1.00 & 1.00 \\
\hline Oil D (Jutila, et al. 2001) & 14.11 & 148.9 & 220 & 90 & 1.10 & 1.11 \\
\hline Oil D (Jutila, et al. 2001) & 14.11 & 148.9 & 220 & 80 & 1.21 & 1.22 \\
\hline Oil D (Jutila, et al. 2001) & 14.11 & 148.9 & 220 & 70 & 1.34 & 1.33 \\
\hline Oil D (Jutila, et al. 2001) & 14.11 & 148.9 & 220 & 60 & 1.50 & 1.44 \\
\hline Hong (1982) & 35.57 & 245.4 & 110 & 100 & 1.00 & 1.00 \\
\hline Hong (1982) & 35.57 & 245.4 & 110 & 90 & 1.17 & 1.18 \\
\hline Hong (1982) & 35.57 & 245.4 & 110 & 80 & 1.36 & 1.37 \\
\hline Hong (1982) & 35.57 & 245.4 & 110 & 70 & 1.54 & 1.55 \\
\hline Hong (1982) & 35.57 & 245.4 & 110 & 60 & 1.72 & 1.73 \\
\hline Hong (1982) & 35.57 & 245.4 & 130 & 100 & 1.00 & 1.00 \\
\hline Hong (1982) & 35.57 & 245.4 & 130 & 90 & 1.14 & 1.15 \\
\hline Hong (1982) & 35.57 & 245.4 & 130 & 80 & 1.29 & 1.29 \\
\hline Hong (1982) & 35.57 & 245.4 & 130 & 70 & 1.43 & 1.44 \\
\hline Hong (1982) & 35.57 & 245.4 & 130 & 60 & 1.58 & 1.58 \\
\hline Hong (1982) & 35.57 & 245.4 & 160 & 100 & 1.00 & 1.00 \\
\hline Hong (1982) & 35.57 & 245.4 & 160 & 90 & 1.11 & 1.10 \\
\hline Hong (1982) & 35.57 & 245.4 & 160 & 80 & 1.21 & 1.21 \\
\hline Hong (1982) & 35.57 & 245.4 & 160 & 70 & 1.32 & 1.31 \\
\hline Hong (1982) & 35.57 & 245.4 & 160 & 60 & 1.43 & 1.42 \\
\hline Hong (1982) & 35.57 & 245.4 & 200 & 100 & 1.00 & 1.00 \\
\hline Hong (1982) & 35.57 & 245.4 & 200 & 90 & 1.07 & 1.08 \\
\hline Hong (1982) & 35.57 & 245.4 & 200 & 80 & 1.15 & 1.16 \\
\hline Hong (1982) & 35.57 & 245.4 & 200 & 70 & 1.22 & 1.23 \\
\hline Hong (1982) & 35.57 & 245.4 & 200 & 60 & 1.30 & 1.31 \\
\hline Hong (1982) & 35.57 & 245.4 & 220 & 100 & 1.00 & 1.00 \\
\hline Hong (1982) & 35.57 & 245.4 & 220 & 90 & 1.06 & 1.08 \\
\hline Hong (1982) & 35.57 & 245.4 & 220 & 80 & 1.13 & 1.15 \\
\hline Hong (1982) & 35.57 & 245.4 & 220 & 70 & 1.19 & 1.23 \\
\hline Hong (1982) & 35.57 & 245.4 & 110 & 100 & 1.00 & 1.00 \\
\hline
\end{tabular}


Table 2.4 cont'd

\begin{tabular}{|c|c|c|c|c|c|c|}
\hline & Mole \% & $\begin{array}{c}\text { Molecular } \\
\text { Weight of } \\
\mathrm{C}_{7+}-\mathrm{C}_{6}\end{array}$ & $\begin{array}{c}\text { Temperature } \\
\left({ }^{0} \mathrm{~F}\right)\end{array}$ & $\begin{array}{c}\% \mathrm{CO}_{2} \text { in } \\
\text { injection } \\
\text { gas }\end{array}$ & $\begin{array}{c}\frac{\mathrm{MMP}_{\text {imp }}}{\mathrm{MMP}_{\text {pure }}} \\
\text { (Analytical ) }\end{array}$ & $\begin{array}{c}\frac{\mathrm{MMP}_{\text {imp }}}{\mathrm{MMP}_{\text {pure }}} \\
\text { (from Eq. 2.2) }\end{array}$ \\
\hline Hong (1982) & 35.57 & 245.4 & 110 & 90 & 1.17 & 1.18 \\
\hline Hong (1982) & 35.57 & 245.4 & 110 & 80 & 1.36 & 1.37 \\
\hline Hong (1982) & 35.57 & 245.4 & 110 & 70 & 1.54 & 1.55 \\
\hline Hong (1982) & 35.57 & 245.4 & 110 & 60 & 1.72 & 1.73 \\
\hline Hong (1982) & 35.57 & 245.4 & 130 & 100 & 1.00 & 1.00 \\
\hline Hong (1982) & 35.57 & 245.4 & 130 & 90 & 1.14 & 1.15 \\
\hline Hong (1982) & 35.57 & 245.4 & 130 & 80 & 1.29 & 1.29 \\
\hline Hong (1982) & 35.57 & 245.4 & 130 & 70 & 1.43 & 1.44 \\
\hline Hong (1982) & 35.57 & 245.4 & 130 & 60 & 1.58 & 1.58 \\
\hline Hong (1982) & 35.57 & 245.4 & 160 & 100 & 1.00 & 1.00 \\
\hline Hong (1982) & 35.57 & 245.4 & 160 & 90 & 1.11 & 1.10 \\
\hline Hong (1982) & 35.57 & 245.4 & 160 & 80 & 1.21 & 1.21 \\
\hline Hong (1982) & 35.57 & 245.4 & 160 & 70 & 1.32 & 1.31 \\
\hline Hong (1982) & 35.57 & 245.4 & 160 & 60 & 1.43 & 1.42 \\
\hline Hong (1982) & 35.57 & 245.4 & 200 & 100 & 1.00 & 1.00 \\
\hline Hong (1982) & 35.57 & 245.4 & 200 & 90 & 1.07 & 1.08 \\
\hline Hong (1982) & 35.57 & 245.4 & 200 & 80 & 1.15 & 1.16 \\
\hline Hong (1982) & 35.57 & 245.4 & 200 & 70 & 1.22 & 1.23 \\
\hline Hong (1982) & 35.57 & 245.4 & 200 & 60 & 1.30 & 1.31 \\
\hline
\end{tabular}

Table 2.5: Comparison of MMP ratio estimated from correlations to slim-tube MMP ratios for oil displacements by impure $\mathrm{CO}_{2}$

\begin{tabular}{|c|c|c|c|c|c|c|c|c|}
\hline Reference & $\begin{array}{l}\text { Mole } \\
\% \mathrm{C}_{1}\end{array}$ & $\begin{array}{c}\text { Mole } \\
\% \\
\mathrm{C}_{2}-\mathrm{C}_{6}\end{array}$ & $\begin{array}{c}\text { Molecular } \\
\text { Weight of } \\
\mathrm{C}_{7+}\end{array}$ & $\begin{array}{l}\text { Temp } \\
\left({ }^{\circ} \mathrm{F}\right)\end{array}$ & $\begin{array}{c}\% \mathrm{CO}_{2} \text { in } \\
\text { injection } \\
\text { gas }\end{array}$ & $\begin{array}{l}\frac{\mathrm{MMP}_{\text {imp }}}{\mathrm{MMP}_{\text {pure }}} \\
\text { (slim-tube) }\end{array}$ & $\begin{array}{l}\frac{\mathrm{MMP}_{\text {imp }}}{\mathrm{MMP}_{\text {pure }}} \\
\text { (from Eq. 2.2) }\end{array}$ & $\begin{array}{l}\frac{\mathrm{MMP}_{\text {imp }}}{\mathrm{MMP}_{\text {pure }}} \\
\text { Sebastian's } \\
\text { Correlation } \\
(1985)\end{array}$ \\
\hline $\begin{array}{l}\text { Sebastian } \\
\text { et al (1985) }\end{array}$ & 16.48 & 23.62 & 240 & 106 & 90 & 1.33 & 1.31 & 1.28 \\
\hline $\begin{array}{l}\text { Sebastian } \\
\text { et al (1985) }\end{array}$ & 16.48 & 23.62 & 240 & 106 & 81 & 1.54 & 1.60 & 1.60 \\
\hline $\begin{array}{l}\text { Sebastian } \\
\text { et al }(1985)\end{array}$ & 10.5 & 24.4 & 206 & 105 & 90 & 1.33 & 1.25 & 1.28 \\
\hline $\begin{array}{c}\text { Sebastian } \\
\text { et al (1985) }\end{array}$ & 10.5 & 24.4 & 206 & 105 & 80 & 1.83 & 1.50 & 1.60 \\
\hline $\begin{array}{l}\text { Sebastian } \\
\text { et al (1985) }\end{array}$ & 10.5 & 24.4 & 206 & 137 & 90 & 1.29 & 1.17 & 1.28 \\
\hline $\begin{array}{c}\text { Sebastian } \\
\text { et al (1985) }\end{array}$ & 10.5 & 24.4 & 206 & 137 & 80 & 1.59 & 1.35 & 1.60 \\
\hline
\end{tabular}




\section{Chapter 3 Improved Fluid Characterizations Using Equations of State}

An improved tuning procedure for EOS fluid characterizations that is more reliable for miscible gas compositional simulation is presented. MMP and MME are shown to be the two key displacement parameters that improve the tuning process. The Peng-Robinson (1976) EOS was used for all the characterized models. The EOS model is tuned to match some PVT data and then, the MMP (or MME). The tuning procedure is validated by the successful lumping of a 12-component oil EOS to four pseudocomponents and an 11-component EOS model to five pseudocomponents. 1-D compositional simulations are made to compare the pseudocomponent models to the original multicomponent model. The effect of different levels of dispersion on the oil recovery is also demonstrated.

The process of characterization proceeds in four steps:

1. Generate analytical PVT data using a detailed EOS model as the truth.

2. Select pseudocomponent

3. Tune lumped EOS model using a non-linear regression tool.

4. Validate the model with compositional simulation results.

\subsection{PVT DATA}

PVT experiments are carried out to provide phase equilibria and volumetric data for tuning EOS characterizations. In this research, PVT data are generated analytically from the original multicomponent EOS characterizations using PVTSim. The detailed EOS characterizations are taken as truth models to compare with lumped models derived from further pseudoization of the multicomponent models. Data from differential liberation tests (DD), separator tests, constant mass expansion (CME), and swelling tests (SWT) were generated. Multicontact experimental data are not used in this research 
because the drive mechanism for all the cases considered is CV. A brief description of each experiment is given below.

\section{Differential Liberation Test}

This experiment provides important information about the solution gas-oil ratio $\left(R_{s}\right)$, oil formation volume factor $\left(B_{o}\right)$, density of the reservoir fluid at different pressures, gas specific gravity, gas formation volume factor $\left(\mathrm{B}_{\mathrm{g}}\right)$, and compressibility factor $\mathrm{Z}$. Reservoir fluid is charged to a PVT cell at the reservoir temperature and pressure above the oil bubble point pressure. Pressure is reduced in increments. After each reduction, the system is allowed to equilibrate and the vapor phase is removed by bleeding. The volume of the cell before and after the pressure reduction is measured to determine liquid saturation for $\mathrm{B}_{\mathrm{o}}$ calculation. The bled gas stream is used to compute $\mathrm{R}_{\mathrm{s}}$. The process of pressure reduction is continued for the range of pressure depletion expected in the reservoir. In the final stage, the vapor is bled to atmospheric pressure and the density of the remaining liquid is measured.

\section{Constant Mass Expansion Test}

Constant mass expansion tests simulate the depletion of a black oil reservoir from pressures above the bubble point to those below the bubble point pressure. In this experiment, the mass of the total system is fixed (i.e. no fluid is withdrawn from the PVT cell). Reservoir oil is placed in a PVT cell at a pressure far above the bubble point pressure of the oil. The pressure of the cell is reduced in increments. At each reduction, single-phase compressibility, liquid volume normalized with the bubble point liquid volume, etc... are measured. This process is carried out over a pressure range above and below the bubble point pressure. 


\section{Swelling Test}

The objective of this test is to provide PVT and phase equilibrium information for oil/injected gas mixtures that might reflect compositional changes that occur as the displacement takes place in the reservoir. The constant mass expansion test can be performed as part of this test. In this test, a reservoir fluid is charged to a PVT cell and a fixed amount of the injection gas is added to it. The pressure of the system is raised to single-phase conditions and then gradually reduced until the saturation vapor pressure (SVP) is reached. The SVP value and total volume are measured. This process is repeated with incremental additions of the injection gas. The composition of the injection gas/oil critical mixture is also useful information obtained from this test.

\section{Separator Test}

Separator tests are designed to give information about the behavior of the reservoir fluids at surface conditions. Information obtained from this test includes; the total gas-oil ratio (GOR), stage GOR, formation volume factor of the oil, density and molecular weight of the stock tank oil. This test can be done in multiple stages and the relevant PVT data measured. The final stage is the stock tank stage at standard temperature and pressure.

\subsection{PSEUDOCOMPONENT SELECTION}

The successful assignment of components or groups of components to pseudocomponents may depend on the lumping criterion selected. The lumping schemes work well for EOS characterization of extended fluid analysis. Some of the methods may be inaccurate for the pseudoization of an existing multicomponent EOS characterization. The Newley and Merrill (1991) scheme gives very good results for the pseudoization of detailed multicomponent EOS characterizations. This is the scheme used in this research. A brief outline of the method is given below. 


\section{The Newley and Merrill Methodology}

This lumping scheme is based on the K-values of the components. The scheme aims to minimize the difference between the $\mathrm{K}$-values of components or group of components and the K-value of the pseudocomponent to which it is assigned. This ensures that the predicted phase behavior agrees with that of the detailed EOS model. A well-behaved objective function is defined and minimized to give the best lumping of components.

The pseudocomponents K-values are defined as

$$
K_{m}=\sum_{i \in m} y_{i} / \sum_{i \in m} x_{i}
$$

where $K_{m}$ is the effective pseudocomponent $\mathrm{K}$-value of a pseudocomponent $m . x_{i}$ and $y_{i}$ are the equilibrium phase compositions determined at an appropriate feed composition. The objective function is defined as

$$
\sigma=\sum_{m} \sum_{i \in m} \frac{\left(K_{m}-K_{i}\right)}{K_{i}^{2}}
$$

$K_{i}$ is the $\mathrm{K}$-value of the individual component or group of components making up a particular pseudocomponent. Thus, the procedure is reduced to minimizing the objective function by grouping components of similar K-values into the same pseudocomponent.

The first step is to flash an appropriate feed composition of the multicomponent EOS. This is usually at the saturation vapor pressure of the oil or at a composition close to the critical point. The components are then ordered according to their K-values. The initial grouping of components can be made on an equal mole fraction basis by lumping 
successive components into the same pseudocomponent. This initial grouping is modified by moving components between adjacent pseudocomponents and $\sigma$ is calculated for each realization. The realization with the least $\sigma$ is the best component grouping. The displacement process depends on the K-values of the components. Thus, the average critical properties of the lumped pseudocomponent model can be determined by using a mixing rule based on $\mathrm{K}$-value weighting. The equations are given as:

$$
\beta_{c m}=\sum_{i \in m} \beta_{c i} Z_{i} K_{i}^{-1 / 2} / \sum_{i \in m} Z_{i} K_{i}^{-1 / 2}
$$

where $\beta_{c m}=T_{c m}, V_{c m}, P_{c m}$ or $\omega_{c m}$, and $\mathrm{Z}_{\mathrm{i}}$ is overall component composition These are the average critical properties of the pseudocomponents. The pseudocomponents molecular weights are based on the detailed fluid composition and component molecular weights and are given by:

$$
M_{m}=\sum_{i \in m} M_{i} Z_{i} / \sum_{i \in m} Z_{i}
$$

Binary interaction parameters are determined from

$$
\delta_{m n}=\frac{\sum_{i \in m} \sum_{j \in n} Z_{i} Z_{j} \delta_{i j} K_{i}^{-1 / 2} K_{j}^{-1 / 2}}{\sum_{i \in m} \sum_{j \in n} Z_{i} Z_{j} K_{i}^{-1 / 2} K_{j}^{-1 / 2}}
$$

where $m$ and $n$ represent two distinct pseudocomponents.

To summarize, the steps are:

1. Flash the detailed multicomponent EOS oil characterization at an appropriate feed composition close to the critical point to obtain representative K-values for the 
components. This is could also be done at the bubble point of the oil at the reservoir temperature.

2. Order the components according to their K-values.

3. Lump successive components on equal mole fraction basis. This is only an initial components grouping.

4. Move the component between adjacent pseudocomponents to minimize the objective function.

5. Calculate the average critical properties of the pseudocomponents using the mixing rule in Eq. 3.3

For the purpose of this research, the above steps were implemented in a fortran code (see appendix D). The lumping scheme is implemented for two multicomponent EOS characterizations: a 12-component EOS model lumped to four pseudocomponents and an 11-component EOS model lumped to five pseudocomponents. Tables 3.1-3.6 show the critical properties of the 12-component and the lumped four-pseudocomponent EOS models, while Tables 3.7-3.12 show the properties of the 11-component and the fivepseudocomponent EOS model. These models are the starting points for further tuning.

\subsection{IMPROVED TUNING PROCEDURE FOR EOS}

Tuning is an art in that there is no unique way to match relevant data. We follow the philosophy that only pseudocomponent properties with a large degree of uncertainty are adjusted in the tuning process. The properties of the heavier pseudocomponents have large uncertainties because they contain many components lumped as a single pseudocomponent. The only measured property of the heaviest pseudocomponent from extended fluid analysis is the molecular weight. This has a measurement error of about $10 \%$ (Christensen 1999). All other properties are determined from correlations. These 
Table 3.1: Component properties for twelve-component EOS model.

\begin{tabular}{|l|c|c|c|c|c|c|c|c|}
\hline Component & Mole $\%$ & $\mathrm{M}_{\mathrm{w}}$ & $\mathrm{T}_{\mathrm{C}}\left({ }^{\circ} \mathrm{F}\right)$ & $\mathrm{P}_{\mathrm{C}}(\mathrm{psia})$ & $\begin{array}{c}\mathrm{V}_{\mathrm{C}} \\
(\mathrm{ft} / \mathrm{lb}-\mathrm{mol})\end{array}$ & $\omega$ & $\Omega_{A}$ & $\Omega_{B}$ \\
\hline $\mathrm{CO}_{2}$ & 4.484 & 44.01 & 87.56 & 1071.34 & 1.50 & 0.225 & 0.45724 & 0.0778 \\
\hline $\mathrm{CH}_{4}-\mathrm{N}_{2}$ & 36.918 & 16.00 & -117.07 & 671.17 & 1.59 & 0.013 & 0.45724 & 0.0778 \\
\hline $\mathrm{C}_{2}$ & 3.205 & 30.07 & 89.72 & 708.35 & 2.37 & 0.097 & 0.45724 & 0.0778 \\
\hline $\mathrm{C}_{3}$ & 2.333 & 44.10 & 205.82 & 617.38 & 3.25 & 0.152 & 0.45724 & 0.0778 \\
\hline $\mathrm{C}_{4}$ & 1.532 & 58.12 & 294.58 & 543.31 & 4.09 & 0.187 & 0.45724 & 0.0778 \\
\hline $\mathrm{C}_{5}$ & 0.877 & 72.15 & 366.46 & 475.28 & 4.87 & 0.252 & 0.45724 & 0.0778 \\
\hline $\mathrm{C}_{6}$ & 1.265 & 86.18 & 439.41 & 419.54 & 5.98 & 0.314 & 0.45724 & 0.0778 \\
\hline $\mathrm{C}_{7+}$ & 9.168 & 108 & 584.35 & 417.69 & 7.03 & 0.374 & 0.45724 & 0.0778 \\
\hline $\mathrm{C}_{10+}$ & 11.185 & 152 & 670.78 & 407.14 & 8.11 & 0.549 & 0.45724 & 0.0778 \\
\hline $\mathrm{C}_{14+}$ & 11.220 & 213 & 808.24 & 314.34 & 12.21 & 0.755 & 0.45724 & 0.0778 \\
\hline $\mathrm{C}_{20+}$ & 9.094 & 312 & 954.60 & 205.28 & 21.74 & 0.875 & 0.45724 & 0.0778 \\
\hline $\mathrm{C}_{30+}$ & 8.719 & 451 & 1136.59 & 171.07 & 30.64 & 1.026 & 0.45724 & 0.0778 \\
\hline
\end{tabular}

Table 3.2: Non-zero binary interaction parameters for twelve-component EOS model.

\begin{tabular}{|l|c|c|c|c|c|}
\hline & $\mathrm{CO}_{2}$ & $\mathrm{CH}_{4}-\mathrm{N}_{2}$ & $\mathrm{C}_{2}$ & $\mathrm{C}_{3}$ & $\mathrm{C}_{4}$ \\
\hline $\mathrm{CO}_{2}$ & 0.0000 & & & & \\
\hline $\mathrm{CH}_{4}-\mathrm{N}_{2}$ & 0.1000 & & & & \\
\hline $\mathrm{C}_{2}$ & 0.1300 & & & & \\
\hline $\mathrm{C}_{3}$ & 0.1350 & & & & \\
\hline $\mathrm{C}_{4}$ & 0.1300 & & & & \\
\hline $\mathrm{C}_{5}$ & 0.1250 & & & & \\
\hline $\mathrm{C}_{6}$ & 0.1200 & 0.0200 & 0.0300 & 0.0300 & 0.0300 \\
\hline $\mathrm{C}_{7+}$ & 0.1200 & 0.0300 & 0.0300 & 0.0300 & 0.0300 \\
\hline $\mathrm{C}_{10+}$ & 0.1200 & 0.0400 & 0.0300 & 0.0300 & 0.0300 \\
\hline $\mathrm{C}_{14+}$ & 0.1200 & 0.0600 & 0.0300 & 0.0300 & 0.0300 \\
\hline $\mathrm{C}_{20+}$ & 0.2250 & -0.0239 & 0.0400 & -0.0175 & 0.0400 \\
\hline $\mathrm{C}_{30+}$ & 0.2250 & 0.2000 & 0.0400 & 0.1417 & 0.0400 \\
\hline
\end{tabular}


Table 3.3: Pseudocomponents selection for twelve-component EOS model.

\begin{tabular}{|l|c|c|c|c|c|c|c|c|c|c|cc|}
\hline Components & $\mathrm{CH}_{4}-\mathrm{N}_{2}$ & $\mathrm{CO}_{2}$ & $\mathrm{C}_{2}$ & $\mathrm{C}_{3}$ & $\mathrm{C}_{4}$ & $\mathrm{C}_{5}$ & $\mathrm{C}_{6}$ & $\mathrm{C}_{7+}$ & $\mathrm{C}_{10+}$ & $\mathrm{C}_{14+}$ & $\mathrm{C}_{20+}$ & $\mathrm{C}_{30+}$ \\
\hline $\mathrm{CH}_{4}-\mathrm{N}_{2}$ & $\mathrm{X}$ & & & & & & & & & & & \\
\hline $\mathrm{C}_{2+}$ & & $\mathrm{X}$ & $\mathrm{X}$ & $\mathrm{X}$ & $\mathrm{X}$ & & & & & & & \\
\hline $\mathrm{C}_{5+}$ & & & & & & $\mathrm{X}$ & $\mathrm{X}$ & $\mathrm{X}$ & $\mathrm{X}$ & $\mathrm{X}$ & $\mathrm{X}$ & \\
\hline $\mathrm{C}_{30+}$ & & & & & & & & & & & & $\mathrm{X}$ \\
\hline
\end{tabular}

Table 3.4: Injection gas composition and the flash data for twelve-component feed composition at $200^{\circ} \mathrm{F}$.

\begin{tabular}{|c|c|c|c|c|c|c|}
\hline Component & $\begin{array}{c}\text { Oil Mole } \\
\text { Fraction }\end{array}$ & $\begin{array}{c}\text { Injection } \\
\text { Gas Mole } \\
\text { Fraction }\end{array}$ & $\begin{array}{c}\text { Feed } \\
\text { Composition for } \\
\text { Pseudocomponent } \\
\text { Selection }\end{array}$ & $\mathrm{Y}_{\mathrm{i}}$ & $\mathrm{X}_{\mathrm{i}}$ & $\mathrm{K}_{\mathrm{i}}$ \\
\hline $\mathrm{CO}_{2}$ & 0.0448 & 0.2081 & 0.1831 & 0.1921 & 0.1308 & 1.4687 \\
\hline $\mathrm{CH}_{4-\mathrm{N}_{2}}$ & 0.3692 & 0.3277 & 0.3340 & 0.3545 & 0.2155 & 1.6450 \\
\hline $\mathrm{C}_{2}$ & 0.0321 & 0.2008 & 0.1750 & 0.1786 & 0.1537 & 1.1620 \\
\hline $\mathrm{C}_{3}$ & 0.0233 & 0.2223 & 0.1918 & 0.1964 & 0.1657 & 1.1853 \\
\hline $\mathrm{C}_{4}$ & 0.0153 & 0.0411 & 0.0372 & 0.0367 & 0.0396 & 0.9268 \\
\hline $\mathrm{C}_{5}$ & 0.0088 & & 0.0013 & 0.0013 & 0.0018 & 0.7222 \\
\hline $\mathrm{C}_{6}$ & 0.0127 & & 0.0019 & 0.0017 & 0.0030 & 0.5667 \\
\hline $\mathrm{C}_{7+}$ & 0.0917 & & 0.0140 & 0.0113 & 0.0296 & 0.3818 \\
\hline $\mathrm{C}_{10+}$ & 0.1119 & & 0.0171 & 0.0119 & 0.0475 & 0.2505 \\
\hline $\mathrm{C}_{14+}$ & 0.1122 & & 0.0172 & 0.0086 & 0.0670 & 0.1284 \\
\hline $\mathrm{C}_{20+}$ & 0.0909 & & 0.0139 & 0.0061 & 0.0594 & 0.1027 \\
\hline $\mathrm{C}_{30+}$ & 0.0872 & & 0.0133 & 0.0008 & 0.0864 & 0.0093 \\
\hline
\end{tabular}


Table 3.5: Component properties for untuned four-component EOS model.

\begin{tabular}{|l|c|c|c|c|c|c|c|c|}
\hline Component & $\mathrm{Mol} \%$ & $\mathrm{M}_{\mathrm{W}}$ & $\mathrm{T}_{\mathrm{C}}\left({ }^{\circ} \mathrm{F}\right)$ & $\mathrm{P}_{\mathrm{C}}(\mathrm{psia})$ & $\begin{array}{c}\mathrm{V}_{\mathrm{C}} \\
(\mathrm{ft} / / \mathrm{b}-\mathrm{mol})\end{array}$ & $\omega$ & $\Omega_{A}$ & $\Omega_{B}$ \\
\hline $\mathrm{CH}_{4}-\mathrm{N}_{2}$ & 36.918 & 16.00 & -117.07 & 671.17 & 1.59 & 0.013 & 0.45724 & 0.0778 \\
\hline $\mathrm{C}_{2+}$ & 11.554 & 40.72 & 142.80 & 769.79 & 2.54 & 0.159 & 0.45724 & 0.0778 \\
\hline $\mathrm{C}_{5+}$ & 42.809 & 208.34 & 775.05 & 322.86 & 13.06 & 0.674 & 0.45724 & 0.0778 \\
\hline $\mathrm{C}_{30+}$ & 8.719 & 451 & 1136.59 & 171.07 & 30.64 & 1.026 & 0.45724 & 0.0778 \\
\hline
\end{tabular}

Table 3.6: Binary interaction parameters for untuned four-component EOS model.

\begin{tabular}{|l|c|c|c|c|}
\hline & $\mathrm{CH}_{4}-\mathrm{N}_{2}$ & $\mathrm{C}_{2+}$ & $\mathrm{C}_{5+}$ & $\mathrm{C}_{30+}$ \\
\hline $\mathrm{CH}_{4}-\mathrm{N}_{2}$ & 0.0000 & & & \\
\hline $\mathrm{C}_{2+}$ & 0.0286 & 0.0000 & & \\
\hline $\mathrm{C}_{5+}$ & 0.0258 & 0.0607 & 0.0000 & \\
\hline $\mathrm{C}_{30+}$ & 0.2000 & 0.1269 & 0.0000 & 0.0000 \\
\hline
\end{tabular}


Table 3.7: Component properties for eleven-component EOS model.

\begin{tabular}{|l|c|c|c|c|c|c|c|c|}
\hline Component & $\mathrm{Mol} \%$ & $\mathrm{M}_{\mathrm{W}}$ & $\mathrm{T}_{\mathrm{C}}\left({ }^{\circ} \mathrm{F}\right)$ & $\mathrm{P}_{\mathrm{C}}(\mathrm{psia})$ & $\begin{array}{c}\mathrm{V}_{\mathrm{C}} \\
\mathrm{ft} / \mathrm{lb}-\mathrm{bol})\end{array}$ & $\omega$ & $\Omega_{A}$ & $\Omega_{B}$ \\
\hline $\mathrm{CO}_{2}$ & 0.1 & 44.01 & 87.62 & 1071.34 & 1.51 & 0.225 & 0.45724 & 0.0778 \\
\hline $\mathrm{C}_{1}$ & 34.67 & 16.043 & -116.58 & 667.80 & 1.59 & 0.010 & 0.45724 & 0.0778 \\
\hline $\mathrm{C}_{2}$ & 3.13 & 30.07 & 89.72 & 708.40 & 2.37 & 0.099 & 0.45724 & 0.0778 \\
\hline $\mathrm{C}_{3}$ & 3.96 & 44.097 & 205.82 & 617.40 & 3.25 & 0.152 & 0.45724 & 0.0778 \\
\hline $\mathrm{C}_{4}$ & 5.95 & 58.124 & 294.60 & 543.30 & 4.08 & 0.187 & 0.45724 & 0.0778 \\
\hline $\mathrm{C}_{5}$ & 4.06 & 72.151 & 366.52 & 475.30 & 4.87 & 0.252 & 0.45724 & 0.0778 \\
\hline $\mathrm{C}_{6}$ & 3.06 & 86.178 & 453.92 & 431 & 5.93 & 0.296 & 0.45724 & 0.0778 \\
\hline $\mathrm{C}_{7}$ & 4.95 & 100.205 & 512.92 & 397 & 6.92 & 0.351 & 0.45724 & 0.0778 \\
\hline $\mathrm{C}_{8+}$ & 4.97 & 114.232 & 564.42 & 264 & 7.88 & 0.394 & 0.45724 & 0.0778 \\
\hline $\mathrm{C}_{10+}$ & 30.11 & 142.285 & 647.62 & 320 & 9.66 & 0.491 & 0.45724 & 0.0778 \\
\hline $\mathrm{C}_{14+}$ & 5.04 & 198.4 & 790.02 & 230 & 13.30 & 0.755 & 0.45724 & 0.0778 \\
\hline
\end{tabular}

Table 3.8: Non-zero binary interaction parameters for eleven-component EOS model.

\begin{tabular}{|c|c|c|c|c|c|c|c|c|c|c|c|}
\hline & $\mathrm{CO}_{2}$ & $\mathrm{C}_{1}$ & $\mathrm{C}_{2}$ & $\mathrm{C}_{3}$ & $\mathrm{C}_{4}$ & $\mathrm{C}_{5}$ & $\mathrm{C}_{6}$ & $\mathrm{C}_{7}$ & $\mathrm{C}_{8+}$ & $\mathrm{C}_{10+}$ & $\mathrm{C}_{14+}$ \\
\hline $\mathrm{CO}_{2}$ & & 0.100 & 0.130 & 0.135 & 0.130 & 0.130 & 0.140 & 0.140 & 0.140 & 0.140 & 0.140 \\
\hline $\mathrm{C}_{1}$ & & & & & & & 0.020 & 0.030 & 0.035 & 0.040 & 0.060 \\
\hline
\end{tabular}


Table 3.9: Pseudocomponent selection for eleven-component model.

\begin{tabular}{|l|c|c|c|c|c|c|c|c|c|c|c|}
\hline & $\mathrm{CO}_{2}$ & $\mathrm{C}_{1}$ & $\mathrm{C}_{2}$ & $\mathrm{C}_{3}$ & $\mathrm{C}_{4}$ & $\mathrm{C}_{5}$ & $\mathrm{C}_{6}$ & $\mathrm{C}_{7}$ & $\mathrm{C}_{8+}$ & $\mathrm{C}_{10+}$ & $\mathrm{C}_{14+}$ \\
\hline $\mathrm{CO}_{2}$ & $\mathrm{X}$ & & & & & & & & & & \\
\hline $\mathrm{C}_{1+}$ & & $\mathrm{X}$ & $\mathrm{X}$ & & & & & & & & \\
\hline $\mathrm{C}_{3+}$ & & & & $\mathrm{X}$ & $\mathrm{X}$ & $\mathrm{X}$ & $\mathrm{X}$ & & & & \\
\hline $\mathrm{C}_{7+}$ & & & & & & & & $\mathrm{X}$ & $\mathrm{X}$ & $\mathrm{X}$ & \\
\hline $\mathrm{C}_{14+}$ & & & & & & & & & & & $\mathrm{X}$ \\
\hline
\end{tabular}

Table 3.10: Eleven-component EOS model flash data at 1553 psia and $150^{\circ} \mathrm{F}$.

\begin{tabular}{|l|c|c|c|c|}
\hline Component & $\begin{array}{c}\text { Oil Mole } \\
\text { Fraction }\end{array}$ & $\mathrm{Y}_{\mathrm{i}}$ & $\mathrm{X}_{\mathrm{i}}$ & $\mathrm{K}_{\mathrm{i}}$ \\
\hline $\mathrm{CO}_{2}$ & 0.1000 & 0.00166 & 0.0010 & 1.6600 \\
\hline $\mathrm{C}_{1}$ & 0.3467 & 0.92131 & 0.34613 & 2.6617 \\
\hline $\mathrm{C}_{2}$ & 0.3130 & 0.02952 & 0.03130 & 0.9431 \\
\hline $\mathrm{C}_{3}$ & 0.3960 & 0.01888 & 0.03962 & 0.4765 \\
\hline $\mathrm{C}_{4}$ & 0.5950 & 0.01559 & 0.05954 & 0.2618 \\
\hline $\mathrm{C}_{5}$ & 0.4060 & 0.00593 & 0.04063 & 0.1460 \\
\hline $\mathrm{C}_{6}$ & 0.3060 & 0.00209 & 0.03063 & 0.0682 \\
\hline $\mathrm{C}_{7}$ & 0.4950 & 0.00182 & 0.04955 & 0.0367 \\
\hline $\mathrm{C}_{8+}$ & 0.4970 & 0.00118 & 0.04975 & 0.0237 \\
\hline $\mathrm{C}_{10+}$ & 0.3011 & 0.00202 & 0.30140 & 0.0067 \\
\hline $\mathrm{C}_{14+}$ & 0.5040 & 0.00002 & 0.05045 & 0.0004 \\
\hline
\end{tabular}


Table 3.11: Component properties for untuned five-component EOS model.

\begin{tabular}{|l|c|c|c|c|c|c|c|c|}
\hline Component & $\mathrm{Mol} \%$ & $\mathrm{M}_{\mathrm{w}}$ & $\mathrm{T}_{\mathrm{C}}\left({ }^{\circ} \mathrm{F}\right)$ & $\mathrm{P}_{\mathrm{C}}(\mathrm{psia})$ & $\begin{array}{c}\mathrm{V}_{\mathrm{C}} \\
(\mathrm{ft} / / \mathrm{lb}-\mathrm{mol})\end{array}$ & $\omega$ & $\Omega_{A}$ & $\Omega_{B}$ \\
\hline $\mathrm{CO}_{2}$ & 0.10 & 44.01 & 87.89 & 1069.87 & 1.51 & 0.2250 & 0.45724 & 0.0778 \\
\hline $\mathrm{C}_{1+}$ & 37.80 & 17.84 & -89.41 & 673.15 & 1.60 & 0.0217 & 0.45724 & 0.0778 \\
\hline $\mathrm{C}_{3+}$ & 17.03 & 67.99 & 348.03 & 502.67 & 4.72 & 0.2310 & 0.45724 & 0.0778 \\
\hline $\mathrm{C}_{7+}$ & 40.03 & 137.33 & 633.15 & 320.43 & 9.36 & 0.4750 & 0.45724 & 0.0778 \\
\hline $\mathrm{C}_{14+}$ & 5.04 & 198 & 790.02 & 230 & 13.30 & 0.7550 & 0.45724 & 0.0778 \\
\hline
\end{tabular}

Table 3.12: Binary interaction parameters for untuned five-component EOS model.

\begin{tabular}{|l|c|c|c|c|c|}
\hline & $\mathrm{CO}_{2}$ & $\mathrm{C}_{1+}$ & $\mathrm{C}_{3+}$ & $\mathrm{C}_{7+}$ & $\mathrm{C}_{14+}$ \\
\hline $\mathrm{CO}_{2}$ & 0.0000 & & & & \\
\hline $\mathrm{C}_{1+}$ & 0.1040 & 0.0000 & & & \\
\hline $\mathrm{C}_{3+}$ & 0.1337 & 0.0051 & 0.0000 & & \\
\hline $\mathrm{C}_{7+}$ & 0.1400 & 0.0339 & 0.0000 & 0.0000 & \\
\hline $\mathrm{C}_{14+}$ & 0.1400 & 0.0521 & 0.0000 & 0.0000 & 0.0000 \\
\hline
\end{tabular}


correlations also have error margins. Therefore, the critical properties of the heavier pseudocomponents are adjustable. The binary interaction parameters between the lightest components and heaviest components have large uncertainties. They are adjustable too. The tuning approach adopted in this study is summarized below:

- Lump the components into pseudocomponents by the Newley and Merrill approach.

- Generate PVT data from differential liberation tests, swelling test, separator test and constant mass expansion using the detailed multicomponent characterization as a truth model.

- Calculate the bubble point pressure of the oil at the reservoir temperature.

- Match the PVT data using the critical temperature, pressure and accentric factor of the two heaviest pseudocomponents.

- Adjust the binary interaction parameters (BIP) between $\mathrm{CO}_{2}$ and the heaviest component to match the MMP analytically determined from the multicomponent EOS model. Adjust the BIP between the two lightest components in the injection gas and the heaviest component in the lumped models to match both the MME and SVP determined from the multicomponent EOS model. Do a sensitivity analysis to determine the most sensitive BIPs to tune the EOS models. The process of matching the MMP proceeds by repeated adjustment of the suggested BIPs and calculation of the analytical MMP.

- Check to ensure that none of other PVT data predictions have been adversely affected after tuning to the MMP or MME. Otherwise, the process is repeated until a reasonable match is obtained for all the data considered. 
The procedure is demonstrated for two EOS characterizations. All regressions were done using the PVTSim regression tool. PVTSim allows the user to weight the PVT data for regression differently as well as assign maximum adjustment that should be made to any of the EOS parameters during the tuning process. Therefore, it is possible to get a good match to PVT data considered to be more important by assigning larger weights to those data. Assigning an upper limit for EOS parameter adjustment ensures that properties are not reduced to unphysical values. Appendix D contains illustrations from the PVTSim regression tool.

\subsection{VALIDATION OF EOS MODELS}

This is the final step in the fluid characterization procedure. After the models have been tuned to match the PVT and MMP data of the original multicomponent model, it is important to verify that they can adequately simulate the displacement process for miscible gas floods. In this section, 1-D compositional simulations are carried out to compare saturation and compositional profiles. Recovery plots are also generated to compare compositional and cumulative oil recovery from the reservoir. The results for the lumped models are compared to those of the original multicomponent models.

\section{Compositional Simulation Model}

The simulator used for all the simulations in this section of the report is the commercially available Computer Modeling Group (CMG) compositional simulator called GEM (2003). All simulations were done at relatively constant pressure to ensure

that the phase behavior remains approximately unchanged during the simulation. A reservoir of $1000 \mathrm{ft}$ length and $20 \mathrm{ft}$ thickness was used. The relative permeability model used is a simple Corey-type relative permeability model with arbitrary end point values of 0.64 for the oil and gas phase. The relative permeability exponents are two. The residual oil saturation $\left(\mathrm{S}_{\mathrm{or}}\right)$ is 0.20 with zero critical gas saturation and zero initial water 
saturation. The Peng-Robinson EOS is used for all the simulation calculations. The number of grid-blocks for the simulations is varied from 200 to 4000 grid-blocks. This wide range is important for showing the effect of different levels of dispersion on the EOS models. GEM variable time step option was employed for all the simulations. A sample input file used for the simulation is given in appendix $\mathrm{F}$.

\subsection{APPLICATION OF THE IMPROVED TUNING TECHNIQUE}

The detailed tuning procedure outlined above is tested for two oil samples: a 12component EOS characterization and an 11-component EOS characterization. These two multicomponent models are taken as the truth models. The 12-component model is lumped to a four pseudocomponent model by tuning to the MME while the 11component model is lumped to a five pseudocomponent model by tuning to the MMP.

\subsubsection{Twelve-Component EOS Pseudoization}

A 12-component EOS characterization (Table 3.1) was lumped to a fourpseudocomponent model using the lumping scheme and tuning technique outlined in section 3.3. In lumping the components, $\mathrm{CH}_{4}-\mathrm{N}_{2}$ was selected as a separate pseudocomponent so that its composition in the injection gas can be varied. $\mathrm{C}_{30+}$ was also selected as a separate pseudocomponent because it has a very low K-value (see Table 3.4). The other two pseudocomponents are defined when the objective function is minimum. Table 3.5 shows the resulting lumped, four-pseudocomponent model.

The pseudocomponent model was then tuned to PVT data and the MME for the oil. At the end of the tuning, two primary models result: one tuned to only the PVT data and the other tuned to both the PVT data and the MME. The PVT data were generated from the 12-component, truth model at $200^{\circ} \mathrm{F}$. 
Tables 3.13-3.16 show the properties of the tuned pseudocomponent models. Four lumped models were developed from the 12-component model to illustrate the impact of obtaining an accurate match to either the pressure-composition data $(\mathrm{P}-\mathrm{X})$ data or $\mathrm{MME}$. The models are:

1. 4-PVT: model tuned to PVT data, which excludes the P-X data.

2. 4-PVTX: model tuned to all the available PVT data.

3. 4-PVT \& MME: model tuned to PVT data and MME, which excludes the P-X data.

4. 4-MME \& PVTX: model tuned to all the available PVT data and the MME.

Table 3.17 compares how well the four-component models predict the SVP and MMP of the 12-component model at $200^{\circ} \mathrm{F}$. Figures3.1-3.9 show the match of the models to the analytical PVT data from the different PVT tests.

To match the PVT data, the critical temperature and pressure of $\mathrm{C}_{30+}$ was adjusted by $2 \%$ and $5 \%$ respectively. It was difficult to get a good match to the $\mathrm{P}-\mathrm{X}$ data from the swelling test and the MME simultaneously. The MME was given a greater weight in the tuning process. All other swelling test data (GOR, swollen volume, etc) were well matched. A match to the SVP, and MME was obtained by adjusting the BIP between $\mathrm{CH}_{4}-\mathrm{N}_{2}$ and $\mathrm{C}_{30+}$ by $10 \%$ (0.20 to 0.1809$), \mathrm{C}_{2+}$ and $\mathrm{C}_{5+}$ by $45 \%$ (0.0607 to 0.0335$)$, and $\mathrm{C}_{2+}$ and $\mathrm{C}_{30+}$ from 0.1269 to 0.127 .

BIPs are usually adjusted to get a match to the P-X data and the MME (or MMP). When the BIPs were adjusted to match the P-X data without considering the match to MME, the resulting EOS model did not give accurate simulation predictions for the displacement process (see Figure 3.10). Adjusting a particular BIP could have opposite effects on the MME and P-X data predictions. 
Table 3.13: Component properties for four-component EOS model tuned to only PVT data at $200^{\circ} \mathrm{F}$.

\begin{tabular}{|l|c|c|c|c|c|c|c|c|}
\hline Component & Mol \% & $\mathrm{M}_{\mathrm{W}}$ & $\mathrm{T}_{\mathrm{C}}\left({ }^{\circ} \mathrm{F}\right)$ & $\mathrm{P}_{\mathrm{C}}(\mathrm{psia})$ & $\begin{array}{c}\mathrm{V}_{\mathrm{C}} \\
(\mathrm{ft} / \mathrm{lb}-\mathrm{mol})\end{array}$ & $\omega$ & $\Omega_{A}$ & $\Omega_{B}$ \\
\hline $\mathrm{CH}_{4}-\mathrm{N}_{2}$ & 36.918 & 16.00 & -117.07 & 671.17 & 1.59 & 0.013 & 0.45724 & 0.0778 \\
\hline $\mathrm{C}_{2+}$ & 11.554 & 40.72 & 142.80 & 769.79 & 2.54 & 0.159 & 0.45724 & 0.0778 \\
\hline $\mathrm{C}_{5+}$ & 42.809 & 208.34 & 775.05 & 322.58 & 13.06 & 0.674 & 0.45724 & 0.0778 \\
\hline $\mathrm{C}_{30+}$ & 8.719 & 451 & 1104.67 & 162.68 & 30.64 & 1.026 & 0.45724 & 0.0778 \\
\hline
\end{tabular}

Table 3.14: Binary interaction parameters for four-component model tuned to only PVT data.

\begin{tabular}{|c|c|c|c|c|}
\hline & $\mathrm{CH}_{4}-\mathrm{N}_{2}$ & $\mathrm{C}_{2+}$ & $\mathrm{C}_{5+}$ & $\mathrm{C}_{30+}$ \\
\hline $\mathrm{CH}_{4}-\mathrm{N}_{2}$ & 0.0000 & & & \\
\hline $\mathrm{C}_{2+}$ & 0.0286 & 0.0000 & & \\
\hline $\mathrm{C}_{5+}$ & 0.0258 & 0.0607 & 0.0000 & \\
\hline $\mathrm{C}_{30+}$ & 0.2000 & 0.1269 & 0.0000 & 0.0000 \\
\hline
\end{tabular}


Table 3.15: Component properties for four-component EOS model tuned to both the PVT data and MME at $200^{\circ} \mathrm{F}$.

\begin{tabular}{|l|c|c|c|c|c|c|c|c|}
\hline Component & Mol \% & $\mathrm{M}_{\mathrm{w}}$ & $\mathrm{T}_{\mathrm{C}}\left({ }^{\circ} \mathrm{F}\right)$ & $\mathrm{P}_{\mathrm{C}}(\mathrm{psia})$ & $\begin{array}{c}\mathrm{V}_{\mathrm{C}} \\
\left(\mathrm{ft}^{3} / \mathrm{lb}-\mathrm{mol}\right)\end{array}$ & $\omega$ & $\Omega_{A}$ & $\Omega_{B}$ \\
\hline $\mathrm{CH}_{4}-\mathrm{N}_{2}$ & 36.918 & 16 & -117.07 & 671.17 & 1.59 & 0.013 & 0.45724 & 0.0778 \\
\hline $\mathrm{C}_{2+}$ & 11.554 & 40.72 & 142.80 & 769.79 & 2.54 & 0.159 & 0.45724 & 0.0778 \\
\hline $\mathrm{C}_{5+}$ & 42.809 & 208.34 & 775.05 & 322.86 & 13.06 & 0.674 & 0.45724 & 0.0778 \\
\hline $\mathrm{C}_{30+}$ & 8.719 & 451 & 1136.59 & 171.07 & 30.64 & 1.026 & 0.45724 & 0.0778 \\
\hline
\end{tabular}

Table 3.16: Binary interaction parameters for four-component model tuned to both PVT data and MME.

\begin{tabular}{|c|c|c|c|c|}
\hline & $\mathrm{CH}_{4}-\mathrm{N}_{2}$ & $\mathrm{C}_{2+}$ & $\mathrm{C}_{5+}$ & $\mathrm{C}_{30+}$ \\
\hline $\mathrm{CH}_{4}-\mathrm{N}_{2}$ & 0.0000 & & & \\
\hline $\mathrm{C}_{2+}$ & 0.0286 & 0.0000 & & \\
\hline $\mathrm{C}_{5+}$ & 0.0258 & 0.0335 & 0.0000 & \\
\hline $\mathrm{C}_{30+}$ & 0.1809 & 0.1270 & 0.0000 & 0.0000 \\
\hline
\end{tabular}

Table 3.17: Prediction of MMP and SVP by four-component EOS models.

\begin{tabular}{|l|c|c|c|}
\hline EOS Model & $\begin{array}{c}\text { Temperature } \\
\left({ }^{\circ} \mathrm{F}\right)\end{array}$ & SVP (psia) & MMP (psia) \\
\hline 12-component & 200 & 3200.37 & 3311.80 \\
\hline 4-PVT & 200 & 3201.75 & 3949.75 \\
\hline 4-PVTX & 200 & 3218.71 & 4248.81 \\
\hline 4-PVT \& MME (no P-X) & 200 & 3202.00 & 3311.12 \\
\hline 4-MME \& PVTX & 200 & 3188.03 & 3426.01 \\
\hline
\end{tabular}


However, when the P-X data was not matched at all, the 1-D simulation results obtained were unstable with oscillations in the saturation velocities. Table 3.17 compares the MMP predictions for the four lumped models developed by tuning to different combinations of PVT data and the MME. The most inaccurate predictions were by the models tuned to only PVT data. The 4-PVTX model over predicted the MMP by 638 psia. The results obtained suggest that the best approach would be to give more weight to the MMP or MME while ensuring a reasonable match to the P-X data. A fair match to the P-X data ensured stability of the simulations while a match to the MMP or MME ensured accuracy of prediction of the displacement process.

In the separator test, the four-component model predicted a total GOR (at 14.7 psia and $60^{\circ} \mathrm{F}$ ) of $463 \mathrm{scf} / \mathrm{stb}$, which compared well with the 12-component model total GOR of $462 \mathrm{scf} / \mathrm{stb}$.

Figures 3.1 and 3.3-3.8 generally show a good match to the PVT data. Figure 3.2 shows a relatively poor fit to the solution gas/oil ratio $\left(R_{s}\right)$. This is due to the inherent difficulty of matching all PVT data simultaneously. A better match of the $\mathrm{R}_{\mathrm{s}}$ data resulted in a poorer prediction of the densities. A match to the density data could be achieved by adjusting the volume shift parameters but this adversely impacts the prediction of $R_{\mathrm{s}}$. The best fit obtained for both data is a trade off between an excellent match to the densities and a fair match to the $\mathrm{R}_{\mathrm{s}}$.

\section{Validation of the lumped four-component EOS models.}

The MMP of the oil at $200^{\circ} \mathrm{F}$ for displacement by injection gas of fixed composition $\left(67.23 \% \mathrm{C}_{2+}\right.$ enrichment) is 3311 psia. Therefore, to investigate miscible gas floods above the MMP for this oil, a pressure of 3650 psia at $200^{\circ} \mathrm{F}$ was selected for the compositional simulations. 
1-D, 400 grid-blocks simulation was made to compare the four lumped models developed from tuning to different combinations of the PVT data and MMP. Figure 3.9 compares the simulated gas saturation velocity distribution for the models for 0.5 HCPVI. Figure 3.10 compares the model tuned to only PVT data and that tuned to both the PVT data and MME with the 12-component model for analytically calculated MME predictions at different pressures (or the MMP at different injection gas enrichment). The 4-PVT \& MME model closely predicts the 12-component model MME data than the 4-PVT model. There is a perfect match at $67.23 \% \mathrm{C}_{2+}$ enrichment because this was the MME at which the model was tuned. However, there is an increase in the deviation from the 12component model MME predictions as the pressure is decreased. As the pressure decreases, the 4-PVT \& MME model predicts a lower MME value than the multicomponent model. The 4-PVT model consistently over predicts the MMEs.

The tuned models (4-PVT and 4-MME \& PVT) are further compared to the 12component model by making 1-D simulations at $3650 \mathrm{psia}, 200^{\circ} \mathrm{F}$ and fixed injection gas enrichment $\left(67.23 \% \mathrm{C}_{2+}\right)$. The simulations were made for 1000 grid-blocks to minimize the effect of numerical dispersion. Figure 3.11 compares the gas saturation velocity distribution for the EOS models while Figures 3.12-3.15 compare the component velocities. The velocities were generated for 0.3 HCPVI. Figures 3.16-3.18 compare the 1-D simulation oil recoveries to that of the 12-component model.

Figure 3.9 shows that the 4-PVT \& MME model gave as good a prediction of the 12-components EOS gas saturation velocities as the 4-MME \& PVTX model. This suggests that a rigorous match to the P-X data may not be required to give a good prediction of the miscible displacement. This result is likely because the P-X data may not represent the true $\mathrm{CO}_{2}$-oil mixture compositions that occur along the composition path. 


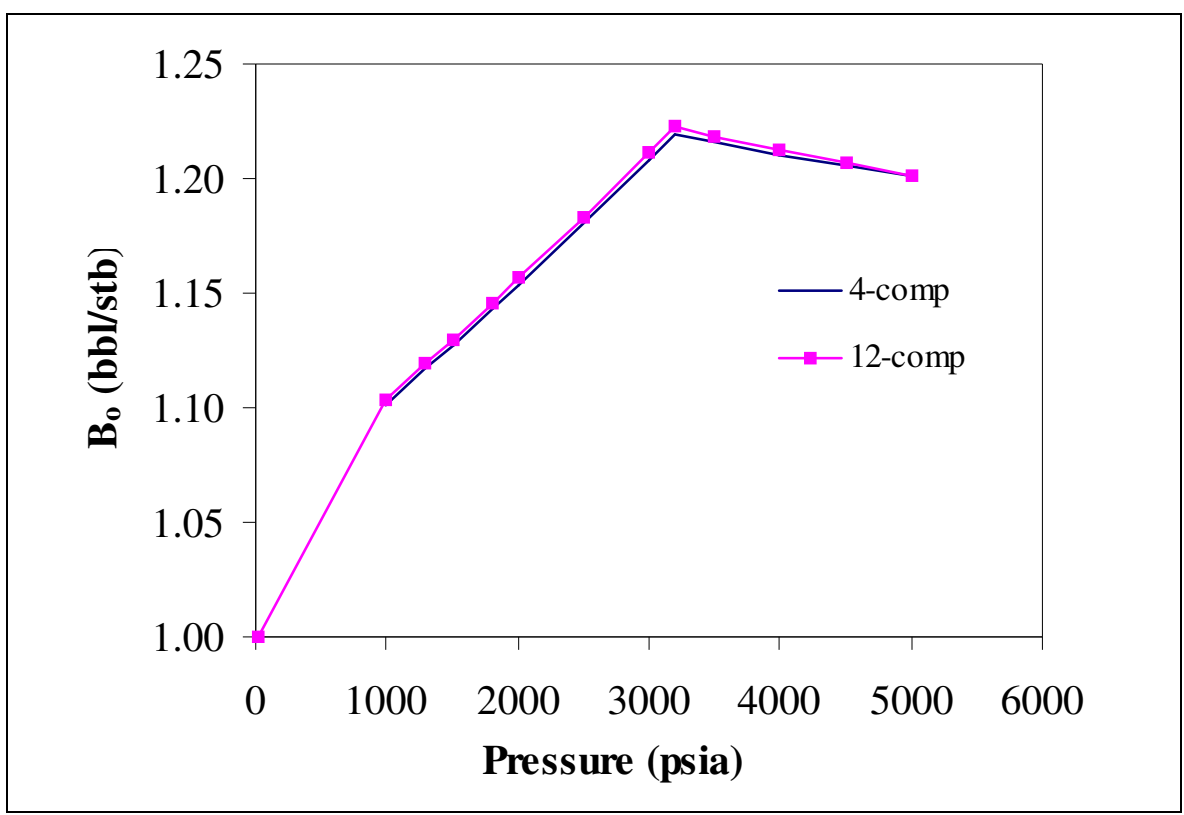

Figure 3.1: Tuned four-component model prediction for oil formation volume factor from differential liberation test at $200^{\circ} \mathrm{F}$.

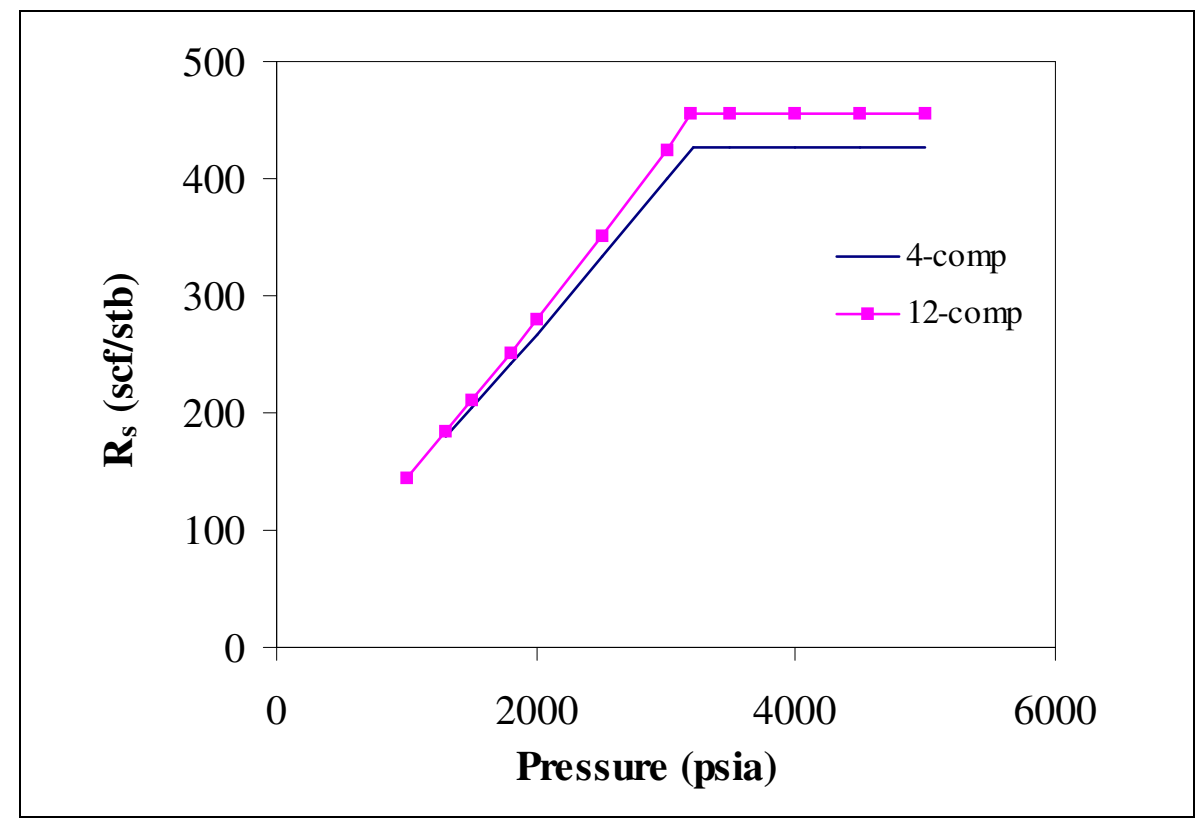

Figure 3.2: Tuned four-component model prediction for solution gas-oil ratio from differential liberation test at $200^{\circ} \mathrm{F}$. 


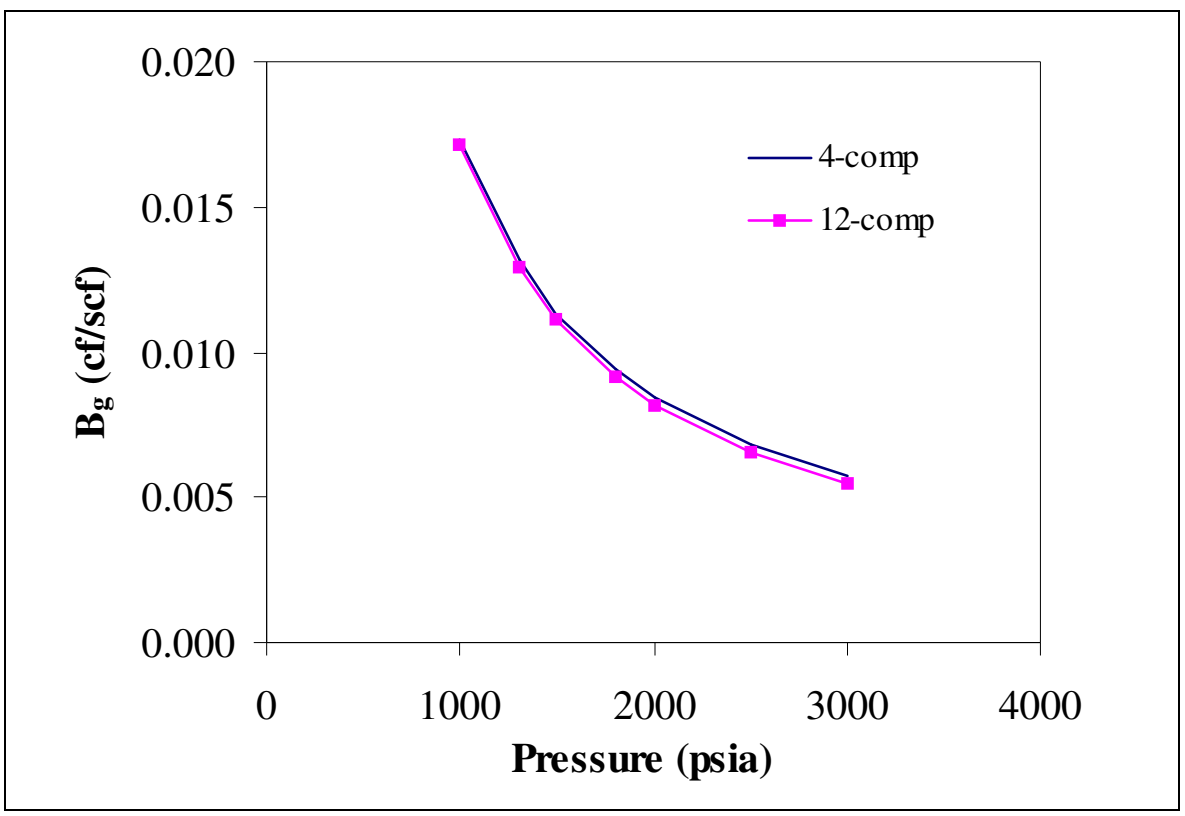

Figure 3.3: Tuned four-component model prediction for gas formation volume factor from differential liberation test at $200^{\circ} \mathrm{F}$.

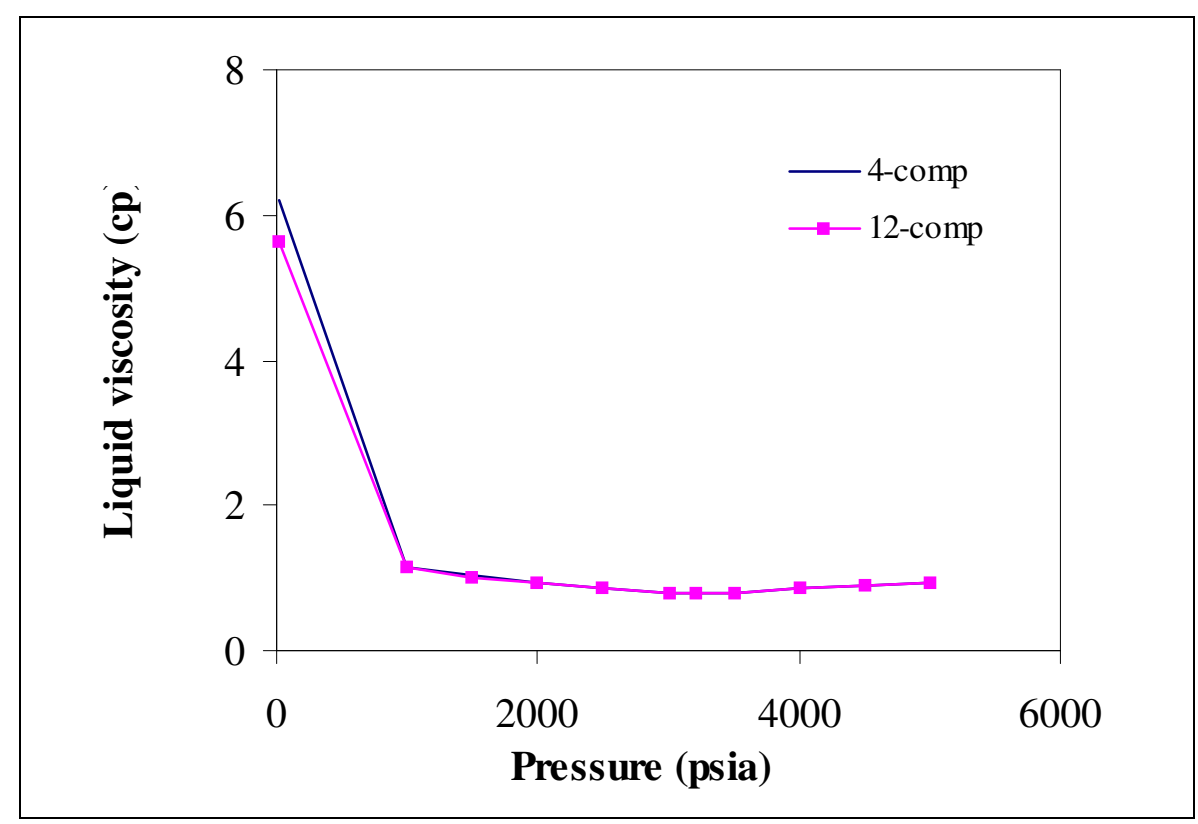

Figure3.4: Tuned four-component model prediction for oil viscosity from differential liberation test at $200^{\circ} \mathrm{F}$. 


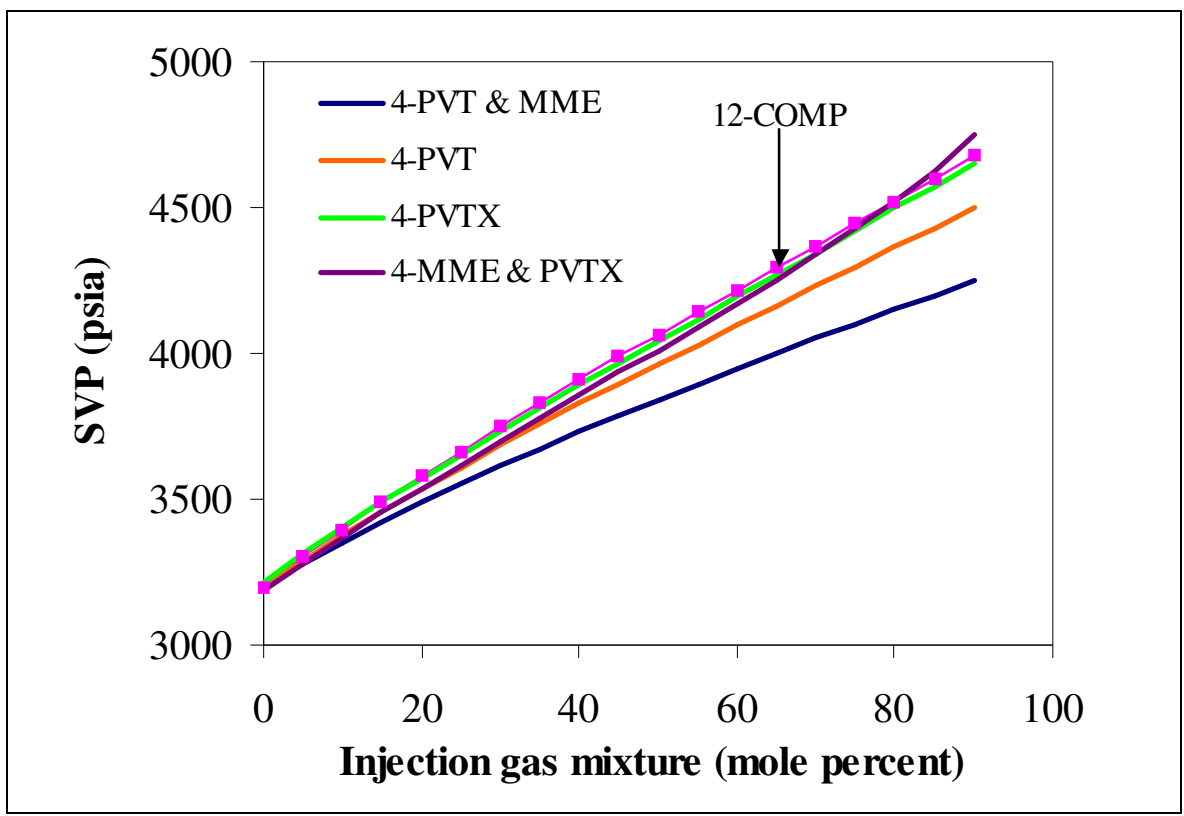

Figure 3.5: Four-component model predictions for the pressure composition data from swelling test at $200^{\circ} \mathrm{F}$.

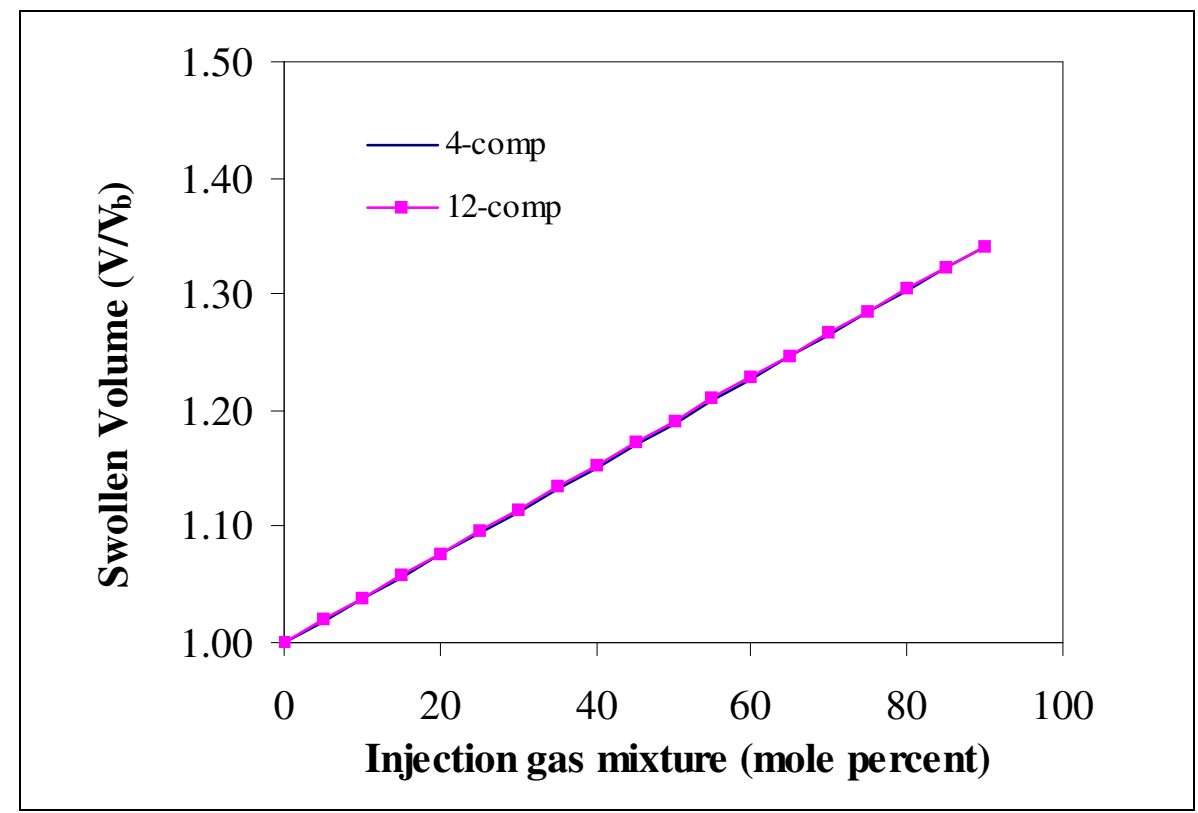

Figure 3.6: Tuned four-component model prediction for the swollen volume from swelling test at $200^{\circ} \mathrm{F}$. 


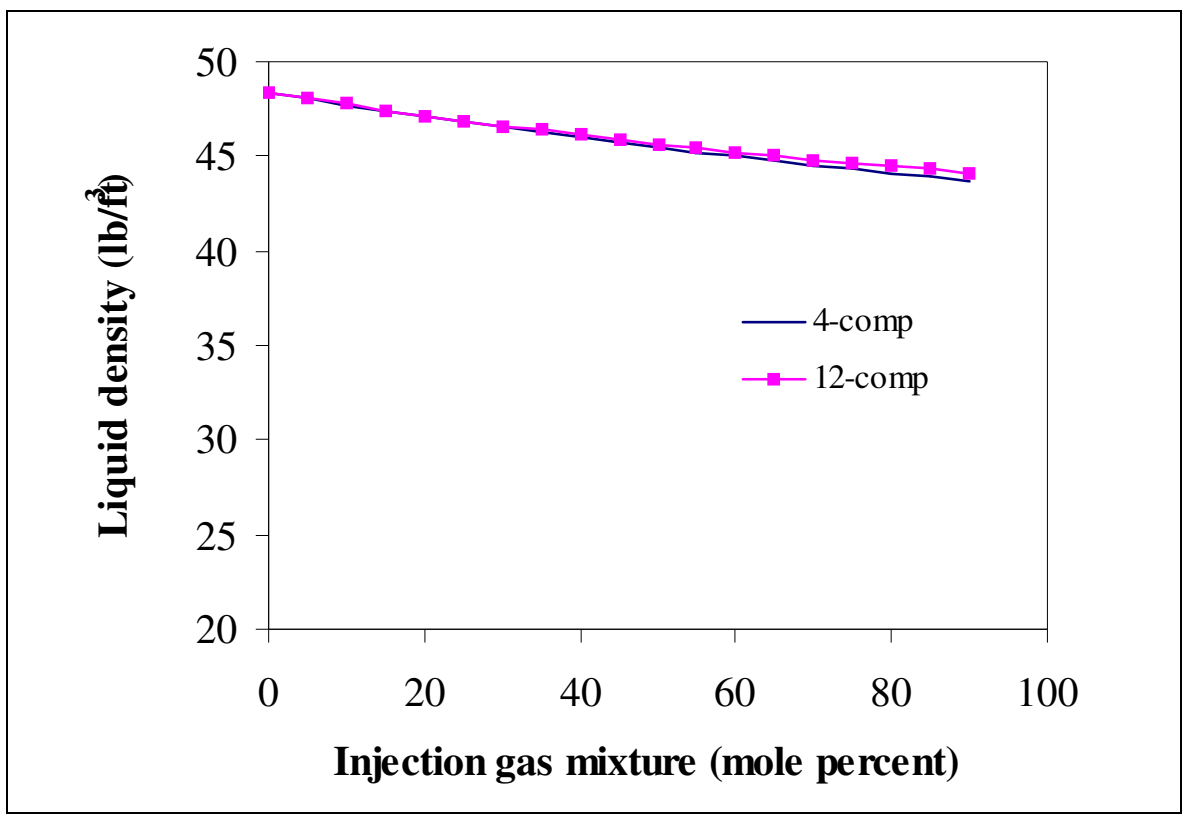

Figure 3.7: Tuned four-component model prediction for the oil/gas mixture density from swelling test at 3200 psia and $200^{\circ} \mathrm{F}$.

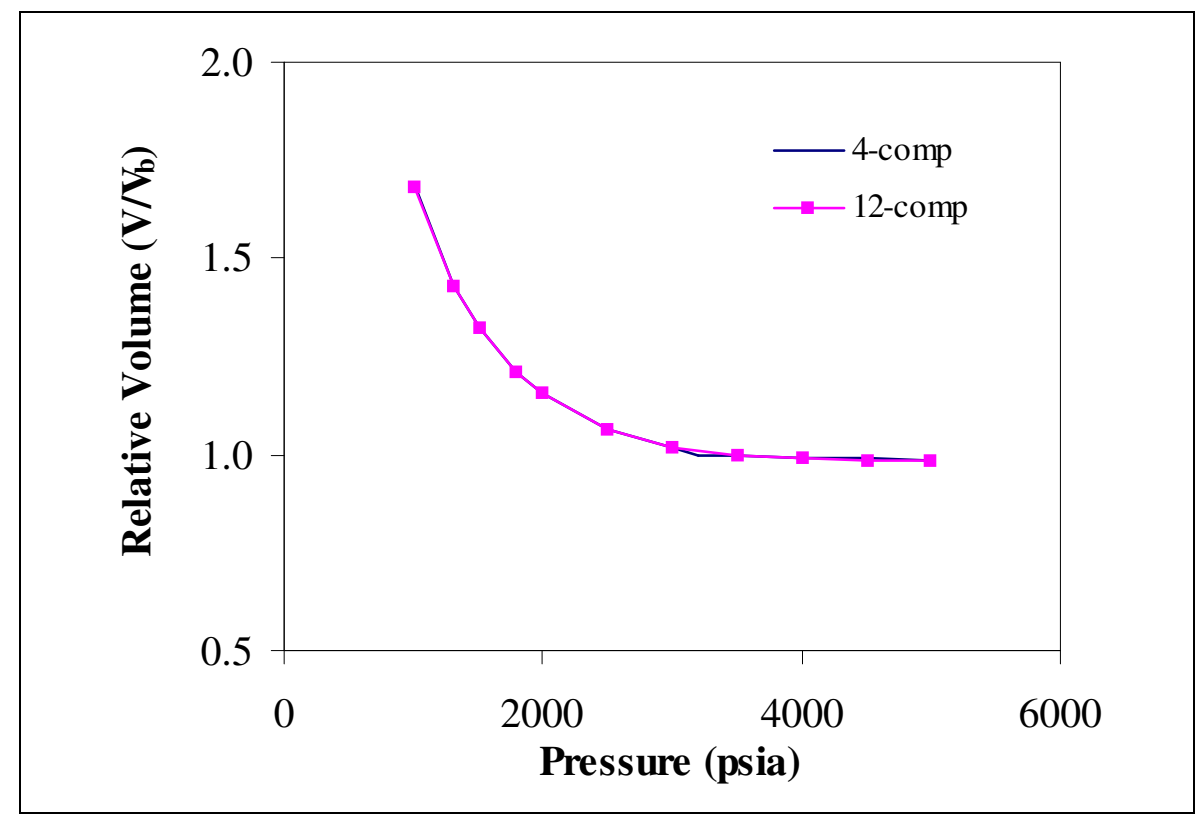

Figure 3.8: Four-component model prediction for relative volume from constant mass expansion test at $200^{\circ} \mathrm{F}$. 
The other two models (4-PVT and 4-PVTX) showed a poorer fit to the 12-component EOS model profile. Although the 4-PVTX model was tuned to match all the PVT data, it over predicts the MMP for displacement by the injection gas. The MMP for the 12component model at $200^{\circ} \mathrm{F}$ is 3311 psia, 3950 psia for 4-PVT, and 4249 psia for 4-PVTX model. This shows a disadvantage of fitting to only PVT data.

Figure 3.10 shows that the four-component model may not accurately predict the displacement process at higher enrichments. The model would be adequate for $67.23 \%$ $80 \% \mathrm{C}_{2+}$ enrichment. The model will require tuning to a new MME value for enrichment levels higher than $80 \% \mathrm{C}_{2}$.

The 4-MME \& PVT model composition and saturation velocity distributions are a closer fit to that of the 12-component model than the 4-PVT model. At the simulation pressure (3650 psia) and injection gas enrichment, the 4-PVT model predicted a more immiscible flood. The model predicted the MMP to be 3950 psia. This implies that the simulated flood is completely in the two-phase region (i.e. miscibility is never developed). The plots show that the 4-MME \& PVT model closely predicts the performance of the 12-component model. However, the 4-MME \& PVT model predicts a delayed gas front and as such overestimates the oil recovery given by the 12-component model by a small amount. This probably indicates that lumping to a higher number of pseudocomponents (say five pseudocomponents) would capture better the details of the 12-component predictions.

This research effort was aimed at demonstrating the significance of tuning EOS models to a displacement parameter like the MME or MMP and not to find the minimum number of pseudocomponents required to get a perfect fit. 


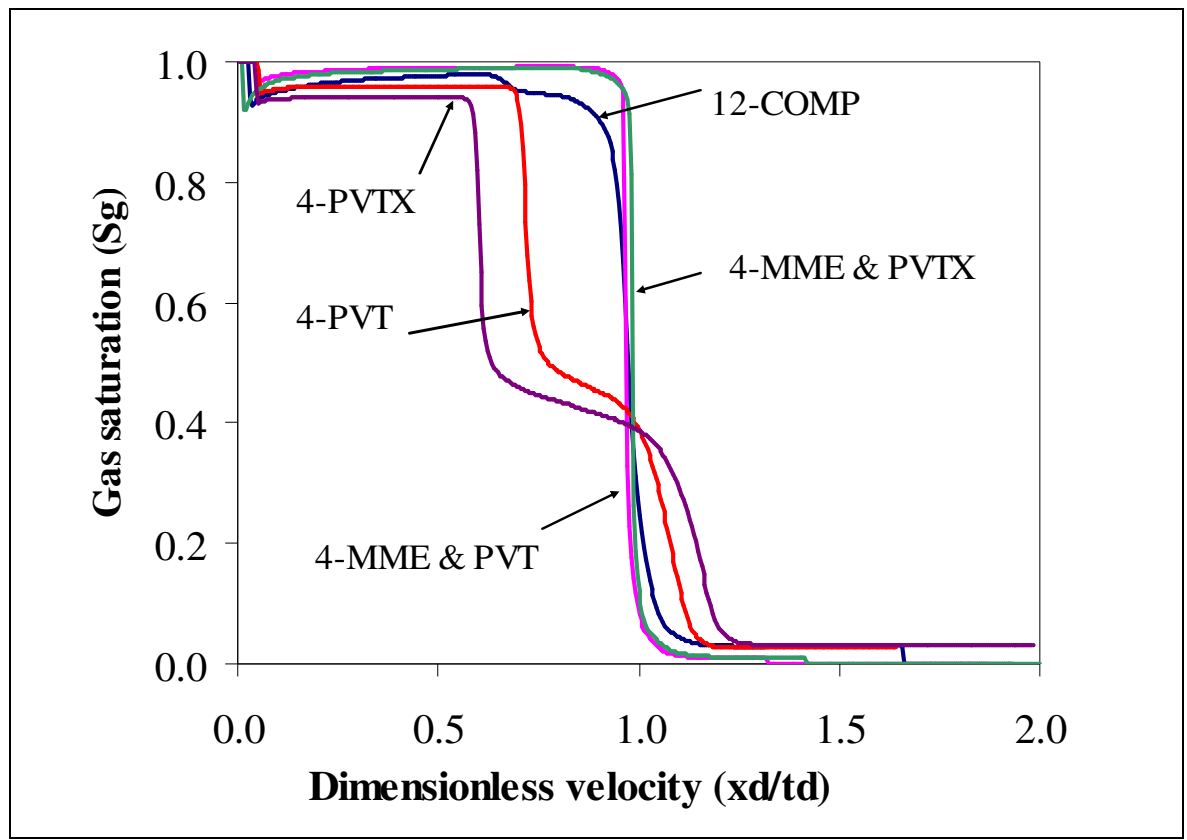

Figure 3.9: Comparison of simulated gas saturation velocities for four-component models at $0.3 \mathrm{HCPVI}, 3650 \mathrm{psia}, 200^{\circ} \mathrm{F}$ and fixed injection gas enrichment.

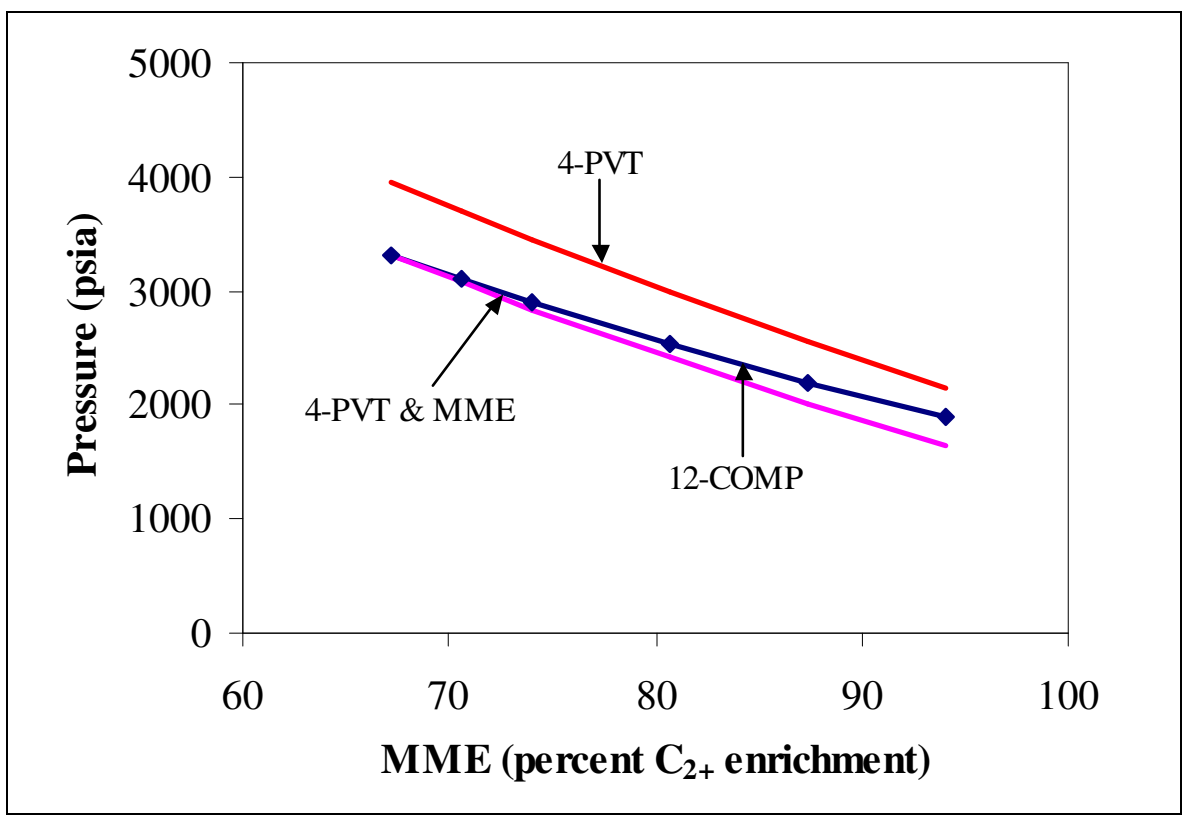

Figure 3.10: Analytical MME predictions by EOS models at $200^{\circ} \mathrm{F}$ and different pressures. 


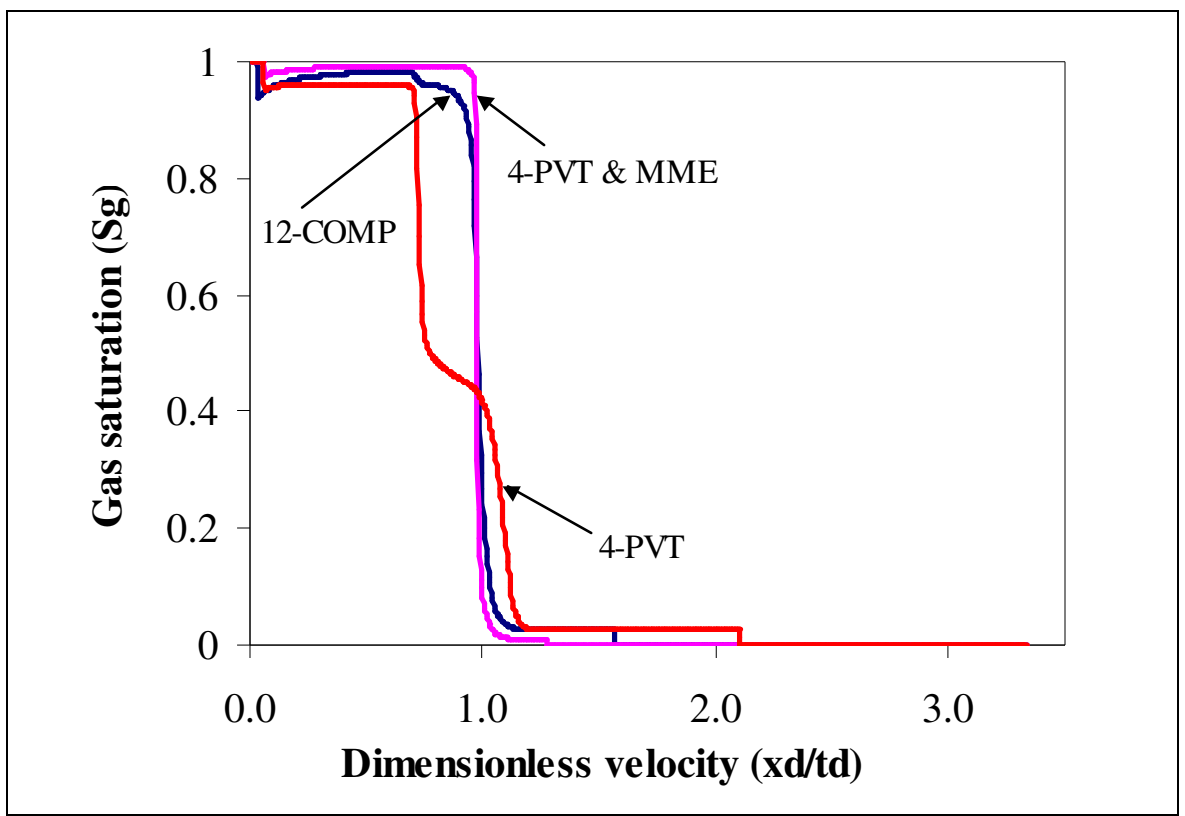

Figure 3.11: Comparison of 12- and four-component EOS models simulated gas saturation velocities for $0.3 \mathrm{HCPVI}$ at $3650 \mathrm{psia}, 200^{\circ} \mathrm{F}$ and fixed injection gas enrichment.

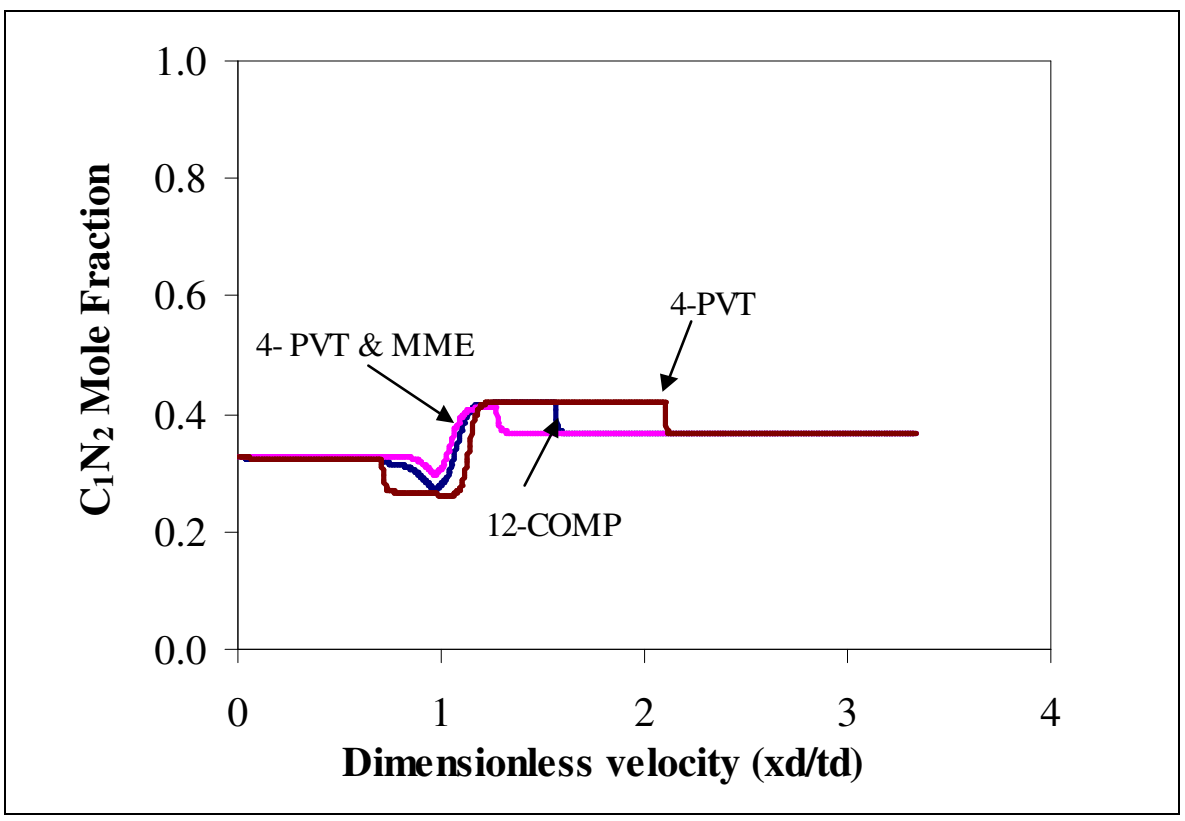

Figure 3.12: Comparison of 12- and four-component EOS models simulated $\mathrm{C}_{1} \mathrm{~N}_{2}$ component velocities for $0.3 \mathrm{HCPVI}$ at $3650 \mathrm{psia}, 200^{\circ} \mathrm{F}$ and fixed injection gas enrichment. 


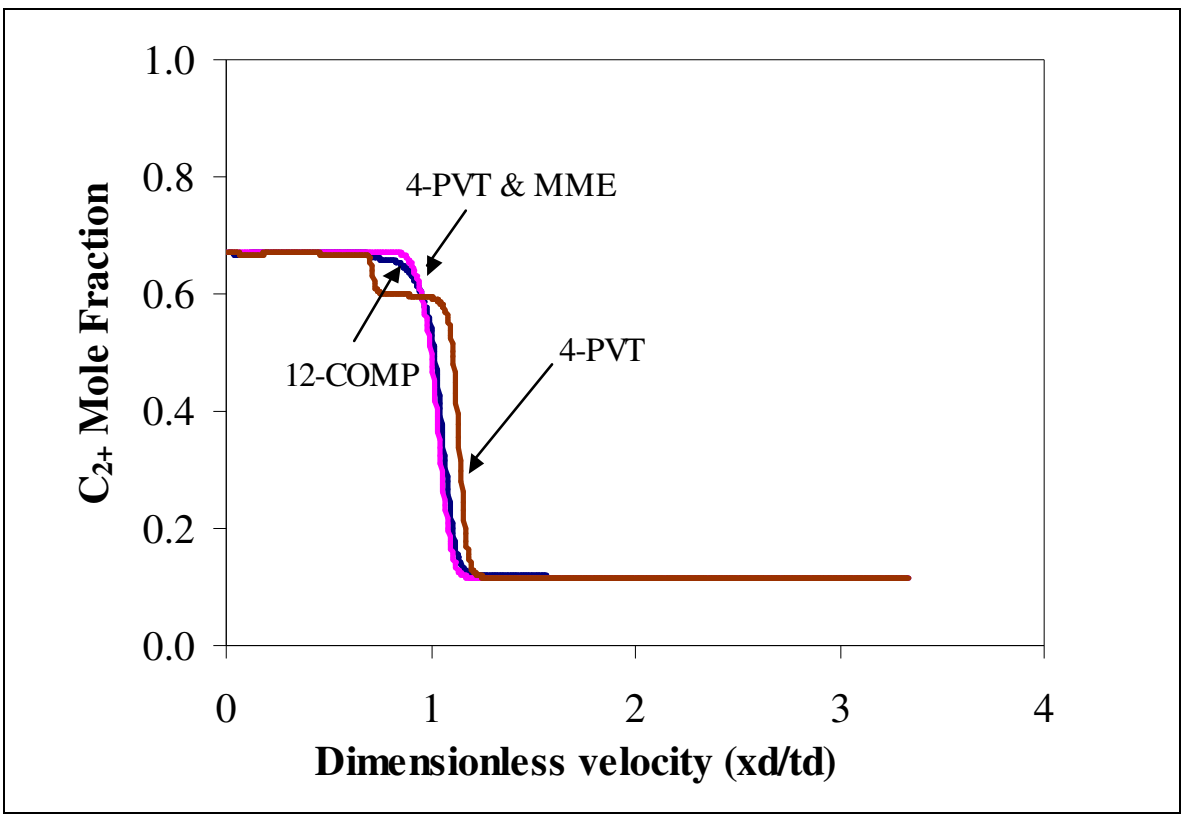

Figure 3.13: Comparison of 12- and four-component EOS models simulated $\mathrm{C}_{2+}$ component velocities for $0.3 \mathrm{HCPVI}$ at $3650 \mathrm{psia}, 200^{\circ} \mathrm{F}$ and fixed injection gas enrichment.

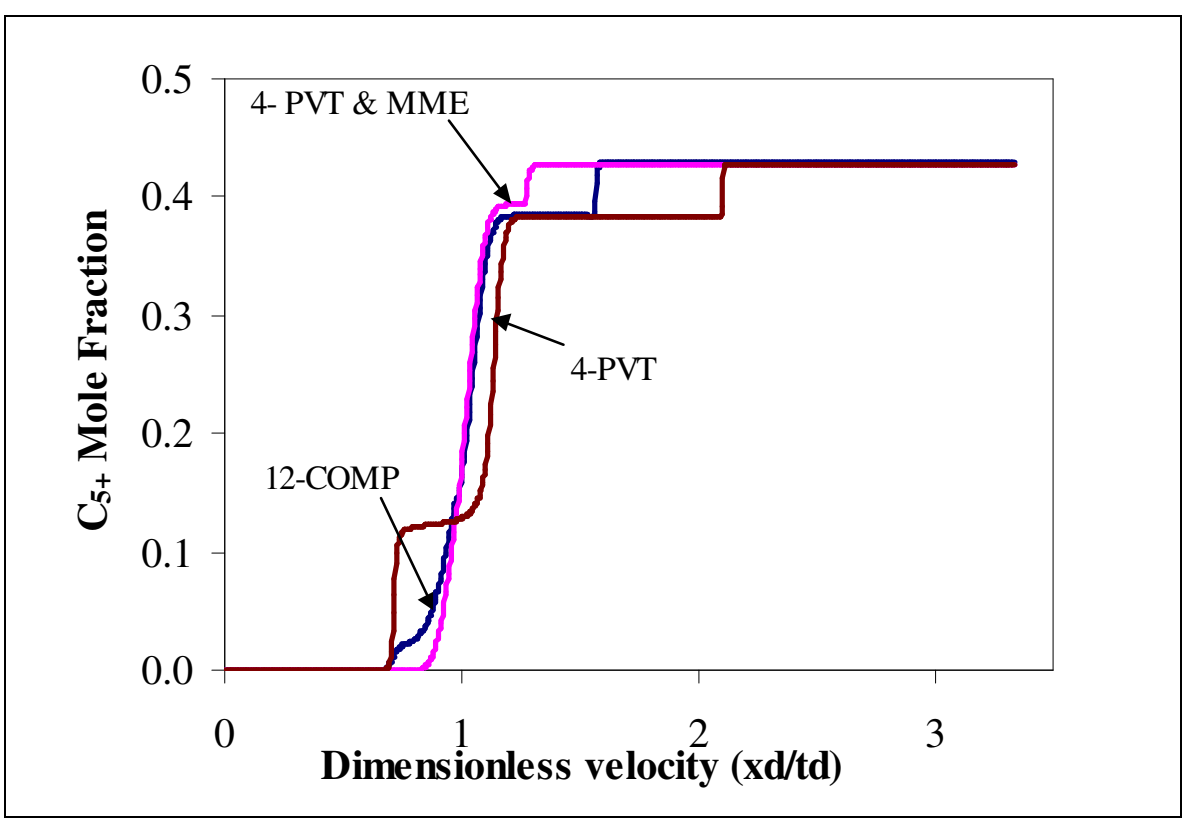

Figure 3.14: Comparison of 12- and four-component EOS models simulated $\mathrm{C}_{5+}$ component velocities for $0.3 \mathrm{HCPVI}$ at $3650 \mathrm{psia}, 200^{\circ} \mathrm{F}$ and fixed injection gas enrichment. 


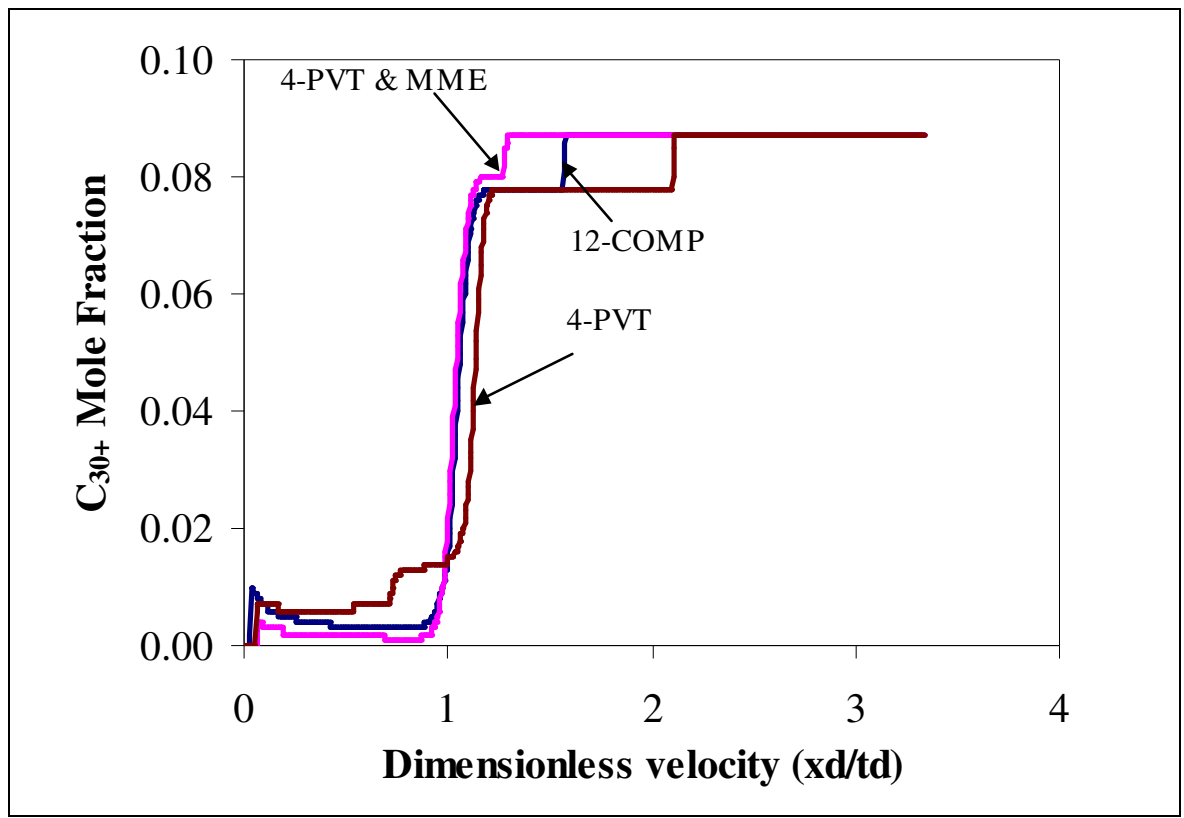

Figure 3.15: Comparison of 12- and four-component EOS models simulated $\mathrm{C}_{30+}$ component velocities for $0.3 \mathrm{HCPVI}$ at $3650 \mathrm{psia}, 200^{\circ} \mathrm{F}$ and fixed injection gas enrichment.

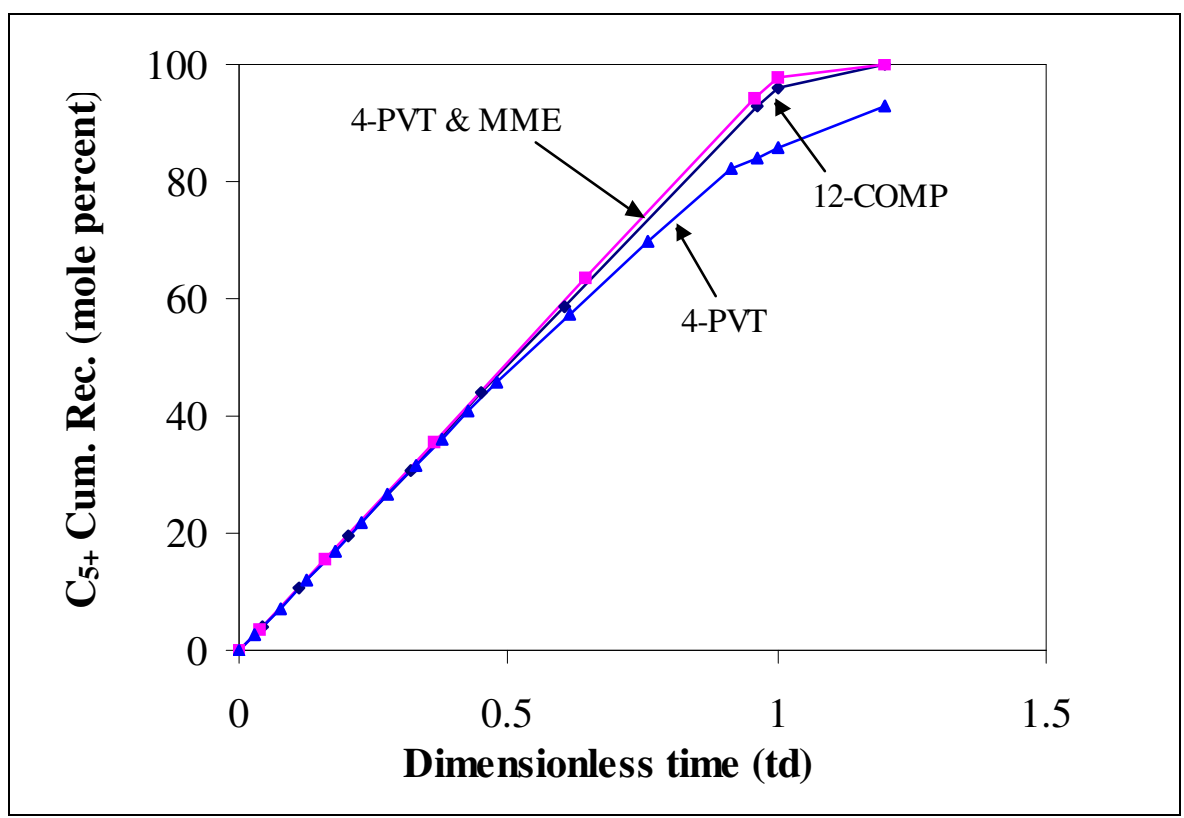

Figure 3.16: Comparison of 12- and four-component EOS models simulated $\mathrm{C}_{5+}$ component recovery at $3650 \mathrm{psia}, 200^{\circ} \mathrm{F}$ and fixed injection gas enrichment. 


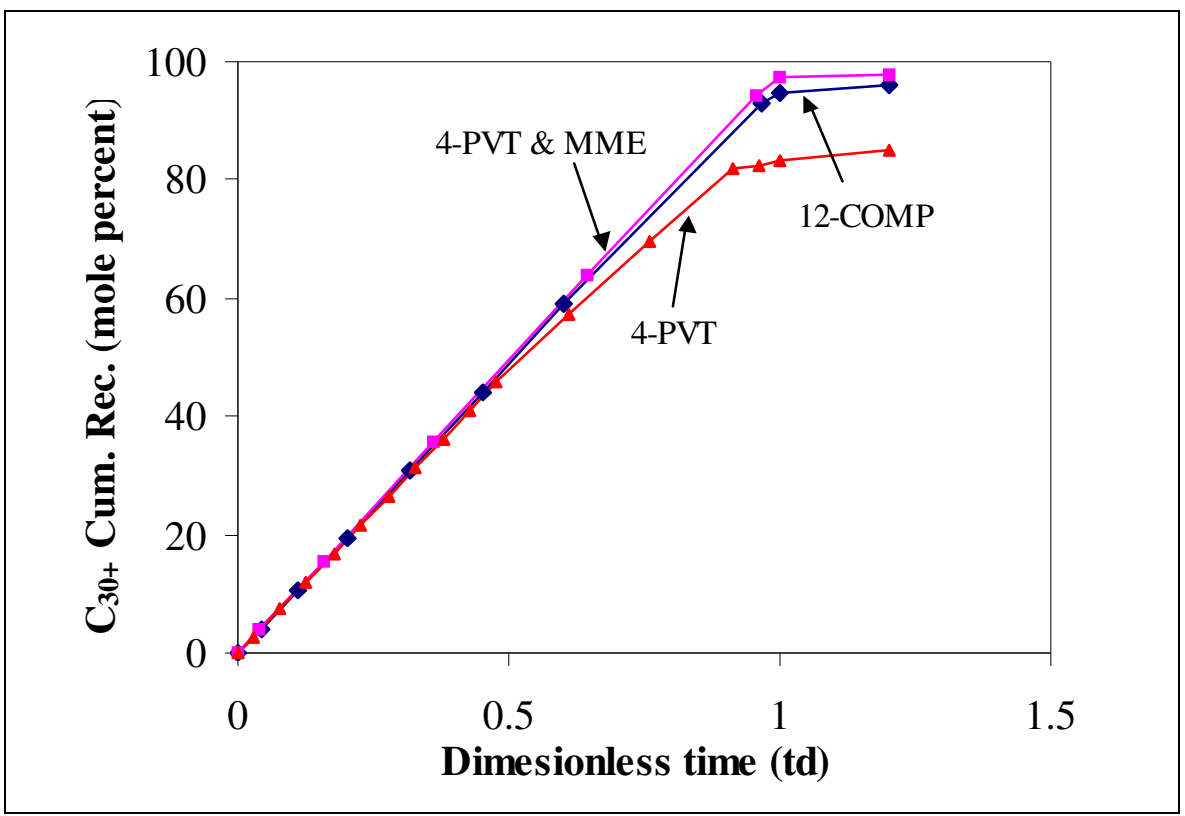

Figure 3.17: Comparison of 12- and four-component EOS models simulated $\mathrm{C}_{30+}$ component recovery at $3650 \mathrm{psia}, 200^{\circ} \mathrm{F}$ and fixed injection gas enrichment.

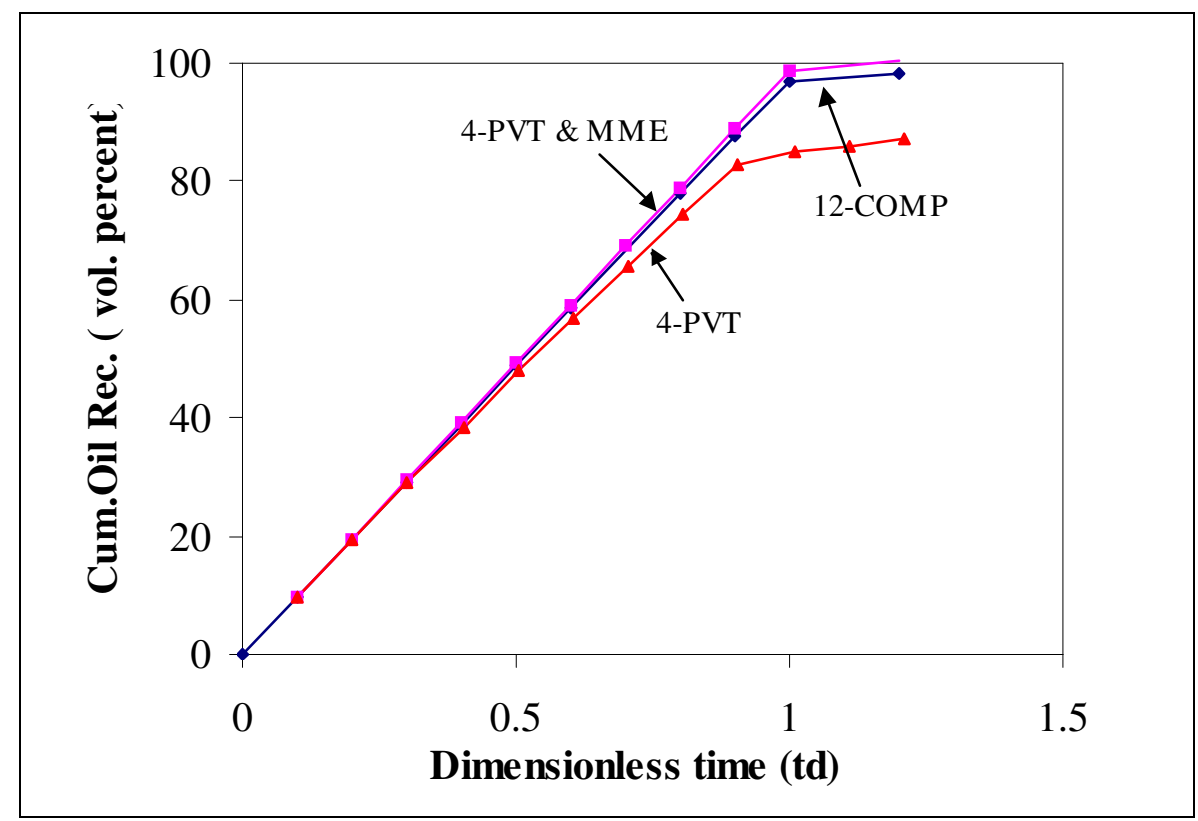

Figure 3.18: Comparison of 12- and four-component EOS models simulated oil recovery at 3650 psia, $200^{\circ} \mathrm{F}$ and fixed injection gas enrichment. 
However, it is interesting to observe that only a few pseudocomponents can be used to adequately describe the reservoir oil using the proposed tuning technique. Such a reduced pseudocomponent model would significantly improve the speed of compositional simulations.

\subsubsection{Eleven-Component EOS Pseudoization}

The 11-component model was lumped to five pseudocomponents. The key displacement parameter included in the tuning process is the MMP for displacement by pure $\mathrm{CO}_{2}$ at $150^{\circ} \mathrm{F}$. In selecting the pseudocomponents, $\mathrm{CO}_{2}$ was selected as a separate pseudocomponent because it is present in both the oil and gas. This reduces the number of components tracked in a compositional simulation for $\mathrm{CO}_{2}$ floods. $\mathrm{C}_{14+}$ was also selected as a separate component because of its very low K-value. The other pseudocomponents were selected by the approach of Newley and Merrill. The representative K-values (Table 3.10) used for the lumping and properties calculation were determined at 1553 psia and $150^{\circ} \mathrm{F}$.

Tables 3.19-3.20 show the critical properties of the final five-component model tuned to PVT data and MMP for pure $\mathrm{CO}_{2}$ injection. Figures 3.19-3.26 compare the match of the final lumped model to the 11-component model for the different PVT experiments. The five-component model gave good predictions for most of the PVT data generated from the 11-component model without requiring adjustment to the critical properties of the components. This shows the advantage of the Newley \& Merrill approach to lumping pseudocomponents and calculation of EOS properties based on Kvalue averaged mixing rule. To get a perfect match to the SVP, a $2.2 \%$ and $1.3 \%$ adjustment was made to the critical pressure and temperature of $\mathrm{C}_{14+}$ respectively otherwise the adjustment was unnecessary. 
Table 3.18: Prediction of MMP and SVP by five-component EOS models.

\begin{tabular}{|l|c|c|c|}
\hline EOS Model & $\begin{array}{c}\text { Temperature } \\
\left({ }^{\circ} \mathrm{F}\right)\end{array}$ & $\begin{array}{c}\text { SVP } \\
(\mathrm{psia})\end{array}$ & $\begin{array}{c}\text { MMP } \\
(\mathrm{psia})\end{array}$ \\
\hline 11-component & 150 & 1553.12 & 1876 \\
\hline 5- PVTX & 150 & 1553.52 & 1868 \\
\hline 5-PVT & 150 & 1553.52 & 2158 \\
\hline 5-PVT \& MMP & 150 & 1553.52 & 1876 \\
\hline
\end{tabular}

Table 3.19: Component properties for five-component EOS model tuned to PVT data and MMP at $150^{\circ} \mathrm{F}$.

\begin{tabular}{|c|c|c|c|c|c|c|c|c|}
\hline Component & Mol \% & $\mathrm{M}_{\mathrm{w}}$ & $\mathrm{T}_{\mathrm{C}}\left({ }^{\circ} \mathrm{F}\right)$ & $\mathrm{P}_{\mathrm{C}}(\mathrm{psia})$ & $\begin{array}{c}\mathrm{V}_{\mathrm{C}} \\
\left(\mathrm{ft}^{3} / \mathrm{lb}-\mathrm{mol}\right)\end{array}$ & $\omega$ & $\Omega_{A}$ & $\Omega_{B}$ \\
\hline $\mathrm{CO}_{2}$ & 0.10 & 44.01 & 87.89 & 1069.87 & 1.51 & 0.2250 & 0.45724 & 0.0778 \\
\hline $\mathrm{C}_{1+}$ & 37.80 & 17.84 & -89.41 & 673.15 & 1.60 & 0.0217 & 0.45724 & 0.0778 \\
\hline $\mathrm{C}_{3+}$ & 17.03 & 67.99 & 348.03 & 502.67 & 4.72 & 0.2310 & 0.45724 & 0.0778 \\
\hline $\mathrm{C}_{7+}$ & 40.03 & 137 & 633.15 & 320.43 & 9.36 & 0.4750 & 0.45724 & 0.0778 \\
\hline $\mathrm{C}_{14+}$ & 5.04 & 198 & 800 & 235 & 13.30 & 0.7550 & 0.45724 & 0.0778 \\
\hline
\end{tabular}

Table 3.20: Binary interaction parameters for tuned five-component model.

\begin{tabular}{|c|c|c|c|c|c|}
\hline & $\mathrm{CO}_{2}$ & $\mathrm{C}_{1+}$ & $\mathrm{C}_{3+}$ & $\mathrm{C}_{7+}$ & $\mathrm{C}_{14+}$ \\
\hline $\mathrm{CO}_{2}$ & 0.0000 & & & & \\
\hline $\mathrm{C}_{1+}$ & 0.1040 & 0.0000 & & & \\
\hline $\mathrm{C}_{3+}$ & 0.1337 & 0.0051 & 0.0000 & & \\
\hline $\mathrm{C}_{7+}$ & 0.1210 & 0.0339 & 0.0000 & 0.0000 & \\
\hline $\mathrm{C}_{14+}$ & 0.1160 & 0.0521 & 0.0000 & 0.0000 & 0.0000 \\
\hline
\end{tabular}




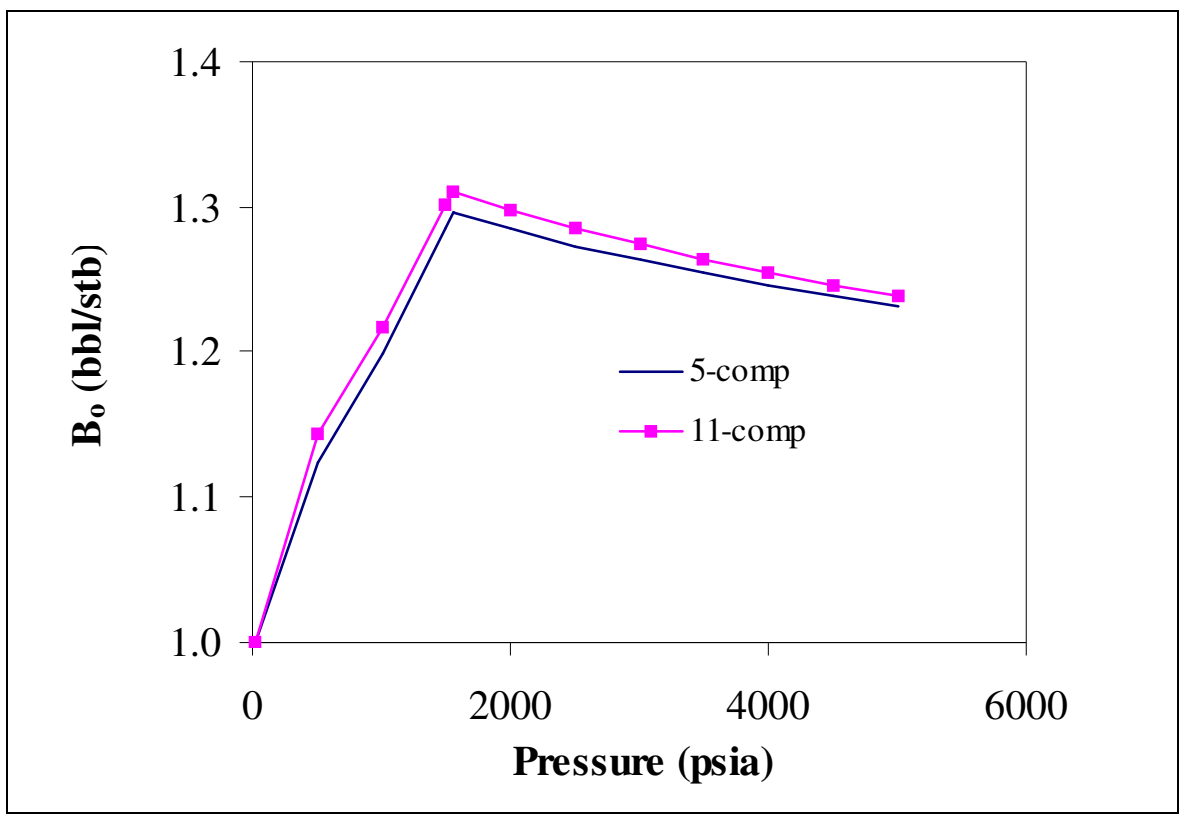

Figure 3.19: Tuned five-component model prediction for oil formation volume factor from differential liberation test at $150^{\circ} \mathrm{F}$.

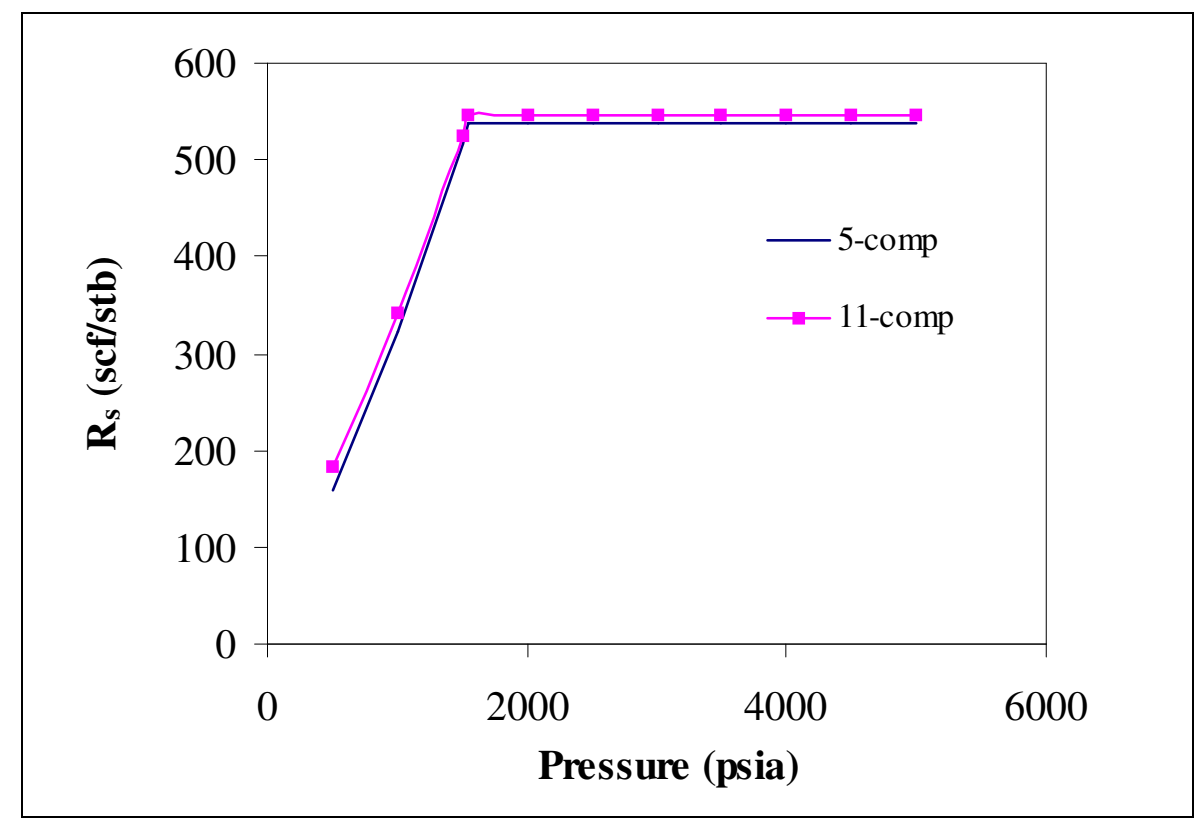

Figure 3.20: Tuned five-component model prediction for solution gas-oil ratio from differential liberation test at $150^{\circ} \mathrm{F}$. 


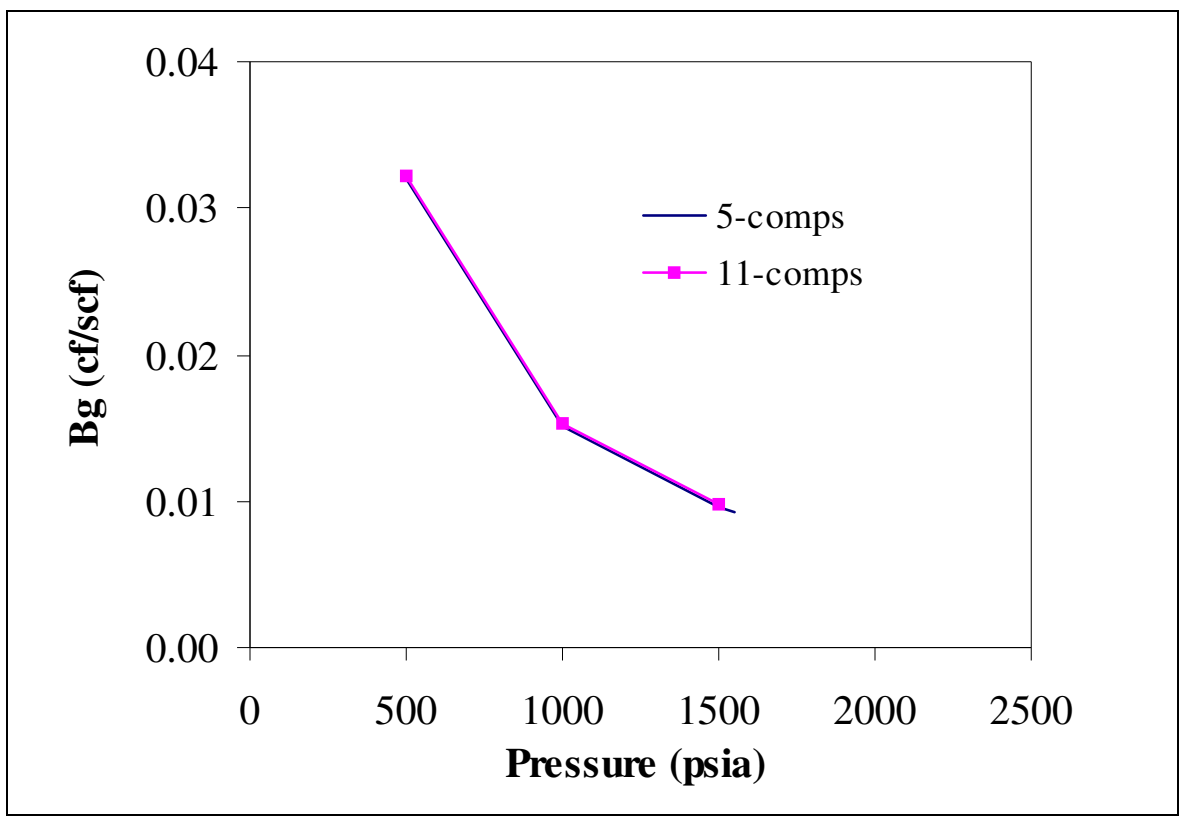

Figure 3.21: Tuned five-component model prediction for gas formation volume factor from differential liberation test at $150^{\circ} \mathrm{F}$.

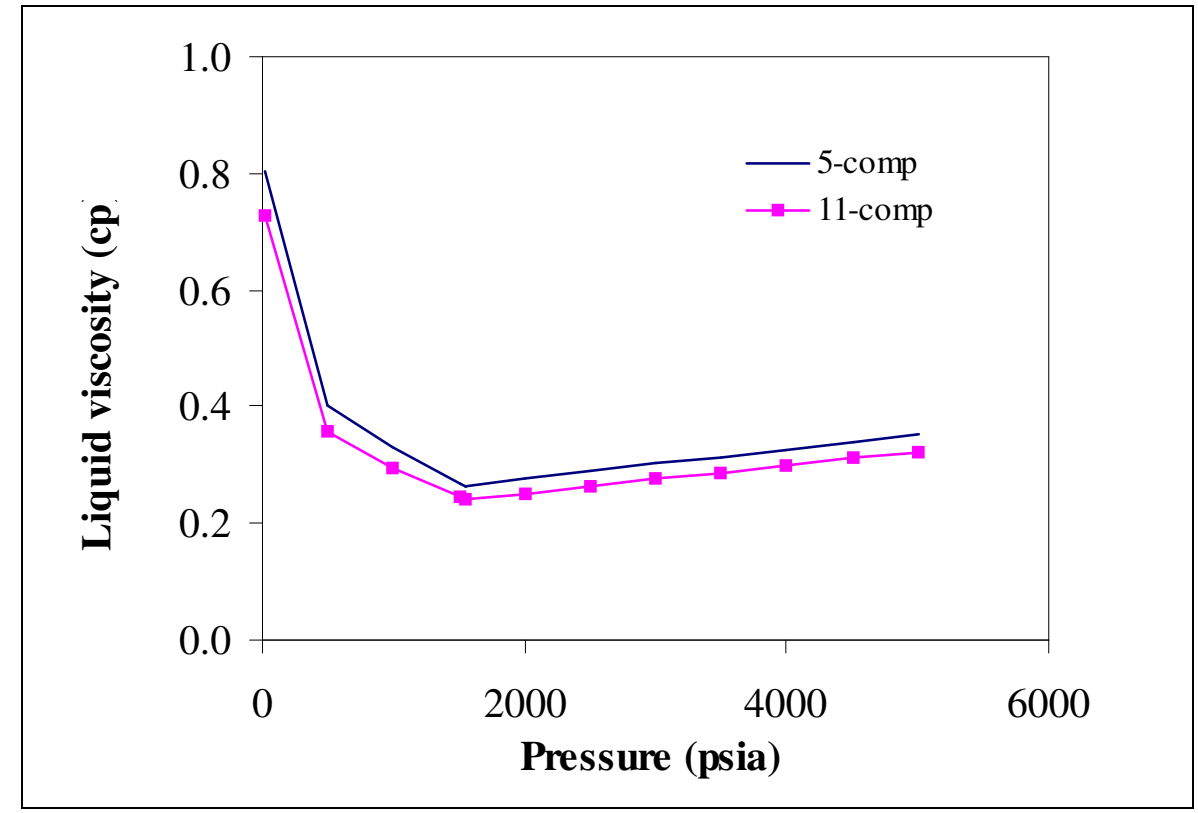

Figure 3.22: Tuned five-component model prediction for oil viscosity from differential liberation test at $150^{\circ} \mathrm{F}$. 


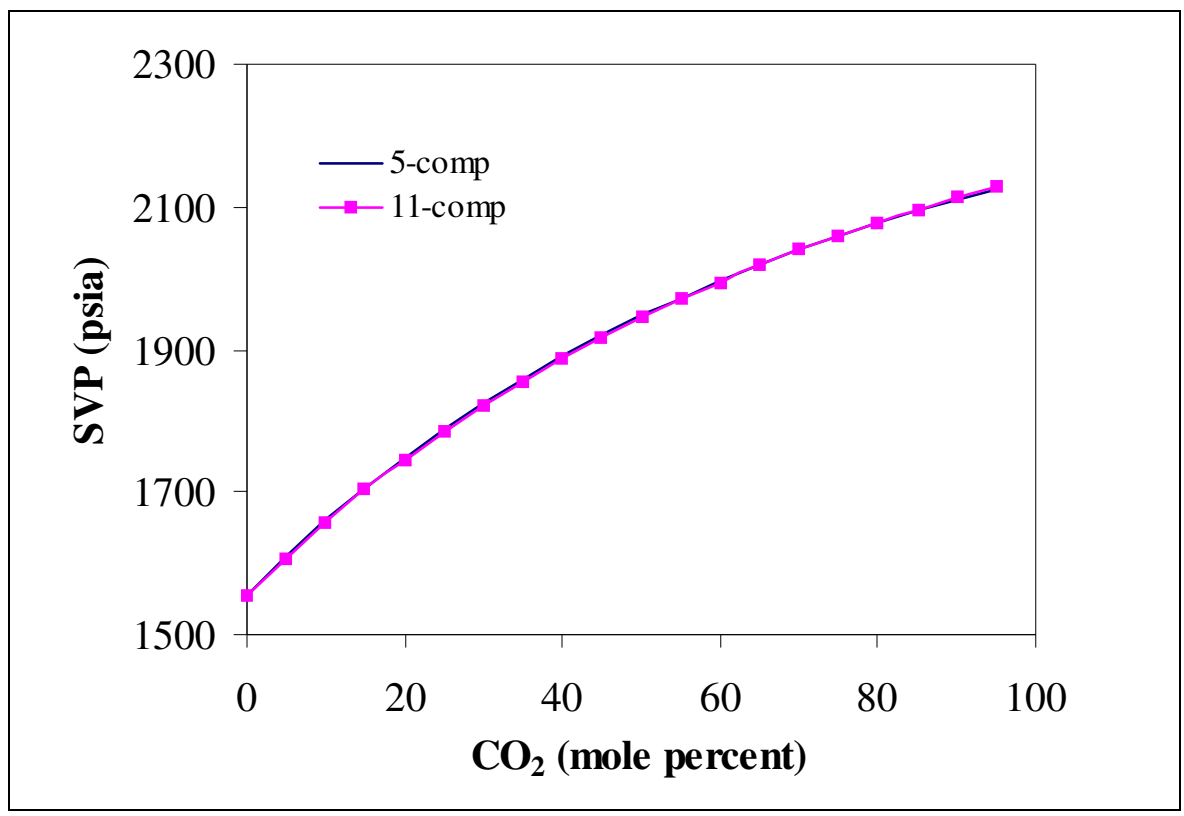

Figure 3.23: Tuned five-component model prediction for the pressure composition data from swelling test at $150^{\circ} \mathrm{F}$.

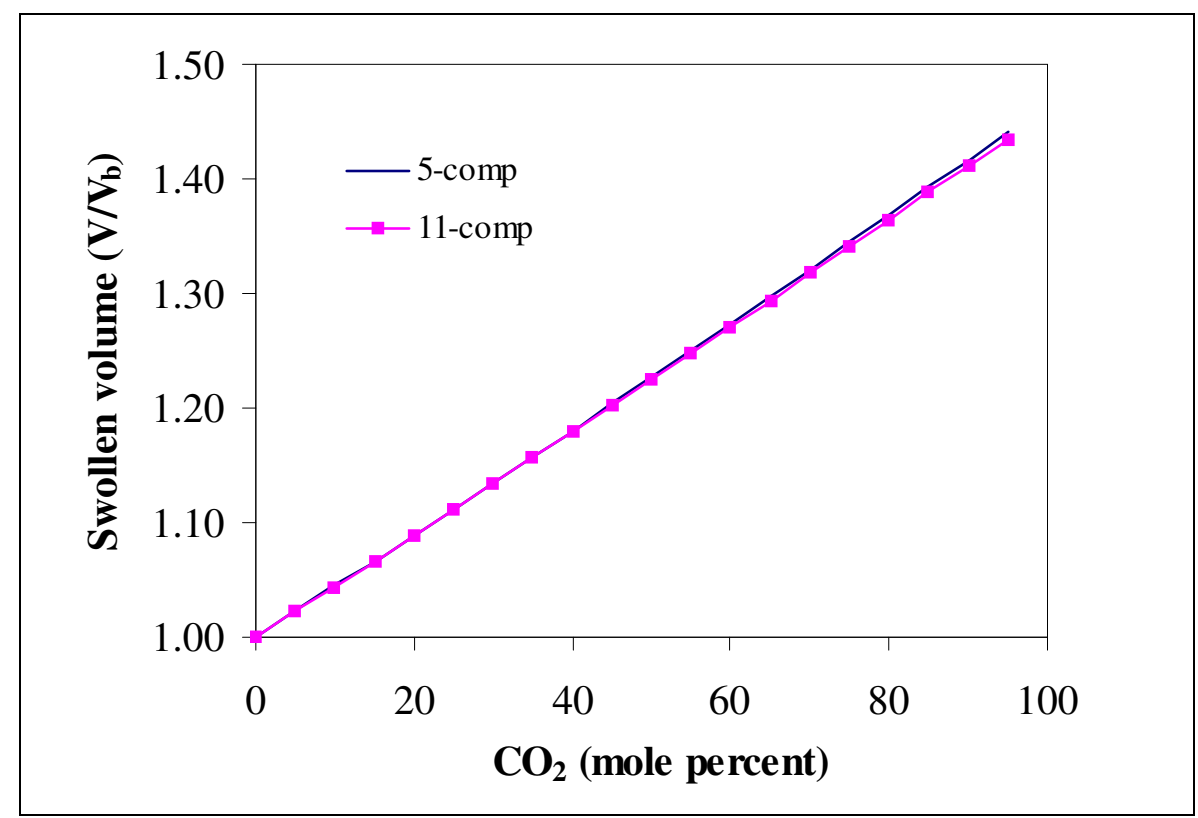

Figure 3.24: Tuned five-component model prediction for the swollen volume from swelling test at $150^{\circ} \mathrm{F}$. 


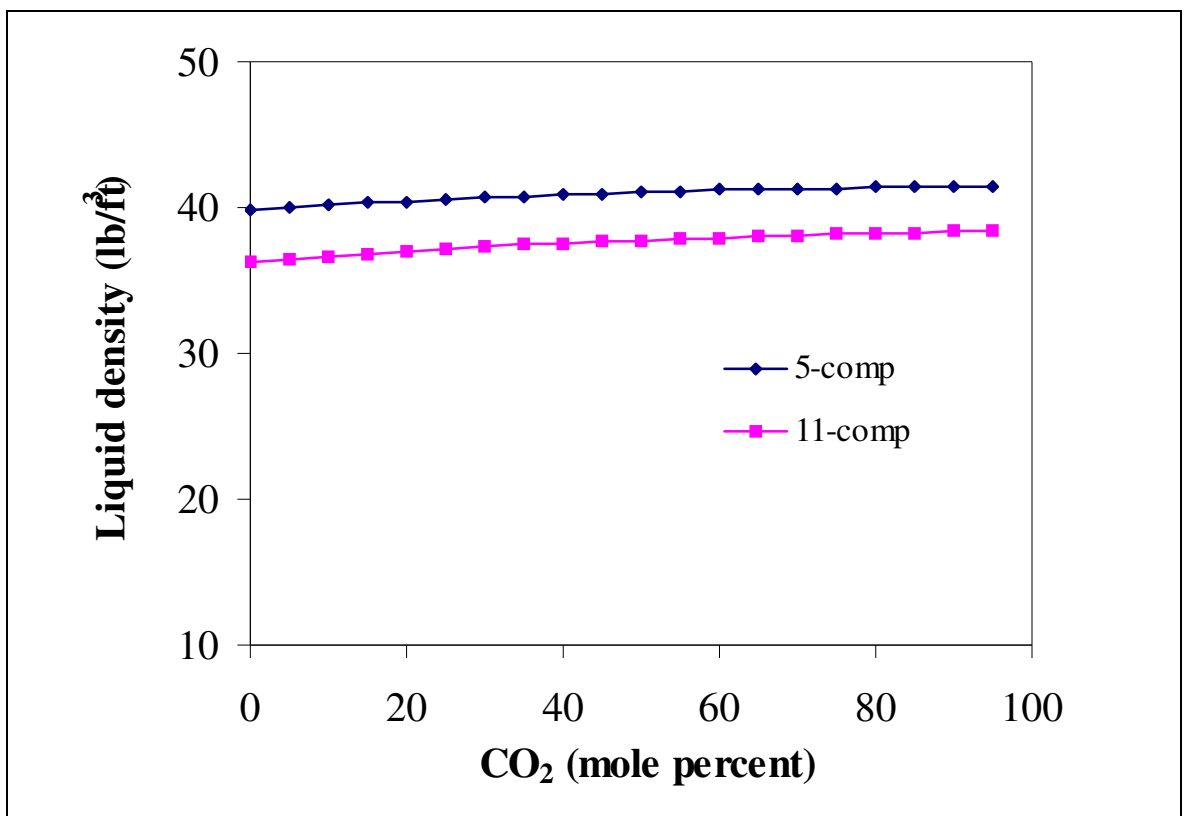

Figure 3.25: Tuned five-component model prediction for the oil/ $\mathrm{CO}_{2}$ mixture density from swelling test at $150^{\circ} \mathrm{F}$.

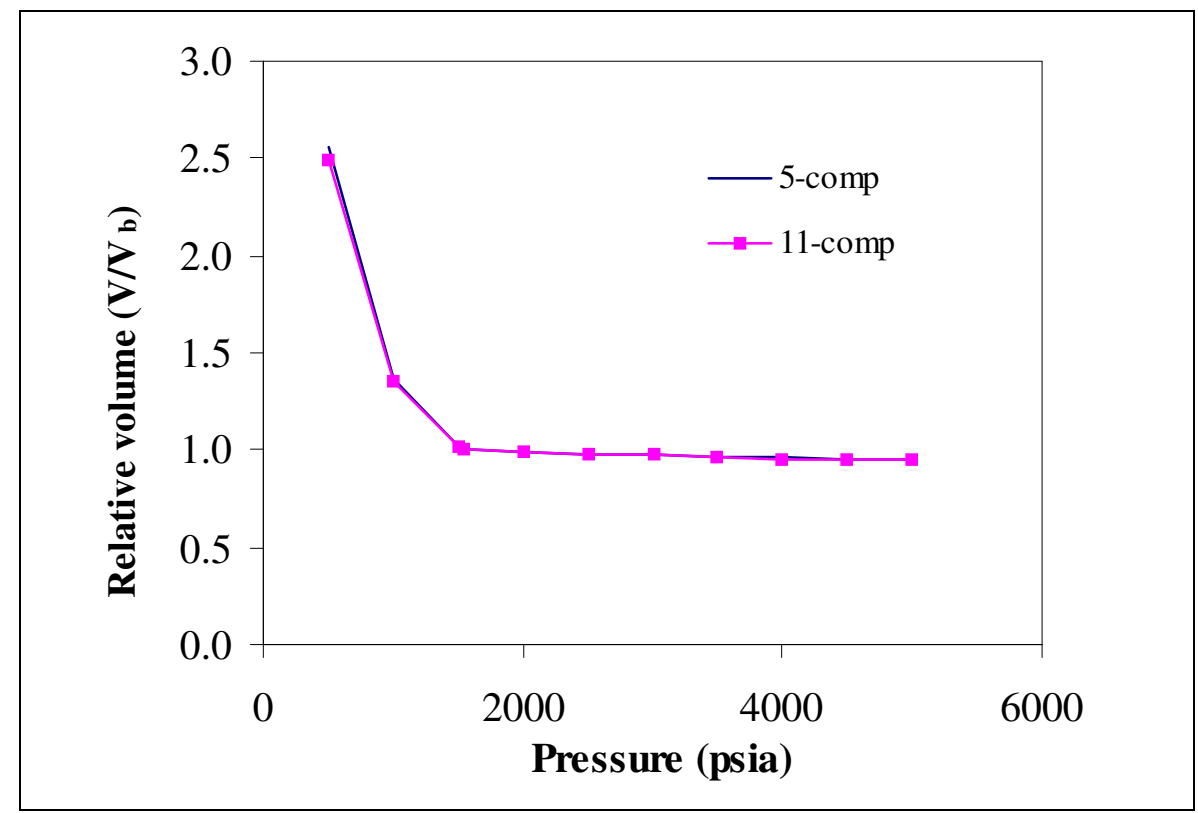

Figure 3.26: Tuned five-component model prediction for relative volume from constant mass expansion test at $150^{\circ} \mathrm{F}$. 
The five-component model generally gave a good match to the PVT data. The density and P-X data predictions were fair. Similar to the 12-component example, the primary goal was to match the MMP of the oil and then the P-X data. The density data can be matched by adjusting the volume shift parameters but this also affects the match to solution gas/oil ratio and oil formation volume factor. Attempts to improve the match to the density data resulted in a poorer fit to the $R_{s}$ and $B_{o}$ data. This suggests more pseudocomponents are required to represent the oil in order to increase the degrees of freedom in the parameters available to match the density data. For the purpose of this research, an excellent match to the density was not required because all simulations were 1-D.

The MMP determined analytically for the $\mathrm{CO}_{2}$-oil displacement was 1876 psia (Table 3.18). PVTSim had difficulties in the calculation of MMPs for the five-component model. All MMP calculations for this model were made with the MMPE code. The binary interaction parameter between $\mathrm{CO}_{2}$ and $\mathrm{C}_{5+}$ was adjusted from 0.14 to 0.121 while that of $\mathrm{CO}_{2}-\mathrm{C}_{14+}$ was adjusted from 0.14 to 0.116 to get an exact match to the MMP. The P-X data for the 11-component model was matched exactly after the model was successfully tuned to the MMP. This may be just a coincidence. Perhaps, if the lumped model's pseudocomponent properties are computed such that only a small adjustment is required to give a good match to the original multicomponent model, then both data may be well matched. However, if a multicomponent gas is used as the displacement injection gas, it is reasonable not to expect a simultaneous match to the MMP and P-X data because of the opposite effects that may occur from adjusting more than one binary interaction parameter to match either data. For the purpose of illustrating the effect of a poor prediction of the P-X data (see 1-D compositional simulation results), the model was tuned to PVT data, which excluded the P-X data. 


\section{Validation of Tuned Five-Component EOS Model.}

The 11-component EOS model was lumped and tuned to give two, fivecomponent EOS models. One of the lumped models was tuned to the PVT data and $\mathrm{CO}_{2}$ /oil displacement $\mathrm{MMP}$ at $150^{\circ} \mathrm{F}$ while the other was fitted only to the PVT data (excluding P-X data).

The simulation results of the lumped models were compared to that of 11component model for a 400 grid-blocks simulation at $2200 \mathrm{psia}$ and $150^{\circ} \mathrm{F}$. The displacement is a MCM flood above the MMP. Figure 3.27 compares the saturation velocities of the models for 0.3 HCPVI. In the plot, the 5-PVT represents a model tuned to PVT data, which excludes the P-X data while 5-PVTX is the model tuned to all the PVT data. The model tuned to all the PVT data and the MMP is represented by 5-PVT \& MMP.

Figure 3.28 compares the models' MMP predictions at different temperatures. The MMP for the 5-PVT \& MMP model coincides with that of the 11-component model at $150^{\circ} \mathrm{F}$. As the temperature is increased, the model's MMP predictions deviate from that of the 11-component model. The error grows with increasing temperature.

1-D simulations were made for a 1000 grid-blocks reservoir at a pressure of 2200 psia and $150^{\circ} \mathrm{F}$ to compare saturation and composition velocities as well as component recoveries for all the models. The injection gas was pure $\mathrm{CO}_{2}$. Figure 3.29 shows the simulated saturation velocity distribution for 0.3 HCPVI. Figures 3.30-3.34 show the composition velocities while Figures 3.35-3.36 show the cumulative component recoveries. The 5-PVT \& MMP model predicts similar saturation and composition velocity distribution as the 11-component model while the 5-PVT model predictions deviate from the 11-component model velocities. 


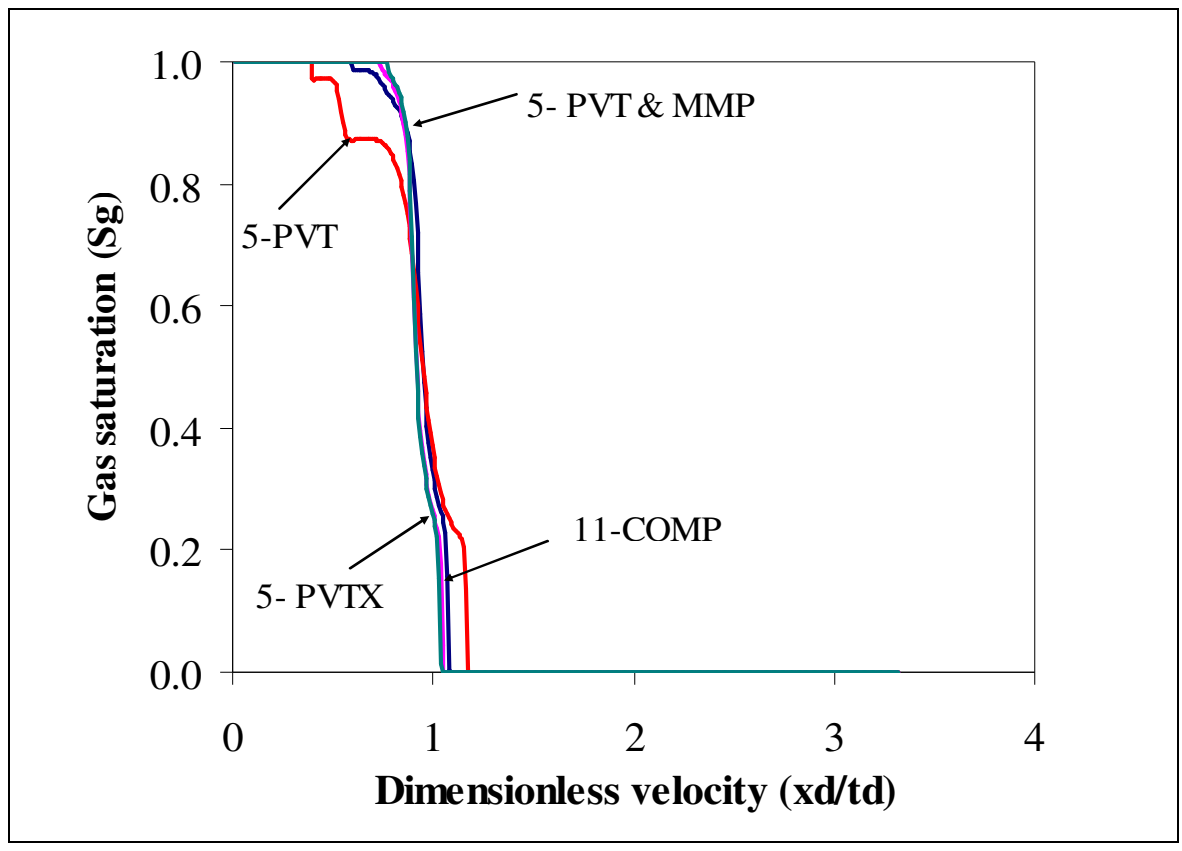

Figure 3.27: Comparison of 11- and five-component EOS simulated gas saturation velocities at $0.3 \mathrm{HCPVI}, 2200 \mathrm{psia}$ and $150^{\circ} \mathrm{F}$.

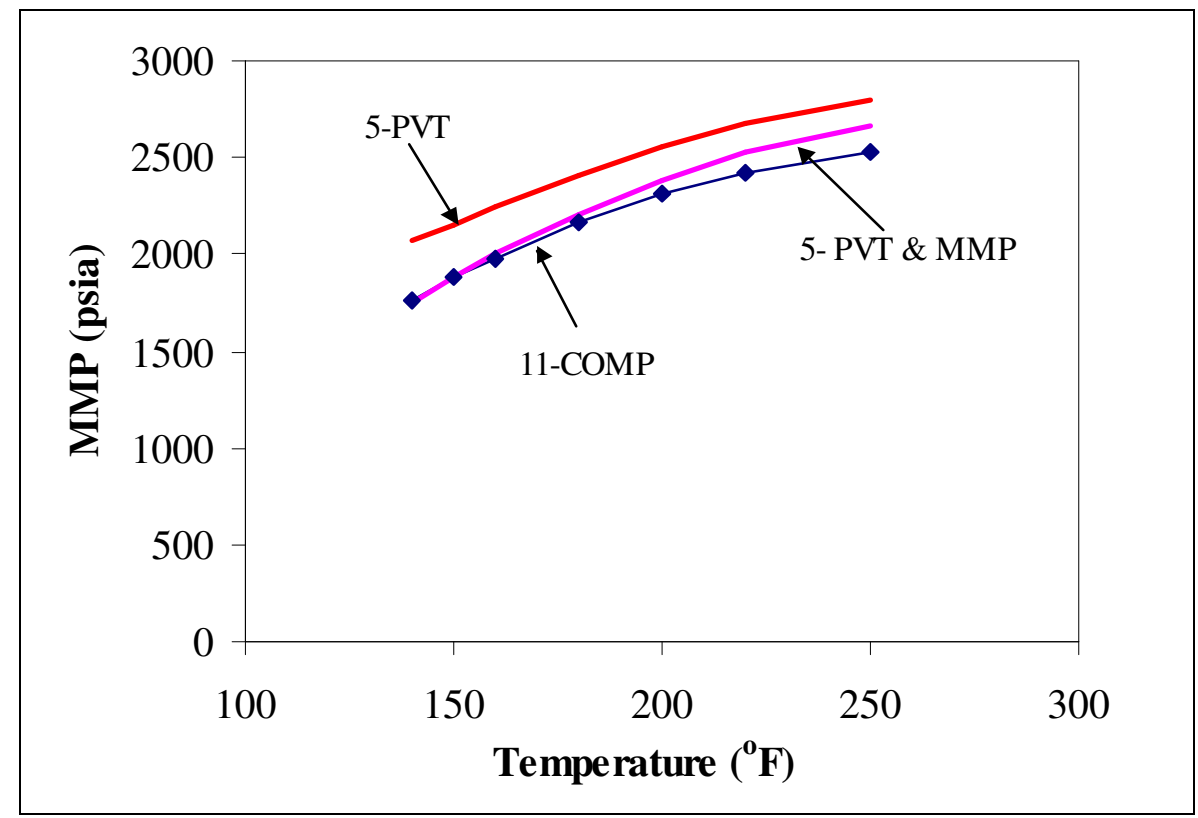

Figure 3.28: Comparison of 11-and five-component EOS models analytical MMP predictions for pure $\mathrm{CO}_{2}$ injection. 


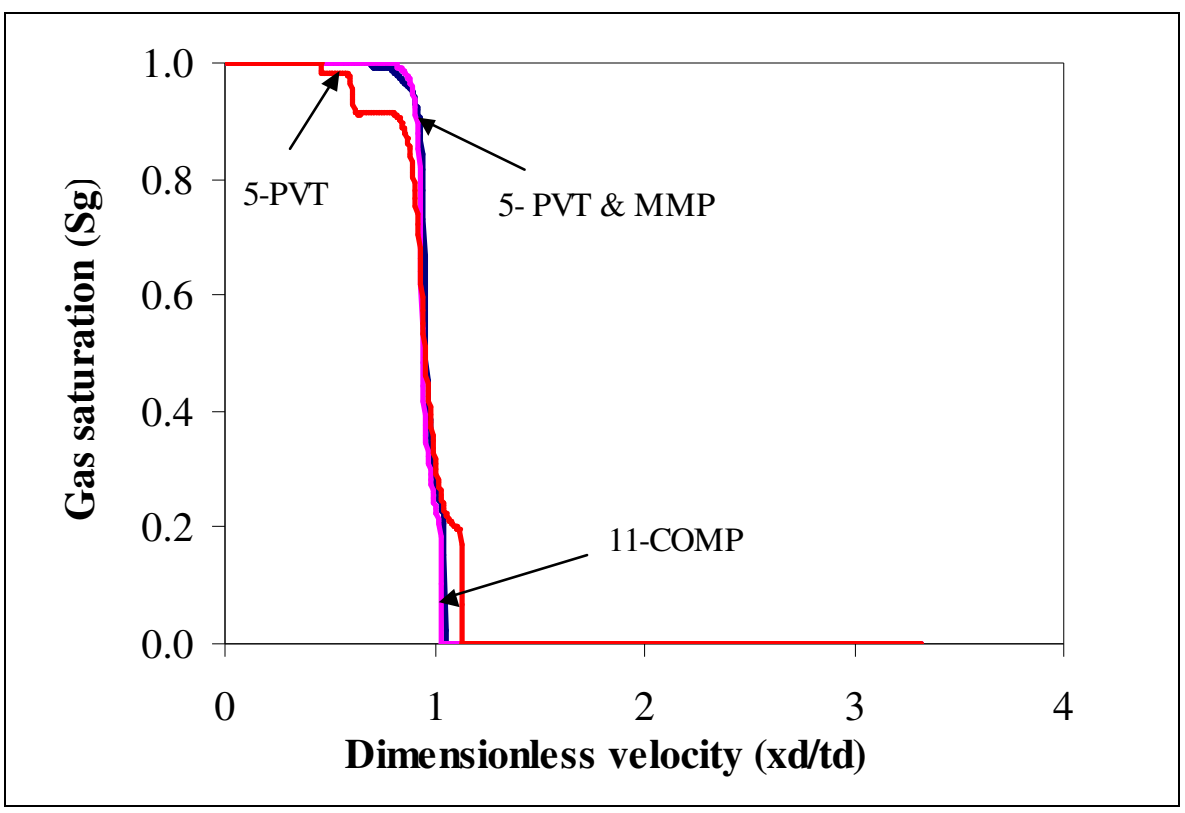

Figure 3.29: Comparison of 11- and five-component EOS simulated gas saturation velocities at for $0.3 \mathrm{HCPVI}$ at $2200 \mathrm{psia} 150^{\circ} \mathrm{F}$. The displacement is by pure $\mathrm{CO}_{2}$.

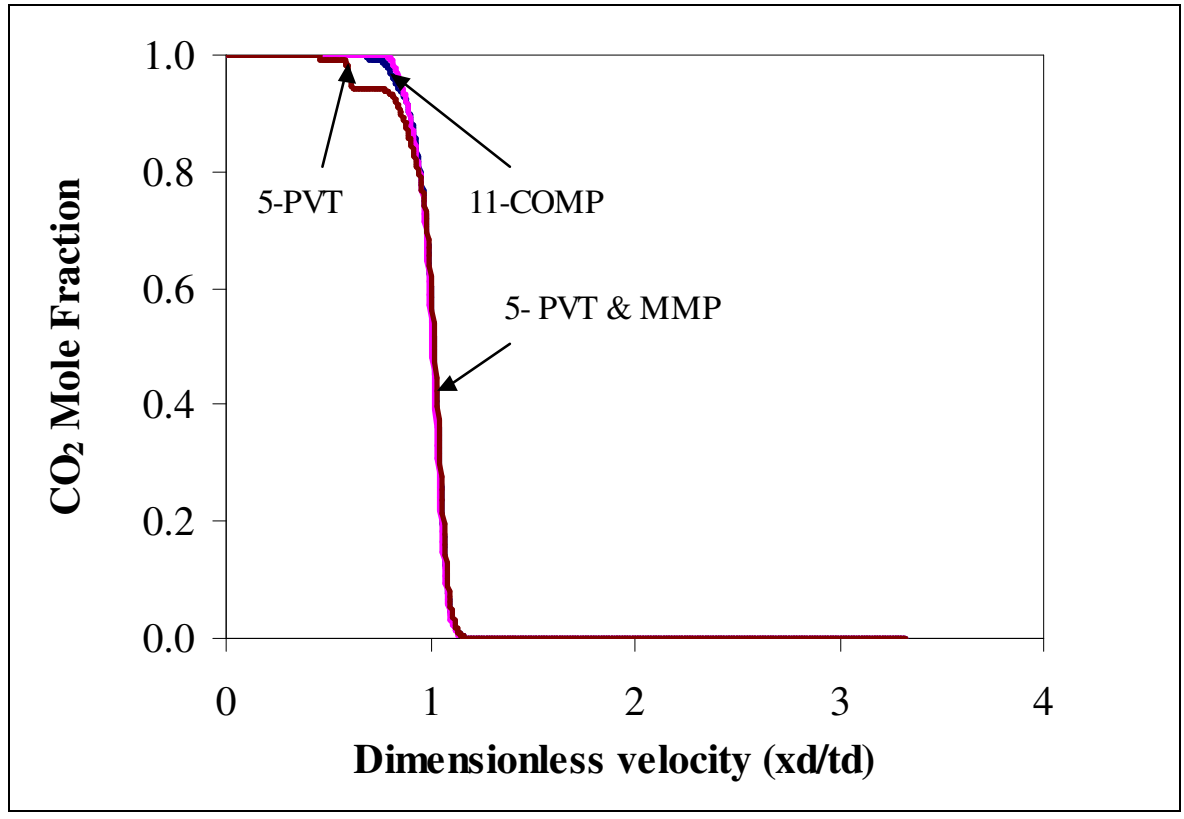

Figure 3.30: Comparison of 11- and five-component EOS models simulated $\mathrm{CO}_{2}$ component velocities for $0.3 \mathrm{HCPVI}$ at $2200 \mathrm{psia}, 150^{\circ} \mathrm{F}$. The displacement is by pure $\mathrm{CO}_{2}$. 


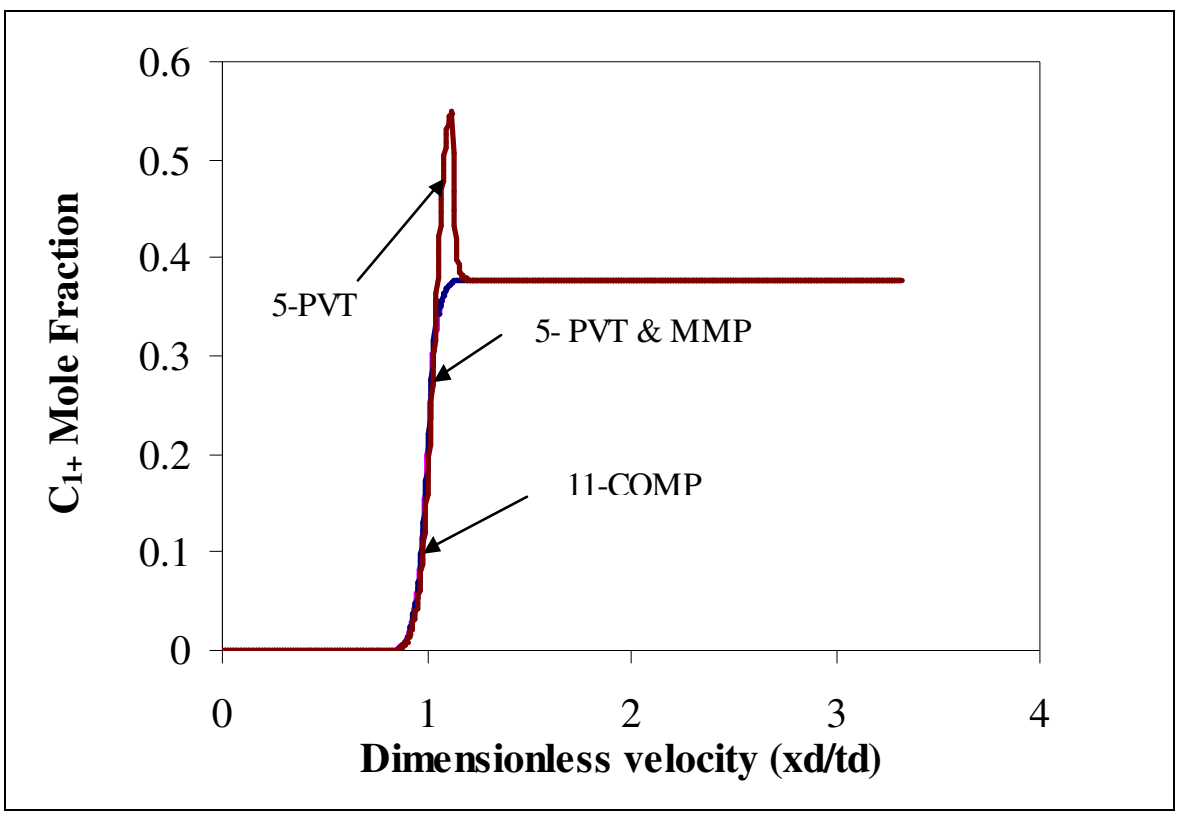

Figure 3.31: Comparison of 11- and five-component EOS models simulated $\mathrm{C}_{1+}$ component velocities for $0.3 \mathrm{HCPVI}$ at $2200 \mathrm{psia}$ and $150^{\circ} \mathrm{F}$. The displacement is by pure $\mathrm{CO}_{2}$.

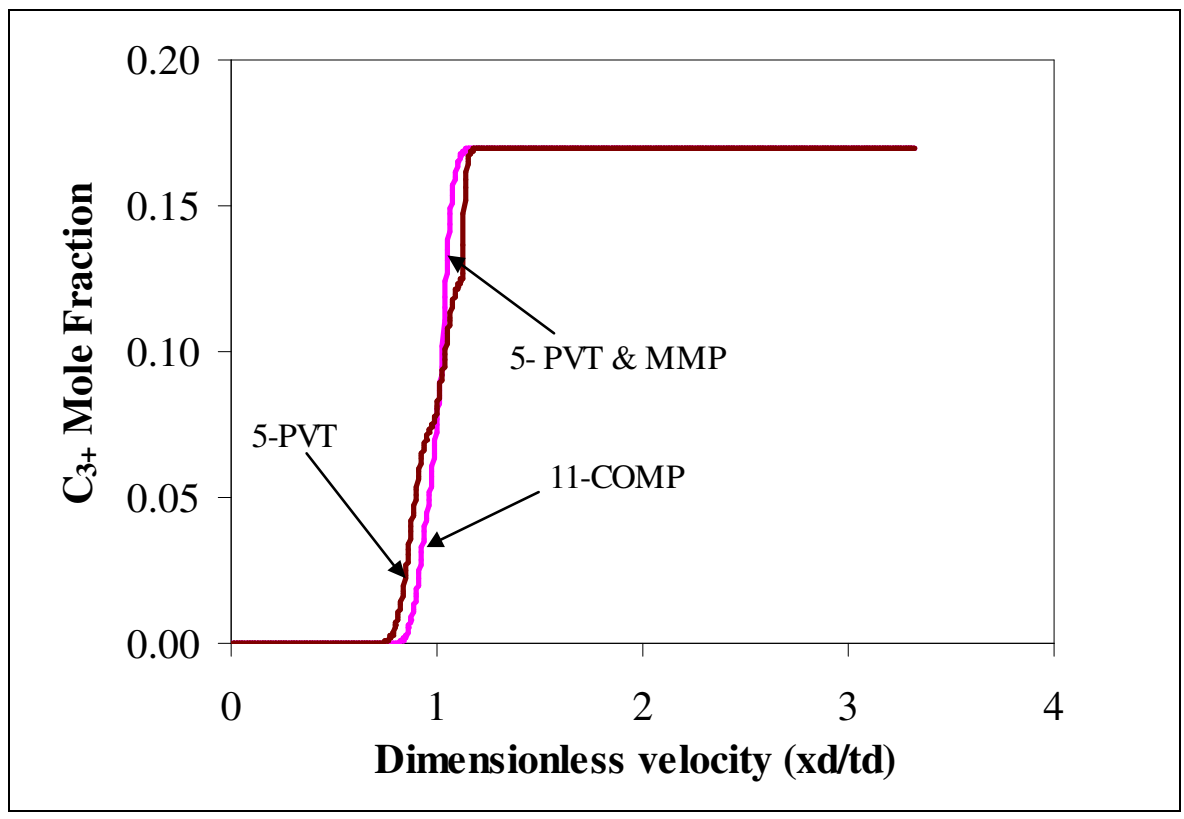

Figure 3.32: Comparison of 11- and five-component EOS models simulated $\mathrm{C}_{3+}$ component velocities for $0.3 \mathrm{HCPVI}$ at $2200 \mathrm{psia}$ and $150^{\circ} \mathrm{F}$. The displacement is by pure $\mathrm{CO}_{2}$. 


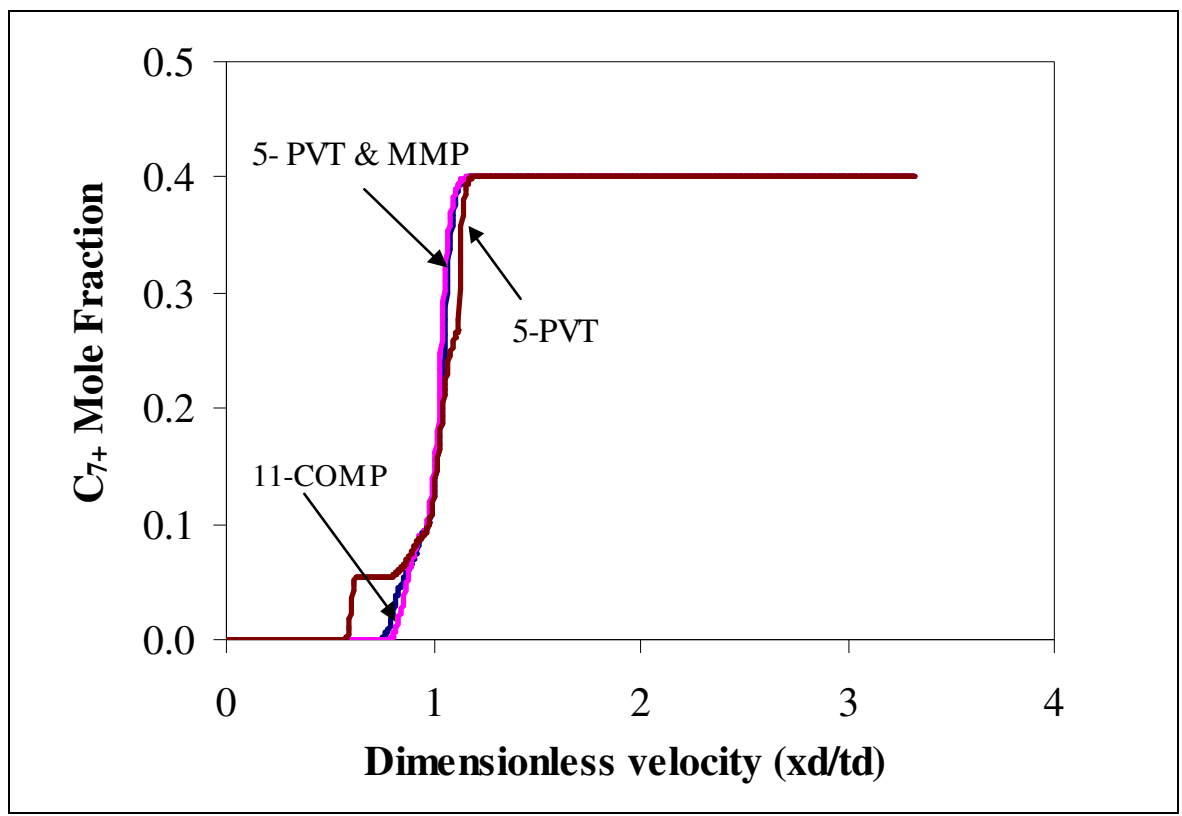

Figure 3.33: Comparison of 11- and five-component EOS models simulated $\mathrm{C}_{7+}$ component velocities for $0.3 \mathrm{HCPVI}$ at $2200 \mathrm{psia}$, and $150^{\circ} \mathrm{F}$. The displacement is by pure $\mathrm{CO}_{2}$.

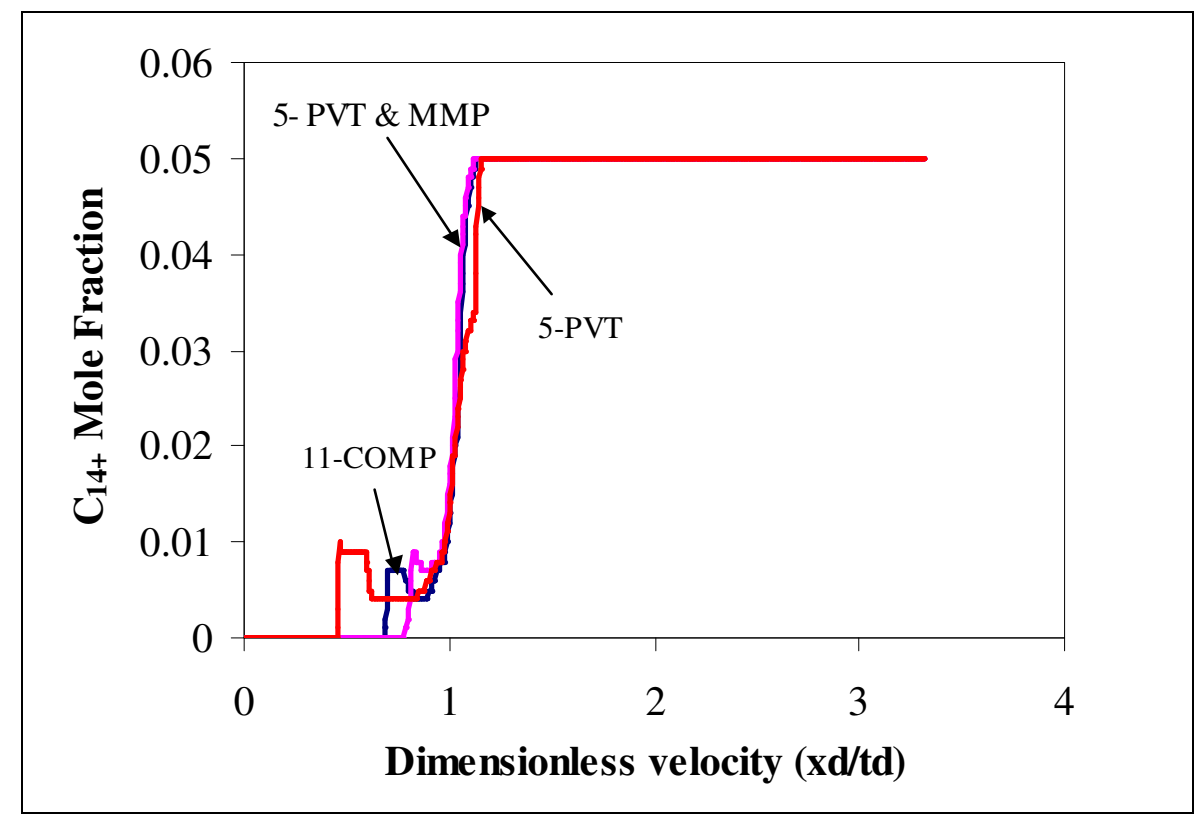

Figure3.34: Comparison of 11- and five-component EOS models simulated $\mathrm{C}_{14+}$ component velocities for $0.3 \mathrm{HCPVI}$ at $2200 \mathrm{psia}$, and $150^{\circ} \mathrm{F}$. The displacement is by pure $\mathrm{CO}_{2}$. 


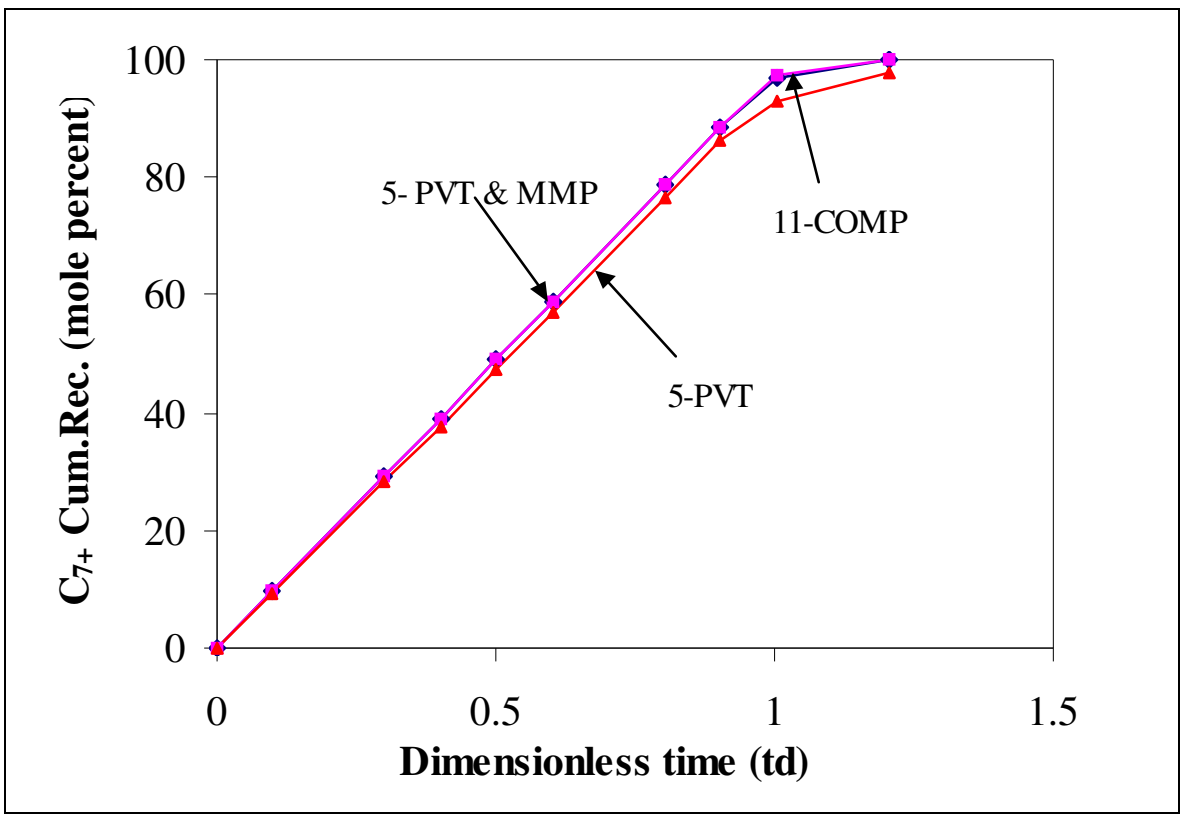

Figure 3.35: Comparison of 11- and five-component EOS models simulated $\mathrm{C}_{7+}$ component cumulative mole percent recovery at $2200 \mathrm{psia}$ and $150^{\circ} \mathrm{F}$.

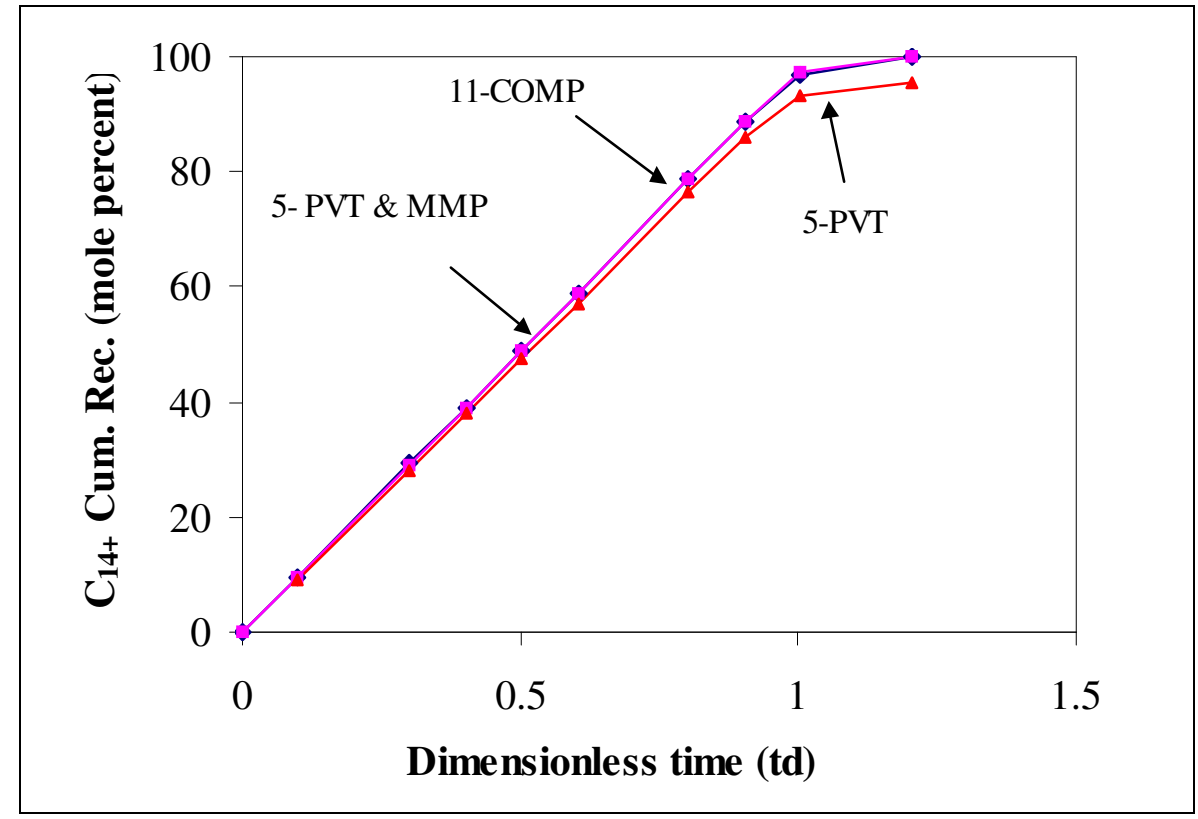

Figure 3.36: Comparison of 11- and five-component EOS models simulated $\mathrm{C}_{14+}$ component cumulative mole percent recovery at $2200 \mathrm{psia}$ and $150^{\circ} \mathrm{F}$. 
The 11-and 5-PVT \& MMP model components recoveries overlap while that of the 5-PVT model consistently predicted lower components recovery for all recovery plots. Figure 3.28 demonstrates that the MMP model and the PVTX model compares very well with the 11-component model. The PVTX model predicts a gas saturation front speed only slightly lower than that of the MMP and 11-component models. The 5-PVT model gave the worst saturation predictions. The 5-PVTX model predicted the MMP within a $0.42 \%$ error margin. The $\mathrm{CO}_{2}$-MMP for the 11 -component oil is 1876 psia while that for 5-PVTX is 1868 psia. The 5-PVT model over predicts the MMP by 282 psi.

In Figure 3.28, the 5-PVT \& MMP model gave a better prediction of the 11component MMP than the 5-PVT model The MMP model can adequately represent the 11-component oil within the temperature range of $150-220^{\circ} \mathrm{F}$. The model may have to be tuned to a new MMP outside of this temperature range.

The 5-PVT \& MMP and 11-component models' component velocities also compare very well with each other. The 5-PVT model velocity distribution deviates from that of the truth model. There is a spike observed in the lumped $\mathrm{C}_{1+}$ component velocity distribution, which is completely unobserved in the truth model. This is due to instability in the solution, which may be due to the inadequate match to the P-X data. The recovery plot for $\mathrm{C}_{7+}$ and $\mathrm{C}_{14+}$ components further confirm the 5-PVT \& MMP to be the best characterized model. The 5-PVT model predicts a lower component recovery than the other models. This is expected because the model predicts an earlier gas saturation front break through time than either the 11-component or 5-PVT \& MMP EOS model.

The importance of including a displacement parameter like the MMP or MME in the process of oil characterization cannot be overemphasized. It is evident from all the discussions and case studies, that a few pseudocomponents can adequately represent the 
multicomponent EOS model without any significant loss in accuracy when the improved tuning approach is adopted.

\subsection{EFFECT OF DISPERSION ON RECOVERY USING THE EOS MODELS}

Numerical dispersion is often used to account for the physical dispersivity. Dispersion causes an otherwise MCM flow to become two-phase flow and thus, miscibility is not attained. Numerical dispersion produces the same dissipating effect on the velocities as physical dispersion. It is usually adjusted by changing the grid-block size. According to Lantz (1971), the numerical Peclet number $\left(P_{\mathrm{e}}\right)$ can be estimated as:

$$
\begin{aligned}
& P_{e}=\frac{2 * L}{\Delta x} \\
& \alpha=\frac{\Delta x}{2}
\end{aligned}
$$

where $\alpha$ is the numerical dispersivity, $\Delta x$ is the size of a grid-block, and $\mathrm{L}$ is reservoir length. The effect of dispersion on the calibrated EOS models was studied by carrying out numerical simulations for 200-4000 grid-blocks. The length of the reservoir was 1000 ft. For the 12-and four-component EOS models, simulations were made at 3650 psia, $200^{\circ} \mathrm{F}$ for 200,400 and 1000 grid-blocks. The 11 - and five-component models were studied at 2200 psia and $150^{\circ} \mathrm{F}$ for 400,1000 and 4000 grid-blocks. Table 3.21 gives a summary of the number of grid-blocks and the corresponding Peclet number.

Table 3.21: Summary of grid-blocks used, Peclet numbers and dispersivities.

\begin{tabular}{|c|c|c|}
\hline $\begin{array}{l}\text { Number of } \\
\text { Grid-blocks }\end{array}$ & $\begin{array}{l}\text { Numerical } \\
\text { Dispersivity }\end{array}$ & Peclet Number \\
\hline 200 & 2.500 & 400 \\
\hline 400 & 1.250 & 800 \\
\hline 1000 & 0.500 & 2000 \\
\hline 4000 & 0.125 & 8000 \\
\hline
\end{tabular}


Figures 3.37-3.40 show the simulated saturation velocities for the different models for different levels of dispersion. The gas saturation velocities for the 12component (Figure 3.37) and four-component (Figure 3.38) EOS models approach the dispersion-free solution closely. At 3650 psia, the process is at a pressure above the MMP (3311 psia) for the injection gas mixture/oil displacement. The dispersion-free solution is a piston like displacement with a gas saturation front dimensionless velocity of unity. The four-component model approaches the dispersion-free solution much better than the 12component model. As the numerical Peclet number increases, the effect of dispersion decreases. The break-through time predicted also increases because the gas saturation front velocities slow down. Dispersion has less effect on the four-component model as compared to the 12-component model.

Figures 3.39 and 3.40 show the simulated gas saturation velocity distribution for the 11- and five-component EOS models for different levels of dispersion. The models are more influenced by dispersion than the four-component models above. At a Peclet number of 8000 , both models closely approach the dispersion-free solution whose saturations shock between zero and one. The gas saturation front velocity closely approach unity for MCM flow. This suggests that the composition path is near the critical point.

In general, the lumped models' predicted oil recoveries are not significantly affected by numerical dispersion. However, this implies that in order to match core or field recovery data, some value for dispersivity will have to be input to the numerical simulator. This also means that the numerical simulation can be made using a relatively smaller number of grid-blocks without significantly affecting the overall accuracy of the results. Simulations with less number of grid-blocks and pseudocomponents would 
increase computational speed significantly. This is especially important for extensive field studies. 


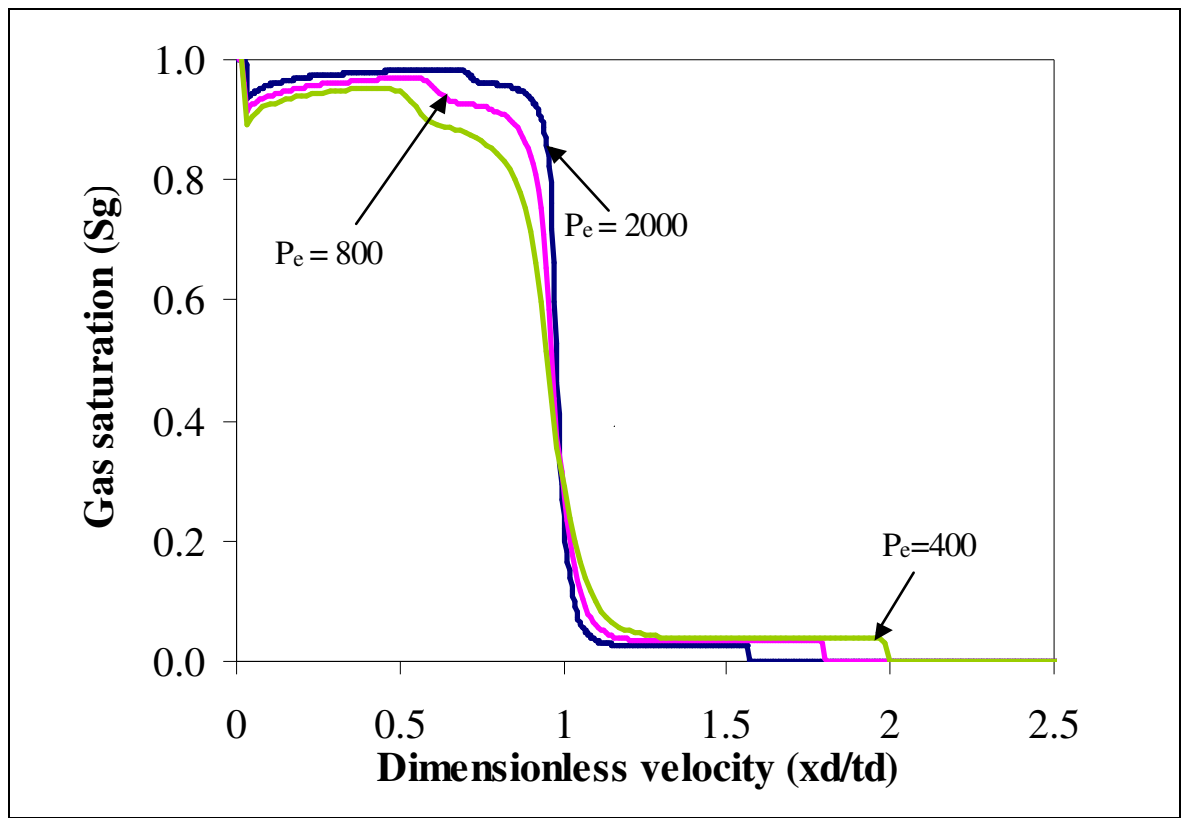

Figure 3.37: Twelve-component EOS model simulated gas saturation velocities for different levels of dispersion at $0.3 \mathrm{HCPVI}, 3650 \mathrm{psia}$ and $200^{\circ} \mathrm{F}$.

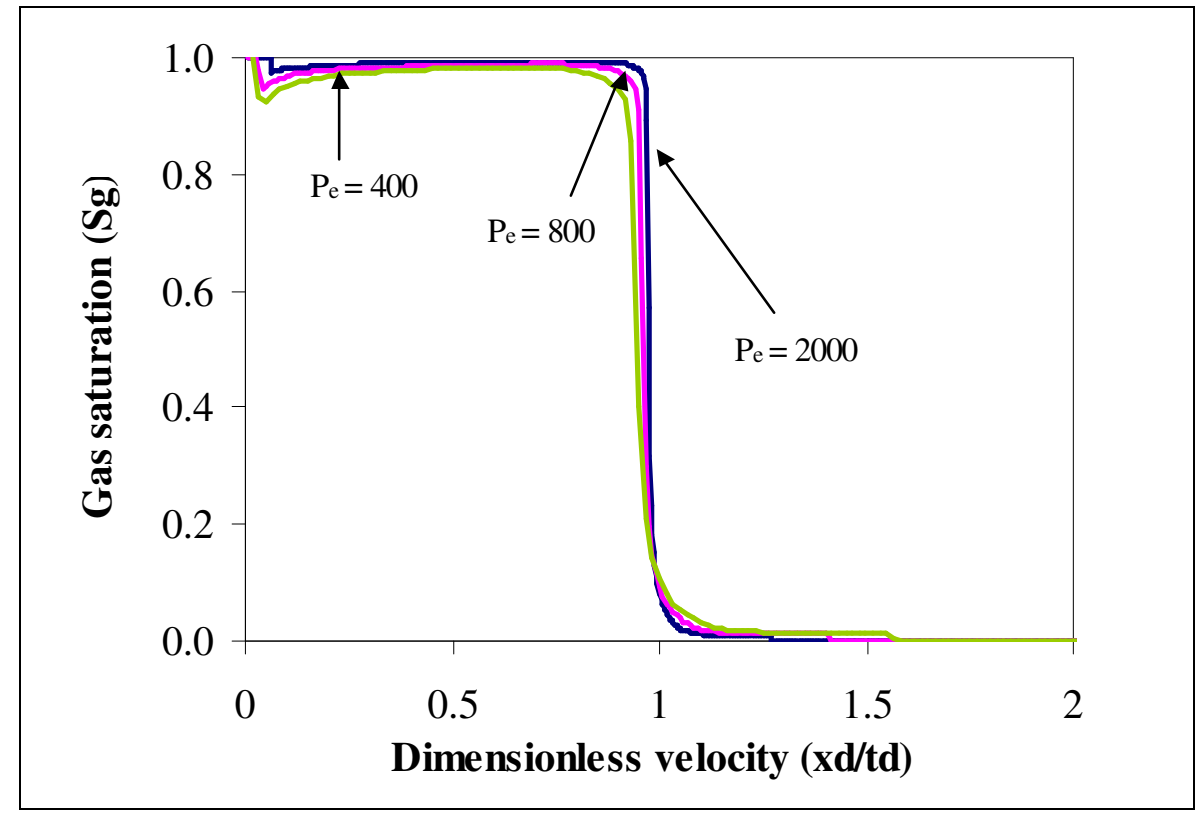

Figure 3.38: Four-component EOS model simulated gas saturation velocities for different levels of dispersion at $0.3 \mathrm{HCPVI}, 3650 \mathrm{psia}$ and $200^{\circ} \mathrm{F}$. 


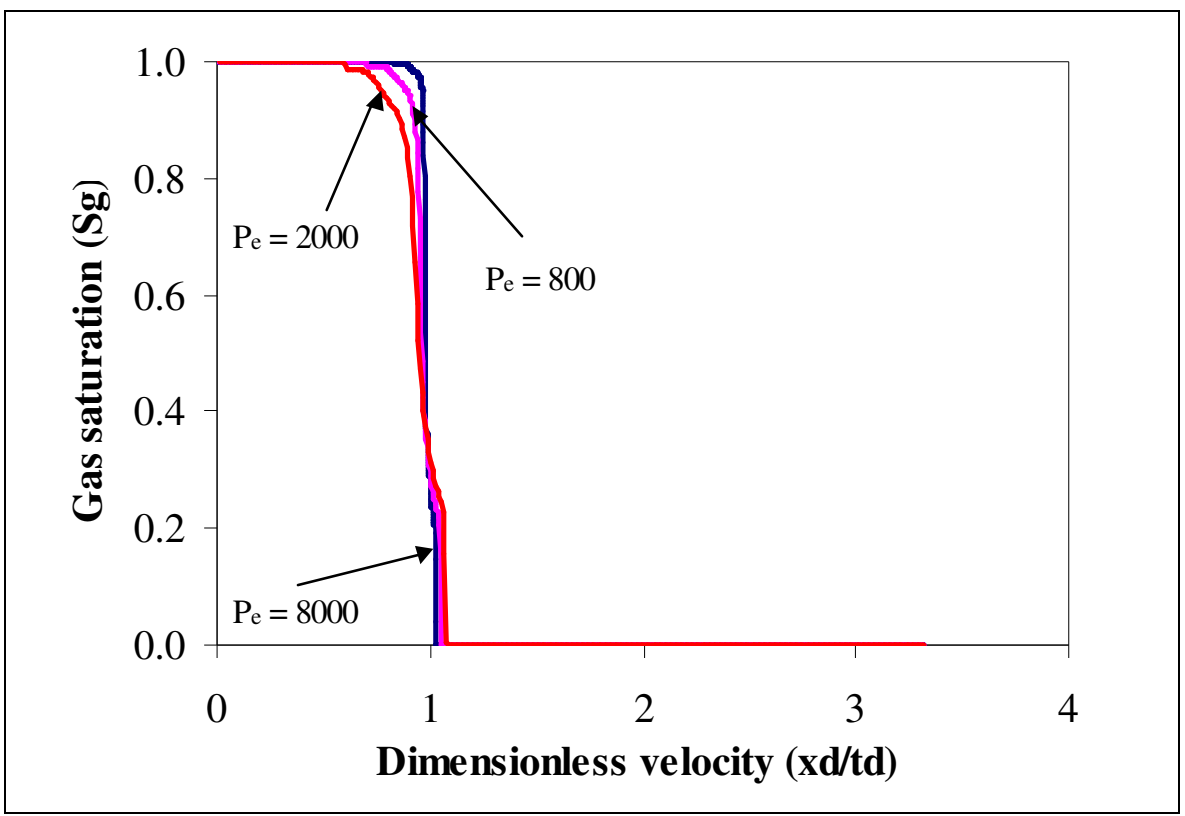

Figure 3.39: Eleven-component EOS model simulated gas saturation velocities for different levels of dispersion at $0.3 \mathrm{HCPVI}, 2200 \mathrm{psia}$ and $150^{\circ} \mathrm{F}$.

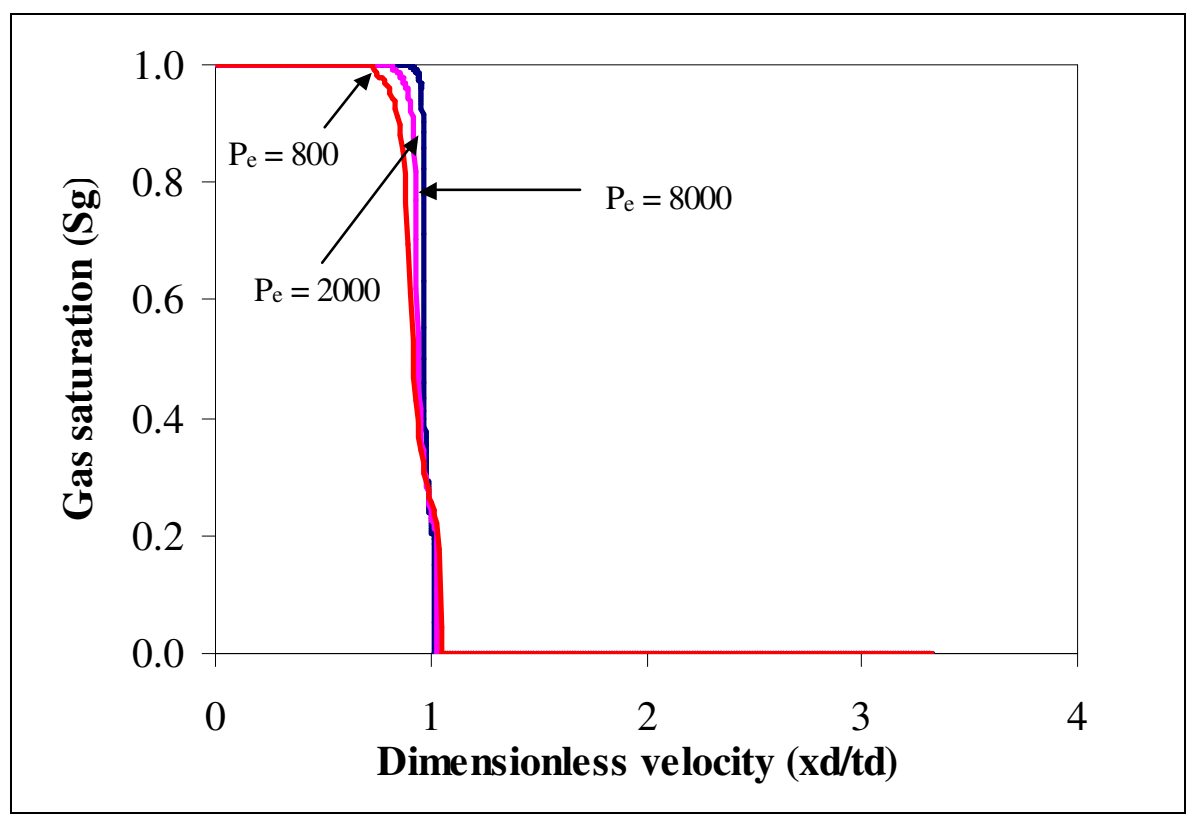

Figure 3.40: Five-component EOS model simulated gas saturation velocities for different levels of dispersion at $0.3 \mathrm{HCPVI}, 2200$ psia and $150^{\circ} \mathrm{F}$. 


\section{Chapter 4: Conclusions and Recommendations}

This research was split into two parts; the development of new correlations for pure and impure $\mathrm{CO}_{2}$ floods and an improved tuning procedure for EOS characterization. The main conclusions for each part are summarized below:

\section{NEW $\mathrm{CO}_{2}$ CORRELATIONS}

- The new MMP correlation for pure $\mathrm{CO}_{2}$ injection is significantly more accurate than the currently most widely used correlations.

- The new MMP correlations for impure $\mathrm{CO}_{2}$ injection account for different fluid types, methane concentration in the gas, and reservoir temperature. The currently most widely used correlation by Sebastian et al (1985) is only accurate for the Levelland field.

- The MMP ratio increases as the methane content in the injection gas increases at constant temperature and decreases as the reservoir temperature is increased at constant gas composition. The MMP increase above the MMP for pure $\mathrm{CO}_{2}$ injection is greatest for a volatile oil.

- More accurate EOS characterizations and slim-tube MMPs are needed to further increase the robustness of the correlations.

- The approach developed here using the analytical theory could also be used to develop other reliable correlations where accurate EOS characterizations are available.

\section{IMPROVED EQUATION OF STATE FLUID CHARACTERIZATIONS}

- The MMP or MME is the most important parameter to be tuned for gas compositional processes. 
- Multicomponent EOS characterizations can be successfully lumped to fewer pseudocomponents by tuning the EOS to match the PVT data and the MME or MMP for the oil. For one case studied here, four pseudocomponents were sufficient.

- 1-D simulation results showed an excellent match between the multicomponent models and the reduced models tuned to fit the MMP and MME. Otherwise, the matches were poor.

- EOS models consisting of only a few pseudocomponents are less affected by numerical dispersion than the original multicomponent models.

\section{RECOMMENDATIONS FOR FURTHER RESEARCH}

The following suggestions for further research are made:

- The impure $\mathrm{CO}_{2} \mathrm{MMP}$ correlation can be improved further by generation of more analytical MMP data using additional EOS characterizations. Slim-tube data can be used to make the impure $\mathrm{CO}_{2}$ correlation more robust and reduce the error margin in the prediction of slim-tube MMPs.

- The EOS characterizations were used to generate MMP data over a large temperature range. EOS characterizations are usually developed at a given temperature and may be completely unsuitable for other temperatures. The existing analytical correlation can be further improved by using only analytical MMP data generated at the temperature for which the EOS characterizations were developed.

- A correlation for impure $\mathrm{CO}_{2}$ injection with $\mathrm{N}_{2}$ as the major contaminant needs to be developed for projects where the nitrogen content of the injection gas stream is 
large. This will provide information for the determination of the degree of separation required for recycled $\mathrm{CO}_{2}$ gas.

- The Sebastian correlation for impure $\mathrm{CO}_{2}$ injection can be modified to account for reservoir temperature and oil composition. This approach would likely yield a correlation, which is applicable to any injection gas mixture. This correlation would be given as a function of the reservoir temperature, oil composition and average critical temperature of the injection gas mixture.

- In this research, it was shown that for an example 11-component EOS characterization, the resulting lumped 5-component model gave an accurate prediction of the pressure composition data when it was tuned to the pure $\mathrm{CO}_{2}$ MMP. It would be interesting to confirm whether this observation is consistent for other EOS characterizations.

- The multicomponent models were successfully lumped to a few pseudocomponents. There is a need to carry out de-lumping to confirm that the resulting multicomponent model is representative of the reservoir oil. This is important for smooth transition between the multicomponent and lumped models for field scale simulations.

- The K-values used in the Newley \& Merrill approach were generated for a single composition and pressure. K-values depend on pressure and composition. The lumped model EOS properties could be calculated by using an average of $\mathrm{K}$ values determined from the key tie lines along the true composition path. This would probably give more representative K-values for the displacement process. 


\section{Appendix A: Steps for MMP Calculations in PVTSim}

These are the steps to calculate MMPs using the PVTSim code:

1. Open the PVTSim package and select the equation of state desired from the tools' bar.

2. Select a unit system from the options icon on the tools' bar.

3. Create a new database to store all fluid information from 'File-Create new database'.

4. From the 'Fluid' icon on the tool bar, select 'Enter new fluid' and a fluid properties spreadsheet appears as shown in Illustration A1.

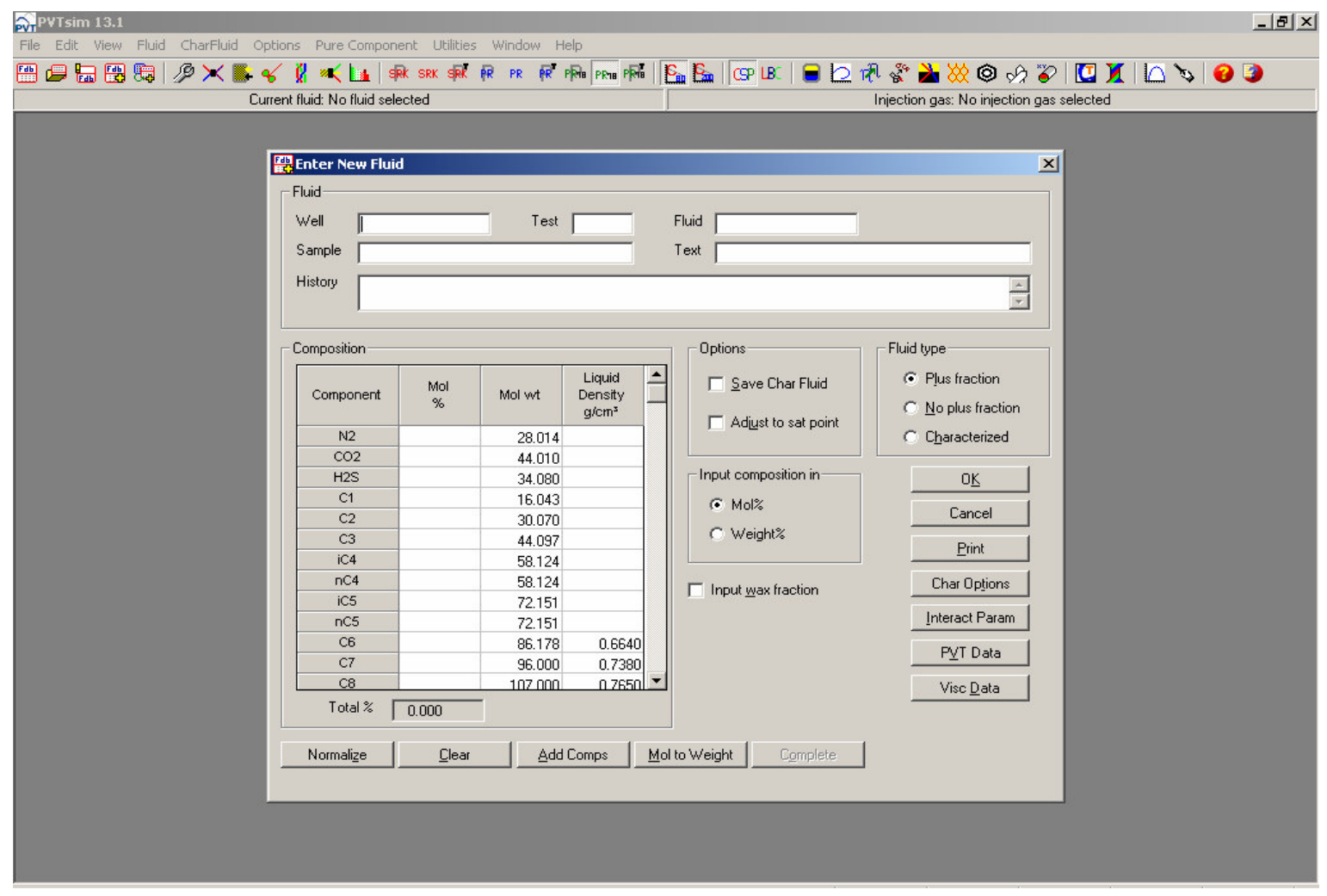

Illustration A1 PVTSim input menu for fluid composition and properties. 
5. On the left hand side of the spreadsheet, there is an option to enter the fluid description either as originally obtained from extended fluid analysis (i.e. no pseudocomponent lumping yet) or as a characterized fluid. If the fluid is characterized, then select the 'Characterized' fluid option and not the 'Plus fraction' option. It is important to have selected the appropriate EOS from step 1 because this is associated with the properties of the characterized fluid to be input.

6. Input the fluid properties and enter a name for the file in the name field for easy tracking. The software has a database of single carbon number components and their properties. Additional components can be selected from the 'Add comps' icon at the bottom of the spreadsheet. Blank input fields for pseudocomponent properties are selected by indicating the number of pseudocomponents in the characterization.

7. At the bottom right side of the same spreadsheet, select the 'Interact. Param' button and input the binary interaction parameters $\left(\mathrm{K}_{\mathrm{ij}}\right)$ in the appropriate field.

8. Save the file and create another fluid file for the injection gas by following steps four to eight.

9. Make sure the same EOS is selected for the whole procedure.

10. Go back and reselect the oil created in the first steps, from 'Fluid-database' option.

11. On the tool bar, select 'Window-Simulations' option and a windows form with different simulation options will appear.

12. Select the MMP module and another interface appear.

13. Select the drive mechanism and input the temperature. Also, select the injection gas from the injection gas option on the users interface displayed.

14. Click 'Ok' on the MMP menu to make the calculation. 


\begin{tabular}{|c|c|c|c|c|c|c|c|c|}
\hline \multicolumn{9}{|c|}{ Interaction Parameters (PR) } \\
\hline \multicolumn{8}{|c|}{ 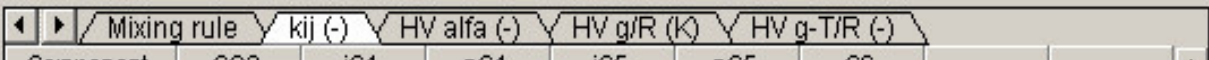 } & Vokii's \\
\hline Component & $\mathrm{CO} 2$ & $\mathrm{iC4} 4$ & $\mathrm{nC4} 4$ & ic5 & $\mathrm{nC5}$ & $\mathrm{C} 6$ & $\Delta$ & \multirow{2}{*}{ Exponent $n$} \\
\hline $\mathrm{CO} 2$ & & & & & & & & \\
\hline $\mathrm{iC4}$ & 0.1200 & & & & & & & 1.0 \\
\hline $\mathrm{nC4}$ & 0.1200 & 0.0000 & & & & & & \\
\hline ic5 & 0.1200 & 0.0000 & 0.0000 & & & & & \\
\hline $\mathrm{nC5}$ & 0.1200 & 0.0000 & 0.0000 & 0.0000 & & & & \\
\hline C6 & 0.1200 & 0.0000 & 0.0000 & 0.0000 & 0.0000 & & & \\
\hline & & & & & & & & \\
\hline & & & & & & & & \\
\hline & & & & & & & & \\
\hline & & & & & & & & OKK \\
\hline & & & & & & & & \\
\hline & & & & & & & & Print \\
\hline 11 & & & & & & & $\vec{\square}$ & Cancel \\
\hline
\end{tabular}

Illustration A.2: PVTSim input field for binary interaction parameters.

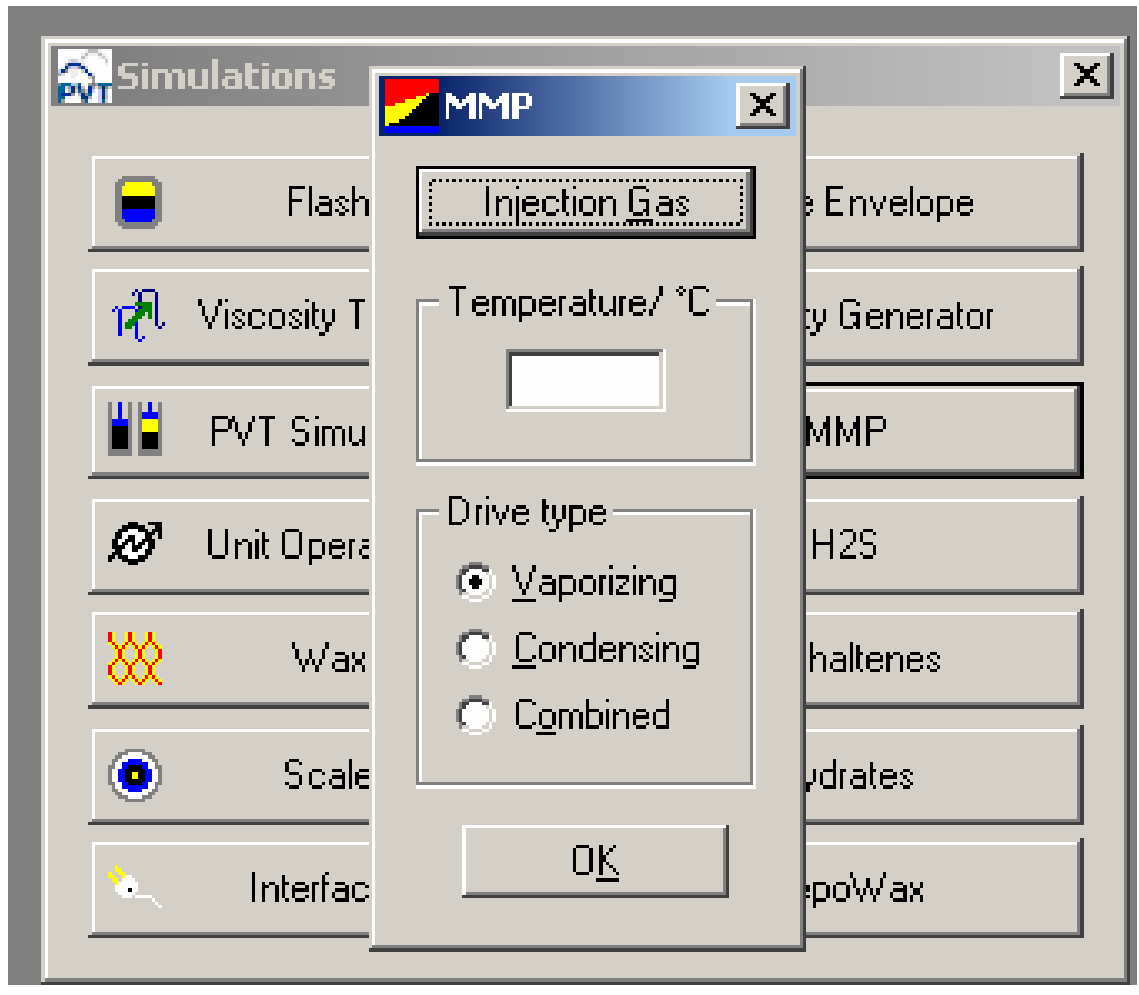

Illustration A.3: MMP simulation menu for PVTSim. 


\section{Appendix B: EOS Properties for Oils Used in the MMP Correlations}

Tables B1-B12 give a summary of the EOS properties of the multicomponent EOS fluid characterizations used to develop the MMP correlations.

Table B1: Component properties for Wang and Orr (2002) EOS model.

\begin{tabular}{|l|c|c|c|c|c|c|c|c|}
\hline Component & $\mathrm{Mol} \%$ & $\mathrm{M}_{\mathrm{w}}$ & $\mathrm{T}_{\mathrm{C}}\left({ }^{\circ} \mathrm{F}\right)$ & $\mathrm{P}_{\mathrm{C}}(\mathrm{psia})$ & $\begin{array}{c}\mathrm{V}_{\mathrm{C}} \\
(\mathrm{ft} / \mathrm{lb}-\mathrm{mol})\end{array}$ & $\omega$ & $\Omega_{A}$ & $\Omega_{B}$ \\
\hline $\mathrm{CO}_{2}$ & 0.1 & 44.01 & 87.62 & 1071.34 & 1.51 & 0.225 & 0.45724 & 0.0778 \\
\hline $\mathrm{C}_{1}$ & 34.67 & 16.043 & -116.58 & 667.80 & 1.59 & 0.01 & 0.45724 & 0.0778 \\
\hline $\mathrm{C}_{2}$ & 3.13 & 30.07 & 89.72 & 708.40 & 2.37 & 0.099 & 0.45724 & 0.0778 \\
\hline $\mathrm{C}_{3}$ & 3.96 & 44.097 & 205.82 & 617.40 & 3.25 & 0.152 & 0.45724 & 0.0778 \\
\hline $\mathrm{C}_{4}$ & 5.95 & 58.124 & 294.6 & 543.30 & 4.08 & 0.187 & 0.45724 & 0.0778 \\
\hline $\mathrm{C}_{5}$ & 4.06 & 72.151 & 366.52 & 475.30 & 4.87 & 0.252 & 0.45724 & 0.0778 \\
\hline $\mathrm{C}_{6}$ & 3.06 & 86.178 & 453.92 & 431.00 & 5.93 & 0.296 & 0.45724 & 0.0778 \\
\hline $\mathrm{C}_{7}$ & 4.95 & 100.205 & 512.92 & 397.00 & 6.92 & 0.351 & 0.45724 & 0.0778 \\
\hline $\mathrm{C}_{8+}$ & 4.97 & 114.232 & 564.42 & 264.00 & 7.88 & 0.394 & 0.45724 & 0.0778 \\
\hline $\mathrm{C}_{10+}$ & 30.11 & 142.285 & 647.62 & 320.00 & 9.66 & 0.491 & 0.45724 & 0.0778 \\
\hline $\mathrm{C}_{14+}$ & 5.04 & 198.4 & 790.02 & 230.00 & 13.3 & 0.755 & 0.45724 & 0.0778 \\
\hline
\end{tabular}

Table B2: Non-zero binary interaction parameters Wang and Orr (2002) EOS model.

\begin{tabular}{|l|c|c|c|c|c|c|c|c|c|c|c|}
\hline & $\mathrm{CO}_{2}$ & $\mathrm{C}_{1}$ & $\mathrm{C}_{2}$ & $\mathrm{C}_{3}$ & $\mathrm{C}_{4}$ & $\mathrm{C}_{5}$ & $\mathrm{C}_{6}$ & $\mathrm{C}_{7}$ & $\mathrm{C}_{8+}$ & $\mathrm{C}_{10+}$ & $\mathrm{C}_{14+}$ \\
\hline $\mathrm{CO}_{2}$ & 0.0000 & 0.1000 & 0.1300 & 0.1350 & 0.1300 & 0.1300 & 0.1400 & 0.1400 & 0.1400 & 0.1400 & 0.1400 \\
\hline $\mathrm{C}_{1}$ & & & & & & & 0.0200 & 0.0300 & 0.0350 & 0.0400 & 0.0600 \\
\hline
\end{tabular}


Table B3: Component properties for Oil A (Yuan et al., 2002) EOS model.

\begin{tabular}{|l|c|c|c|c|c|c|c|c|}
\hline Component & Mol \% & $\mathrm{M}_{\mathrm{w}}$ & $\mathrm{T}_{\mathrm{C}}\left({ }^{\circ} \mathrm{F}\right)$ & $\mathrm{P}_{\mathrm{C}}(\mathrm{psia})$ & $\begin{array}{c}\mathrm{V}_{\mathrm{C}} \\
\left(\mathrm{ft}^{3} / \mathrm{lb}-\mathrm{mol}\right)\end{array}$ & $\omega$ & $\Omega_{A}$ & $\Omega_{B}$ \\
\hline $\mathrm{CO}_{2}$ & 0.31 & 44.01 & 87.89 & 1069.87 & 1.51 & 0.225 & 0.45724 & 0.0778 \\
\hline $\mathrm{C}_{2}$ & 5.35 & 30.07 & 90.05 & 708.35 & 2.37 & 0.098 & 0.45724 & 0.0778 \\
\hline $\mathrm{C}_{3+}$ & 9.45 & 49.61 & 246.55 & 582.14 & 3.60 & 0.168 & 0.45724 & 0.0778 \\
\hline $\mathrm{C}_{5+}$ & 4.46 & 77.77 & 411.32 & 463.69 & 5.39 & 0.265 & 0.45724 & 0.0778 \\
\hline $\mathrm{C}_{1} \mathrm{~N}_{2}$ & 47.92 & 16.07 & -116.97 & 666.62 & 1.62 & 0.008 & 0.45724 & 0.0778 \\
\hline $\mathrm{C}_{7+}$ & 19.09 & 128.16 & 694.67 & 332.16 & 9.36 & 0.458 & 0.45724 & 0.0778 \\
\hline $\mathrm{C}_{14+}$ & 8.17 & 227.29 & 1109.84 & 222.73 & 17.46 & 0.733 & 0.45724 & 0.0778 \\
\hline $\mathrm{C}_{21+}$ & 5.24 & 387.29 & 1494.36 & 177.58 & 25.14 & 1.020 & 0.45724 & 0.0778 \\
\hline
\end{tabular}

Table B4: Binary interaction parameters for oil A (Yuan, et al. 2002) EOS model.

\begin{tabular}{|c|c|c|c|c|c|c|c|c|}
\hline & $\mathrm{CO}_{2}$ & $\mathrm{C}_{2}$ & $\mathrm{C}_{3+}$ & $\mathrm{C}_{5+}$ & $\mathrm{C}_{1} \mathrm{~N}_{2}$ & $\mathrm{C}_{7+}$ & $\mathrm{C}_{14+}$ & $\mathrm{C}_{21+}$ \\
\hline $\mathrm{CO}_{2}$ & 0.0000 & & & & & & & \\
\hline $\mathrm{C}_{2}$ & 0.1200 & 0.0000 & & & & & & \\
\hline $\mathrm{C}_{3+}$ & 0.1200 & 0.0000 & 0.0000 & & & & & \\
\hline $\mathrm{C}_{5+}$ & 0.1200 & 0.0000 & 0.0000 & 0.0000 & & & & \\
\hline $\mathrm{C}_{1} \mathrm{~N}_{2}$ & 0.1197 & 0.0001 & 0.0002 & 0.0002 & 0.0000 & & & \\
\hline $\mathrm{C}_{7+}$ & 0.1000 & 0.0000 & 0.0000 & 0.0000 & 0.0013 & 0.0000 & & \\
\hline $\mathrm{C}_{14+}$ & 0.1000 & 0.0000 & 0.0000 & 0.0000 & 0.0013 & 0.0000 & 0.0000 & \\
\hline $\mathrm{C}_{21+}$ & 0.1000 & 0.0000 & 0.0000 & 0.0000 & 0.0013 & 0.0000 & 0.0000 & 0.0000 \\
\hline
\end{tabular}


Table B5: Component properties for oil B (unpublished) EOS model.

\begin{tabular}{|l|c|c|c|c|c|c|c|c|}
\hline Component & $\mathrm{Mol} \%$ & $\mathrm{M}_{\mathrm{w}}$ & $\mathrm{T}_{\mathrm{C}}\left({ }^{\circ} \mathrm{F}\right)$ & $\mathrm{P}_{\mathrm{C}}(\mathrm{psia})$ & $\begin{array}{c}\mathrm{V}_{\mathrm{C}} \\
(\mathrm{ft} / / \mathrm{lb}-\mathrm{mol})\end{array}$ & $\omega$ & $\Omega_{A}$ & $\Omega_{B}$ \\
\hline $\mathrm{N}_{2}$ & 0.45 & 28.01 & -232.51 & 493.79 & 1.44 & 0.040 & 0.45724 & 0.0778 \\
\hline $\mathrm{CO}_{2}$ & 1.64 & 44.01 & 87.89 & 1071.34 & 1.51 & 0.228 & 0.45724 & 0.0778 \\
\hline $\mathrm{C}_{1}$ & 45.85 & 16.04 & -116.59 & 667.20 & 1.59 & 0.008 & 0.45724 & 0.0778 \\
\hline $\mathrm{C}_{2}$ & 7.15 & 30.07 & 90.05 & 708.35 & 2.37 & 0.098 & 0.45724 & 0.0778 \\
\hline $\mathrm{C}_{3}$ & 6.74 & 44.10 & 205.97 & 615.76 & 3.25 & 0.152 & 0.45724 & 0.0778 \\
\hline $\mathrm{iC}_{4}$ & 0.84 & 58.12 & 274.91 & 529.06 & 4.21 & 0.176 & 0.45724 & 0.0778 \\
\hline $\mathrm{nC}_{4}$ & 3.11 & 58.12 & 305.69 & 551.10 & 4.08 & 0.193 & 0.45724 & 0.0778 \\
\hline $\mathrm{iC}_{5}$ & 1.03 & 72.15 & 369.05 & 490.85 & 4.90 & 0.227 & 0.45724 & 0.0778 \\
\hline $\mathrm{nC}_{5}$ & 1.65 & 72.15 & 385.61 & 489.38 & 4.87 & 0.251 & 0.45724 & 0.0778 \\
\hline $\mathrm{C}_{6}$ & 2.52 & 86.18 & 453.65 & 430.59 & 5.93 & 0.296 & 0.45724 & 0.0778 \\
\hline $\mathrm{nC}_{7+}$ & 12.44 & 100.21 & 679.37 & 445.27 & 6.92 & 0.184 & 0.45724 & 0.0778 \\
\hline $\mathrm{nC}_{11+}$ & 6.32 & 156.30 & 727.62 & 344.77 & 10.57 & 0.477 & 0.45724 & 0.0778 \\
\hline $\mathrm{nC}_{16+}$ & 5.02 & 226.40 & 806.89 & 283.49 & 14.74 & 0.820 & 0.45724 & 0.0778 \\
\hline $\mathrm{nC}_{23+}$ & 3.24 & 324.64 & 920.03 & 246.68 & 20.90 & 1.211 & 0.45724 & 0.0778 \\
\hline $\mathrm{nC}_{33+}$ & 2.00 & 464.91 & 1035.23 & 222.35 & 29.71 & 1.372 & 0.45724 & 0.0778 \\
\hline
\end{tabular}

Table B6: Binary interaction parameters for oil B (unpublished) EOS model.

\begin{tabular}{|c|c|c|c|}
\hline & $\mathrm{N}_{2}$ & $\mathrm{CO}_{2}$ & $\mathrm{NC}_{7}$ \\
\hline $\mathrm{N}_{2}$ & 0.0000 & 0.0000 & 0.1441 \\
\hline $\mathrm{CO}_{2}$ & -0.0170 & 0.0000 & 0.1000 \\
\hline $\mathrm{C}_{1}$ & 0.0311 & 0.1200 & 0.0352 \\
\hline $\mathrm{C}_{2}$ & 0.0515 & 0.1200 & 0.0067 \\
\hline $\mathrm{C}_{3}$ & 0.0852 & 0.1200 & 0.0056 \\
\hline $\mathrm{iC}_{4}$ & 0.1033 & 0.1200 & 0.0000 \\
\hline $\mathrm{nC}_{4}$ & 0.0800 & 0.1200 & 0.0033 \\
\hline $\mathrm{iC}_{5}$ & 0.0922 & 0.1200 & 0.0000 \\
\hline $\mathrm{nC}_{5}$ & 0.1000 & 0.1200 & 0.0074 \\
\hline $\mathrm{C}_{6}$ & 0.0800 & 0.1200 & 0.0000 \\
\hline $\mathrm{nC}_{11+}$ & 0.0800 & 0.1000 & 0.0000 \\
\hline $\mathrm{nC}_{16+}$ & 0.0800 & 0.1000 & 0.0000 \\
\hline $\mathrm{nC}_{23+}$ & 0.0000 & 0.0000 & 0.0000 \\
\hline $\mathrm{nC}_{33+}$ & 0.0000 & 0.0000 & 0.0000 \\
\hline
\end{tabular}


Table B7: Component properties for oil C (unpublished) EOS model.

\begin{tabular}{|l|c|c|c|c|c|c|c|c|}
\hline Component & $\mathrm{Mol} \%$ & $\mathrm{M}_{\mathrm{W}}$ & $\mathrm{T}_{\mathrm{C}}\left({ }^{\circ} \mathrm{F}\right)$ & $\mathrm{P}_{\mathrm{C}}(\mathrm{psia})$ & $\begin{array}{c}\mathrm{V}_{\mathrm{C}} \\
\mathrm{ft} / \mathrm{lb}-\mathrm{mol})\end{array}$ & $\omega$ & $\Omega_{A}$ & $\Omega_{B}$ \\
\hline $\mathrm{N}_{2}$ & 0.67 & 28.01 & -232.60 & 493.00 & 1.44 & 0.045 & 0.45724 & 0.0778 \\
\hline $\mathrm{CO}_{2}$ & 1.29 & 44.01 & 87.90 & 1071.00 & 1.51 & 0.231 & 0.45724 & 0.0778 \\
\hline $\mathrm{C}_{1}$ & 74.91 & 16.04 & -116.90 & 667.80 & 1.59 & 0.012 & 0.45724 & 0.0778 \\
\hline $\mathrm{C}_{2}$ & 7.69 & 30.07 & 89.90 & 707.80 & 2.37 & 0.091 & 0.45724 & 0.0778 \\
\hline $\mathrm{C}_{3}$ & 3.89 & 44.10 & 205.80 & 616.30 & 3.25 & 0.145 & 0.45724 & 0.0778 \\
\hline $\mathrm{iC}_{4}$ & 0.79 & 58.12 & 274.80 & 529.10 & 4.21 & 0.176 & 0.45724 & 0.0778 \\
\hline $\mathrm{nC}_{4}$ & 1.84 & 58.12 & 305.40 & 550.70 & 4.08 & 0.193 & 0.45724 & 0.0778 \\
\hline $\mathrm{iC}_{5}$ & 0.74 & 72.15 & 368.90 & 490.40 & 4.90 & 0.227 & 0.45724 & 0.0778 \\
\hline $\mathrm{nC}_{5}$ & 0.93 & 72.15 & 385.50 & 488.60 & 4.87 & 0.251 & 0.45724 & 0.0778 \\
\hline $\mathrm{C}_{6}$ & 1.11 & 86.18 & 453.50 & 436.90 & 5.93 & 0.296 & 0.45724 & 0.0778 \\
\hline $\mathrm{nC}_{7+}$ & 3.10 & 100.21 & 612.30 & 390.30 & 6.92 & 0.346 & 0.45724 & 0.0778 \\
\hline $\mathrm{nC}_{9_{+}}$ & 1.59 & 128.26 & 786.10 & 288.70 & 8.78 & 0.514 & 0.45724 & 0.0778 \\
\hline $\mathrm{nC}_{14+}$ & 0.88 & 198.40 & 923.10 & 222.30 & 13.30 & 0.691 & 0.45724 & 0.0778 \\
\hline $\mathrm{C}_{20+}$ & 0.45 & 100.00 & 1056.40 & 171.90 & 20.78 & 0.908 & 0.45724 & 0.0778 \\
\hline $\mathrm{C}_{30+}$ & 0.14 & 200.00 & 1239.50 & 124.60 & 29.19 & 1.270 & 0.45724 & 0.0778 \\
\hline
\end{tabular}

Table B8: Non-zero binary interaction parameters for oil C (unpublished) EOS model.

\begin{tabular}{|c|c|c|c|}
\hline & $\mathrm{N}_{2}$ & $\mathrm{CO}_{2}$ & $\mathrm{C}_{1}$ \\
\hline $\mathrm{C}_{1}$ & 0.1050 & 0.0250 & \\
\hline $\mathrm{C}_{2}$ & 0.1300 & 0.0100 & \\
\hline $\mathrm{C}_{3}$ & 0.1250 & 0.0900 & \\
\hline $\mathrm{iC}_{4}$ & 0.1200 & 0.0950 & \\
\hline $\mathrm{nC}_{4}$ & 0.1150 & 0.0950 & \\
\hline $\mathrm{iC}_{5}$ & 0.1150 & 0.1000 & \\
\hline $\mathrm{nC}_{5}$ & 0.1150 & 0.1100 & \\
\hline $\mathrm{C}_{6}$ & 0.1150 & 0.1100 & \\
\hline $\mathrm{nC}_{7+}$ & 0.1150 & 0.1100 & 0.0351 \\
\hline $\mathrm{nC}_{9+}$ & 0.1150 & 0.1100 & 0.0508 \\
\hline $\mathrm{nC}_{14+}$ & 0.1150 & 0.1100 & 0.0638 \\
\hline $\mathrm{C}_{20+}$ & 0.1150 & 0.1100 & 0.0768 \\
\hline $\mathrm{C}_{30+}$ & 0.1150 & 0.1100 & 0.0945 \\
\hline
\end{tabular}


Table B9: Component properties for oil D (Jutila, et al. 2001) EOS model.

\begin{tabular}{|l|c|c|c|c|c|c|c|c|}
\hline Component & $\mathrm{Mol} \%$ & $\mathrm{M}_{\mathrm{W}}$ & $\mathrm{T}_{\mathrm{C}}\left({ }^{\circ} \mathrm{F}\right)$ & $\mathrm{P}_{\mathrm{C}}(\mathrm{psia})$ & $\begin{array}{c}\mathrm{V}_{\mathrm{C}} \\
(\mathrm{ft} / \mathrm{lb}-\mathrm{mol})\end{array}$ & $\omega$ & $\Omega_{A}$ & $\Omega_{B}$ \\
\hline $\mathrm{N}_{2}$ & 0.57 & 28.01 & -232.40 & 493.00 & 1.44 & 0.045 & 0.45724 & 0.0778 \\
\hline $\mathrm{CO}_{2}$ & 1.65 & 44.01 & 87.90 & 1070.90 & 1.51 & 0.231 & 0.45724 & 0.0778 \\
\hline $\mathrm{C}_{1}$ & 81.35 & 16.04 & -116.60 & 667.80 & 1.59 & 0.012 & 0.45724 & 0.0778 \\
\hline $\mathrm{C}_{2}$ & 6.86 & 30.07 & 90.10 & 707.80 & 2.37 & 0.091 & 0.45724 & 0.0778 \\
\hline $\mathrm{C}_{3}$ & 2.80 & 44.10 & 206.00 & 616.30 & 3.25 & 0.145 & 0.45724 & 0.0778 \\
\hline $\mathrm{nC}_{4}$ & 1.49 & 58.12 & 305.70 & 550.70 & 4.08 & 0.193 & 0.45724 & 0.0778 \\
\hline $\mathrm{nC}_{5}$ & 0.77 & 72.15 & 385.70 & 488.60 & 4.87 & 0.251 & 0.45724 & 0.0778 \\
\hline $\mathrm{C}_{6}$ & 0.54 & 86.18 & 453.70 & 436.90 & 5.93 & 0.296 & 0.45724 & 0.0778 \\
\hline PS1 & 1.09 & 97.21 & 509.53 & 410 & 6.80 & 0.257 & 0.45724 & 0.0778 \\
\hline PS2 & 1.58 & 129.02 & 675.33 & 355 & 8.96 & 0.335 & 0.45724 & 0.0778 \\
\hline PS3 & 1.00 & 191.40 & 825.33 & 285 & 12.03 & 0.488 & 0.45724 & 0.0778 \\
\hline PS4 & 0.30 & 300 & 1020.33 & 218 & 16.86 & 0.724 & 0.45724 & 0.0778 \\
\hline
\end{tabular}

Table B10: Non-zero binary interaction parameters for oil D (Jutila, et al. 2001) EOS model.

\begin{tabular}{|l|c|c|c|}
\hline & $\mathrm{N}_{2}$ & $\mathrm{CO}_{2}$ & $\mathrm{C}_{1}$ \\
\hline $\mathrm{N}_{2}$ & 0.0000 & & \\
\hline $\mathrm{CO}_{2}$ & 0.0000 & 0.0000 & \\
\hline $\mathrm{C}_{1}$ & 0.0250 & 0.1050 & 0.0000 \\
\hline $\mathrm{C}_{2}$ & 0.0100 & 0.1300 & 0.0000 \\
\hline $\mathrm{C}_{3}$ & 0.0900 & 0.1250 & 0.0000 \\
\hline $\mathrm{nC}_{4}$ & 0.1100 & 0.1150 & 0.0000 \\
\hline $\mathrm{nC}_{5}$ & 0.1100 & 0.1150 & 0.0000 \\
\hline $\mathrm{C}_{6}$ & 0.1100 & 0.1150 & 0.0000 \\
\hline $\mathrm{PS} 1$ & 0.1100 & 0.1150 & 0.0560 \\
\hline $\mathrm{PS} 2$ & 0.1100 & 0.1150 & 0.0749 \\
\hline $\mathrm{PS} 3$ & 0.1100 & 0.1150 & 0.1040 \\
\hline $\mathrm{PS} 4$ & 0.1100 & 0.1150 & 0.1390 \\
\hline
\end{tabular}


Table B11: Component properties for Hong oil (1982) EOS model.

\begin{tabular}{|c|c|c|c|c|c|c|c|c|}
\hline Component & Mol \% & $\mathrm{M}_{\mathrm{w}}$ & $\mathrm{T}_{\mathrm{C}}\left({ }^{\circ} \mathrm{F}\right)$ & $\mathrm{P}_{\mathrm{C}}$ (psia) & $\begin{array}{c}\mathrm{V}_{\mathrm{C}} \\
\left(\mathrm{ft} \mathrm{ft}^{3} / \mathrm{lb}-\mathrm{mol}\right)\end{array}$ & $\omega$ & $\Omega_{A}$ & $\Omega_{B}$ \\
\hline $\mathrm{CO}_{2}$ & 0.01 & 44.01 & 87.89 & 1069.87 & 1.51 & 0.225 & 0.45724 & 0.0778 \\
\hline$C_{1}$ & 31.00 & 16.04 & -116.59 & 667.20 & 1.59 & 0.013 & .45724 & 0.0778 \\
\hline$\underline{\mathrm{C}_{2}}$ & 10.41 & 30.07 & 90.05 & 708.35 & 2.37 & 0.099 & 0.45724 & 0.0778 \\
\hline $\mathrm{C}_{3}$ & 11.87 & 44.10 & 205.97 & 615.76 & 3.25 & 0.152 & 0.45724 & 0.0778 \\
\hline $\mathrm{C}_{4}$ & 7.32 & 58.12 & 305.69 & 551.10 & 4.08 & 0.201 & 0.45724 & 0.0778 \\
\hline $\mathrm{C}_{5}$ & 4.41 & 72.15 & 385.61 & 489.38 & 4.87 & 0.254 & 0.45724 & 0.0778 \\
\hline $\mathrm{C}_{6}$ & 2.55 & 86.18 & 453.65 & 430.59 & 5.93 & 0.301 & 0.45724 & 0.0778 \\
\hline$C_{7}$ & 5.71 & 100.21 & 512.69 & 396.79 & 6.92 & 0.348 & 0.45724 & 0.0778 \\
\hline $\mathrm{C}_{8}$ & 4.72 & 114.23 & 564.17 & 360.05 & 7.88 & 0.391 & 0.45724 & 0.0778 \\
\hline $\mathrm{C}_{9}$ & 2.46 & 128.26 & 610.61 & 335.07 & 8.78 & 0.435 & 0.45 & 0.0778 \\
\hline $\mathrm{C}_{10}$ & 2.33 & 142.29 & 652.01 & 305.68 & 9.66 & 0.478 & 0.45724 & 0.0778 \\
\hline $\mathrm{C}_{11}$ & 2.12 & 156.30 & 690.17 & 285.10 & 10.57 & 0.521 & 0.45724 & 0.0778 \\
\hline $\mathrm{C}_{12}$ & 1.69 & 170.30 & 729.30 & 264.53 & 11.42 & 0.564 & 0.45724 & 0.0778 \\
\hline $\mathrm{C}_{13+}$ & 13.40 & 100.00 & 800.33 & 213.09 & 14.36 & 0.800 & 0.45724 & 0.0778 \\
\hline
\end{tabular}

Table B12: Binary interaction parameters for Hong oil (1982) EOS model.

\begin{tabular}{|c|c|c|}
\hline & $\mathrm{CO}_{2}$ & $\mathrm{C}_{1}$ \\
\hline $\mathrm{CO}_{2}$ & 0.0000 & \\
\hline $\mathrm{C}_{1}$ & 0.2000 & 0.0000 \\
\hline $\mathrm{C}_{2}$ & 0.1900 & 0.0100 \\
\hline $\mathrm{C}_{3}$ & 0.1800 & 0.0100 \\
\hline $\mathrm{C}_{4}$ & 0.1700 & 0.0100 \\
\hline $\mathrm{C}_{5}$ & 0.1600 & 0.0100 \\
\hline $\mathrm{C}_{6}$ & 0.1500 & 0.0100 \\
\hline $\mathrm{C}_{7}$ & 0.1400 & 0.0100 \\
\hline $\mathrm{C}_{8}$ & 0.1400 & 0.0500 \\
\hline $\mathrm{C}_{9}$ & 0.1400 & 0.0700 \\
\hline $\mathrm{C}_{10}$ & 0.1400 & 0.0800 \\
\hline $\mathrm{C}_{11}$ & 0.1400 & 0.1200 \\
\hline $\mathrm{C}_{12}$ & 0.1400 & 0.1300 \\
\hline $\mathrm{C}_{13+}$ & 0.1400 & 0.1600 \\
\hline
\end{tabular}




\section{Appendix C: PVTSim MMP Calculation Failure}

PVTSim had difficulties in the calculation of MMPs for $\mathrm{CO}_{2}$ displacement of an 11-component oil (Wang and Orr 2002) at different temperatures. For these cases where PVTSim failed, the MMPE code was successful.

Table C1: Comparison of 11-component EOS MMP calculation results at different temperatures for displacement by pure $\mathrm{CO}_{2}$.

\begin{tabular}{|l|l|l|}
\hline & \multicolumn{2}{|c|}{ MMP (psia) } \\
\hline Temp $\left({ }^{\circ} \mathrm{F}\right)$ & MMPE & PVTSim \\
\hline 120 & 1536 & failed \\
\hline 140 & 1768 & failed \\
\hline 160 & 1982 & 1981.93 \\
\hline 180 & 2162 & 2162.79 \\
\hline 200 & 2308 & failed \\
\hline 220 & 2422 & failed \\
\hline
\end{tabular}




\section{Appendix D: Computer Code for Pseudocomponent Selection}

Below is a Fortran code (Johns 1992) that implements the Newley Merrill lumping scheme:

c This program forms pseudocomponents from individual components.

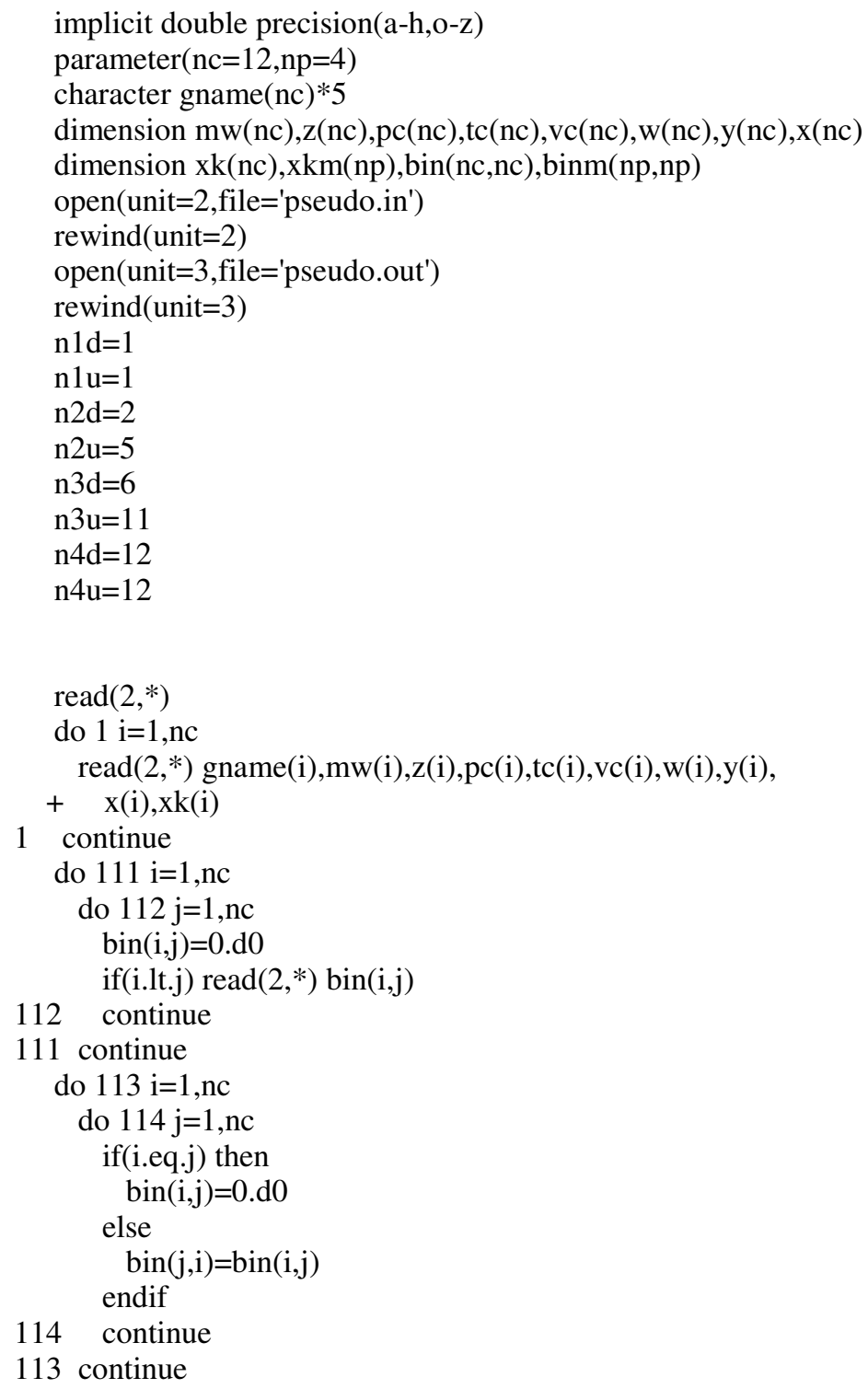


c Calculate effective $\mathrm{K}$ values of pseudo components.

sumy $=0 . \mathrm{d} 0$

$\operatorname{sum} \mathrm{x}=0 . \mathrm{d} 0$

do $2 \mathrm{i}=\mathrm{n} 1 \mathrm{~d}, \mathrm{n} 1 \mathrm{u}$

sumy $=$ sumy $+y(i)$

$\operatorname{sum} x=\operatorname{sum} x+x(i)$

2 continue

$\operatorname{xkm}(1)=$ sumy $/$ sum $x$

sumy $=0 . \mathrm{d} 0$

$\operatorname{sum} \mathrm{x}=0 . \mathrm{d} 0$

do $3 \mathrm{i}=\mathrm{n} 2 \mathrm{~d}, \mathrm{n} 2 \mathrm{u}$

sumy $=$ sumy $+y(i)$

$\operatorname{sum} x=\operatorname{sum} x+x(i)$

3 continue

$\operatorname{xkm}(2)=$ sumy $/$ sumx

sumy $=0 . \mathrm{d} 0$

$\operatorname{sum} x=0 . \mathrm{d} 0$

do $4 \mathrm{i}=\mathrm{n} 3 \mathrm{~d}, \mathrm{n} 3 \mathrm{u}$

sumy $=$ sumy $+y(i)$

$\operatorname{sum} x=\operatorname{sum} x+x(i)$

4 continue

$\operatorname{xkm}(3)=$ sumy/sumx

sumy $=0 . \mathrm{d} 0$

$\operatorname{sum} \mathrm{x}=0 . \mathrm{d} 0$

do $5 \mathrm{i}=\mathrm{n} 4 \mathrm{~d}, \mathrm{n} 4 \mathrm{u}$

sumy $=$ sumy $+y(i)$

$\operatorname{sum} x=\operatorname{sum} x+x(i)$

5 continue

$\operatorname{xkm}(4)=$ sumy $/$ sum $x$

c Check objective function.

sigma $=0 . \mathrm{d} 0$

do $6 \mathrm{i}=\mathrm{n} 1 \mathrm{~d}, \mathrm{n} 1 \mathrm{u}$

sigma $=(x k m(1)-x k(i)) * * 2 . d 0 /(x k(i) * * 2 . d 0)+$ sigma

6 continue

do $61 \mathrm{i}=\mathrm{n} 2 \mathrm{~d}, \mathrm{n} 2 \mathrm{u}$

sigma $=(x k m(2)-x k(i)) * * 2 . d 0 /(x k(i) * * 2 . d 0)+$ sigma

61 continue

do $62 \mathrm{i}=\mathrm{n} 3 \mathrm{~d}, \mathrm{n} 3 \mathrm{u}$

sigma $=(x k m(3)-x k(i)) * * 2 . d 0 /(x k(i) * * 2 . d 0)+$ sigma

62 continue

do $63 \mathrm{i}=\mathrm{n} 4 \mathrm{~d}, \mathrm{n} 4 \mathrm{u}$

sigma $=(x k m(4)-x k(i)) * * 2 . d 0 /(x k(i) * * 2 . d 0)+$ sigma

63 continue

write $\left(3,{ }^{*}\right)$ 'OBJECTIVE FUNCT. VALUE = ',sigma write $(3, *)^{\prime}$

c Calulate pseudo componenet properties

c Component 1

sum $=0 . \mathrm{d} 0$

sum $1=0 . \mathrm{d} 0$

$\operatorname{sum} 2=0 . \mathrm{d} 0$ 


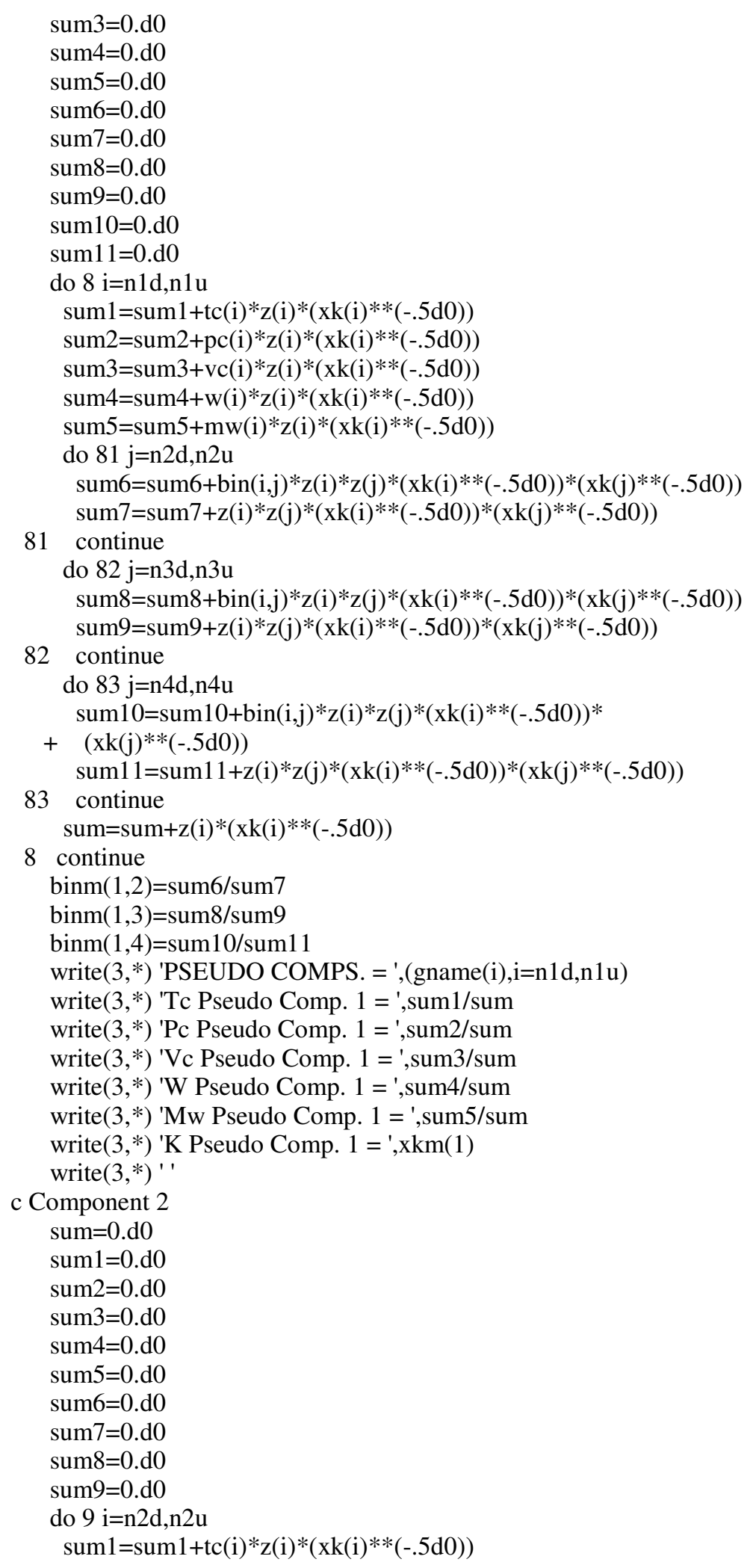




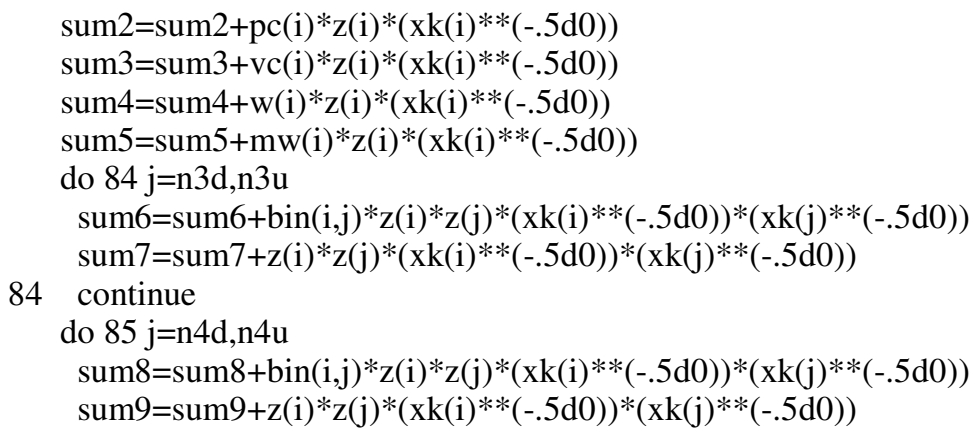




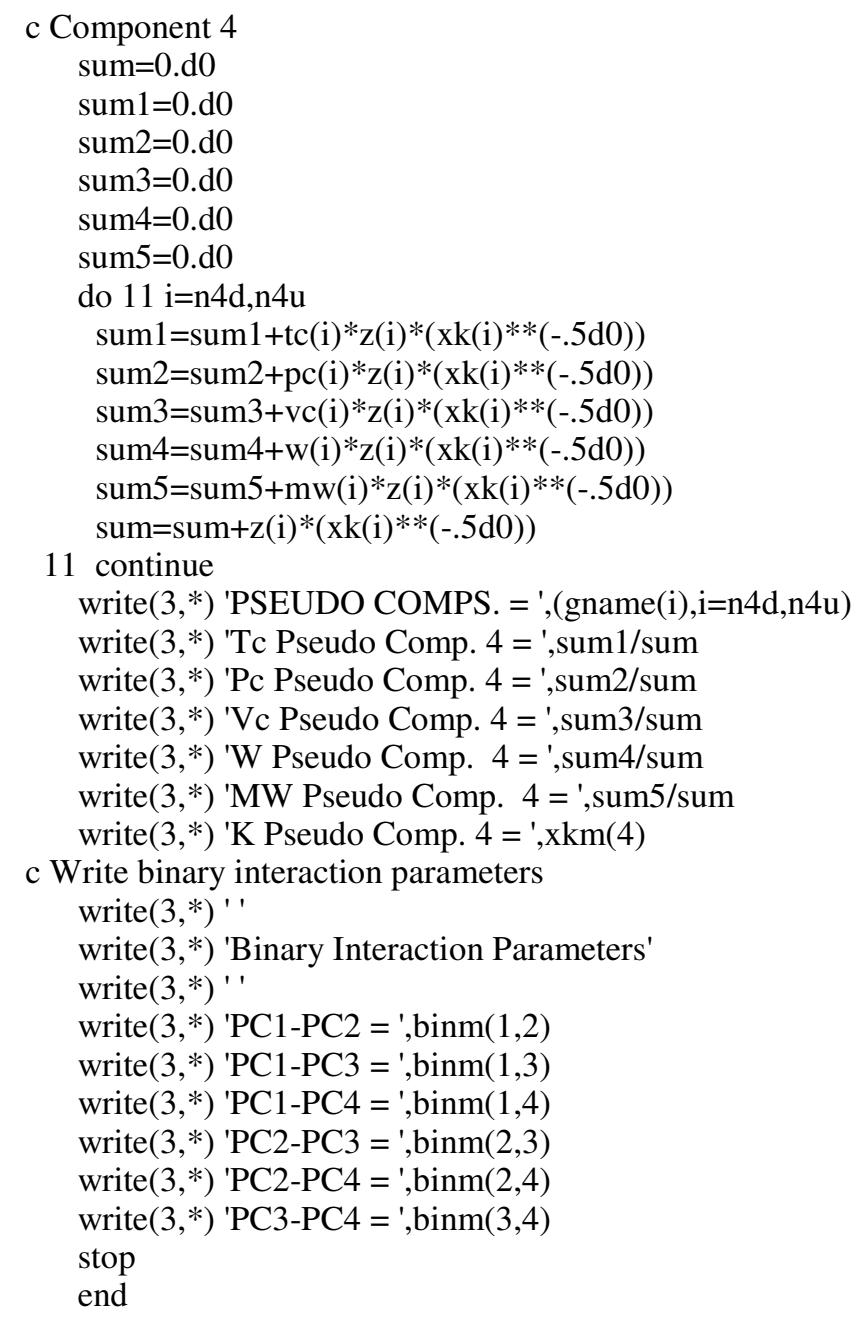

The Fortran input file for 12-component lumping is:

\begin{tabular}{|c|c|c|c|c|c|c|c|c|c|}
\hline Name & $\mathrm{Mw}$ & $\mathrm{Zi}$ & PC & $\mathrm{TC}$ & $\mathrm{VC}$ & $\omega$ & Yi & $\mathrm{Xi}$ & $\mathrm{Ki}$ \\
\hline 'CH4N2' & 16 & 0.334049 & 671.17 & -117.07 & 1.585 & 0.013 & 0.354462 & 0.215487 & 1.644934 \\
\hline 'C02' & 44 & 0.18311 & 1071.34 & 87.56 & 1.504 & 0.225 & 0.192117 & 0.130798 & 1.468809 \\
\hline 'C2' & 30 & 0.17497 & 708.35 & 89.72 & 2.366 & 0.098 & 0.178641 & 0.153651 & 1.162639 \\
\hline 'C3' & 44 & 0.191844 & 617.38 & 205.82 & 3.252 & 0.1524 & 0.196351 & 0.165668 & 1.18521 \\
\hline 'C4' & 58 & 0.037154 & 543.31 & 294.58 & 4.085 & 0.187 & 0.036738 & 0.03957 & 0.928426 \\
\hline 'C5' & 72 & 0.001342 & 475.28 & 366.46 & 4.87 & 0.2523 & 0.001261 & 0.001798 & 0.701545 \\
\hline 'C6' & 86 & 0.001936 & 419.54 & 439.41 & 5.981 & 0.3138 & 0.001746 & 0.003041 & 0.574184 \\
\hline 'C7+' & 108 & 0.014033 & 417.69 & 584.35 & 7.029 & 0.3739 & 0.011345 & 0.029643 & 0.382731 \\
\hline
\end{tabular}




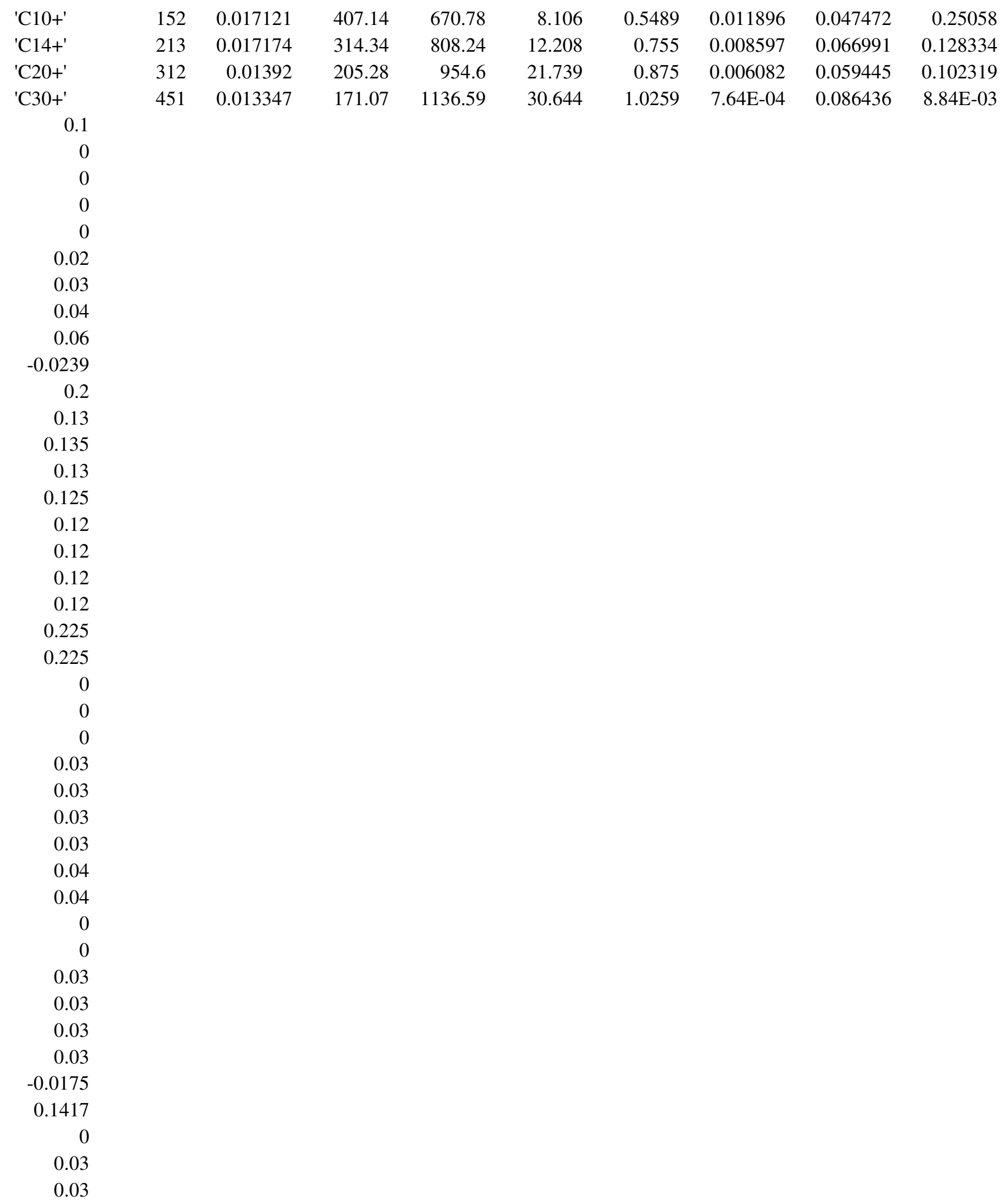


Example output file for the 12-component lumped to 4 pseudocomponents is:

OBJECTIVE FUNCT. VALUE $=2.50065550419702$

PSEUDO COMPS. $=\mathrm{CH} 4 \mathrm{~N} 2$

Tc Pseudo Comp. $1=-117.070000000000$

Pc Pseudo Comp. $1=671.170000000000$

Vc Pseudo Comp. $1=1.58500000000000$

W Pseudo Comp. $1=1.300000000000000 \mathrm{E}-002$

Mw Pseudo Comp. $1=16.0000000000000$ 
K Pseudo Comp. $1=1.64493433865379$

PSEUDO COMPS. $=\mathrm{C} 02 \quad \mathrm{C} 2 \quad \mathrm{C} 3 \quad \mathrm{C} 4$

Tc Pseudo Comp. $2=142.796957035988$

Pc Pseudo Comp. $2=769.790430980971$

Vc Pseudo Comp. $2=2.54052949390466$

W Pseudo Comp. $2=0.158980852374447$

MW Pseudo Comp. $2=40.7206179225850$

K Pseudo Comp. $2=1.23312872746389$

PSEUDO COMPS. $=\mathrm{C} 5 \mathrm{C} 6 \mathrm{C} 7+\mathrm{C} 10+\mathrm{C} 14+\mathrm{C} 20+$

Tc Pseudo Comp. $3=775.053316546237$

Pc Pseudo Comp. $3=322.857602567702$

Vc Pseudo Comp. $3=13.0560109504973$

W Pseudo Comp. $3=0.673660648933066$

MW Pseudo Comp. $3=208.342560039309$

K Pseudo Comp. $3=0.196399413891622$

PSEUDO COMPS. $=\mathrm{C} 30+$

Tc Pseudo Comp. $4=1136.59000000000$

Pc Pseudo Comp. $4=171.070000000000$

Vc Pseudo Comp. $4=30.6440000000000$

W Pseudo Comp. $4=1.02590000000000$

MW Pseudo Comp. $4=451.000000000000$

K Pseudo Comp. $4=8.838886807457022 \mathrm{E}-003$ 
Binary Interaction Parameters

$$
\begin{aligned}
& \text { PC1-PC2 }=2.860771792480373 \mathrm{E}-002 \\
& \text { PC1-PC3 }=2.581008572811162 \mathrm{E}-002 \\
& \text { PC1-PC4 }=0.200000000000000 \\
& \text { PC2-PC3 }=6.067108614431680 \mathrm{E}-002 \\
& \text { PC2-PC4 }=0.126857513116071
\end{aligned}
$$

PC3-PC4 $=0.00000000000000 \mathrm{E}+000$ 


\section{Appendix E: PVTSim EOS Tuning Module}

The regression tool menu showing the different options available for tuning an EOS characterization is given below:

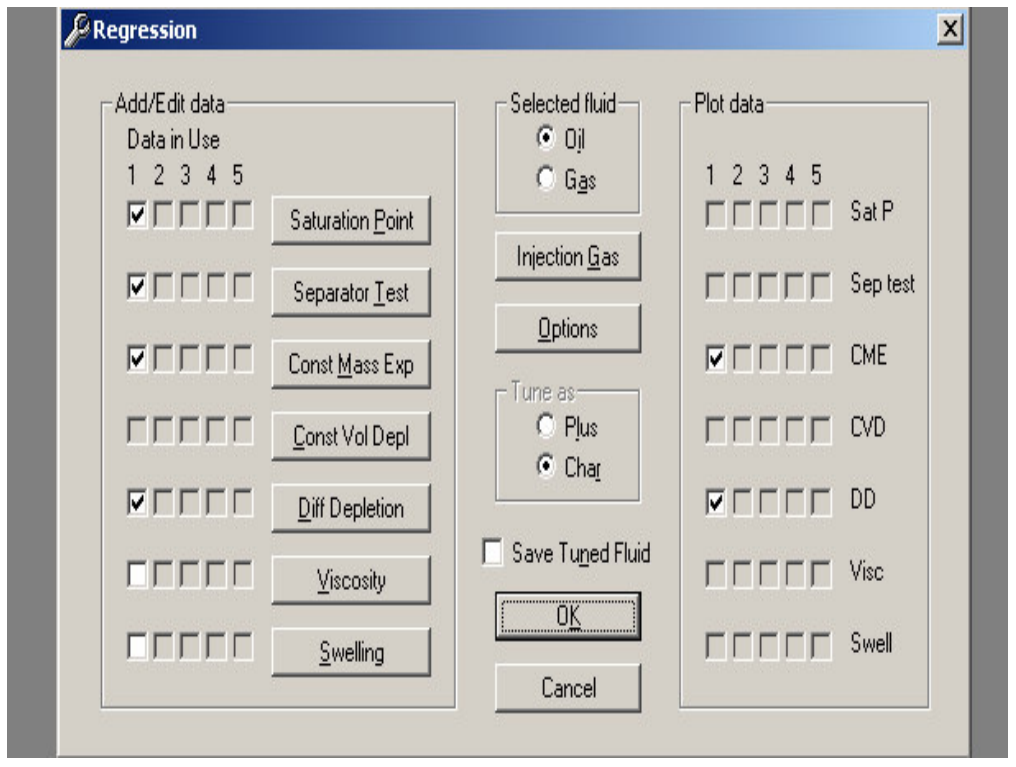

Illustration D.1: PVT data selection menu for PVTSim regression tool. 


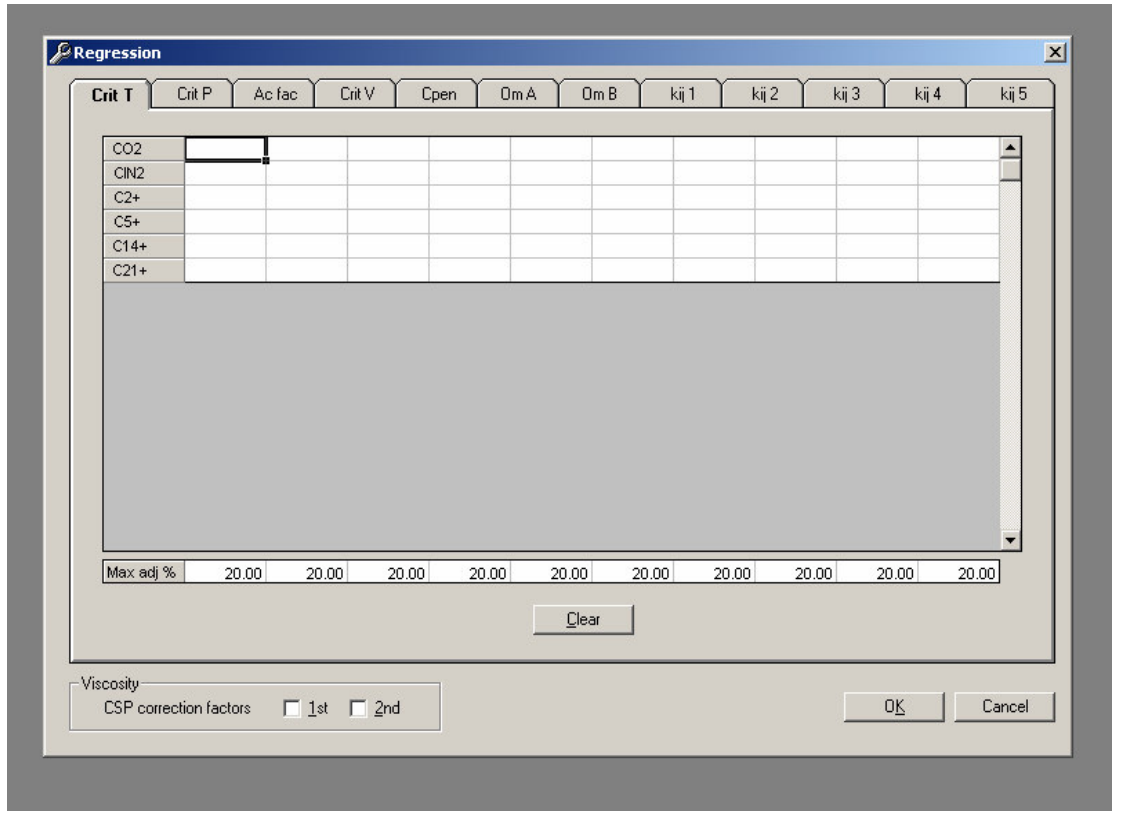

Illustration D.2: Menu of EOS parameters for regression. 


\section{Appendix F: Compositional Simulation Sample Input and Output}

The GEM (2003) simulation input file for the 12-component model is shown below:

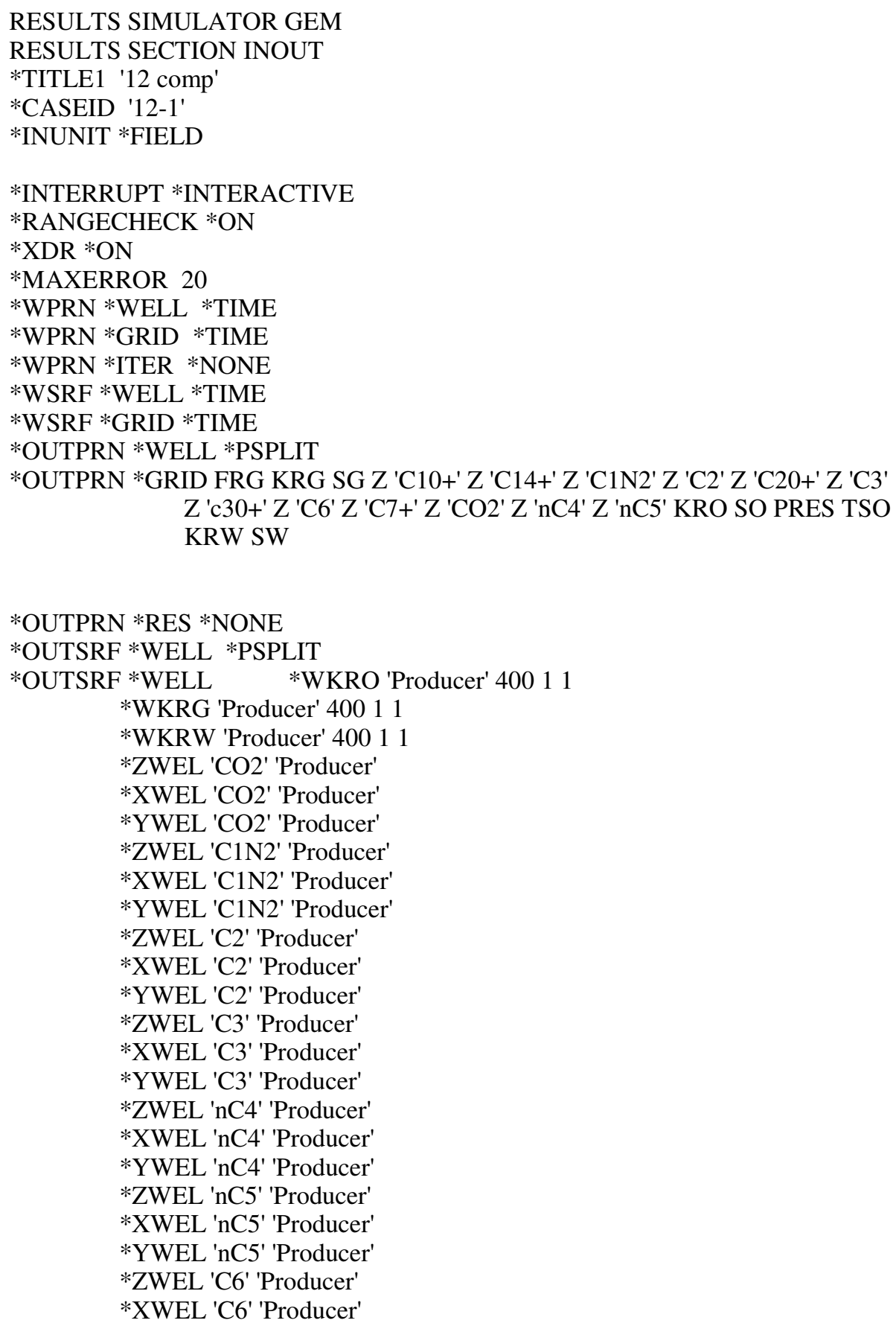




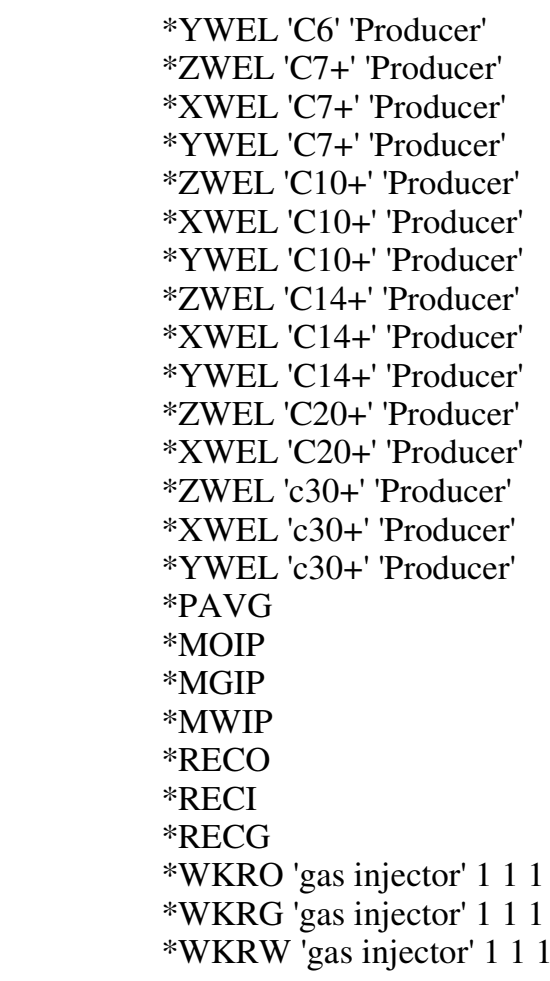

*OUTSRF *GRID KRG SG Z 'C10+' Z 'C14+' Z 'C1N2' Z 'C2' Z 'C20+' Z 'C3'

Z 'c30+' Z 'C6' Z 'C7+' Z 'CO2' Z 'nC4' Z 'nC5' KRO SO PRES TSO VELOCRC KRW SW

*OUTSRF *RES *NONE

RESULTS XOFFSET 0.

RESULTS YOFFSET 0.

RESULTS ROTATION 0

RESULTS AXES-DIRECTIONS 1. -1. 1.

GRID VARI 40011

KDIR DOWN

DI CON 2.5

DJ CON 800.

DK CON 20.

PAYDEPTH ALL

400*7010. 


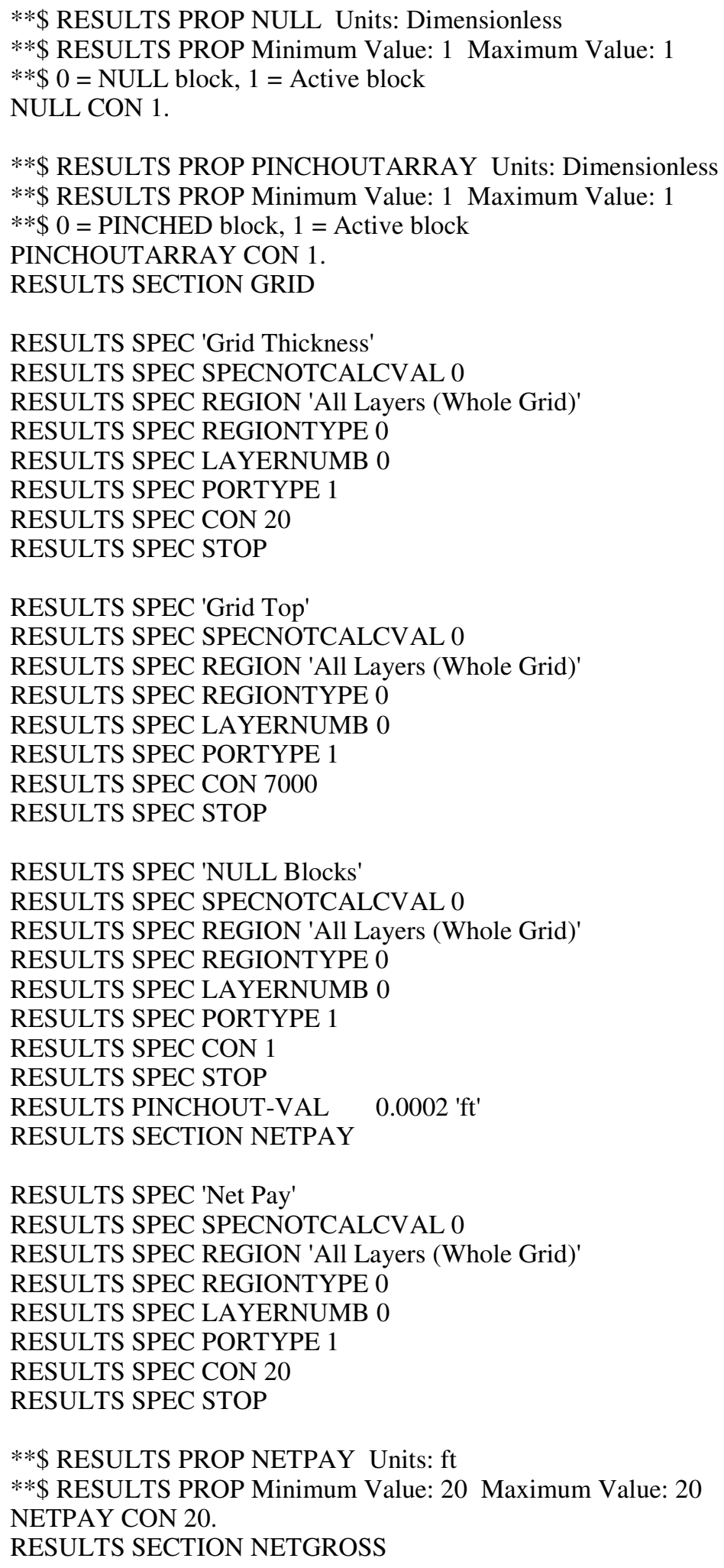




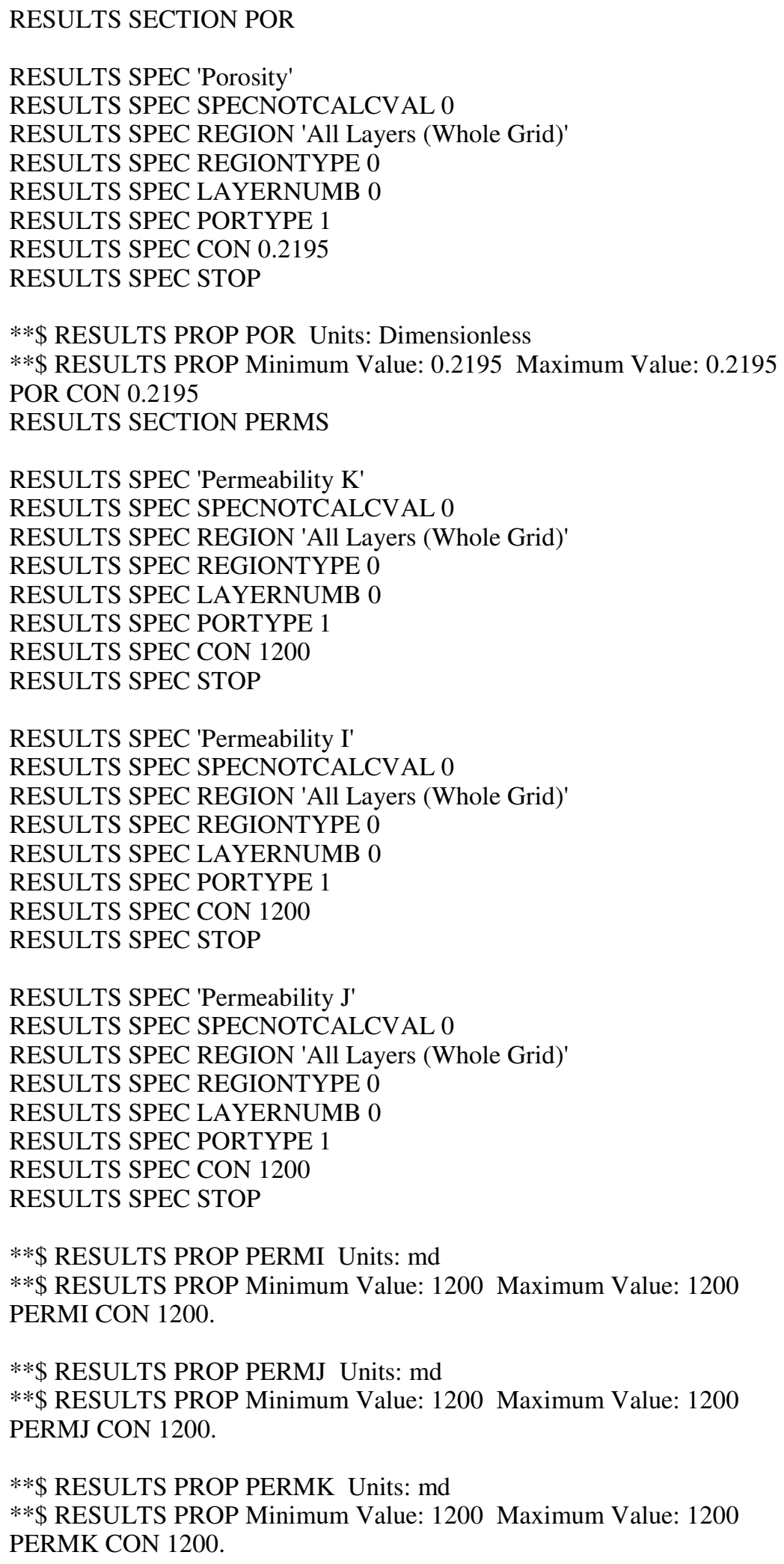




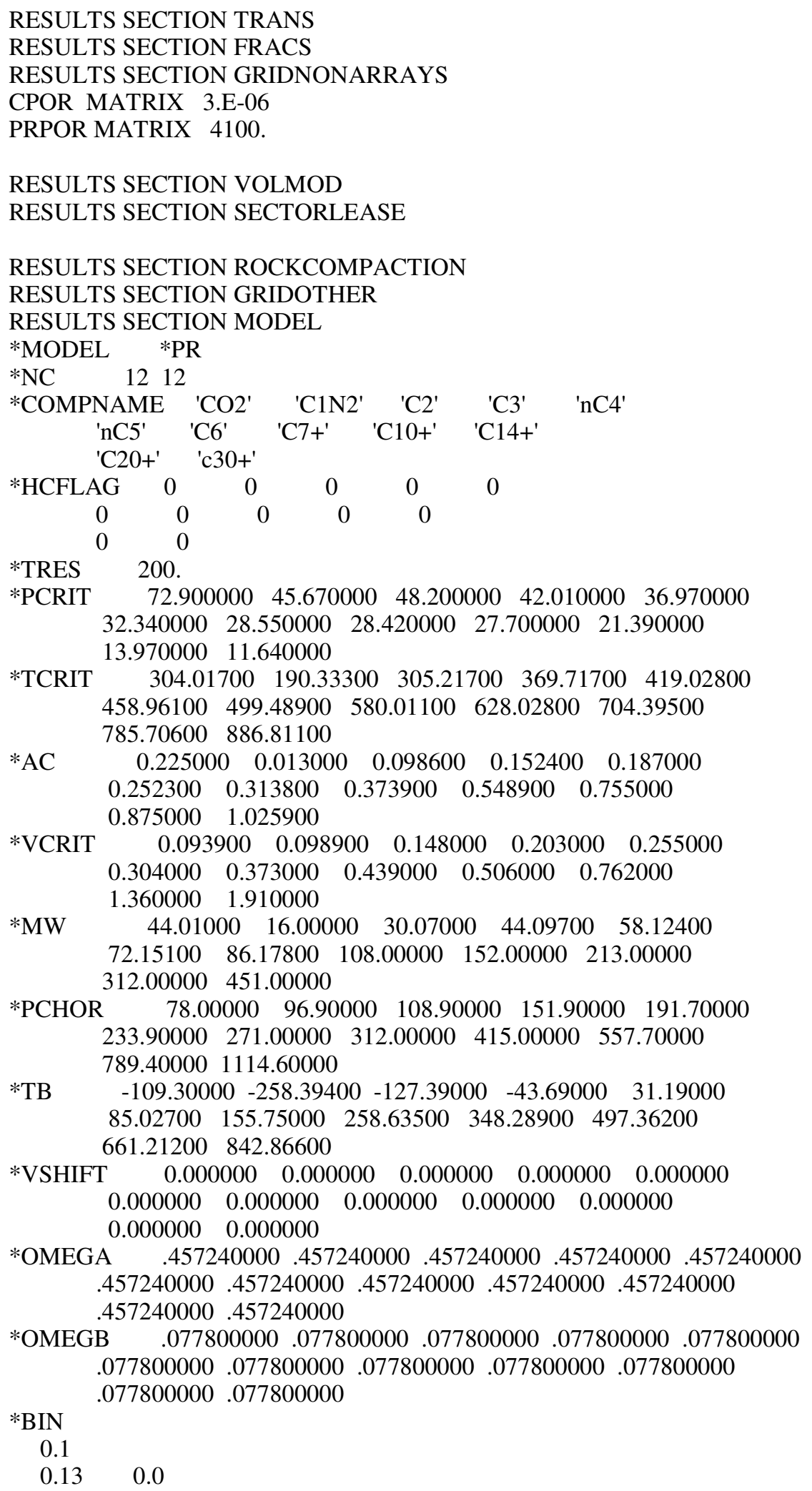




$\begin{array}{cccccc}0.135 & 0.0 & 0.0 & & & \\ 0.13 & 0.0 & 0.0 & 0.0 & & \\ 0.125 & 0.0 & 0.0 & 0.0 & 0.0 & \\ 0.12 & 0.02 & 0.03 & 0.03 & 0.03 & 0.0 \\ 0.12 & 0.03 & 0.03 & 0.03 & 0.03 & 0.0 \\ 0.0 & & & & & \\ 0.12 & 0.04 & 0.03 & 0.03 & 0.03 & 0.0 \\ 0.0 & 0.0 & & & & \\ 0.12 & 0.06 & 0.03 & 0.03 & 0.03 & 0.0 \\ 0.0 & 0.0 & 0.0 & & & \\ 0.225 & -0.0239 & 0.04 & -0.0175 & 0.04 & 0.0 \\ 0.0 & 0.0 & 0.0 & 0.0 & & \\ 0.255 & 0.2 & 0.04 & 0.1417 & 0.04 & 0.0 \\ 0.0 & 0.0 & 0.0 & 0.0 & 0.0 & \\ \text { *PHASEID } & \text { *DEN } & & & \\ \text { *RHOW } & 1572.605 & & & \\ \text { *CW } & 3 . \mathrm{E}-06 & & & & \\ \text { *REFPW } & 4100 . & & & & \end{array}$

RESULTS SECTION MODELARRAYS

RESULTS SECTION ROCKFLUID

*ROCKFLUID

*RPT $1 *$ DRAINAGE

$*$ SWT

$\begin{array}{lllll}0.000000 & 0.000000 & 0.640000 & 0.000000\end{array}$

$\begin{array}{lllll}0.050000 & 0.002500 & 0.562500 & 0.000000\end{array}$

$\begin{array}{lllll}0.100000 & 0.010000 & 0.490000 & 0.000000\end{array}$

$\begin{array}{lllll}0.150000 & 0.022500 & 0.422500 & 0.000000\end{array}$

$\begin{array}{lllll}0.200000 & 0.040000 & 0.360000 & 0.000000\end{array}$

$\begin{array}{lllll}0.250000 & 0.062500 & 0.302500 & 0.000000\end{array}$

$\begin{array}{lllll}0.300000 & 0.090000 & 0.250000 & 0.000000\end{array}$

$\begin{array}{lllll}0.350000 & 0.122500 & 0.202500 & 0.000000\end{array}$

$\begin{array}{lllll}0.400000 & 0.160000 & 0.160000 & 0.000000\end{array}$

$\begin{array}{lllll}0.450000 & 0.202500 & 0.122500 & 0.000000\end{array}$

$\begin{array}{lllll}0.500000 & 0.250000 & 0.090000 & 0.000000\end{array}$

$\begin{array}{lllll}0.550000 & 0.302500 & 0.062500 & 0.000000\end{array}$

$\begin{array}{lllll}0.600000 & 0.360000 & 0.040000 & 0.000000\end{array}$

$\begin{array}{lllll}0.650000 & 0.422500 & 0.022500 & 0.000000\end{array}$

$\begin{array}{lllll}0.700000 & 0.490000 & 0.010000 & 0.000000\end{array}$

$\begin{array}{lllll}0.750000 & 0.562500 & 0.002500 & 0.000000\end{array}$

$\begin{array}{lllll}0.800000 & 0.640000 & 0.000000 & 0.000000\end{array}$

*SGT

$\begin{array}{lllll}0.000000 & 0.000000 & 0.640000 & 0.000000\end{array}$ $\begin{array}{lllll}0.050000 & 0.002500 & 0.562500 & 0.000000\end{array}$

$\begin{array}{lllll}0.100000 & 0.010000 & 0.490000 & 0.000000\end{array}$

$\begin{array}{lllll}0.150000 & 0.022500 & 0.422500 & 0.000000\end{array}$

$\begin{array}{lllll}0.200000 & 0.040000 & 0.360000 & 0.000000\end{array}$

$\begin{array}{llll}0.250000 & 0.062500 & 0.302500 & 0.000000\end{array}$ 
$\begin{array}{lllll}0.300000 & 0.090000 & 0.250000 & 0.000000\end{array}$

$\begin{array}{lllll}0.350000 & 0.122500 & 0.202500 & 0.000000\end{array}$

$\begin{array}{lllll}0.400000 & 0.160000 & 0.160000 & 0.000000\end{array}$

$\begin{array}{lllll}0.450000 & 0.202500 & 0.122500 & 0.000000\end{array}$

$\begin{array}{lllll}0.500000 & 0.250000 & 0.090000 & 0.000000\end{array}$

$\begin{array}{lllll}0.550000 & 0.302500 & 0.062500 & 0.000000\end{array}$

$\begin{array}{lllll}0.600000 & 0.360000 & 0.040000 & 0.000000\end{array}$

$\begin{array}{lllll}0.650000 & 0.422500 & 0.022500 & 0.000000\end{array}$

$\begin{array}{lllll}0.700000 & 0.490000 & 0.010000 & 0.000000\end{array}$

$\begin{array}{lllll}0.750000 & 0.562500 & 0.002500 & 0.000000\end{array}$

$\begin{array}{lllll}0.800000 & 0.640000 & 0.000000 & 0.000000\end{array}$

*MODBUILDER

*TYPE:1_KRWRO_KROCW_KRGRO_KROCG_SWCON_SGCON_SWCR_SGCR_SORW_SORG_SO IRW_SOIRG_NW_NOW_NG_NOG *1_0.64_0.64_0.64_0.64_0_0_0_0_.2_0.2_.2_0.2_2_2_2_2 **\$ ModelBuilder passed through this Keyword

*MODBUILDER *TYPE_1_SWT_KRW_MULT_POWER_SIGMA_DISTMAX_STATUS $0.0000001779 .6449780 .0000000 .000000 *$ SMOOTHING_DONE $* * \$$ ModelBuilder passed through this Keyword

*MODBUILDER *TYPE_1_SWT_KROW_MULT_POWER_SIGMA_DISTMAX_STATUS $0.6400000 .0000000 .0000000 .000000 *$ SMOOTHING_DONE $* * \$$ ModelBuilder passed through this Keyword

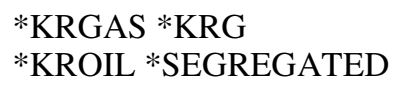

RESULTS SPEC 'Trapped Oil Saturation' RESULTS SPEC SPECNOTCALCVAL 0

RESULTS SPEC REGION 'All Layers (Whole Grid)'

RESULTS SPEC REGIONTYPE 0

RESULTS SPEC LAYERNUMB 0

RESULTS SPEC PORTYPE 1

RESULTS SPEC CON 0

RESULTS SPEC STOP

RESULTS SPEC 'Connate Gas Saturation' RESULTS SPEC SPECNOTCALCVAL 0 RESULTS SPEC REGION 'All Layers (Whole Grid)' RESULTS SPEC REGIONTYPE 0 RESULTS SPEC LAYERNUMB 0 


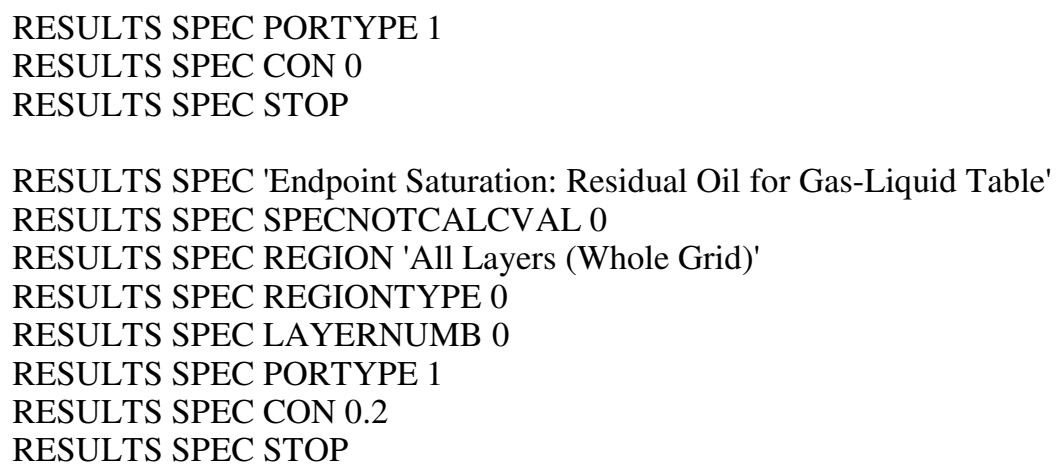

RESULTS SPEC 'Endpoint Saturation: Residual Oil for Water-Oil Table' RESULTS SPEC SPECNOTCALCVAL 0 
RESULTS SPEC 'Water Saturation'

RESULTS SPEC SPECNOTCALCVAL 0

RESULTS SPEC REGION 'All Layers (Whole Grid)'

RESULTS SPEC REGIONTYPE 0

RESULTS SPEC LAYERNUMB 0

RESULTS SPEC PORTYPE 1

RESULTS SPEC CON 0

RESULTS SPEC STOP

**\$ RESULTS PROP SW Units: Dimensionless

**\$ RESULTS PROP Minimum Value: 0 Maximum Value: 0

SW CON 0

**\$ RESULTS PROP PRES Units: psi

**\$ RESULTS PROP Minimum Value: 3650 Maximum Value: 3650

PRES CON 3650.

**\$ RESULTS PROP ZGLOBALC 'CO2' Units: Dimensionless

**\$ RESULTS PROP Minimum Value: 0.04484 Maximum Value: 0.04484

ZGLOBALC 'CO2' CON 0.04484

**\$ RESULTS PROP ZGLOBALC 'C1N2' Units: Dimensionless

**\$ RESULTS PROP Minimum Value: 0.36918 Maximum Value: 0.36918

ZGLOBALC 'C1N2' CON 0.36918

**\$ RESULTS PROP ZGLOBALC 'C2' Units: Dimensionless

**\$ RESULTS PROP Minimum Value: 0.03205 Maximum Value: 0.03205

ZGLOBALC 'C2' CON 0.03205

**\$ RESULTS PROP ZGLOBALC 'C3' Units: Dimensionless

**\$ RESULTS PROP Minimum Value: 0.02333 Maximum Value: 0.02333

ZGLOBALC 'C3' CON 0.02333

**\$ RESULTS PROP ZGLOBALC 'nC4' Units: Dimensionless

**\$ RESULTS PROP Minimum Value: 0.01532 Maximum Value: 0.01532

ZGLOBALC 'nC4' CON 0.01532

**\$ RESULTS PROP ZGLOBALC 'nC5' Units: Dimensionless

**\$ RESULTS PROP Minimum Value: 0.00877 Maximum Value: 0.00877

ZGLOBALC 'nC5' CON 0.00877

**\$ RESULTS PROP ZGLOBALC 'C6' Units: Dimensionless

**\$ RESULTS PROP Minimum Value: 0.01265 Maximum Value: 0.01265

ZGLOBALC 'C6' CON 0.01265

**\$ RESULTS PROP ZGLOBALC 'C7+' Units: Dimensionless

**\$ RESULTS PROP Minimum Value: 0.09168 Maximum Value: 0.09168

ZGLOBALC 'C7+' CON 0.09168

**\$ RESULTS PROP ZGLOBALC 'C10+' Units: Dimensionless

**\$ RESULTS PROP Minimum Value: 0.11185 Maximum Value: 0.11185

ZGLOBALC 'C10+' CON 0.11185

**\$ RESULTS PROP ZGLOBALC 'C14+' Units: Dimensionless 
**\$ RESULTS PROP Minimum Value: 0.1122 Maximum Value: 0.1122

ZGLOBALC 'C14+' CON 0.1122

**\$ RESULTS PROP ZGLOBALC 'C20+' Units: Dimensionless

**\$ RESULTS PROP Minimum Value: 0.09094 Maximum Value: 0.09094

ZGLOBALC 'C20+' CON 0.09094

**\$ RESULTS PROP ZGLOBALC 'c30+' Units: Dimensionless

**\$ RESULTS PROP Minimum Value: 0.08719 Maximum Value: 0.08719

ZGLOBALC 'c30+' CON 0.08719

RESULTS SECTION NUMERICAL

*NUMERICAL

*MAXSTEPS 300000000

*DTMAX 20.

*DTMIN 0.0001

*SORDER *NATURAL

*NORM *PRESS 200.

*NORM *GMOLAR 0.0001

*NORM *SATUR 0.002

*MAXCHANGE *PRESS 200.377

*MAXCHANGE *GMOLAR 0.0001

*MAXCHANGE *SATUR 0.02

*CONVERGE *PRESS 0.514884

RESULTS SECTION NUMARRAYS

RESULTS SECTION GBKEYWORDS

RUN

DATE 20040625

DTWELL 0.0001

*INJECTOR-T 200.

*INJECTOR-EOS $\quad 1$

*DTMAX 20.

*DTMIN 0.0001

*WPRN *WELL *TIME

*WPRN *GRID *TIME

*WPRN *ITER *NONE

*WSRF *WELL *TIME

*WSRF *GRID *TIME

WELL 1 'gas injector'

INJECTOR 'gas injector'

INCOMP SOLVENT 0.20810 .32770 .20080 .22230 .041100000000

OPERATE MAX BHG 151.14 CONT

OPERATE MAX BHP 5000. STOP 
GEOMETRY K 0.250 .37 1. 0.

PERF GEO 'gas injector'

1111 . OPEN FLOW-FROM 'SURFACE'

GUIDEI STG 'gas injector'

151.5

WELL 2 'Producer'

PRODUCER 'Producer'

OPERATE MAX BHF 500. CONT

OPERATE MIN BHP 3650. CONT

GEOMETRY K 0.250 .37 1. 0 .

PERF GEO 'Producer'

40011 1. OPEN FLOW-TO 'SURFACE'

GUIDEP STO 'Producer'

500.

OPEN 'gas injector'

OPEN 'Producer'

TIME 2321

TIME 6962

TIME 9282

TIME 11603

TIME 13923

TIME 18564

TIME 20885

TIME 23205

TIME 27846

STOP

************************************

TERMINATE

SIMULATION

***********************************

RESULTS SECTION WELLDATA

RESULTS SECTION PERFS 


\section{Nomenclature}

$$
\begin{aligned}
& a_{1}-a_{10}=\text { Parameters given in Eq. } 2.1 \& 2.3 \\
& k=\text { Key tie-line number } \\
& K_{i}=\text { Equilibrium constant of component } i \\
& B_{o} \quad=\text { Oil formation volume factor } \\
& B_{g}=\text { Gas formation volume factor } \\
& \mathrm{CH}_{4} \mathrm{~N}_{2}=\text { Pseudocomponent formed by lumping methane and nitrogen } \\
& \text { Cum. }=\text { Cumulative component or oil recovery } \\
& \delta_{i j}=\text { Binary interaction parameter between components } i \text { and } j \\
& \text { EOS }=\text { Equation of state } \\
& \text { GOR = Total gas }- \text { oil ratio } \\
& H C P V I=H y d r o c a r b o n \text { pore volume injected } \\
& L=\text { Liquid phase mole fraction } \\
& M_{w} \quad=\quad \text { Molecular weight } \\
& M_{C_{5+}} \quad=\text { Molar weight of } C_{5} \text { plus fraction } \\
& M_{C_{7+}}=\text { Molar weight of } C_{7} \text { plus fraction } \\
& M M P_{\text {pure }}=\text { Minimum miscibility pressure for pure } \mathrm{CO}_{2} \text { injection, psia } \\
& M M P_{\text {imp }}=\text { Minimum miscibility pressure for impure CO2 injection, psia } \\
& n c=\text { Number of components } \\
& n c-1=\text { Number of key tie lines } \\
& n c-3=\text { Number of crossover tie lines } \\
& \phi \quad=\text { Fugacity coefficient } \\
& P_{\mathrm{CO}_{2}}=\text { Molar percentage } \mathrm{CO}_{2} \text { in the injection gas } \\
& P_{C_{2-6}}=\text { Molar percentage of } C_{2}-C_{6} \\
& P_{c} \quad=\text { Critical pressure } \\
& P V \quad=\text { Pore volume } \\
& \text { PVT = Pressure volume and temperature } \\
& \operatorname{Re} c . \quad=\text { Recovery } \\
& R_{s} \quad=\quad \text { Solution gas-oil ratio } \\
& \text { SVP }=\text { Saturation vapor pressure } \\
& S_{g} \quad=\quad \text { Solution gas-oil ratio } \\
& T \quad=\text { Reservoir temperature, }{ }^{\circ} \mathrm{F} \\
& T_{c}=\text { Critical temperature } \\
& t d=\text { Dimensionless time in pore volume } \\
& V \quad=\quad \text { Vapor phase mole fraction } \\
& V_{c}=\text { Critical volume }
\end{aligned}
$$




$\begin{array}{ll}V_{b} & =\text { Volume of oil at the bubble point pressure } \\ \omega & =\text { Accentric factor } \\ x_{i} & =\text { Equilibrium mole fraction of component } i \text { in the liquid phase } \\ y_{i} & =\text { Equilibrium mole fraction of component } i \text { in the vapor phase } \\ Z_{i} & =\text { Overall mole fraction of component } i \text { in the fluid mixture }\end{array}$




\section{References}

Abdassah, D., Siregar, S. and Kristanto, D.: "The Potential of Carbon Dioxide Gas Injection Application in Improved Oil Recovery," paper SPE 64730 presented at the SPE $7^{\text {th }}$ International Oil and Gas Conference and Exhibition held in Beijing, China, Nov.7-10, 2000.

Alston, R.B., Kokolis, G.P. and James, C.F.: " $\mathrm{CO}_{2}$ Minimum Miscibility Pressure: A Correlation for Impure $\mathrm{CO}_{2}$ Streams and Live Oil Systems," SPEJ, pp. 268-274, Apr. 1985.

Arya, A., Atul, Hewett, T.A., Larson, R.G., and Lake, L.W.: "Dispersion and Reservoir Heterogeneity," SPEREE, pp. 139-148, Feb. 1988.

Cardenas, R.L., Alston, R.B., Nute, A.J. and Kokolis, G.P.: "Laboratory Design of a Gravity-Stable Miscible $\mathrm{CO}_{2}$ Process," JPT, pp. 111-118, Jan. 1984.

Chaback, J.J. and William, M.L.: "Phase Equilibria in the SACROC Oil-Carbon Dioxide System," paper SPE 14923 presented at the SPE/DOE Fifth Symposium on EOR held in Tulsa, OK, Apr. 1986.

Chaback, J.J.: "Phase Equilibria for Enhanced Oil Recovery in an n-Butane Enriched Carbon Dioxide + Black Oil System," paper SPE 17621 presented at the SPE International Meeting on Petroleum Engineering held in Tianjin, China, Nov. 1-4, 1988.

Christensen, P.L.:' Regression to Experimental PVT data," JCPT (38) special edition, pp. $1-9,1999$.

Computer Modelling Group Compositional simulator (GEM), 2003.

Cotterman, R.L. and Prausnitz, J.M.: "Flash Calculations for Continuous or SemiContinuous Mixtures using Equation of State," Ind. \& Eng. Chem. Proc. Des. Dev. (24), pp. 234, 1985.

Cronquist, C.: "Carbon Dioxide Dynamic Miscibility with Light Reservoir Oils," SPE/DOE fourth symposium on EOR held in Tulsa, OK. 1977.

Dichary, R.M., Perryman, T.L. and Ronquille, J.D.: "Evaluation and Design of a $\mathrm{CO}_{2}$ Miscible Flood Project-SACROC Unit, Kelly-Snyder Filed," JPT, pp. 1309-18, Nov. 1973.

Dindoruk, B., Orr, F.M. and Johns, R.T.: "Theory of Multicontact Miscible Displacements with Nitrogen," SPEJ, 2(3), pp. 268-279, Sept, 1997. 
Elsharkway, A.M., Canal, S., Poettmann, F.H. and Christiansen, R.L., "Measuring Minimum Miscibility Pressure: Slim-Tube or Rising-Bubble Method?" SPE 24224 presented at the SPE/DOC $8^{\text {th }}$ Symposium on EOR held in Tulsa, Oklahoma, Apr. 22-24, 1992.

Fong, W.S., Sheffield, R.E., and Emanuel, A.S., "Phase Modeling Techniques for lowTemperature $\mathrm{CO}_{2}$ Applied to McElroy and North Ward Estes Projects," paper SPE 24184, presented at the SPE/DOE $8^{\text {th }}$ Symposium on EOR, held in Tulsa, OK, Apr. 22-24, 1992.

Frimodig, J.P., Reese, N.A. and Williams, C.A.: "Carbon Dioxide Flooding Evaluation of High-Pour-Point, Paraffinic Red Wash Reservoir Oil," SPEJ, pp. 587-594, Aug. 1983.

Guntis, M.: "Oil \& Gas Journal 2004 Oil Recovery Survey Report," Oil and Gas Journal, pp. 53-65, Apr. 12, 2004.

Glaso, O.: "Generalized Minimum Miscibility Pressure Correlation," SPEJ, pp. 927-934, Dec. 1985.

Hamoodi, A.N.: "Discussion of Generalized Minimum Miscibility Pressure Correlation," SPEREE, pp. 535, Sept. 1986.

Helfferich, F.: "Theory of Multicomponent, Multiphase Displacement in Porous Media," SPEJ, pp. 51-62, Feb. 1981.

Henry, R.L. and Metcalfe, R.S.: "Multi-Phase Generation During Carbon Dioxide Flooding," SPEJ, pp.595-601, Aug. 1983.

Hirasaki, G.J.: "Application of the Theory of Multicomponent, Multiphase Displacement to Three-Component, Two phase Surfactant Flooding," SPEJ, pp 191-204, Apr. 1981.

Hoffman, A.E., Crump, J.S., and Hocott, C.R.: "Equilibrium Constants for Gas Condensate System," Trans., AIME (198), pp. 1-10, 1953.

Holm, L.W. and Josendal, V.A.: "Effect of Oil Composition on Miscible-Type Displacement by Carbon Dioxide," paper SPE 8814 presented at the First SPE/DOE Symposium on EOR held in Tulsa, OK, Apr. 20-23, 1980.

Hong, K.C.: "Lumped-Component Characterization of Crude Oils for Compositional Simulation," paper SPE 10691, presented at the SPE/DOE $3^{\text {rd }}$ Symposium on EOR held in Tulsa, OK, Apr. 4-7, 1982.

Jhaveri, B.S. and Youngren, G.K.: "Three-Parameter Modification of the Peng-Robinson Equation of State to Improve Volumetric Predictions," paper SPE 13118, 
presented at the 1984, SPE Annual Technical Conference and Exhibition, Houston Texas, Sept. 16-19, 1984.

Jarrell, P.M., Fox C.E., Stein, M.H., Webb, S.L.: "Practical Aspect of $\mathrm{CO}_{2}$ Flooding," SPE Monograph, H. L Doherty Series, (22), pp. 13-35, 2002.

Jessen, K, Michelsen, M, Stenby, E.H.: "Global Approach for Calculation of Minimum Miscibility Pressure," Fluid Phase Equilibria (153), pp. 251-263, 1998.

Jessen, K., Stenby, E.H., Orr, F.M. jr.: "Interplay of Phase Behavior and Numerical Dispersion in Finite Difference Compositional Simulation," paper SPE 75134 presented at the 2002 SPE/DOE Improved Oil Recovery Symposium held in Tulsa, Ok, 13-17 April 2002.

Johns, R.T.: Analytical Theory of Multicomponent Gas Drives With Two-Phase Mass Transfer, PhD dissertation, Stanford University, CA (May 1992)

Johns, R.T. and Orr, F.M., Jr.: "Miscible Gas Displacement of Multicomponent Oils," SPEJ, 1(1), pp. 39-50, 1996.

Johns, R.T., Orr, F.M. and Dindoruk, B.: "Analytical Theory of Combined Condensing/Vaporizing Gas Drive," SPE Adv. Tech. Series, 1(2), pp. 7-16, 1993.

Johns, R.T., Yuan, H, Dindoruk, B.: "Quantification of Displacement Mechanisms in Multicomponent Gas flood," paper SPE 77696 presented at the 2002 SPE Annual Technical Conference and Exhibition held in San Antonio, TX, Sept. 29- Oct. 2, 2002.

Johns R.T., Fayers, F.J., and Orr, F.M.: "Effect of Gas Enrichment and Dispersion on Nearly Miscible Displacements in Condensing/Vaporizing Drives," paper SPE 24938 presented at the $67^{\text {th }}$ SPE Annual Technical Conference and Exhibition held in Washington, DC, Oct. 4-7, 1992.

Johnson, J.P. and Pollin, J.S.: "Measurement and Correlation of $\mathrm{CO}_{2}$ Miscibility Pressures," paper SPE 9790 presented at the SPE/DOE $2^{\text {nd }}$ Symposium on EOR held in Tulsa, OK, April 5-8, 1981.

Khan, S.A., Pope, G.A. and Sepehrnoori, K.: "Fluid Characterization of Three-Phase $\mathrm{CO}_{2}$ /Oil Mixtures," paper SPE 24130 presented at the SPE/DOE $8^{\text {th }}$ Symposium on EOR held in Tulsa, Oklahoma, Apr. 22-24, 1992.

Klin, M.A.: "CarbonDioxide Flooding," Intl. Human Resources Development Corp., Boston, M.A. 1984.

Kovarik, F.S.: "A Minimum Miscibility Pressure Study Using Impure $\mathrm{CO}_{2}$ and West Texas Oil Systems: Data Base, Correlations, and Compositional Simulation," 
paper SPE 14689 presented at SPE Production Technology Symposium held in Lubbock, Texas, Nov. 11-12, 1985.

Li, Y.K., Nghiem, L.X. and Siu, A.: "Phase Behavior Computations for Reservoir Fluids: Effect of Pseudocomponents on Phase Diagrams and Simulation Results," J. Can. Pet. Tech. (24) 6, pp 29-36, Nov- Dec. 1985.

Liu, K.: "Fully Automatic Procedure for Efficient Reservoir Fluid Characterization", paper SPE 56744, presented at the 1999 SPE Annual Technical Conference and Exhibition held in Houston, Texas, Oct. 3-6, 1999.

Mehra, R.K., Heidemann, R.A., and Aziz, K.: "A Statistical Approach for Combining Reservoir Fluids into Pseudocomponents for Compositional Model Studies," Paper SPE 11201 presented at the 1982 Annual Technical Conference and Exhibition, New Orleans, Sept. 26-29, 1982.

Metcalfe, R.S.: "Effects of Impurities on Minimum Miscibility Pressures and Minimum Enrichment Levels for $\mathrm{CO}_{2}$ and Enriched-Gas Displacement," SPEJ, pp. 219225, Apr. 1982.

Metcalfe, R.S., and Yarborough, L.: " Effect of Phase Equilibria on $\mathrm{CO}_{2}$ Displacement Mechanism," SPEJ, pp.242, Aug. 1979.

Monger, T.G. and Khakoo, A.: "The Phase Behavior of $\mathrm{CO}_{2}$-Appalachian Oil Systems," Paper SPE 10269 presented at the 1981 SPE Annual Technical Conference and Exhibition, San Antonio, Texas, Oct. 5-7, 1981.

Monroe, W.W., Silva, M.K., Larsen, L.L., and Orr, F.M.: "Composition Paths in Four Component Systems: Effect of Dissolved Methane on 1-D $\mathrm{CO}_{2}$ Floods Performance," SPEREE (5), pp 423-432, 1990.

Negahban, S. and Kremesec, V.J.: "Development and Validation of Equation of State Fluid Description for $\mathrm{CO}_{2}$ Reservoir Oil Systems," Paper SPE 19637, presented at the 1989 SPE Annual Technical Conference and Exhibition, San Antonio, Texas, Oct. 1989.

Newley, T.M.J., Merrill, R.C.: "Pseudocomponent Selection for Compositional Simulation," SPEREE, pp. 490-495, Nov. 1991.

Ngheim, L.X. and Li, Y.K.: "Effect of Phase Behavior on $\mathrm{CO}_{2}$ Displacement Efficiency at Low Temperatures: Model Studies with an Equation of State," SPEREE, pp. 414-420, July 1986.

Orr, F.M. Jr. and Silva, M.K.: "Effect of Oil Composition on Minimum Miscibility Pressure-Part 2: Correlation," SPEREE, pp.479-491, 1987. 
Orr, F.M. Jr, and Jessen , C.M.: "Interpretation of Pressure Composition Phase Diagrams for $\mathrm{CO}_{2} /$ Crude-Oil System,” SPEJ, pp. 485-97, Oct. 1984.

Orr, F.M., Johns, R.T., and Dindoruk, B.: "Development of Miscibility in FourComponent $\mathrm{CO}_{2}$ Floods," SPEREE, pp. 135-142, May, 1993.

Pope, G.A.: The Application of Fractional Flow Theory to Enhanced Oil Recovery," SPEJ, pp. 191-205, June 1980.

Pedersen, K.S. Fredenslund, A.A., and Thomassen, P.: " Properties of Oils and Natural Gases, Contributions on Petroleum Geology and Engineering (5)," Gulf publishing Co., Houston, 1989.

Pedersen, K.S., Thomassen, P. and Fredenslund, A.A.: "Thermodynamics of Petroleum Mixtures III: Efficient Flash Calculations Using the SRK Equation of State," Ind. \& Eng. Chem. Proc. Des. Dev. (24), pp. 948, 1985.

Peng, D.Y. and Robinson, D.B.: "A New Two-Constant Equation of State," Ind. Eng. Chem. Fund. (15), pp. 59-64, 1976.

Pontius, S.B. and Tham, M.J.: "North Cross (Devonian unit) $\mathrm{CO}_{2}$ Flood-Review of Flood performance and Numerical Simulation,” JPT, pp 1706-14, Dec. 1978.

Rafael, A., Aguilar, Z. and William, D.M.: "An Efficient Tuning Strategy to Calibrate Cubic EOS for Compositional Simulation," paper SPE 77382 presented at the 2002 SPE Annual Technical Conference Exhibition held in San Antonio, Texas, Sept.29-Oct.2, 2002.

Rathmell, J.J., Stalkup, F.I. and Hassinger, R.C.: “A Laboratory Investigation of Miscible Displacement by Carbon Dioxide," paper SPE 3483 presented at the $46^{\text {th }}$ Annual meeting held in New Orleans, La, Oct. 3-6, 1971.

Sebastian, H.M., Wenger, R.S. and Renner, T.A.: "Correlation of Minimum Miscibility Pressure for Impure $\mathrm{CO}_{2}$ Streams,” JPT, pp. 2076-81, Nov. 1985.

Shelton, J.L. and Yarborough, L.: "Multiple-Phase Behavior in Porous Media During $\mathrm{CO}_{2}$ or Rich Gas flooding," JPT, pp 1171-78, Sept. 1977.

Solano, R. Johns, R.T., and Lake, L.W.: "Impact of Reservoir Mixing on Recovery in Enriched Gas Drives above the Minimum Miscibility Pressure," SPEREE, pp 358-365, Oct. 2001.

Spence, A.P. and Watkins, R.W.: "The Effect of Microscopic Core Heterogeneity on Miscible Flood Residual Oil Saturation," SPE 9229 presented at the 55 ${ }^{\text {th }}$ Annul SPE meeting held in Dallas, TX, Sept. 21-24, 1980. 
Stalkup, F.I: “Status of Miscible Displacement," JPT, pp. 815-826, Apr. 1983.

Stalkup, F.I., Lo, L.L and Dean, R.H.: "Sensitivity to Gridding of Miscible Flood Predictions made with Upstream Differenced Simulators," paper SPE 20178 presented at SPE/DOE $7^{\text {th }}$ symposium on EOR, Tulsa, OK, Apr. 22-25, 1990.

Stalkup, F.I.: "Carbondioxide Injection for Improved Oil Recovery," Exploration and Economics of the Petroleum Industry, Southwestern Legal Foundation, Matthew Bender, New York City, 1981.

Turek, E.A. et al..: "Phase Equilibria in Carbon Dioxide Multicomponent Hydrocarbon Systems: Experimental Data and an Improved Prediction Technique," SPEJ, PP 308-24, June 1984.

Wang, Y. and Orr, F.M., Jr.: "Calculation of Minimum Miscibility Pressure," paper SPE 39683 presented at SPE/DOE Improved Oil Recovery Symposium, Tulsa, OK, Apr. 19-22, 2002.

Whitson, C.H.: "Characterizing Hydrocarbon Plus Fractions," paper EUR 183, Presented at the 1980 SPE European Petroleum Conference, London, Oct.21-24, 1980.

Whitson, C.H.: "Effect of $\mathrm{C}_{7+}$ Properties on Equation of State Predictions," SPEJ, pp. 683-694, Dec. 1984.

Yellig, W.F. and Metcalfe, R.S.: "Determination and Prediction of $\mathrm{CO}_{2}$ Minimum Miscibility Pressures," JPT, pp. 160-168, Jan. 1980.

Yuan, H.: "Application of Miscibility Calculation to Gas Floods," PhD dissertation, The University of Texas at Austin, Austin, TX, 2003.

Yuan, H. and Johns, R.T.: "Simplified Method for Calculation of Minimum Miscibility Pressure or Enrichment", paper SPE 77381 presented at the 2002 SPE Annual Technical Conference and Exhibition held in San Antonio, Texas, Sept. 29 - Oct. $2,2002$.

Yuan, H., Johns, R.T., Egwuenu, A.M., Dindoruk, B.: "Improved MMP Correlation for Miscible Gas Floods, Using Analytical Gas Theory,” paper SPE 89359, presented at the $14^{\text {th }}$ SPE/DOE Symposium on EOR held in Tulsa, OK, Apr. 17-21, 2004.

Zain, Z.M., Kechut, N.I., Nadeson, G. Raja, D.A.: "Evaluation of $\mathrm{CO}_{2}$ Gas Injection For Major Oil Production Fields in Malaysia-Experimental Approach Case Study: Dulang Filed," paper SPE 72106 presented at the SPE Asia Pacific Improved Oil Recovery Conference held in Kula Lumpa, Malaysia, Oct. 8-9, 2001.

Zhou, D and Orr, F.M., Jr.: "Analysis of Rising Bubble Experiments to Determine Minimum Miscibility Pressures,” SPEJ, pp. 19-25, Mar. 1998. 
Zhou, D., Jensen, C. and Tang, R.: "A New Formulation for Simulating Near-Miscible Displacement Processes," paper SPE 56623 presented at the SPE Annual Technical Conference and Exhibition held in Houston, TX, Oct.3-6, 1999.

Zick, A.A.: "A Combined Condensing/Vaporizing Mechanism in the Displacement of Oil by Enriched Gas," paper SPE 15493 presented at the SPE Annual Technical Conference and Exhibition, New Orleans, LA, October 5-8, 1986. 


\section{Vita}

Azubuike Egwuenu was born on the $28^{\text {th }}$ of January, 1976 in Nigeria to the family of late Matthew and Betty Egwuenu. He received his bachelors' degree in Chemical Engineering from the University of Lagos, Nigeria in September 2000. He participated in the Nigeria National Youth Service Corp (N.Y.S.C) May 2001-June 2002 where he worked with Arthur Andersen as a financials auditor. He was admitted to the master program at the Department of Petroleum Engineering in August 2002.

He is an accomplished scholar with several awards in his belt. He was a recipient of the Chevron National University Merit scholarship (1997-2000), Mitchellin-Utagba Uno merit scholarship and the Chevron-Texaco graduate Fellowship award (2002-2003). He has strong research interests in the general field of reservoir engineering and intends to pursue a PhD. Degree in Petroleum Engineering.

Address: 8664 Braebrook drive,

Lanham, MD 20706

United State.

Typist: $\quad$ Azubuike Egwuenu 